\title{
Novel Tetrafunctional Probes Identify Target Receptors and Binding Sites of Small-Molecule Drugs from Living Systems
}

Rin Miyajima,${ }^{1 *}$ Koji Sakai, ${ }^{1}$ Yuki Otani, ${ }^{2}$ Takashi Wadatsu, ${ }^{2}$ Yasuyo Sakata,${ }^{3}$ Yuki Nishikawa, ${ }^{1}$ Masaki Tanaka, ${ }^{2}$ Yu Yamashita, ${ }^{1}$ Mikayo Hayashi, ${ }^{1}$ Kazumi Kondo,${ }^{4}$ and Takashi Hayashi ${ }^{2}{ }^{*}$

${ }^{1}$ Medicinal Chemistry Research Laboratories, New Drug Research Division, Otsuka Pharmaceutical Co., Ltd., 463-10 Kagasuno Kawauchi-cho, Tokushima 771-0192, Japan

${ }^{2}$ Department of Lead Discovery Research, New Drug Research Division, Otsuka Pharmaceutical Co., Ltd., 463-10 Kagasuno Kawauchi-cho, Tokushima 771-0192, Japan

${ }^{3}$ The Time-Limited Research Project for MSM, Otsuka Pharmaceutical Co., Ltd., 463-10 Kagasuno Kawauchi-cho, Tokushima 771-0192, Japan

${ }^{4}$ Pharmaceutical Business Division, Otsuka Pharmaceutical Co., Ltd., 463-10 Kagasuno Kawauchi-cho, Tokushima 771-0192, Japan

Corresponding Authors

Email: Miyajima.Rin@otsuka.jp

Email: Hayashi.Takashi@otsuka.jp 


\section{Table Contents}

\section{Supporting Information}

Page S3-S17 Figures S1-S15 and Table S1.

Page S18 General Information.

Page S18-S21 Biology Materials and Methods.

Page S22-S49 Synthetic Methods and Characterization Data.

Page S50-S92 ${ }^{\mathbf{1}} \mathrm{H}$ and ${ }^{\mathbf{1 3}} \mathrm{C}$ NMR Spectrum.

Page S93-S94 References. 


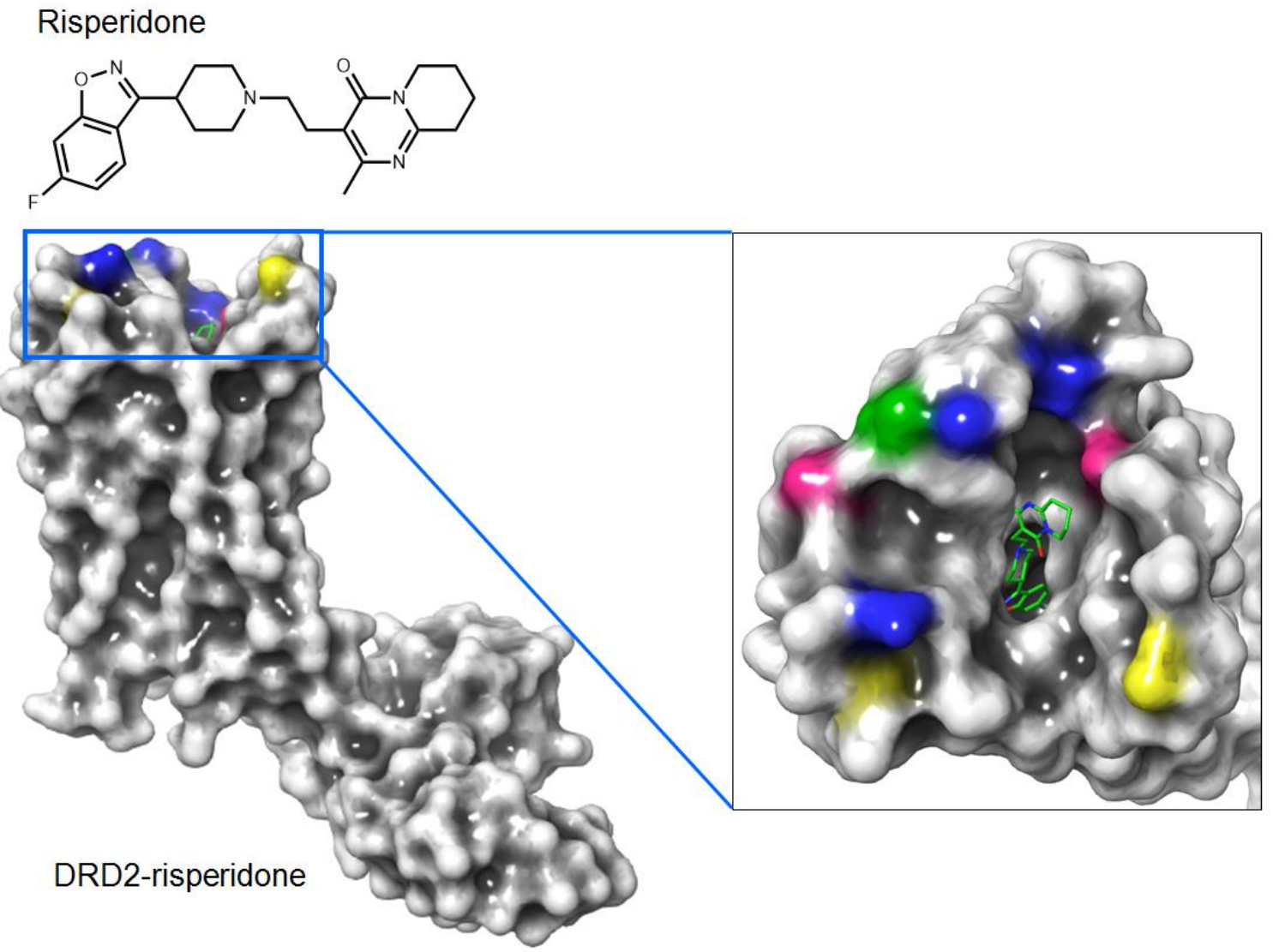

Figure S1. Chemical structure of risperidone and the cocrystal structure of DRD2 and risperidone from parallel to the membrane plane (left) and the extracellular space (right) are shown (PDB: 6CM4). ${ }^{\text {ref.1 }}$ Hydrophilic amino acids that could potentially react with ACT and AI are highlighted. Glu, Asp, Lys, and Ser residues are colored in blue, yellow, green, and pink, respectively. Risperidone is shown in green stick. 
Table S1. Binding affinities ( IC $\left._{50}\right)$ and chemical properties for compound 1 and probes $2 \mathrm{a}, \mathrm{b}, 3 \mathrm{3a}, \mathrm{b}, 4,5$, 6a,b, and 7.

$\begin{array}{cccccccccccc}\begin{array}{c}\text { Reactive } \\ \text { group }\end{array} & \mathbf{1} & \mathbf{2 a} & \mathbf{2 b} & \mathbf{3 a} & \mathbf{3 b} & \mathbf{4} & \mathbf{5} & \mathbf{6 a} & \mathbf{6 b} & \mathbf{7} \\ \begin{array}{c}\text { Cleavable } \\ \text { linker }\end{array} & - & \text { ACT } & \text { ACT } & \begin{array}{c}\text { DA } \\ (\text { Linear })\end{array} & \begin{array}{c}\text { DA } \\ (\text { Branch })\end{array} & \text { BP } & \text { PA } & \text { Al } & \text { Al } & \text { ACT } \\ \text { M.W. } & 435.6 & 1194.5 & 1293.6 & 1115.4 & 1245.6 & 1229.5 & 1180.5 & 1018.3 & 1117.4 & 1445.8 \\ \text { tPSA } & 36.0 & 261.6 & 290.7 & 225.0 & 275.1 & 226.5 & 258.2 & 204.9 & 234.0 & 317.0 \\ \mathrm{IC}_{50}(\mathrm{nM}) & 0.63 & 16 & 24 & 19 & 38 & 39 & 29 & 9.2 & 11 & 33\end{array}$

Human DRD2

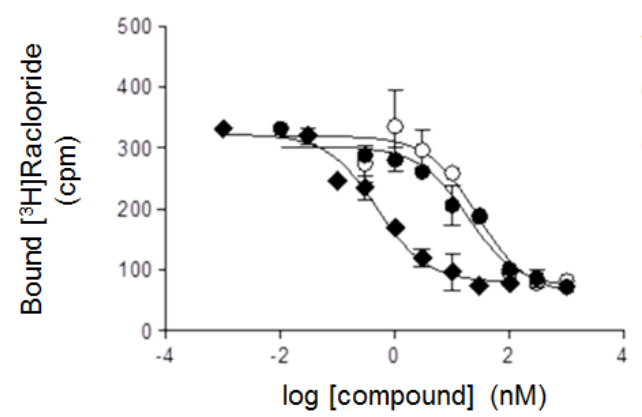

Compound 1

- Probe 2a

O Probe $\mathbf{2 b}$

Human DRD2

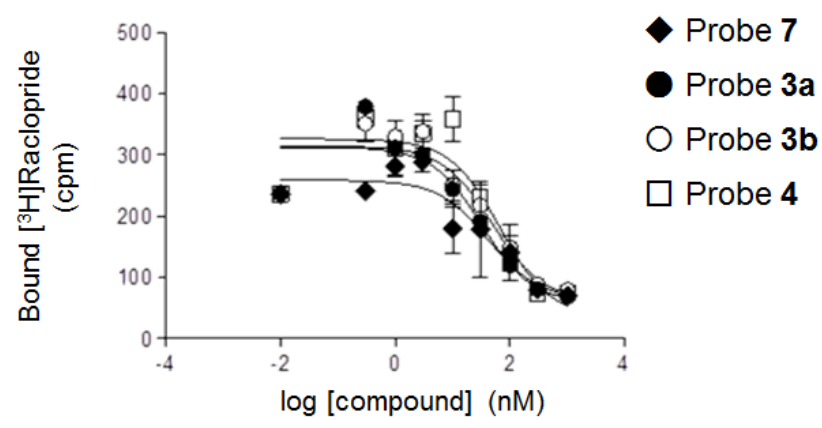

Human DRD2

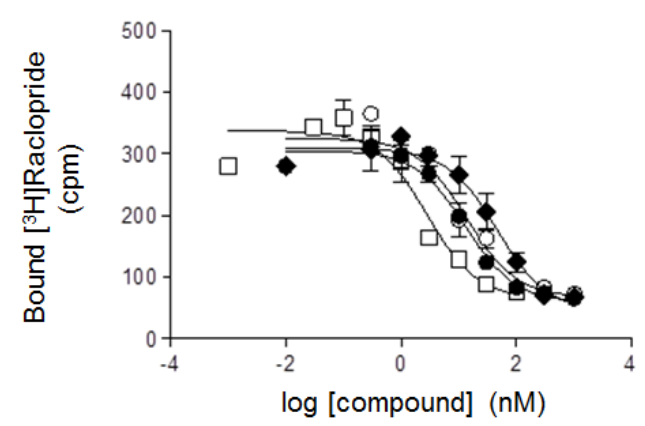

Probe 5

Probe 6a

O Probe $6 \mathbf{b}$

$\square$ Risperidone

(positive control)

Figure S2. $\left[{ }^{3} \mathrm{H}\right]$ Raclopride displacement by compound $\mathbf{1}$ or probes $\mathbf{2 a}, \mathbf{b}, \mathbf{3 a}, \mathbf{b}, \mathbf{4}, \mathbf{5}, \mathbf{6 a}, \mathbf{b}$, and $\mathbf{7}$ using membrane fractions from $\mathrm{CHO}$ cells stably expressing DRD2. 

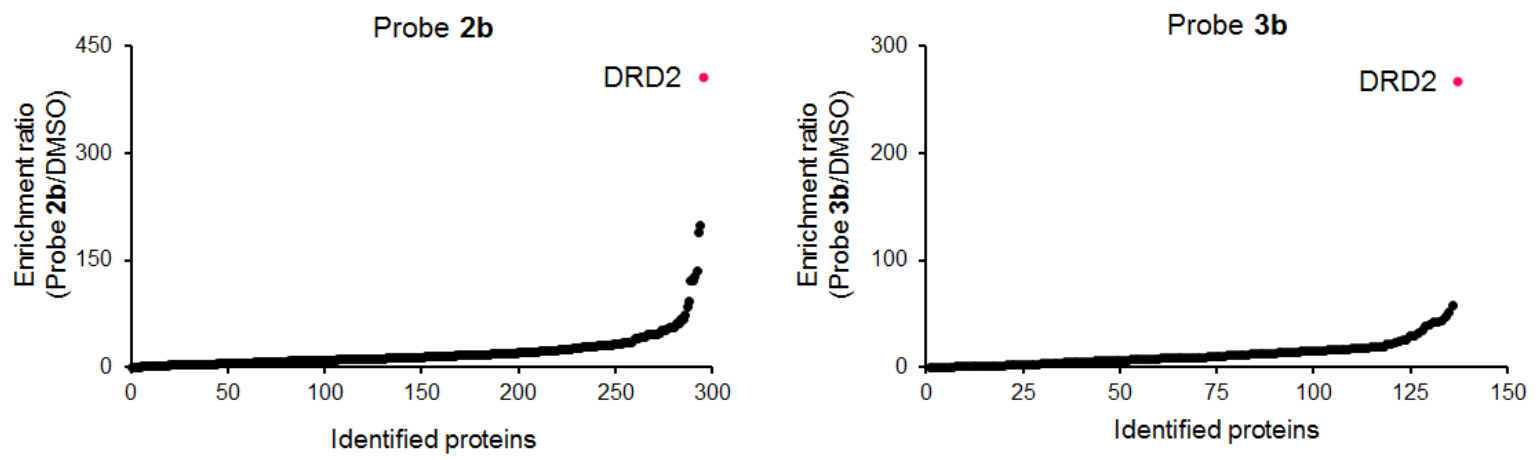

Figure S3. MS-based identification of proteins enriched by probes $\mathbf{2 b}$ and $\mathbf{3 b}$. Data represent enrichment ratio (probe/DMSO) for proteins across three biological replicates. 

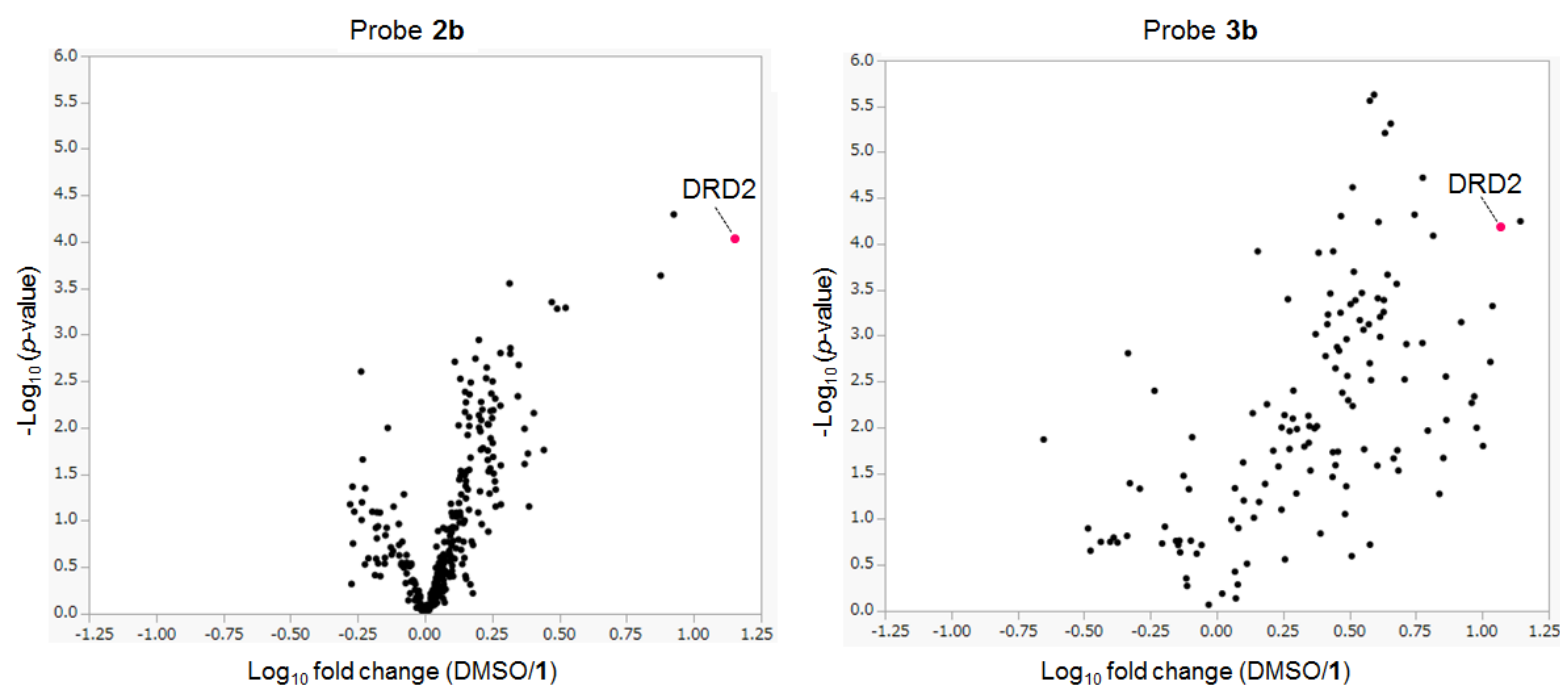

Figure S4. Volcano plot showing results of competition between probe $2 \mathbf{b}(5 \mu \mathrm{M}$, left) or $3 \mathbf{b}(5 \mu \mathrm{M}$, right) and competitor $\mathbf{1}(10 \mu \mathrm{M})$. 


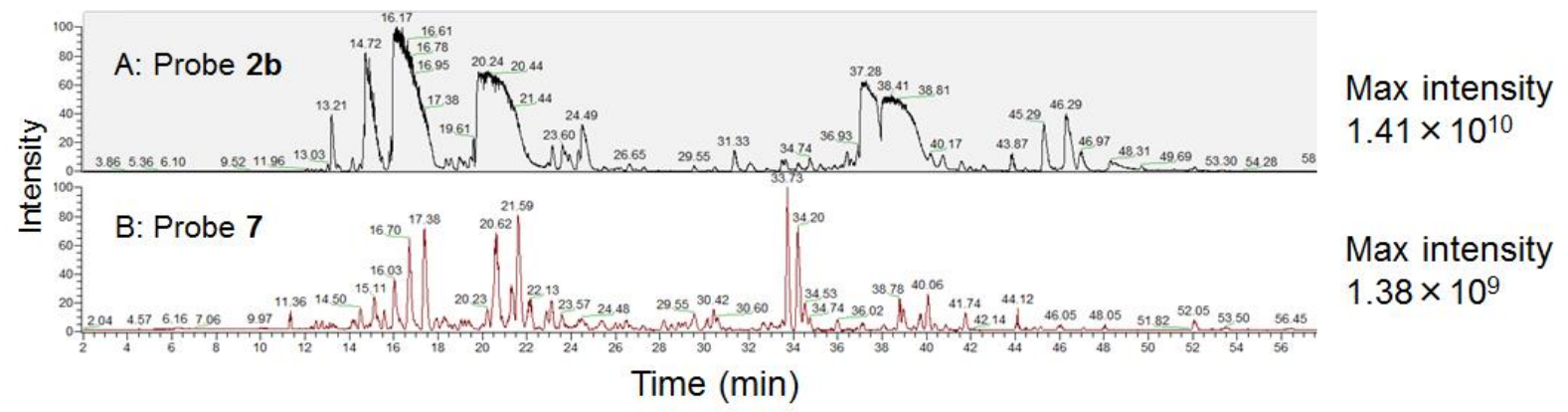

Figure S5. Panels A and B, respectively, are whole MS1 chromatogram of samples treated with probe $\mathbf{2 b}$ and probe 7 . 


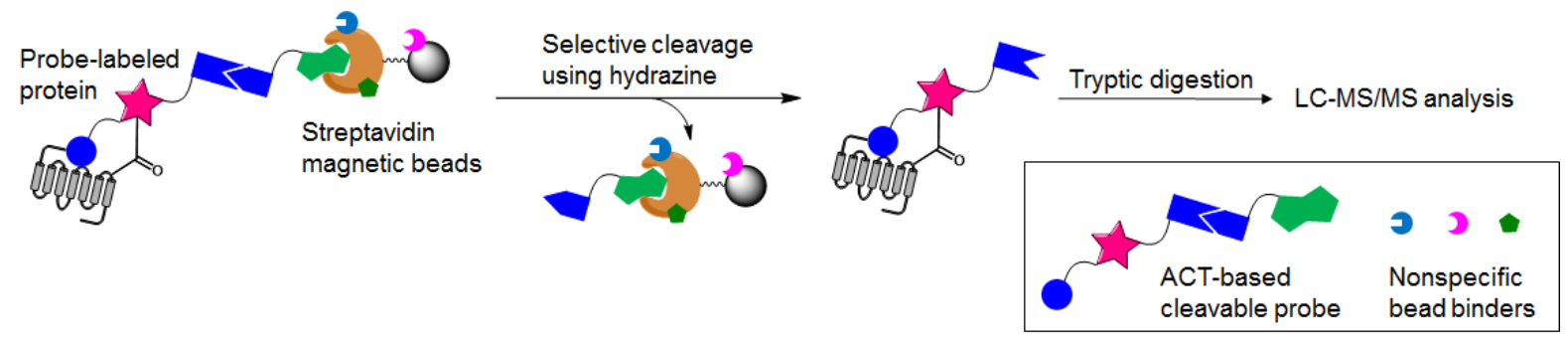

Figure S6. Experimental workflow showing the application of a cleavable probe for identification of target receptors using chemical proteomics. 


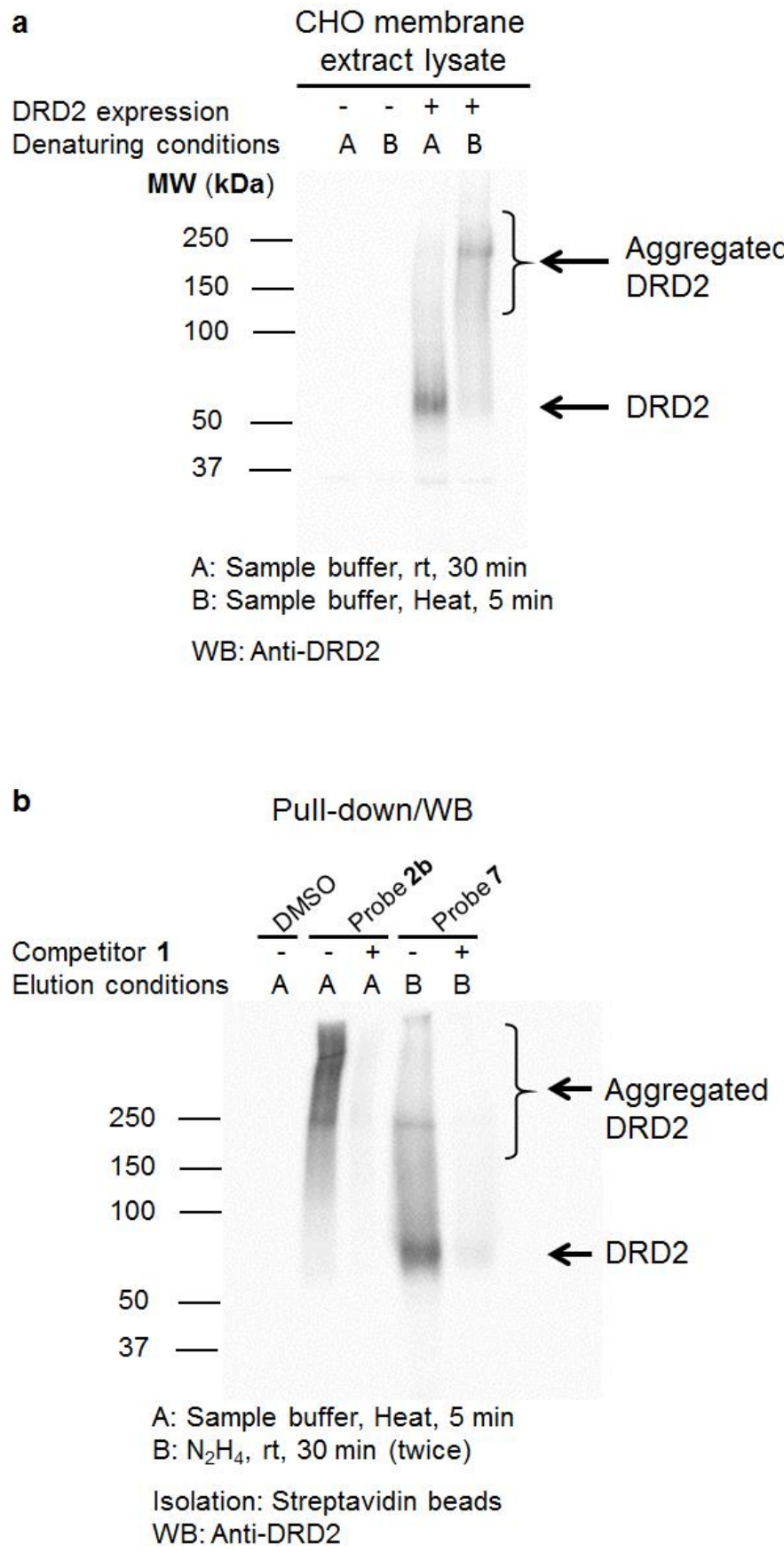

Figure S7. Pull-down/Western blot studies of DRD2 labeled by ACT-based probe $\mathbf{2 b}$ or $\mathbf{7}(5 \mu \mathrm{M})$ in DRD2expressing CHO cells. (a) Anti-DRD2 western blot analysis of membrane extract lysate from non-transfected and transfected CHO cells. (b) Western blot of DRD2 in the pull-downed samples using anti-DRD2 antibodies followed by detection with HRP-linked secondary antibodies. 


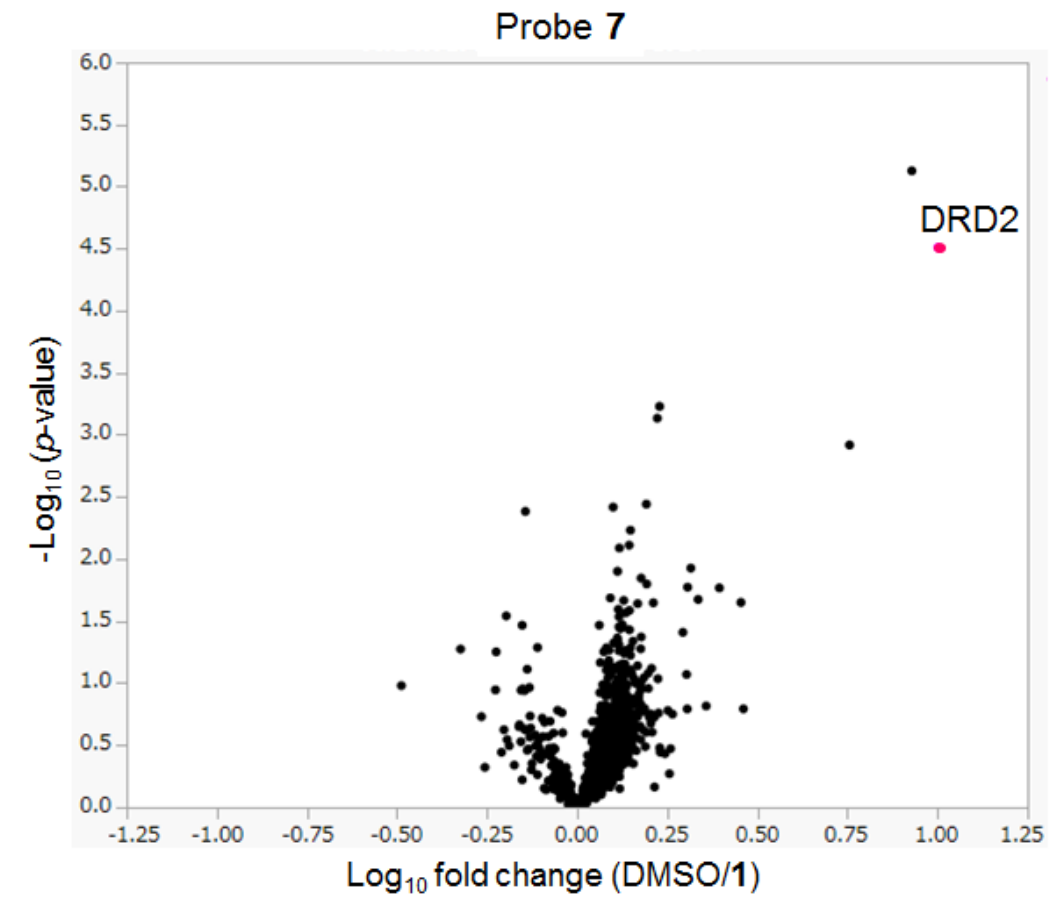

Figure S8. Volcano plot showing results of competition between probe $7(5 \mu \mathrm{M})$ and competitor $\mathbf{1}(10 \mu \mathrm{M})$. 


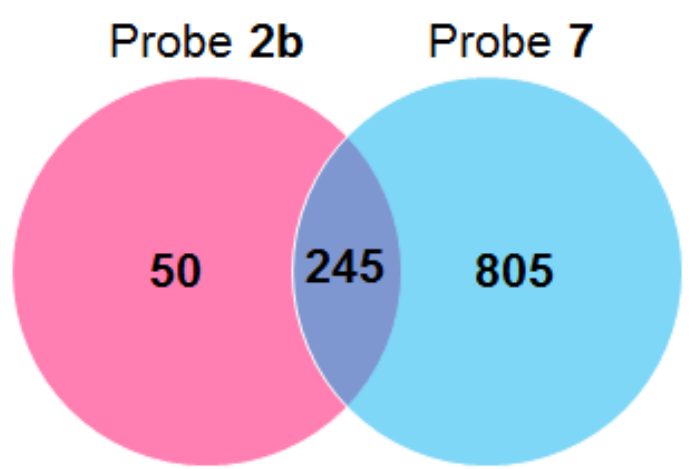

Figure S9. Schematic view of proteins identified by competitive proteome profiling with either probe $\mathbf{2 b}$ (pink) or probe 7 (blue). 


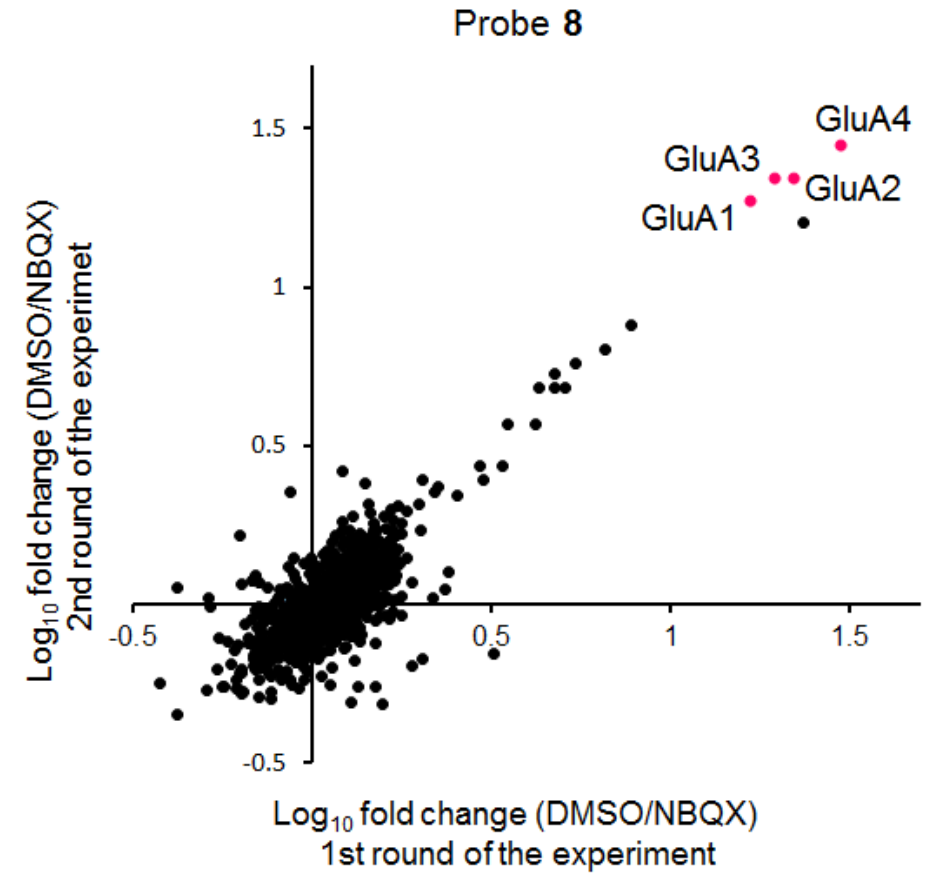

Figure S10. Competition plots showing proteins for which enrichment by probe $8(5 \mu \mathrm{M})$ was blocked by $\operatorname{NBQX}(50 \mu \mathrm{M})$ in brain slices $(\mathrm{n}=2)$. 

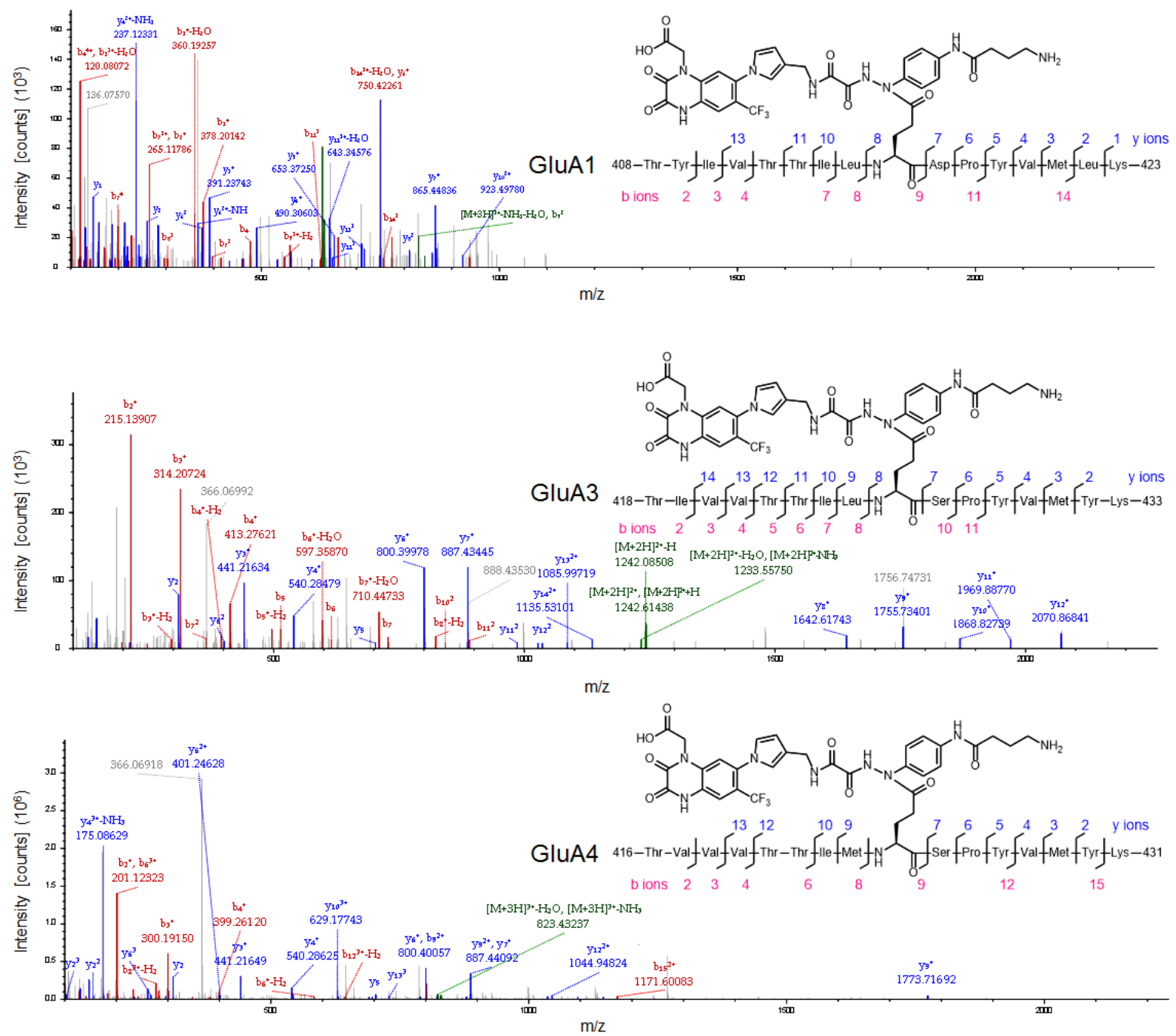

Figure S11. MS/MS spectrum of probe 8 -labeled peptides on GluA1, 3, and 4. 


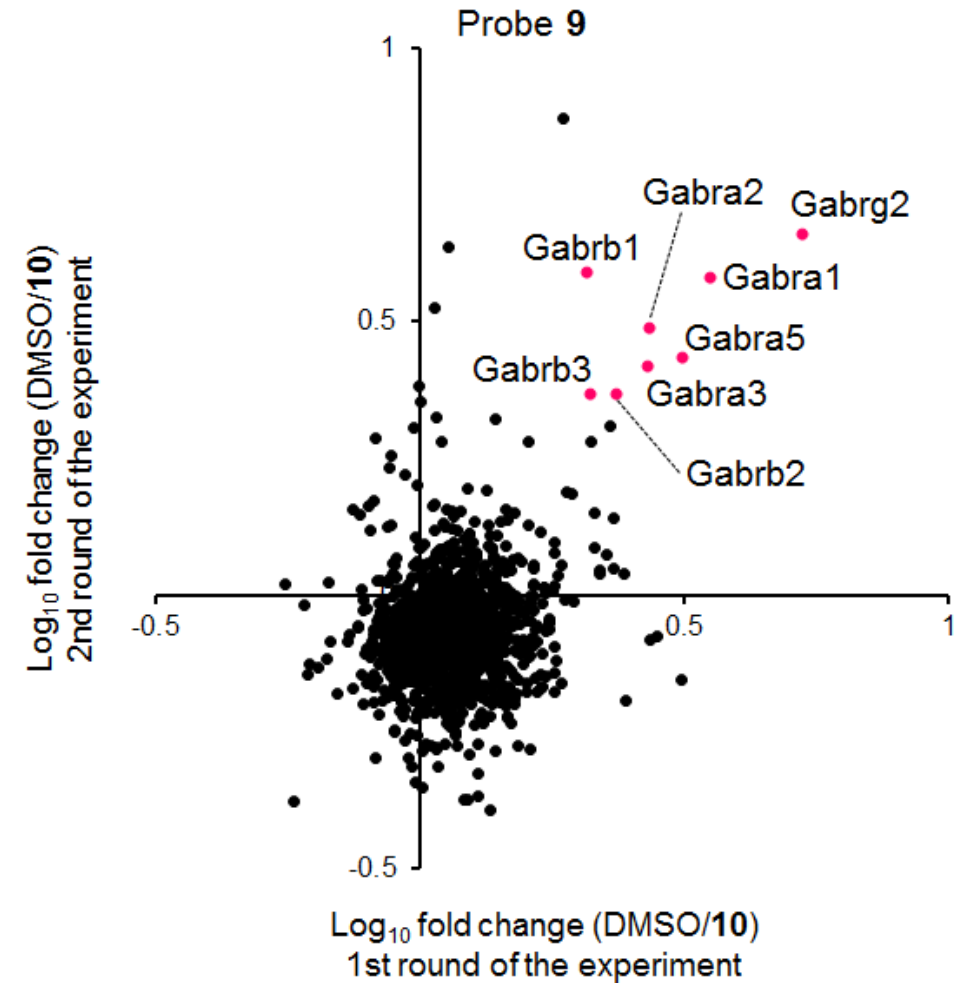

Figure S12. Competition plots showing proteins for which enrichment by probe $\mathbf{9}(5 \mu \mathrm{M})$ was blocked by $10(50 \mu \mathrm{M})$ in brain slices $(\mathrm{n}=2)$. 


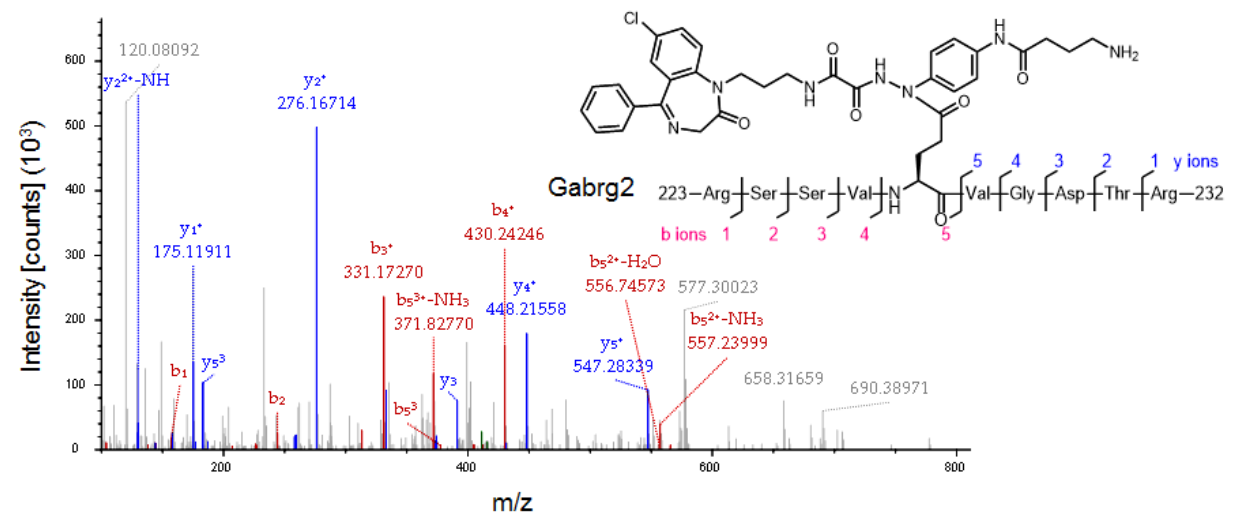

Figure S13. MS/MS spectrum of probe 9-labeled peptide on $\mathrm{GABA}_{A} \mathrm{R} \gamma 2$ subunit. 


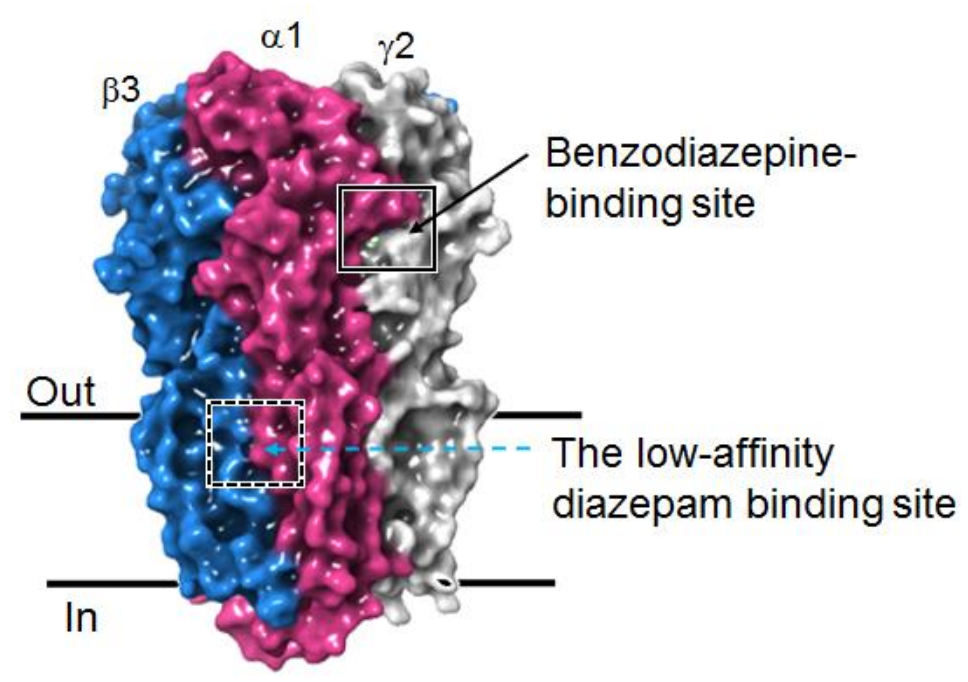

Figure S14. Cryo-electron microscopy structure of the full-length human $\alpha 1 \beta 3 \gamma 2 \mathrm{~L} \mathrm{GABA}_{\mathrm{A}} \mathrm{R}$ in complex with diazepam is shown (PDB: 6HUP). ${ }^{\text {ref. } 2}$ The low-affinity diazepam binding site in the $\beta 3 / \alpha 1$ interface transmembrane domain region is shown in dashed box; Benzodiazepine-binding site is shown in black solidline box. 
a

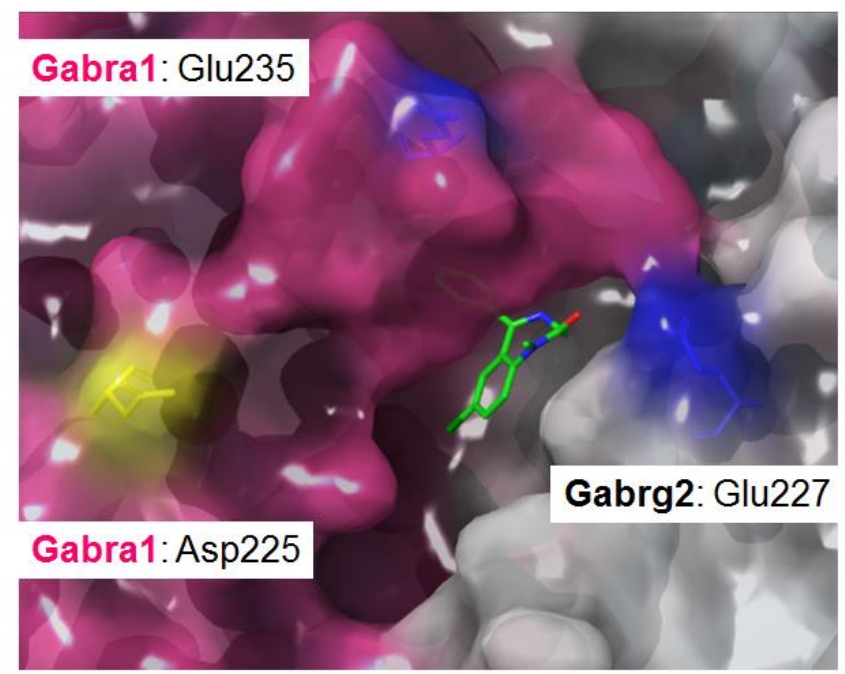

214-LNQYDLLGQTVDSGIVQSSTGEYVVMTTHFHLK-246

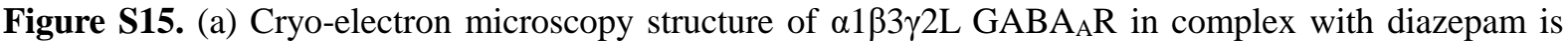
shown (PDB: 6HUP). ${ }^{\text {ref.2 }}$ Asp225 and Glu235 on $\alpha 1$ subunit, which are located near the diazepam-binding pocket and potentially react with ACT-based cleavable probe $\mathbf{9}$, are shown in yellow and blue, respectively. Diazepam is shown in green. Residue numbers of full-length $\mathrm{GABA}_{A} \mathrm{R}$ subunit $\alpha 1$ (NP_034380) and $\gamma 2$ (NP_032099) are shown. (b) The predicted tryptic peptide sequence including Asp 225 and Glu 235 on $\alpha 1$ subunit is shown. Asp 225 and Glu 235 are shown in yellow and blue, respectively. Hydrophobic amino acids are shown in pink. 


\section{General Information}

Solvents and chemicals were purchased from commercial sources and used directly without further purification. Medium-pressure flash chromatography was performed with Biotage Isolera and SNAP Ultra Cartridge. ${ }^{1} \mathrm{H}$ NMR spectra were recorded on BRUKER AVANCE III $400(400 \mathrm{MHz})$ or BRUKER AVANCE III HD 500 (500 MHz). Chemical shifts were reported in ppm using either TMS or deuterated solvents as internal standards (TMS, 0.00; $\mathrm{CDCl}_{3}, 7.26$; DMSO- $d 6,2.50)$. Multiplicity was reported as follows: $\mathrm{s}=$ singlet, $\mathrm{d}=$ doublet, $\mathrm{t}=$ triplet, $\mathrm{q}=$ quartet, quin = quintet, $\mathrm{dd}=$ double doublet, $\mathrm{m}=$ multiplet, $\mathrm{br}=$ broad. ${ }^{13} \mathrm{C}$ NMR spectra were recorded on BRUKER AVANCE III 400 (100 MHz) or BRUKER AVANCE III HD 500 (125 $\mathrm{MHz}$ ). Chemical shifts were reported in ppm using deuterated solvents as internal standards $\left(\mathrm{CDCl}_{3}, 77.0\right.$; DMSO-d6, 39.6; $\left.\mathrm{CD}_{3} \mathrm{OD}, 49.0\right)$. High-resolution mass spectra (HRMS) were obtained using WATERS H-class/Xevo G2-XS for ESI and JEOL JMS-700V mass spectrometer for EI. Analytical purity of the final compounds was determined by ultra pressure liquid chromatography (UPLC; ACQUITY UPLC ${ }^{\circledR}$ ) with an ACQUITY UPLC BEH C18

column $(130 \AA, 1.7 \mu \mathrm{m}, 2.1 \mathrm{~mm} \times 30 \mathrm{~mm})$, measuring UV absorbance by using diode array detector. All compounds showed a single peak and were at least $95 \%$ pure. For photoirradiation with a UV crosslinker [Analytik Jena US, $302 \mathrm{~nm}$ (CL-1000M) or $365 \mathrm{~nm}$ (CL-1000L)] or a hand-held UV lamp (Analytik Jena US, 3UV-36 UV Lamp, $254 \mathrm{~nm}$ ), if not specified, $302 \mathrm{~nm}$ photoirradiation for $1 \mathrm{~min}$ was carried out for ACT-based probes, $365 \mathrm{~nm}$ photoirradiation for $10 \mathrm{~min}$ was carried out for DA-based probes, $365 \mathrm{~nm}$ photoirradiation for $30 \mathrm{~min}$ was carried out for BP-based probes, and $254 \mathrm{~nm}$ photoirradiation for $5 \mathrm{~min}$ was carried out for PA-based probes. All MS-based experiments and biochemical experiments were performed in two more biological replicates.

\section{Cell Lines}

The establishment of the clonal Chinese hamster ovary (CHO) cell line lacking dehydrofolate reductase and stably expressing a high density of human recombinant DRD2 (hD2L, long isoform) was previously reported as CHO-hD2L-high cells. ${ }^{\text {ref.3 }}$ The cells were cultured in Dulbecco's Modified Eagle Medium (DMEM) Nutrient Mixture F-12 (Ham) supplemented with $10 \%$ (v/v) fetal bovine serum (FBS), 100 units $/ \mathrm{mL}$ penicillin, $100 \mu \mathrm{g} / \mathrm{mL}$ streptomycin, $2.5 \mathrm{mM}$ L-glutamine, and $200 \mu \mathrm{g} / \mathrm{mL} \mathrm{G} 418$ in a humidified $5 \% \mathrm{CO}_{2}$ incubator maintained at $37^{\circ} \mathrm{C}$. Whenever thawed, cells were passaged at least three times before being used in experiments.

\section{Preparation of membrane fraction from DRD2-expressing CHO cell lysates for binding competition assay}

Preparation of cell membrane fraction from DRD2 expressing cells was performed as previously reported. ${ }^{\text {ref.3,4 }}$ In brief, DRD2 expressing cells were harvested, resuspended in 
isotonic sucrose solution (50 mM Tris buffer containing $2.5 \mathrm{mM}$ EDTA, $5 \mathrm{mM} \mathrm{MgCl}$, and 320 $\mathrm{mM}$ sucrose) and lysed by sonication (10 pulses, $90 \%$ duty cycle, output setting $=3$ ). The homogenate was centrifuged at 30,000g for $30 \mathrm{~min}$. The pellets were resuspended in ice-cold $50 \mathrm{mM}$ Tris buffer (pH 7.4) containing $120 \mathrm{mM} \mathrm{NaCl}, 5 \mathrm{mM} \mathrm{KCl}, 2 \mathrm{mM} \mathrm{CaCl}_{2}$, and $1 \mathrm{mM}$ $\mathrm{MgCl}_{2}$. The resulting homogenate was stored at $-80{ }^{\circ} \mathrm{C}$ until use.

\section{Radioligand binding competition assay}

Radioligand binding assays were adapted methods previously reported. ${ }^{\text {ref.3,4 }}$

\section{In situ labeling of living DRD2-expressing CHO cells with chemical probes}

$\mathrm{CHO}$ cells were grown to near complete confluence prior to treatment in $10 \mathrm{~cm}$ plates, washed with FBS-free media and treated with FBS-free DMEM Nutrient Mixture F-12 (Ham) containing $10 \mu \mathrm{M}$ compound 1 or DMSO. The cells were incubated for $30 \mathrm{~min}\left(37{ }^{\circ} \mathrm{C}, 5 \%\right.$ $\mathrm{CO}_{2}$ ). Subsequently, chemical probe or DMSO (control) was added (final probe concentration $=5 \mu \mathrm{M})$, and the plates were maintained in the incubator for $30 \mathrm{~min}\left(37{ }^{\circ} \mathrm{C}, 5 \% \mathrm{CO}_{2}\right)$. The cells were washed and resuspended with PBS followed by UV irradiation on ice (254 $\mathrm{nm}$ for PA-based probe; $365 \mathrm{~nm}$ for DA- and BP-based probe; $302 \mathrm{~nm}$ for ACT-based probe). The cells were then harvested by scraping, pelleted and kept frozen at $-80{ }^{\circ} \mathrm{C}$ until use.

\section{Preparation of probe-labeled membrane fraction for MS-based protein analyses}

The pellets were resuspended in isotonic sucrose solution and lysed by sonication. Cell lysates were then centrifuged $(1,000 \mathrm{~g}, 15 \mathrm{~min})$ to remove cell debris. The supernatant was centrifuged at $30,000 \mathrm{~g}$ for $30 \mathrm{~min}$. After removal of the supernatant, the pellets were washed with $0.1 \mathrm{M}$ $\mathrm{Na}_{2} \mathrm{CO}_{3}$ and centrifuged at $452,000 \mathrm{~g}$ for $30 \mathrm{~min}$. Finally, the pellets were rinsed with water and then kept frozen at $-80{ }^{\circ} \mathrm{C}$ until use.

\section{Enrichment of probe-labeled membrane proteome and heat elution procedure}

Prepared membrane fraction was dissolved in RIPA buffer containing urea by sonication. The solution was incubated with pre-equilibrated streptavidin magnetic beads (Pierce) at room temperature (r.t.) for 2 h. After washing the beads with RIPA buffer containing urea $(\times 3)$, proteins were eluted with $20 \mu \mathrm{L}$ of $10 \mathrm{mM}$ Tris- $\mathrm{HCl}$ containing $1 \%(\mathrm{w} / \mathrm{v})$ sodium deoxycholate (SDC) and $5 \mathrm{mM}$ DTT (pH7.4) at $95{ }^{\circ} \mathrm{C}$ for $5 \mathrm{~min}$. The supernatant was treated with $50 \mathrm{mM}$ iodoacetamide for $30 \mathrm{~min}$ in the dark. Then, single-pot solid-phase-enhanced sample preparation (SP3) was performed as previously reported. ${ }^{\text {ref.5,6 }}$ In brief, $2 \mu \mathrm{L}$ prepared bead mix was added to the probe-labeled proteome. $\mathrm{MeCN}$ was then added to a final concentration of $70 \%$ (v/v) and samples were incubated for $18 \mathrm{~min}$. Subsequently, supernatant was removed by magnetic separation, and the bead was rinsed with $70 \%$ (v/v) EtOH in water and $\mathrm{MeCN}$. The bead was then treated with sequencing grade trypsin $\left(25 \mathrm{ng}\right.$, Promega) in $50 \mathrm{mM}\left(\mathrm{NH}_{4}\right)_{2} \mathrm{CO}_{3}$ 
buffer containing $1 \%(\mathrm{w} / \mathrm{v}) \mathrm{SDC}$ for $16 \mathrm{~h}$ at $37^{\circ} \mathrm{C}$. After overnight digestion, MeCN was added to reach a final concentration of $95 \%(\mathrm{v} / \mathrm{v})$. After mixing and incubating, supernatant was removed and the beads were rinsed with $\mathrm{MeCN}$. Tryptic peptides bound to the beads were eluted with $0.1 \%$ (v/v) TFA aq. and applied for LC-MS/MS analysis.

\section{In situ labeling of mouse brain slices with chemical probes ${ }^{\text {ref.7 }}$}

Mouse brain slices (300 $\mu \mathrm{m}$ thickness) were prepared from DBA/2CrSlc mice and incubated with ice-cold artificial cerebrospinal fluid (ACSF) solution (124 mM NaCl, $3.0 \mathrm{mM} \mathrm{KCl}, 2.0$ $\mathrm{mM} \mathrm{CaCl} 2,1.0 \mathrm{mM} \mathrm{MgSO} 4,1.25 \mathrm{mM} \mathrm{KH}_{2} \mathrm{PO}_{4}, 26 \mathrm{mM} \mathrm{NaHCO}$, $10 \mathrm{mM}$ D-glucose). Competitor was added to a final concentration of $50 \mu \mathrm{M}$, and the brain slices were incubated at r.t. for $5 \mathrm{~min}$. Subsequently, chemical probe was added (final probe concentration $=5 \mu \mathrm{M}$ ), and the sample was incubated at r.t. for $30 \mathrm{~min}$. At the end of the incubation, the slices were irradiated with $302 \mathrm{~nm}$ UV lamp for $1 \mathrm{~min}$ on ice after confirming that each brain slice did not overlap. The brain slices were resuspended in PBS and centrifuged (3,000g, 3 min). After removal of the supernatant, the pellets were directly processed.

\section{Preparation, enrichment, and elution by hydrazine cleavage of probe-labeled membrane proteome for MS-based protein analyses}

Preparation of membrane fractions by sonication and ultracentrifugation was as described before. After enrichment of biotinylated proteins by streptavidin magnetic beads, the bead was treated with $2 \%(\mathrm{v} / \mathrm{v}) \mathrm{N}_{2} \mathrm{H}_{4}$ in $0.05 \%$ (w/v) SDS aq. (40 $\mu \mathrm{L}, 2 \times 30 \mathrm{~min}$ ). The supernatant was neutralized by $20 \%$ (v/v) TFA in water and concentrated by using Speedvac Vacuum Concentrator. After concentration, disulfides were reduced with $25 \mathrm{mM}$ DTT at $70{ }^{\circ} \mathrm{C}$ for 15 min. Reduced thiols were alkylated by addition of $250 \mathrm{mM}$ iodoacetamide for $30 \mathrm{~min}$ in the dark. Then, proteins were purified and digested with trypsin by SP3.

\section{Pull-down/Western blotting (WB) analyses of samples treated with cleavable probe 7}

Preparation of membrane fractions treated with probe 7 followed by enrichment and hydrazine treatment was described previously. After concentration of elution fraction using Speedvac Vacuum Concentrator, the concentrated sample was mixed with 4×SDS PAGE loading buffer (Merck Millipore) and incubated at r.t. for $30 \mathrm{~min}$. The samples were applied to SDS-PAGE and electrotransferred onto ImmunoBlot PVDF membranes (Bio-Rad), and were then blocked with $5 \%(\mathrm{w} / \mathrm{v})$ BSA in TBS containing $0.05 \%(\mathrm{v} / \mathrm{v})$ Tween 20 . The membranes were stained with rabbit anti-DRD2 antibody (Merck Millipore, AB5084P) followed by a HRP-linked goat anti-rabbit IgG (Cell Signaling TECHNOLOGY, \#7074). The membranes were developed with ECL Prime Western Blotting Detection reagent (Cytiva). 


\section{Pull-down/WB analyses of samples treated with non-cleavable probe $\mathbf{2 b}$}

Preparation of membrane fractions treated with probe $\mathbf{2 b}$ was described previously. After enrichment of biotinylated proteins by streptavidin magnetic beads, the enriched proteins were eluted by addition of RIPA buffer containing 1×SDS PAGE loading buffer (Merck Millipore) and boiling in heatblock for $5 \mathrm{~min}$. The samples were applied to SDS-PAGE. Following steps were described above.

\section{Mass Spectrometry Procedures ${ }^{\text {ref. } 8}$}

The prepared analysis sample in $0.1 \%$ (v/v) TFA aq. was loaded onto a C18 trap column (Thermo Scientific Acclaim PepMap 100, $3 \mu \mathrm{m}$ particle size, $2 \mathrm{~cm}$ length, $75 \mu \mathrm{m}$ internal diameter) and then separated on an analytical column (Nikkyo Technos NANO HPLC CAPILLARY COLUMN C18, $3 \mu \mathrm{m}$ particle size, $12 \mathrm{~cm}$ length, $75 \mu \mathrm{m}$ internal diameter) at $300 \mathrm{~nL} / \mathrm{min}$ with a Thermo Scientific Ultimate 3000 system connected in line to a Thermo Scientific Q Exactive. The tryptic peptides were separated via a linear gradient from $4 \%$ to $35 \%$ of $0.1 \%(\mathrm{v} / \mathrm{v})$ formic acid/acetonitrile over $48 \mathrm{~min}$. Peptides were ionized in positive mode using a nanospray source at $1.8 \mathrm{kV}$. Full scan acquisition (scan range of 380-1600 m/z) was performed at a resolution of 70000 (at $\mathrm{m} / \mathrm{z} 200$ ), and the 10 most intense ions were sequentially selected and fragmented in HCD (Top10 method). HCD fragmentation was applied with 35\% collision energy and resulting fragments accumulated for up to $100 \mathrm{~ms}$.

\section{Quantitative data analysis using label free quantification ${ }^{\text {ref.8 }}$}

Data analysis was performed in Proteome Discoverer version 2.2 (Thermo Fisher Scientific). All MS/MS spectra were searched against a database containing the Uniprot 2019 annotated Chinese hamster proteome including human DRD2 or mouse proteome and contaminant proteins using Sequest HT with a mass tolerance of $10 \mathrm{ppm}$ for the precursor and 0.02 Da for fragment ions with specific trypsin digestion, 2 missed cleavages, variable oxidation on methionine residues (+15.995 Da), static carboxyamidomethylation of cysteine residues $(+57.021 \mathrm{Da})$, and chemical modification of aspartic acid residues, glutamic acid residues, and cysteine residues by probe $\mathbf{8}$ or probe $\mathbf{9}$ (probe $\mathbf{8}+626.184 \mathrm{Da}$; probe $\mathbf{9}+571.209 \mathrm{Da}$ ). The resulting assignments were filtered to an FDR below $1 \%$ on the protein level. In labeling experiments using $\mathrm{CHO}$ cells expressing DRD2, three independent biological replicates were performed on different days, and only non-contaminant proteins with at least two unique peptides were considered as target proteins of chemical probes; in live tissue labeling using mouse brain slices, two independent biological replicates were performed on different days, and only non-contaminant proteins with at least two unique peptides and at least ten peptide spectrum matches (PSMs) were considered for analysis of target deconvolution. 
Scheme S1. Synthesis of compounds S2-4

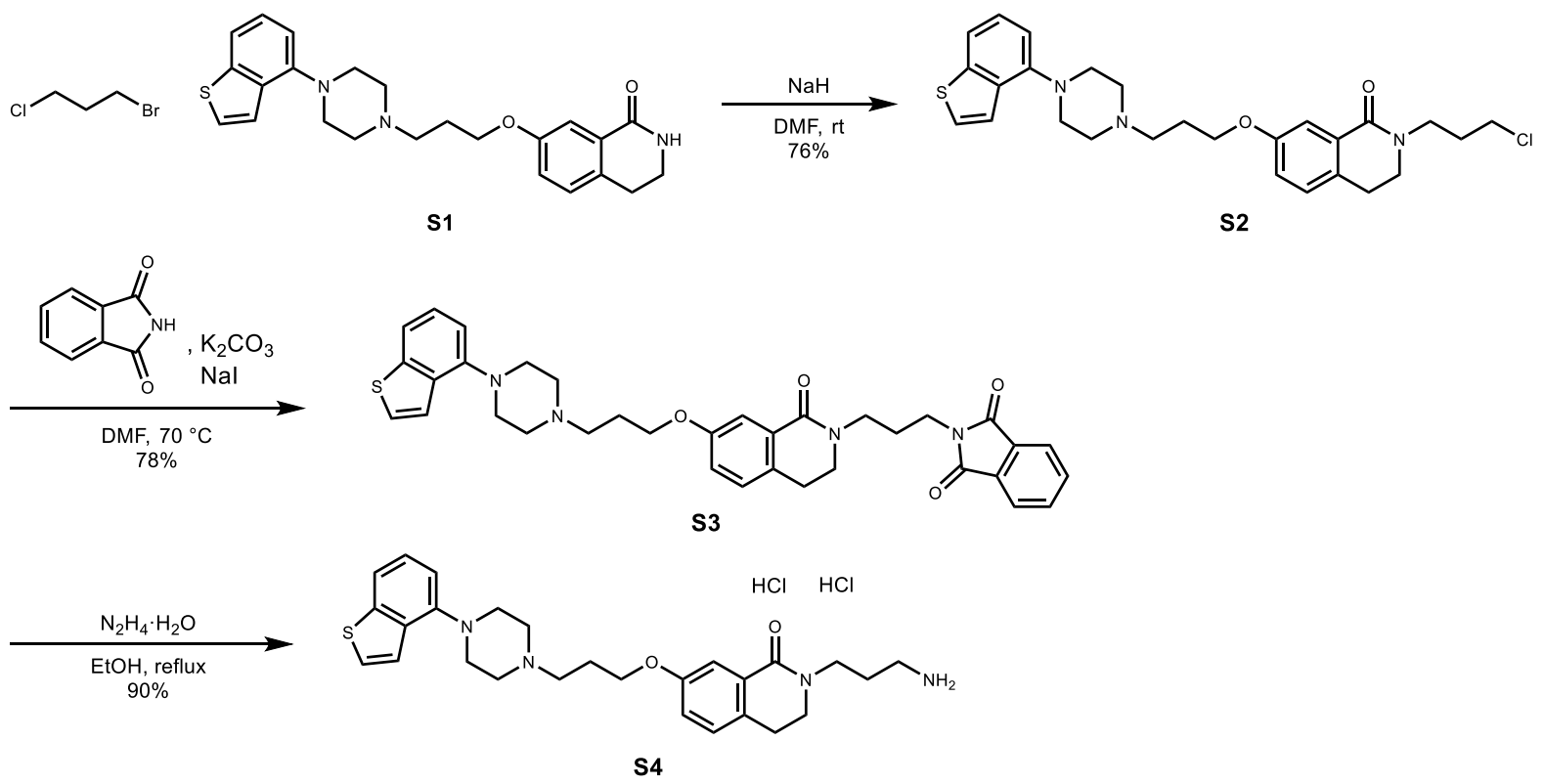

Synthesis of $\mathbf{S} \mathbf{2}$ (S1 was prepared according to a known procedure. ${ }^{\text {ref.9) }}$ )

To a solution of S1 (505 mg, $1.20 \mathrm{mmol})$ in $50 \mathrm{~mL}$ DMF was added 60\% NaH (71.9 mg, 1.80 $\mathrm{mmol})$, and the mixture was stirred at r.t. for $30 \mathrm{~min}$ before 1-bromo-3-chloropropane $(0.178$ $\mathrm{mL}, 1.80 \mathrm{mmol}$ ) was added. The mixture was stirred at r.t. for $60 \mathrm{~h}$. Then $30 \mathrm{~mL}$ water was added to the mixture, and the solvent was removed by evaporation. The residue was dissolved in EtOAc, and the organic layer was washed with water and then dried over $\mathrm{Na}_{2} \mathrm{SO}_{4}$. After removal of the solvent by evaporation, the residue was purified by medium-pressure flash chromatography (column; SNAP Ultra (25 g), mobile phase; EtOAc/MeOH (100:0 $\rightarrow$ 93:7), detection; UV ( $\lambda$-all)). The suitable fractions were pooled, and the solvent was removed by evaporation to give $\mathbf{S 2}$ as a pale brown oil (453 mg, 76\%); ${ }^{1} \mathrm{H}$ NMR (500 MHz, $\left.\mathrm{CDCl}_{3}\right) \delta 7.61$ $(\mathrm{d}, J=2.7 \mathrm{~Hz}, 1 \mathrm{H}), 7.55(\mathrm{~d}, J=8.1 \mathrm{~Hz}, 1 \mathrm{H}), 7.42(\mathrm{~d}, J=5.5 \mathrm{~Hz}, 1 \mathrm{H}), 7.38(\mathrm{~d}, J=5.5 \mathrm{~Hz}, 1 \mathrm{H})$, $7.27(\mathrm{t}, J=7.8 \mathrm{~Hz}, 1 \mathrm{H}), 7.09(\mathrm{~d}, J=8.3 \mathrm{~Hz}, 1 \mathrm{H}), 6.99(\mathrm{dd}, J=8.3,2.7 \mathrm{~Hz}, 1 \mathrm{H}), 6.90(\mathrm{~d}, J=$ $7.6 \mathrm{~Hz}, 1 \mathrm{H}), 4.11(\mathrm{t}, J=6.3 \mathrm{~Hz}, 2 \mathrm{H}), 3.70(\mathrm{t}, J=6.8 \mathrm{~Hz}, 2 \mathrm{H}), 3.63(\mathrm{t}, J=6.4 \mathrm{~Hz}, 2 \mathrm{H}), 3.59$ (t, $J=6.7 \mathrm{~Hz}, 2 \mathrm{H}), 3.20(\mathrm{br}, 4 \mathrm{H}), 2.94(\mathrm{t}, J=6.6 \mathrm{~Hz}, 2 \mathrm{H}), 2.73(\mathrm{br}, 4 \mathrm{H}), 2.64(\mathrm{t}, J=7.3 \mathrm{~Hz}, 2 \mathrm{H})$, 2.15 (quin, $J=6.7 \mathrm{~Hz}, 2 \mathrm{H}$ ), 2.04 (quin, $J=6.5 \mathrm{~Hz}, 2 \mathrm{H}$ ); ${ }^{13} \mathrm{C} \mathrm{NMR}\left(125 \mathrm{MHz}, \mathrm{CDCl}_{3}\right) \delta 164.7$, 158.2, 148.5, 141.1, 134.1, 130.3, 130.1, 128.1, 125.0, 124.9, 121.9, 119.6, 117.0, 112.2, 112.2, 66.6, 55.2, 53.6, 52.1, 47.3, 45.6, 42.6, 30.9, 27.4, 26.7; HRMS (ESI) calcd for $\mathrm{C}_{27} \mathrm{H}_{33} \mathrm{~N}_{3} \mathrm{O}_{2} \mathrm{SCl}$ $498.1982[\mathrm{M}+\mathrm{H}]^{+}$, found 498.1979 .

\section{Synthesis of $\mathbf{S 3}$}

To a solution of $\mathbf{S 2}$ (453 mg, $0.909 \mathrm{mmol})$ in $10 \mathrm{~mL}$ DMF was added phthalimide (161 mg, $1.09 \mathrm{mmol}), \mathrm{K}_{2} \mathrm{CO}_{3}(151 \mathrm{mg}, 1.09 \mathrm{mmol})$, and $\mathrm{NaI}(40.9 \mathrm{mg}, 0.273 \mathrm{mmol})$, and the mixture was stirred at $70{ }^{\circ} \mathrm{C}$ for $17 \mathrm{~h}$. After removal of the solvent by evaporation and addition of 100 
$\mathrm{mL}$ water to the residue, the solvent was extracted with $100 \mathrm{~mL}$ EtOAc twice, and the organic layer was dried over $\mathrm{MgSO}_{4}$. The solvent was removed by evaporation, and the residue was purified by medium-pressure flash chromatography (column; SNAP Ultra (25 g), mobile phase; EtOAc/MeOH (100:0 $\rightarrow 91: 9)$, detection; $U V(\lambda$-all)). The suitable fractions were pooled, and the solvent was removed by evaporation to give $\mathbf{S 3}$ as a pale yellow amorphous (432 $\mathrm{mg}$, $78 \%) ;{ }^{1} \mathrm{H}$ NMR $\left(500 \mathrm{MHz}, \mathrm{CDCl}_{3}\right) \delta 7.84(\mathrm{~d}, J=3.0 \mathrm{~Hz}, 1 \mathrm{H}) 7.83(\mathrm{~d}, J=3.0 \mathrm{~Hz}, 1 \mathrm{H}), 7.60(\mathrm{~d}$, $J=2.7 \mathrm{~Hz}, 1 \mathrm{H}), 7.54(\mathrm{~d}, J=8.1 \mathrm{~Hz}, 1 \mathrm{H}), 7.41(\mathrm{dd}, J=5.5,0.6 \mathrm{~Hz}, 1 \mathrm{H}), 7.38(\mathrm{~d}, J=5.5 \mathrm{~Hz}$, $1 \mathrm{H}), 7.27$ (t, $J=7.8 \mathrm{~Hz}, 1 \mathrm{H}), 7.09(\mathrm{~d}, J=8.3 \mathrm{~Hz}, 1 \mathrm{H}), 6.98(\mathrm{dd}, J=8.3,2.8 \mathrm{~Hz}, 1 \mathrm{H}), 6.90$ (dd, $J=7.7,0.6 \mathrm{~Hz}, 1 \mathrm{H}), 4.10(\mathrm{t}, J=6.4 \mathrm{~Hz}, 2 \mathrm{H}), 3.77(\mathrm{t}, J=7.3 \mathrm{~Hz}, 2 \mathrm{H}), 3.66(\mathrm{t}, J=7.1 \mathrm{~Hz}, 2 \mathrm{H})$, $3.57(\mathrm{t}, J=6.7 \mathrm{~Hz}, 2 \mathrm{H}), 3.20(\mathrm{br}, 4 \mathrm{H}), 2.96(\mathrm{t}, J=6.6 \mathrm{~Hz}, 2 \mathrm{H}), 2.75(\mathrm{br}, 4 \mathrm{H}), 2.65(\mathrm{t}, J=7.4$ $\mathrm{Hz}, 2 \mathrm{H}), 2.07-2.01(\mathrm{~m}, 4 \mathrm{H}) ;{ }^{13} \mathrm{C} \mathrm{NMR}\left(125 \mathrm{MHz}, \mathrm{CDCl}_{3}\right) \delta 168.3,164.5,158.1,148.4,141.1$, 134.1, 134.0, 132.1, 130.3, 130.2, 128.0, 125.0, 124.9, 123.3, 121.9, 119.6, 117.0, 112.3, 112.2, 66.5, 55.2, 53.6, 52.0, 46.4, 45.0, 35.8, 27.4, 26.9, 26.7; HRMS (ESI) calcd for $\mathrm{C}_{35} \mathrm{H}_{37} \mathrm{~N}_{4} \mathrm{O}_{4} \mathrm{~S}$ $609.2535[\mathrm{M}+\mathrm{H}]^{+}$, found 609.2538 .

\section{Synthesis of $\mathbf{S 4}$}

To a solution of $\mathbf{S 3}$ (430 mg, $0.706 \mathrm{mmol}$ ) in $12 \mathrm{~mL} \mathrm{EtOH}$ was added hydrazine hydrate $(68.6$ $\mu \mathrm{L}, 1.41 \mathrm{mmol}$ ), and the mixture was refluxed for $8 \mathrm{~h}$. After removal of the solvent by evaporation and addition of $50 \mathrm{~mL} 1 \mathrm{M} \mathrm{NaOH}$ aq. to the residue, the solvent was extracted with $100 \mathrm{~mL}$ EtOAc. The organic layer was washed with brine and then dried over $\mathrm{Na}_{2} \mathrm{SO}_{4}$. The solvent was removed by evaporation, and the residue was purified by medium-pressure flash chromatography (column; SNAP Ultra (25 g), mobile phase; $\mathrm{CH}_{2} \mathrm{Cl}_{2} / \mathrm{MeOH}$ $(100: 0 \rightarrow 90: 10)$, detection; UV ( $\lambda$-all)). The suitable fractions were pooled, and the solvent was removed by evaporation. After the residue was dissolved in $10 \mathrm{~mL} \mathrm{MeOH}, 2 \mathrm{M} \mathrm{HCl}$ aq. (2.12 $\mathrm{mL}, 4.24 \mathrm{mmol}$ ) was to the solution, and the mixture was stirred at r.t. for $15 \mathrm{~h}$. After removal of the solvent by evaporation, EtOAc was added to the residue, and the mixture was stiired at r.t. for $1 \mathrm{~h}$. The precipitate was collected with a glass filter, washed with EtOAc, and dried under vacuum to give $\mathbf{S} 4$ as a pale brown solid (351 mg, 90\%); ${ }^{1} \mathrm{H}$ NMR (500 MHz, DMSO$\left.d_{6}\right) \delta 11.4(\mathrm{br}, 1 \mathrm{H}), 7.98(\mathrm{br}, 3 \mathrm{H}), 7.78(\mathrm{~d}, J=5.5 \mathrm{~Hz}, 1 \mathrm{H}), 7.71(\mathrm{~d}, J=8.1 \mathrm{~Hz}, 1 \mathrm{H}), 7.50(\mathrm{~d}, J$ $=5.5 \mathrm{~Hz}, 1 \mathrm{H}), 7.43(\mathrm{~d}, J=2.7 \mathrm{~Hz}, 1 \mathrm{H}), 7.33(\mathrm{t}, J=7.8 \mathrm{~Hz}, 1 \mathrm{H}), 7.26(\mathrm{~d}, J=8.4 \mathrm{~Hz}, 1 \mathrm{H}), 7.10$ $(\mathrm{dd}, J=8.3,2.7 \mathrm{~Hz}, 1 \mathrm{H}), 6.98(\mathrm{~d}, J=7.6 \mathrm{~Hz}, 1 \mathrm{H}), 4.13(\mathrm{t}, J=5.9 \mathrm{~Hz}, 2 \mathrm{H}), 3.66(\mathrm{br}, 2 \mathrm{H}), 3.57$ $-3.53(\mathrm{~m}, 6 \mathrm{H}), 3.37$ (br, under the water signal), $3.27(\mathrm{t}, J=11.9 \mathrm{~Hz}, 2 \mathrm{H}), 2.92(\mathrm{t}, J=6.5 \mathrm{~Hz}$, $2 \mathrm{H}$ ), $2.82-2.76(\mathrm{~m}, 2 \mathrm{H}), 2.30-2.25(\mathrm{~m}, 2 \mathrm{H}), 1.88$ (quin, $J=7.3 \mathrm{~Hz}, 2 \mathrm{H}) ;{ }^{13} \mathrm{C}$ NMR $(125$ MHz, DMSO- $\left.d_{6}\right) \delta 163.6,157.2,146.6,140.7,133.4,131.1,130.0,128.6,126.6,125.1,121.8$, 118.7, 117.8, 112.6, 112.4, 65.3, 53.1, 51.4, 48.5, 45.8, 43.9, 36.7, 26.5, 25.5, 23.4; HRMS (ESI) calcd for $\mathrm{C}_{27} \mathrm{H}_{35} \mathrm{~N}_{4} \mathrm{O}_{2} \mathrm{~S} 479.2481[\mathrm{M}+\mathrm{H}]^{+}$, found 479.2482 . 
Scheme S2. Synthesis of compounds S5-S14 for preparation of probes 2a,b

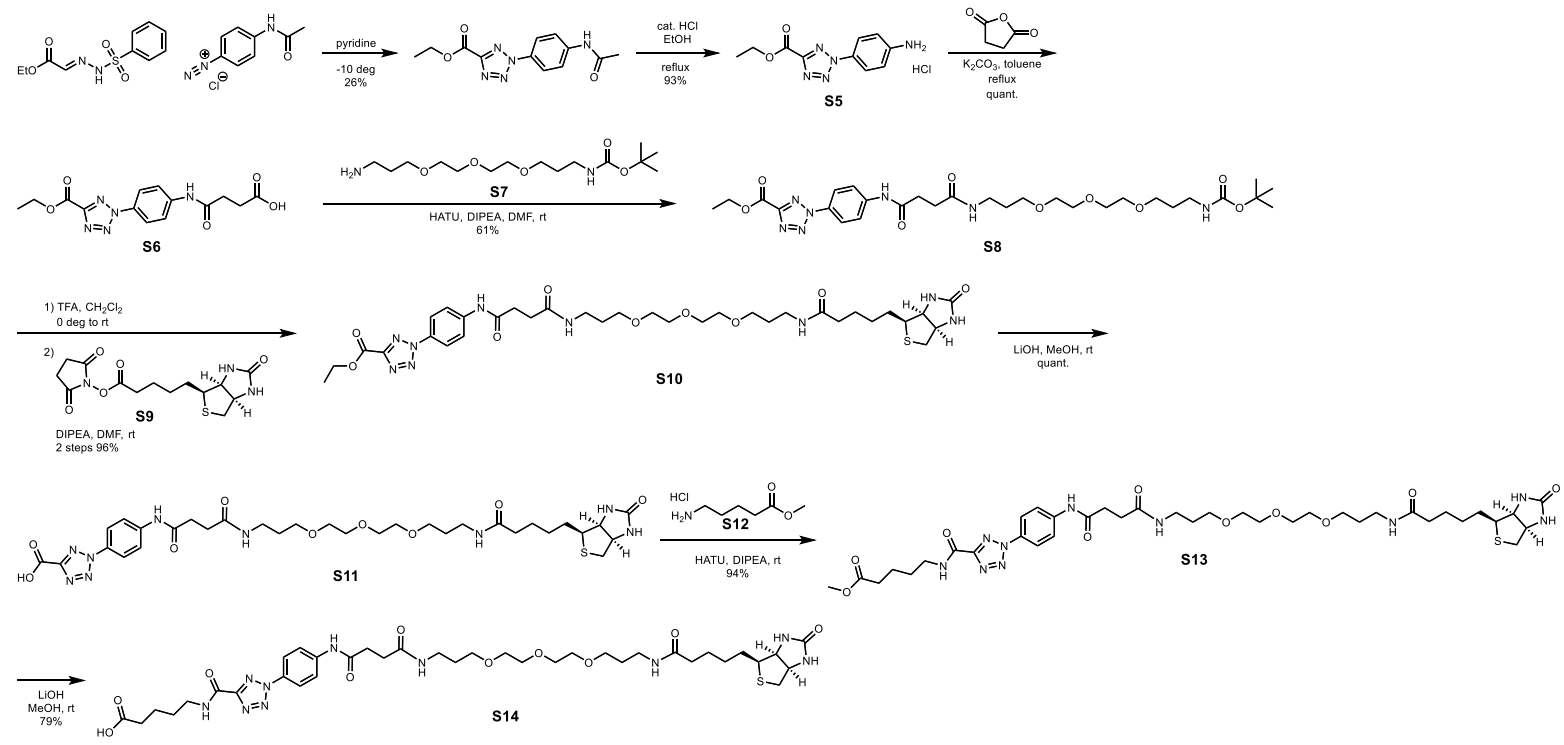

Synthesis of $\mathbf{S 6}$ (S5 was prepared according to a known procedure. ${ }^{\text {ref.10}}$ )

To a suspension $\mathbf{S 5}(0.970 \mathrm{~g}, 3.60 \mathrm{mmol})$ in $10 \mathrm{~mL}$ toluene was added potassium carbonate $(1.09 \mathrm{~g}, 7.92 \mathrm{mmol})$ and succinic anhydride $(1.73 \mathrm{~g}, 17.3 \mathrm{mmol})$, and the mixture was refluxed for $15 \mathrm{~h}$. After removal of the solvent by evaporation, the residue was dissolved in EtOAc. The organic layer was washed successively with $s a t$. $\mathrm{NH}_{4} \mathrm{Cl}, \mathrm{H}_{2} \mathrm{O}(\times 2)$ and then dried over $\mathrm{Na}_{2} \mathrm{SO}_{4}$. The solvent was removed by evaporation to give $\mathbf{S 6}$ (1.43 g, quant.) as pale yellow solid: $\mathrm{R} f=$ $0.20\left(\mathrm{CH}_{2} \mathrm{Cl}_{2} / \mathrm{MeOH}=10: 1\right) ;{ }^{1} \mathrm{H}$ NMR (400 MHz, DMSO-d $d_{6} \delta 12.15$ (s, 1H), $10.38(\mathrm{~s}, 1 \mathrm{H})$, $8.07(\mathrm{~d}, J=9.1 \mathrm{~Hz}, 2 \mathrm{H}), 7.88(\mathrm{~d}, J=9.2 \mathrm{~Hz}, 2 \mathrm{H}), 4.45(\mathrm{q}, J=7.1 \mathrm{~Hz}, 2 \mathrm{H}), 2.64-2.61(\mathrm{~m}, 2 \mathrm{H})$, $2.57-2.53(\mathrm{~m}, 2 \mathrm{H}), 1.37(\mathrm{t}, J=7.2 \mathrm{~Hz}, 3 \mathrm{H}) ;{ }^{13} \mathrm{C}$ NMR (125 MHz, DMSO- $\left.d_{6}\right) \delta 173.8,170.8$, 157.3, 157.2, 141.6, 130.7, 121.3, 119.7, 62.3, 31.2, 28.7, 14.1; HRMS (ESI) calcd for $\mathrm{C}_{14} \mathrm{H}_{16} \mathrm{~N}_{5} \mathrm{O}_{5} 334.1151[\mathrm{M}+\mathrm{H}]^{+}$, found 334.1149 .

\section{Synthesis of $\mathbf{S} 8$}

A solution of S6 (739 mg, $2.14 \mathrm{mmol}), N$-Boc-4,7,10-trioxa-1,13-tridecanediamine S7 (824 $\mathrm{mg}, 2.57 \mathrm{mmol}$ ), HATU (978 mg, $2.57 \mathrm{mmol}$ ), and DIPEA (448 $\mu \mathrm{L}, 2.57 \mathrm{mmol})$ in dry DMF $(20 \mathrm{~mL})$ was stirred at r.t. for $1 \mathrm{~h}$. After removal of the solvent by evaporation, the residue was purified by medium-pressure reverse phase flash chromatography (column; SNAP Ultra C18 (30 g), mobile phase; $0.1 \%(\mathrm{v} / \mathrm{v}) \mathrm{AcOH}$ aqueous solution/0.1\% (v/v) $\mathrm{AcOH}$ in $\mathrm{MeCN}$ $(95: 5 \rightarrow 25: 75)$, detection; UV $(\lambda$-all)). The suitable fractions were pooled and lyophilized to give $\mathbf{S 8}$ as a white powder (835 mg, 61\%): $\mathrm{R} f=0.30\left(\mathrm{CH}_{2} \mathrm{Cl}_{2} / \mathrm{MeOH}=95: 5\right) ;{ }^{1} \mathrm{H} \mathrm{NMR}(400$ $\left.\mathrm{MHz}, \mathrm{CDCl}_{3}\right) \delta 9.82(\mathrm{~s}, 1 \mathrm{H}), 8.11(\mathrm{~d}, J=9.1 \mathrm{~Hz}, 2 \mathrm{H}), 7.81(\mathrm{~d}, J=9.0 \mathrm{~Hz}, 2 \mathrm{H}), 6.84(\mathrm{br}, 1 \mathrm{H})$, 4.95 (br, 1H), 4.57 (q, $J=7.2 \mathrm{~Hz}, 2 \mathrm{H}), 3.66-3.64(\mathrm{~m}, 4 \mathrm{H}), 3.61-3.58(\mathrm{~m}, 4 \mathrm{H}), 3.52(\mathrm{t}, J=$ $6.1 \mathrm{~Hz}, 2 \mathrm{H}), 3.42(\mathrm{q}, J=6.1 \mathrm{~Hz}, 2 \mathrm{H}), 3.21(\mathrm{q}, J=6.2 \mathrm{~Hz}, 2 \mathrm{H}), 2.73-2.70(\mathrm{~m}, 2 \mathrm{H}), 2.65-2.62$ $(\mathrm{m}, 2 \mathrm{H}), 1.83-1.72(\mathrm{~m}, 4 \mathrm{H}), 1.49(\mathrm{t}, J=7.2 \mathrm{~Hz}, 3 \mathrm{H}), 1.44(\mathrm{~s}, 9 \mathrm{H}) ;{ }^{13} \mathrm{C}$ NMR $(125 \mathrm{MHz}$, 
$\left.\mathrm{CDCl}_{3}\right) \delta 172.6,171.3,157.9,157.6,156.1,140.9,131.7,121.0,120.1,79.1,70.5,70.4,70.2$, 70.0, 69.4, 62.8, 38.8, 38.4, 33.4, 31.5, 29.8, 28.5, 14.2; HRMS (ESI) calcd for $\mathrm{C}_{29} \mathrm{H}_{46} \mathrm{~N}_{7} \mathrm{O}_{9}$ $636.3357[\mathrm{M}+\mathrm{H}]^{+}$, found 636.3366 .

\section{Synthesis of $\mathbf{S 1 0}$}

A solution of $\mathbf{S 8}(834 \mathrm{mg}, 1.31 \mathrm{mmol})$ and TFA (3.01 mL, $39.4 \mathrm{mmol})$ in $\mathrm{CH}_{2} \mathrm{Cl}_{2}(10 \mathrm{~mL})$ was stirred at r.t. for $1 \mathrm{~h}$. After removal of the solvent by evaporation, the residual TFA was further removed azeotropically with toluene $(\times 2)$ to give deprotected S8. Then, a solution of deprotected S8, (+)-biotin $N$-hydroxysuccinimide ester S9 (740 mg, $2.17 \mathrm{mmol}$ ) and DIPEA $(1.14 \mathrm{~mL}, 6.57 \mathrm{mmol})$ in dry DMF $(14 \mathrm{~mL})$ was stirred at r.t. for $2 \mathrm{~h}$. After removal of the solvent by evaporation, the residue was purified by medium-pressure reverse phase flash chromatography (column; SNAP Ultra C18 (30 g), mobile phase; 0.1\% (v/v) AcOH aqueous solution/0.1\% (v/v) $\mathrm{AcOH}$ in $\mathrm{MeCN}(95: 5 \rightarrow 35: 65)$, detection; UV ( $\lambda$-all)). The suitable fractions were pooled and lyophilized to give $\mathbf{S 1 0}$ as a white powder (956 $\mathrm{mg}, 2$ steps 96\%); ${ }^{1} \mathrm{H}$ NMR $\left(500 \mathrm{MHz}, \mathrm{CDCl}_{3}\right) \delta 10.22(\mathrm{~s}, 1 \mathrm{H}), 8.09$ (d, $\left.J=9.1 \mathrm{~Hz}, 2 \mathrm{H}\right), 7.85(\mathrm{~d}, J=9.1 \mathrm{~Hz}, 2 \mathrm{H})$, $6.94(\mathrm{t}, J=5.4 \mathrm{~Hz}, 1 \mathrm{H}), 6.68-6.66(\mathrm{~m}, 2 \mathrm{H}), 5.03(\mathrm{br}, 1 \mathrm{H}), 4.59-4.53(\mathrm{~m}, 3 \mathrm{H}), 4.37-4.34$ $(\mathrm{m}, 1 \mathrm{H}), 3.69-3.51(\mathrm{~m}, 12 \mathrm{H}), 3.43-3.30(\mathrm{~m}, 3 \mathrm{H}), 3.30-3.24(\mathrm{~m}, 1 \mathrm{H}), 3.16-3.13(\mathrm{~m}, 1 \mathrm{H})$, $2.92(\mathrm{dd}, J=12.6,4.9 \mathrm{~Hz}, 1 \mathrm{H}), 2.89-2.84(\mathrm{~m}, 1 \mathrm{H}), 2.76-2.67(\mathrm{~m}, 3 \mathrm{H}), 2.64-2.58(\mathrm{~m}, 1 \mathrm{H})$, $2.10-2.00(\mathrm{~m}, 2 \mathrm{H}), 1.81-1.75(\mathrm{~m}$, under the water signal), $1.71-1.52(\mathrm{~m}, 4 \mathrm{H}), 1.49(\mathrm{t}, J=$ $7.2 \mathrm{~Hz}, 3 \mathrm{H}), 1.46-1.33(\mathrm{~m}, 2 \mathrm{H}) ;{ }^{13} \mathrm{C} \mathrm{NMR}\left(125 \mathrm{MHz}, \mathrm{CDCl}_{3}\right) \delta 173.1,172.4,171.8,163.8$, 157.9, 157.6, 141.1, 131.6, 120.9, 120.4, 70.5, 70.3, 69.9, 69.9, 69.8, 69.6, 62.8, 62.1, 60.0, 55.6, 40.6, 38.1, 37.3, 35.6, 32.7, 31.3, 28.9, 28.7, 28.0, 28.0, 25.5, 14.2; HRMS (ESI) calcd for $\mathrm{C}_{34} \mathrm{H}_{52} \mathrm{~N}_{9} \mathrm{O}_{9} \mathrm{~S} 762.3609[\mathrm{M}+\mathrm{H}]^{+}$, found 762.3597 .

\section{Synthesis of $\mathbf{S 1 1}$}

To a solution of $\mathbf{S 1 0}$ (955 mg, $1.25 \mathrm{mmol}$ ) in $20 \mathrm{~mL} \mathrm{MeOH}$ was added $1.38 \mathrm{~mL} 1 \mathrm{M} \mathrm{LiOH}$ aq. and $4.06 \mathrm{~mL}$ water, and the mixture was stirred at r.t. for $2 \mathrm{~h}$. After addition of $0.1 \%(\mathrm{v} / \mathrm{v})$ TFA aqueous solution to acidify the solution, the solvent was removed by evaporation. The residue was purified by medium-pressure reverse phase flash chromatography (column; SNAP Ultra C18 (30 g), mobile phase; $0.1 \%$ (v/v) TFA aqueous solution/0.1\% (v/v) TFA in MeCN $(100: 0 \rightarrow 45: 55)$, detection; UV $(\lambda$-all $))$. The suitable fractions were pooled and lyophilized to give $\mathbf{S 1 1}$ as a white powder (948 mg, quant.) ; ${ }^{1} \mathrm{H}$ NMR (500 MHz, DMSO- $\left.d_{6}\right) \delta 10.37(\mathrm{~s}, 1 \mathrm{H})$, $8.06(\mathrm{~d}, J=9.1 \mathrm{~Hz}, 2 \mathrm{H}), 7.87(\mathrm{~d}, J=9.2 \mathrm{~Hz}, 2 \mathrm{H}), 7.74(\mathrm{t}, J=5.5 \mathrm{~Hz}, 1 \mathrm{H}), 6.42(\mathrm{br}, 1 \mathrm{H}), 6.35$ (br, $1 \mathrm{H}), 4.30(\mathrm{dd}, J=7.8,5.1 \mathrm{~Hz}, 1 \mathrm{H}), 4.12(\mathrm{dd}, J=7.8,4.6 \mathrm{~Hz}, 1 \mathrm{H}), 3.51-3.50(\mathrm{~m}, 4 \mathrm{H})$, $3.47-3.45(\mathrm{~m}, 4 \mathrm{H}), 3.40-3.37(\mathrm{~m}$, under the water signal), $3.11-3.04(\mathrm{~m}, 5 \mathrm{H}), 2.81(\mathrm{dd}, J$ $=12.3,5.1 \mathrm{~Hz}, 1 \mathrm{H}), 2.62-2.56(\mathrm{~m}, 3 \mathrm{H}), 2.42(\mathrm{t}, J=7.1 \mathrm{~Hz}, 2 \mathrm{H}), 2.04(\mathrm{t}, J=7.4 \mathrm{~Hz}, 2 \mathrm{H}), 1.64$ $-1.57(\mathrm{~m}, 5 \mathrm{H}), 1.54-1.42(\mathrm{~m}, 3 \mathrm{H}), 1.35-1.25(\mathrm{~m}, 2 \mathrm{H}) ;{ }^{13} \mathrm{C}$ NMR $\left(125 \mathrm{MHz}, \mathrm{DMSO}-d_{6}\right) \delta$ 172.0, 171.2, 171.1, 162.8, 158.7, 158.1, 141.5, 130.7, 121.1, 119.7, 69.8, 69.6, 68.2, 68.1, 61.1, 
59.2, 55.5, 35.9, 35.8, 35.3, 31.8, 30.2, 29.5, 29.5, 28.3, 28.1, 25.4; HRMS (ESI) calcd for $\mathrm{C}_{32} \mathrm{H}_{48} \mathrm{~N}_{9} \mathrm{O}_{9} \mathrm{~S} 734.3296[\mathrm{M}+\mathrm{H}]^{+}$, found 734.3285 .

\section{Synthesis of $\mathbf{S 1 3}$}

A solution of S11 (394 mg, $0.537 \mathrm{mmol}), \mathbf{S 1 2}$ (117 mg, $0.698 \mathrm{mmol})$, HATU (265 mg, 0.698 mmol), and DIPEA (309 $\mu \mathrm{L}, 1.77 \mathrm{mmol})$ in DMF (5 mL) was stirred at r.t. for $1 \mathrm{~h}$. After removal of the solvent by evaporation, the residue was purified by medium-pressure reverse phase flash chromatography (column; SNAP Ultra C18 (30 g), mobile phase; 0.1\% (v/v) TFA aqueous solution/0.1\% (v/v) TFA in MeCN (100:0 $\rightarrow 45: 55)$, detection; UV ( $\lambda$-all)). The suitable fractions were pooled and lyophilized to give $\mathbf{S 1 3}$ as a white powder (428 $\mathrm{mg}, 94 \%$ ); ${ }^{1} \mathrm{H}$ NMR (500 MHz, DMSO- $\left.d_{6}\right) 10.37(\mathrm{~s}, 1 \mathrm{H}), 9.16(\mathrm{t}, J=5.9 \mathrm{~Hz}, 1 \mathrm{H}), 8.06$ (d, $\left.J=9.1 \mathrm{~Hz}, 2 \mathrm{H}\right)$, $7.89-7.87(\mathrm{~m}, 3 \mathrm{H}), 7.74(\mathrm{t}, J=5.5 \mathrm{~Hz}, 1 \mathrm{H}), 6.42(\mathrm{~s}, 1 \mathrm{H}), 6.35(\mathrm{~s}, 1 \mathrm{H}), 4.31-4.29(\mathrm{~m}, 1 \mathrm{H})$, $4.13-4.11(\mathrm{~m}, 1 \mathrm{H}), 3.58(\mathrm{~s}, 1 \mathrm{H}), 3.51-3.49(\mathrm{~m}, 4 \mathrm{H}), 3.47-3.45(\mathrm{~m}, 4 \mathrm{H}), 3.38(\mathrm{q}, J=6.4$ $\mathrm{Hz}, 4 \mathrm{H}), 3.31-3.30(\mathrm{~m}$, under the water signal), $3.11-3.04(\mathrm{~m}, 5 \mathrm{H}), 2.81(\mathrm{dd}, J=12.4,5.2$ $\mathrm{Hz}, 1 \mathrm{H}), 2.62-2.56(\mathrm{~m}, 3 \mathrm{H}), 2.42(\mathrm{t}, J=7.1 \mathrm{~Hz}, 2 \mathrm{H}), 2.37-2.34(\mathrm{~m}, 2 \mathrm{H}), 2.04(\mathrm{t}, J=7.4 \mathrm{~Hz}$, $2 \mathrm{H}), 1.64-1.56(\mathrm{~m}, 9 \mathrm{H}), 1.53-1.42(\mathrm{~m}, 3 \mathrm{H}), 1.35-1.23(\mathrm{~m}, 2 \mathrm{H}) ;{ }^{13} \mathrm{C}$ NMR $(125 \mathrm{MHz}$, DMSO- $\left.d_{6}\right) \delta 173.4,172.0,171.2,171.1,162.8,159.9,156.2,141.4,130.8,121.2,119.7,69.8$, 69.6, 68.2, 68.1, 61.1, 59.3, 55.5, 51.3, 38.6, 35.9, 35.8, 35.3, 32.9, 31.8, 30.2, 29.5, 29.5, 28.3, 28.3, 28.1, 25.4, 21.9; HRMS (ESI) calcd for $\mathrm{C}_{38} \mathrm{H}_{58} \mathrm{~N}_{10} \mathrm{NaO}_{10} \mathrm{~S} 869.3956[\mathrm{M}+\mathrm{Na}]^{+}$, found 869.3962 .

\section{Synthesis of $\mathbf{S 1 4}$}

To a solution of $\mathbf{S 1 3}$ (426 mg, $0.503 \mathrm{mmol}$ ) in $10 \mathrm{~mL} \mathrm{MeOH}$ was added $754 \mu \mathrm{L} 1 \mathrm{M} \mathrm{LiOH}$ aq. and $2.08 \mathrm{~mL}$ water, and the mixture was stirred at r.t. for $36 \mathrm{~h}$. After addition of $0.1 \%(\mathrm{v} / \mathrm{v})$ TFA aqueous solution to acidify the solution, the solvent was removed by evaporation. The residue was purified by medium-pressure reverse phase flash chromatography (column; SNAP Ultra C18 (30 g), mobile phase; 0.1\% (v/v) TFA aqueous solution/0.1\% (v/v) TFA in MeCN $(100: 0 \rightarrow 45: 55)$, detection; UV ( $\lambda$-all)). The suitable fractions were pooled and lyophilized to give S14 as a white powder (330 mg, 79\%) ; ${ }^{1} \mathrm{H}$ NMR (500 MHz, DMSO- $\left.d_{6}\right) \delta 12.01(\mathrm{br}, 1 \mathrm{H})$, 10.36 (s, 1H), 9.15 (t, $J=5.9 \mathrm{~Hz}, 1 \mathrm{H}), 8.06(\mathrm{~d}, J=9.1 \mathrm{~Hz}, 2 \mathrm{H}), 7.89-7.87(\mathrm{~m}, 3 \mathrm{H}), 7.74(\mathrm{t}, J$ $=5.5 \mathrm{~Hz}, 1 \mathrm{H}), 6.42(\mathrm{br}, 1 \mathrm{H}), 6.36(\mathrm{br}, 1 \mathrm{H}), 4.30(\mathrm{dd}, J=7.8,5.0 \mathrm{~Hz}, 1 \mathrm{H}), 4.12(\mathrm{dd}, J=7.8$, $4.5 \mathrm{~Hz}, 1 \mathrm{H}), 3.51-3.50(\mathrm{~m}, 4 \mathrm{H}), 3.47-3.45(\mathrm{~m}, 4 \mathrm{H}), 3.38(\mathrm{q}, J=6.4 \mathrm{~Hz}$, under the water signal), $3.32(\mathrm{q}, J=6.1 \mathrm{~Hz}, 2 \mathrm{H}), 3.11-3.04(\mathrm{~m}, 5 \mathrm{H}), 2.81(\mathrm{dd}, J=12.4,5.1 \mathrm{~Hz}, 1 \mathrm{H}), 2.62-$ $2.56(\mathrm{~m}, 3 \mathrm{H}), 2.42(\mathrm{t}, J=7.0 \mathrm{~Hz}, 2 \mathrm{H}), 2.25(\mathrm{t}, J=7.0 \mathrm{~Hz}, 2 \mathrm{H}), 2.04(\mathrm{t}, J=7.4 \mathrm{~Hz}, 2 \mathrm{H}), 1.64-$ $1.42(\mathrm{~m}, 12 \mathrm{H}), 1.35-1.22(\mathrm{~m}, 2 \mathrm{H}) ;{ }^{13} \mathrm{C}$ NMR (125 MHz, DMSO-d $) \delta 174.5,172.0,171.2$, 171.1, 162.8, 160.0, 156.2, 141.4, 130.8, 121.2, 119.7, 69.8, 69.6, 68.2, 68.1, 61.1, 59.3, 55.5, 38.7, 35.9, 35.8, 35.3, 33.3, 31.8, 30.2, 29.5, 29.5, 28.4, 28.3, 28.1, 25.4, 22.0; HRMS (ESI) calcd for $\mathrm{C}_{37} \mathrm{H}_{56} \mathrm{~N}_{10} \mathrm{NaO}_{10} \mathrm{~S} 855.3799[\mathrm{M}+\mathrm{Na}]^{+}$, found 855.3802. 
Scheme S3. Synthesis of probe $\mathbf{2 a}$

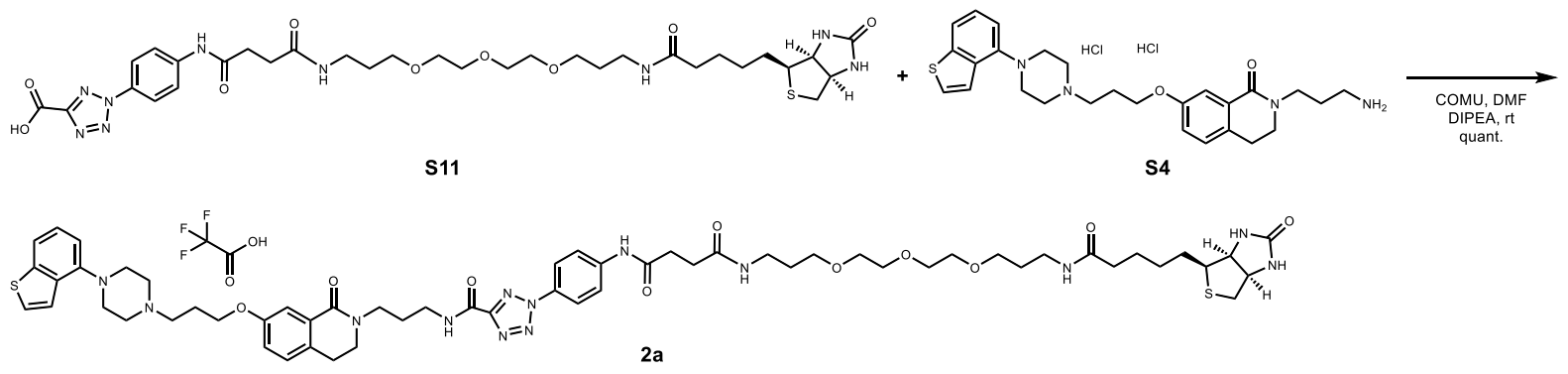

A solution of S11 (20 mg, $27 \mu \mathrm{mol}), \mathbf{S 4}(15 \mathrm{mg}, 27 \mu \mathrm{mol})$, COMU (13 mg, $30 \mu \mathrm{mol})$, and DIPEA $(16 \mu \mathrm{L}, 90 \mu \mathrm{mol})$ in DMF (1 mL) was stirred at r.t. for $2 \mathrm{~h}$. After removal of the solvent by evaporation, the residue was purified by medium-pressure reverse phase flash chromatography (column; SNAP Ultra C18 (12 g), mobile phase; 0.1\% (v/v) TFA aqueous solution/0.1\% (v/v) TFA in MeCN (95:5 $\rightarrow 40: 60)$, detection; UV ( $\lambda$-all)). The suitable fractions were pooled and lyophilized to give probe $\mathbf{2 a}$ as a white powder (38 mg, quant.) ; ${ }^{1} \mathrm{H}$ NMR (500 MHz, DMSO- $\left.d_{6}\right) \delta 10.37(\mathrm{~s}, 1 \mathrm{H}), 9.63(\mathrm{br}, 1 \mathrm{H}), 9.16(\mathrm{t}, J=5.9 \mathrm{~Hz}, 1 \mathrm{H}), 8.06$ (d, $J=9.0$ $\mathrm{Hz}, 2 \mathrm{H}), 7.90-7.86(\mathrm{~m}, 3 \mathrm{H}), 7.78(\mathrm{~d}, J=5.5 \mathrm{~Hz}, 1 \mathrm{H}), 7.75-7.71(\mathrm{~m}, 2 \mathrm{H}), 7.51(\mathrm{~d}, J=5.6$ $\mathrm{Hz}, 1 \mathrm{H}), 7.45(\mathrm{~d}, J=2.8 \mathrm{~Hz}, 1 \mathrm{H}), 7.33(\mathrm{t}, J=7.9 \mathrm{~Hz}, 1 \mathrm{H}), 7.25(\mathrm{~d}, J=8.4 \mathrm{~Hz}, 1 \mathrm{H}), 7.07$ (dd, $J=8.4,2.8 \mathrm{~Hz}, 1 \mathrm{H}), 6.99(\mathrm{~d}, J=7.5 \mathrm{~Hz}, 1 \mathrm{H}), 6.42(\mathrm{br}, 1 \mathrm{H}), 6.36$ (br, $1 \mathrm{H}), 4.30$ (dd, $J=7.8$, $4.9 \mathrm{~Hz}, 1 \mathrm{H})), 4.14-4.11(\mathrm{~m}, 3 \mathrm{H}), 3.70(\mathrm{br}, 2 \mathrm{H}), 3.61-3.55(\mathrm{~m}, 6 \mathrm{H}), 3.51-3.49(\mathrm{~m}, 4 \mathrm{H}), 3.47$ $-3.43(\mathrm{~m}, 4 \mathrm{H}), 3.40-3.34(\mathrm{~m}$, under the water signal), $3.10-3.04(\mathrm{~m}, 7 \mathrm{H}), 2.92(\mathrm{t}, J=6.5$ $\mathrm{Hz}, 2 \mathrm{H}), 2.81(\mathrm{dd}, J=12.4,5.1 \mathrm{~Hz}, 1 \mathrm{H}), 2.62-2.56(\mathrm{~m}, 3 \mathrm{H}), 2.42(\mathrm{t}, J=7.0 \mathrm{~Hz}, 2 \mathrm{H}), 2.23-$ $2.17(\mathrm{~m}, 2 \mathrm{H}), 2.04(\mathrm{t}, J=7.5 \mathrm{~Hz}, 2 \mathrm{H}), 1.86$ (quin, $J=6.8 \mathrm{~Hz}, 2 \mathrm{H}), 1.64-1.57(\mathrm{~m}, 5 \mathrm{H}), 1.53-$ $1.41(\mathrm{~m}, 3 \mathrm{H}), 1.34-1.22(\mathrm{~m}, 2 \mathrm{H}) ;{ }^{13} \mathrm{C}$ NMR (125 MHz, DMSO- $\left.d_{6}\right) \delta$ 172.0, 171.2, 171.0, 163.3, 162.8, 159.9, 158.3, 158.0, 157.1, 156.2, 146.5, 141.5, 140.7, 133.4, 131.2, 130.8, 130.3, 128.6, 126.7, 125.1, 121.8, 121.1, 119.7, 118.6, 117.9, 112.7, 112.4, 69.8, 69.6, 68.2, 68.1, 65.0, 61.1, 59.3, 55.5, 53.3, 51.6, 48.8, 45.8, 44.5, 36.8, 35.9, 35.8, 35.3, 31.8, 30.1, 29.5, 29.5, 28.3, 28.1, 27.2, 26.6, 25.4, 23.6; HRMS (ESI) calcd for $\mathrm{C}_{59} \mathrm{H}_{80} \mathrm{~N}_{13} \mathrm{O}_{10} \mathrm{~S}_{2} 1194.5593[\mathrm{M}+\mathrm{H}]^{+}$, found 1194.5602 .

Scheme S4. Synthesis of probe $\mathbf{2 b}$
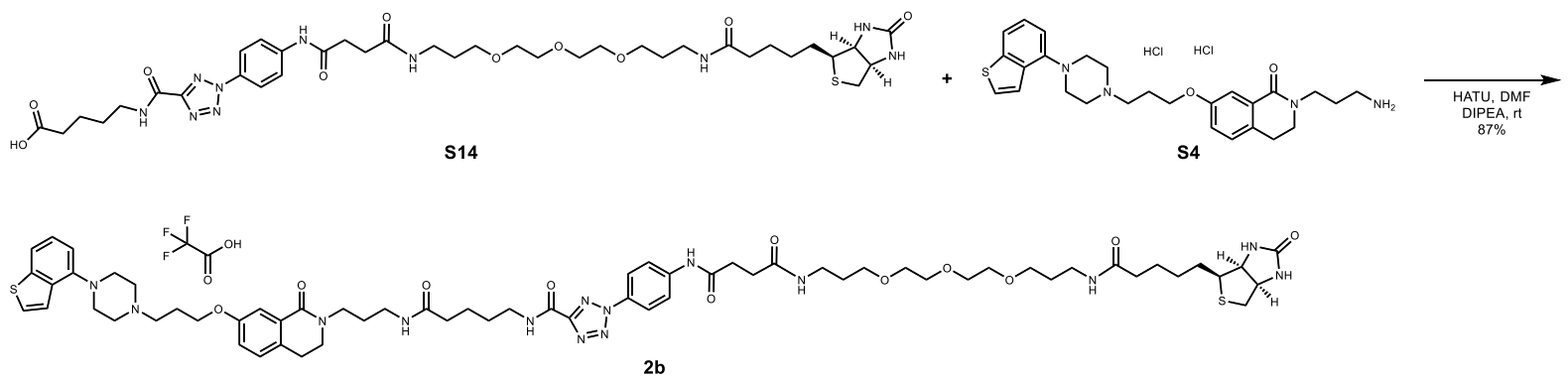

A solution of S14 $(25 \mathrm{mg}, 30 \mu \mathrm{mol}), \mathbf{S 4}(15 \mathrm{mg}, 27 \mu \mathrm{mol})$, HATU (12 mg, $33 \mu \mathrm{mol})$, and 
DIPEA (24 $\mu \mathrm{L}, 0.14 \mathrm{mmol})$ in DMF ( $3 \mathrm{~mL}$ ) was stirred at r.t. for $1 \mathrm{~h}$. After removal of the solvent by evaporation, the residue was purified by medium-pressure reverse phase flash chromatography (column; SNAP Ultra C18 (12 g), mobile phase; 0.1\% (v/v) TFA aqueous solution/0.1\% (v/v) TFA in MeCN (95:5 $\rightarrow 40: 60)$, detection; UV ( $\lambda$-all)). The suitable fractions were pooled and lyophilized to give probe $\mathbf{2 b}$ as a white powder (33 mg, 87\%); ${ }^{1} \mathrm{H}$ NMR (500 MHz, DMSO- $\left.d_{6}\right) \delta 10.36(\mathrm{~s}, 1 \mathrm{H}), 9.58(\mathrm{br}, 1 \mathrm{H}), 9.14(\mathrm{t}, J=5.9 \mathrm{~Hz}, 1 \mathrm{H}), 8.03(\mathrm{~d}, J=9.1 \mathrm{~Hz}$, 2H), $7.88-7.86(\mathrm{~m}, 3 \mathrm{H}), 7.82(\mathrm{t}, J=5.6 \mathrm{~Hz}, 1 \mathrm{H}), 7.78(\mathrm{~d}, J=5.5 \mathrm{~Hz}, 1 \mathrm{H}), 7.75-7.71(\mathrm{~m}$, 2H), $7.51(\mathrm{~d}, J=5.6 \mathrm{~Hz}, 1 \mathrm{H}), 7.43(\mathrm{~d}, J=2.7 \mathrm{~Hz}, 1 \mathrm{H}), 7.33$ (t, $J=7.9 \mathrm{~Hz}, 1 \mathrm{H}), 7.22(\mathrm{~d}, J=8.4$ $\mathrm{Hz}, 1 \mathrm{H}), 7.06$ (dd, $J=8.3,2.7 \mathrm{~Hz}, 1 \mathrm{H}), 6.99$ (d, $J=7.4 \mathrm{~Hz}, 1 \mathrm{H}), 6.42$ (br, 1H), 6.36 (br, 1H), 4.30 (dd, $J=7.8,5.0 \mathrm{~Hz}, 1 \mathrm{H}), 4.13-4.11$ (m, 3H), 3.70 (br, 2H), 3.59 (br, 2H), $3.51-3.49$ (m, $6 \mathrm{H}), 3.47-3.45(\mathrm{~m}, 6 \mathrm{H}), 3.42-3.36(\mathrm{~m}, 8 \mathrm{H}), 3.33-3.30(\mathrm{~m}, 2 \mathrm{H}), 3.10-3.04(\mathrm{~m}, 9 \mathrm{H}), 2.88$ $(\mathrm{t}, J=6.5 \mathrm{~Hz}, 2 \mathrm{H}), 2.81(\mathrm{dd}, J=12.6,5.2 \mathrm{~Hz}, 1 \mathrm{H}), 2.62-2.58(\mathrm{~m}, 3 \mathrm{H}), 2.42(\mathrm{t}, J=7.0 \mathrm{~Hz}$, 2H), $2.22-2.17(\mathrm{~m}, 2 \mathrm{H}), 2.10(\mathrm{br}, 2 \mathrm{H}), 2.04(\mathrm{t}, J=7.5 \mathrm{~Hz}, 2 \mathrm{H}), 1.68$ (quin, $J=7.0 \mathrm{~Hz}, 2 \mathrm{H}$ ), $1.64-1.59(\mathrm{~m}, 5 \mathrm{H}), 1.57-1.53(\mathrm{~m}, 4 \mathrm{H}), 1.52-1.41(\mathrm{~m}, 3 \mathrm{H}), 1.34-1.23(\mathrm{~m}, 2 \mathrm{H}) ;{ }^{13} \mathrm{C} \mathrm{NMR}$ $\left(125 \mathrm{MHz}, \mathrm{DMSO}-d_{6}\right) \delta 172.0,171.9,171.2,171.0,163.1,162.8,160.0,158.2,157.9,157.1$, 156.2, 146.5, 141.4, 140.7, 133.4, 131.1, 130.8, 130.3, 128.6, 126.7, 125.1, 121.8, 121.1, 119.7, $118.6,117.9,112.7,112.3,69.8,69.6,68.2,68.1,65.0,61.1,59.3,55.5,53.3,51.6,48.8,45.9$, 44.7, 38.8, 36.3, 35.9, 35.8, 35.3, 35.2, 31.8, 30.1, 29.5, 29.5, 28.6, 28.3, 28.1, 27.5, 26.6, 25.4, 23.6, 22.8; HRMS (ESI) calcd for $\mathrm{C}_{64} \mathrm{H}_{89} \mathrm{~N}_{14} \mathrm{O}_{11} \mathrm{~S}_{2} 1293.6277[\mathrm{M}+\mathrm{H}]^{+}$, found 1293.6284.

Scheme S5. Synthesis of compound S17 and probe 3a

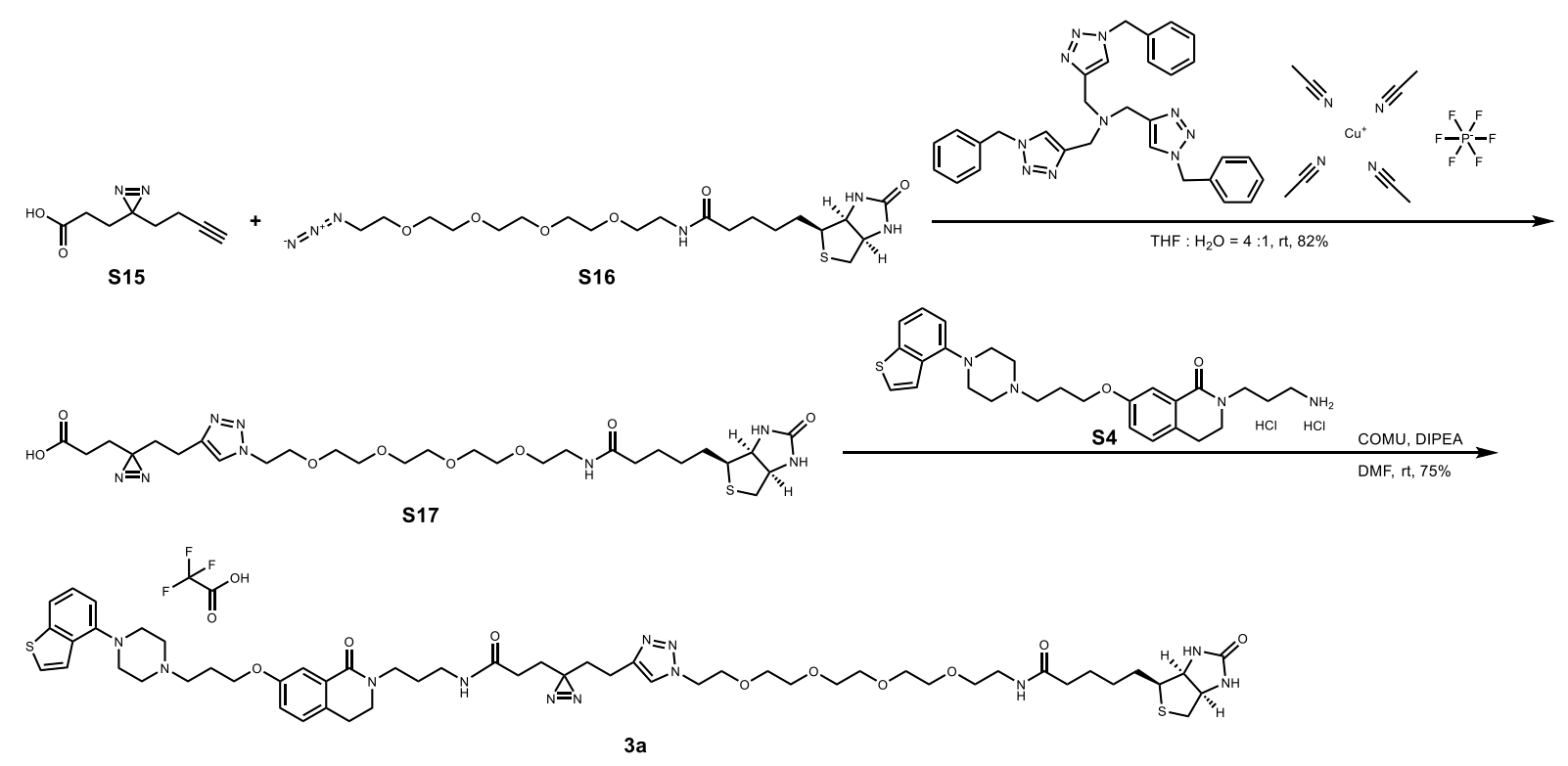

Synthesis of $\mathbf{S 1 7}$ (S15 was prepared according to a known procedure. ${ }^{\text {ref.11 }}$ )

A solution of S15 (510 mg, $3.07 \mathrm{mmol})$, azide-PEG4-biotin S16 (1.50 g, $3.07 \mathrm{mmol})$, tetrakis(acetonitrile)copper(I) hexafluorophosphate $(114 \mathrm{mg}, 0.307 \mathrm{mmol})$, and TBTA (163 $\mathrm{mg}, 0.307 \mathrm{mmol})$ in $30 \mathrm{~mL} \mathrm{THF} / \mathrm{H}_{2} \mathrm{O}(4 / 1)$ was stirred at r.t. for $48 \mathrm{~h}$. After removal of the 
solvent by evaporation, the residue was purified by medium-pressure reverse phase flash chromatography (column; SNAP Ultra C18 (60 g), mobile phase; 0.1\% (v/v) AcOH aqueous solution/0.1\% (v/v) $\mathrm{AcOH}$ in $\mathrm{MeCN}(95: 5 \rightarrow 0: 100)$, detection; UV ( $\lambda$-all)). The suitable fractions were pooled and lyophilized to give $\mathbf{S 1 7}$ as a pale yellow amorphous $(1.65 \mathrm{~g}, 82 \%)$; ${ }^{1} \mathrm{H}$ NMR (500 MHz, DMSO- $\left.d_{6}\right) \delta 12.18$ (br, 1H), 7.84 - 7.81 (m, 2H), 6.41 (br, 1H), 6.35 (br, $1 \mathrm{H}), 4.46(\mathrm{t}, J=5.3 \mathrm{~Hz}, 2 \mathrm{H}), 4.30(\mathrm{dd}, J=7.8,5.1 \mathrm{~Hz}, 1 \mathrm{H}), 4.14-4.11(\mathrm{~m}, 1 \mathrm{H}), 3.78(\mathrm{t}, J=$ $5.3 \mathrm{~Hz}, 2 \mathrm{H}), 3.52-3.46(\mathrm{~m}, 12 \mathrm{H}), 3.38(\mathrm{t}, J=6.0 \mathrm{~Hz}, 2 \mathrm{H}), 3.18(\mathrm{q}, J=5.8 \mathrm{~Hz}, 2 \mathrm{H}), 3.11-$ $3.07(\mathrm{~m}, 1 \mathrm{H}), 2.82(\mathrm{dd}, J=12.6,5.1 \mathrm{~Hz}, 1 \mathrm{H}), 2.57(\mathrm{~d}, J=12.5 \mathrm{~Hz}, 1 \mathrm{H}), 2.41(\mathrm{t}, J=8.0 \mathrm{~Hz}$, 2H), $2.06(\mathrm{t}, J=7.5 \mathrm{~Hz}, 2 \mathrm{H}), 2.02(\mathrm{t}, J=7.5 \mathrm{~Hz}, 2 \mathrm{H}), 1.75-1.72(\mathrm{~m}, 2 \mathrm{H}), 1.64(\mathrm{t}, J=7.5 \mathrm{~Hz}$, $2 \mathrm{H}), 1.62-1.57(\mathrm{~m}, 1 \mathrm{H}), 1.54-1.42(\mathrm{~m}, 3 \mathrm{H}), 1.36-1.23(\mathrm{~m}, 2 \mathrm{H}) ;{ }^{13} \mathrm{C}$ NMR $(125 \mathrm{MHz}$, DMSO- $\left.d_{6}\right) \delta 173.3,172.2,162.8,145.3,122.5,69.8,69.8,69.8,69.7,69.6,69.2,68.9,61.1$, 59.3, 55.5, 49.3, 38.5, 35.2, 32.0, 28.3, 28.3, 28.1, 28.0, 27.6, 25.3, 19.6; HRMS (ESI) calcd for $\mathrm{C}_{28} \mathrm{H}_{47} \mathrm{~N}_{8} \mathrm{O}_{8} \mathrm{~S} 655.3238[\mathrm{M}+\mathrm{H}]^{+}$, found 655.3246 .

\section{Synthesis of probe $3 a$}

A solution of S17 (19 mg, $27 \mu \mathrm{mol}), \mathbf{S 4}(15 \mathrm{mg}, 27 \mu \mathrm{mol})$, COMU (13 mg, $30 \mu \mathrm{mol})$, and DIPEA $(16 \mu \mathrm{L}, 90 \mu \mathrm{mol})$ in DMF $(1 \mathrm{~mL})$ was stirred at r.t. for $1 \mathrm{~h}$. After removal of the solvent by evaporation, the residue was purified by medium-pressure reverse phase flash chromatography (column; SNAP Ultra C18 (12 g), mobile phase; 0.1\% (v/v) TFA aqueous solution/0.1\% (v/v) TFA in MeCN (95:5 $\rightarrow 50: 50)$, detection; UV ( $\lambda$-all)). The suitable fractions were pooled and lyophilized to give probe 3a as a white powder $(25 \mathrm{mg}, 75 \%) ;{ }^{1} \mathrm{H}$ NMR (400 MHz, DMSO- $\left.d_{6}\right) \delta 9.60(\mathrm{br}, 1 \mathrm{H}), 7.86(\mathrm{t}, J=5.7 \mathrm{~Hz}, 1 \mathrm{H}), 7.82-7.79(\mathrm{~m}, 2 \mathrm{H}), 7.78(\mathrm{~d}, J=5.5$ $\mathrm{Hz}, 1 \mathrm{H}), 7.72(\mathrm{~d}, J=8.1 \mathrm{~Hz}, 1 \mathrm{H}), 7.51(\mathrm{dd}, J=5.5,0.5 \mathrm{~Hz}, 1 \mathrm{H}), 7.44(\mathrm{~d}, J=2.8 \mathrm{~Hz}, 1 \mathrm{H}), 7.33$ $(\mathrm{t}, J=7.8 \mathrm{~Hz}, 1 \mathrm{H}), 7.24(\mathrm{~d}, J=8.4 \mathrm{~Hz}, 1 \mathrm{H}), 7.07$ (dd, $J=8.3,2.8 \mathrm{~Hz}, 1 \mathrm{H}), 6.99$ (dd, $J=7.8$, $0.5 \mathrm{~Hz}, 1 \mathrm{H}), 6.40-6.35(\mathrm{~m}, 2 \mathrm{H}), 4.46(\mathrm{t}, J=5.3 \mathrm{~Hz}, 2 \mathrm{H}), 4.30(\mathrm{dd}, J=8.0,4.8 \mathrm{~Hz}, 1 \mathrm{H}), 4.15$ $-4.10(\mathrm{~m}, 3 \mathrm{H}), 3.77(\mathrm{t}, J=5.3 \mathrm{~Hz}, 2 \mathrm{H}), 3.70(\mathrm{br}, 2 \mathrm{H}), 3.60(\mathrm{br}, 2 \mathrm{H}), 3.53-3.46(\mathrm{~m}, 16 \mathrm{H}), 3.45$ $-3.37(\mathrm{~m}, 6 \mathrm{H}), 3.17(\mathrm{q}, J=5.7 \mathrm{~Hz}, 2 \mathrm{H}), 3.12-3.03(\mathrm{~m}, 5 \mathrm{H}), 2.89(\mathrm{t}, J=6.5 \mathrm{~Hz}, 2 \mathrm{H}), 2.81$ $(\mathrm{dd}, J=12.3,5.1 \mathrm{~Hz}, 1 \mathrm{H}), 2.57(\mathrm{~d}, J=12.4 \mathrm{~Hz}, 1 \mathrm{H}), 2.43-2.39(\mathrm{~m}, 2 \mathrm{H}), 2.24-2.17(\mathrm{~m}, 2 \mathrm{H})$, $2.06(\mathrm{t}, J=7.3 \mathrm{~Hz}, 2 \mathrm{H}), 1.91-1.87(\mathrm{~m}, 2 \mathrm{H}), 1.75-1.56(\mathrm{~m}, 7 \mathrm{H}), 1.53-1.40(\mathrm{~m}, 3 \mathrm{H}), 1.37-$ $1.24(\mathrm{~m}, 2 \mathrm{H}) ;{ }^{13} \mathrm{C}$ NMR (125 MHz, DMSO- $\left.d_{6}\right) \delta 172.2,170.6,163.1,162.8,158.3,158.0$, 157.1, 146.5, 145.3, 140.7, 133.4, 131.1, 130.4, 128.6, 126.7, 125.2, 122.5, 121.8, 118.6, 117.9, $112.7,112.3,69.8,69.8,69.8,69.7,69.6,69.2,68.9,65.0,61.1,59.3,55.5,53.3,51.7,49.3$, 48.8, 45.9, 44.6, 38.5, 36.4, 35.2, 32.0, 29.7, 28.6, 28.3, 28.3, 28.1, 27.5, 26.6, 25.3, 23.6, 19.7; HRMS (ESI) calcd for $\mathrm{C}_{55} \mathrm{H}_{79} \mathrm{~N}_{12} \mathrm{O}_{9} \mathrm{~S}_{2} 1115.5534[\mathrm{M}+\mathrm{H}]^{+}$, found 1115.5529 . 
Scheme S6. Synthesis of compounds S19-S24 for preparation of probe $\mathbf{3 b}$

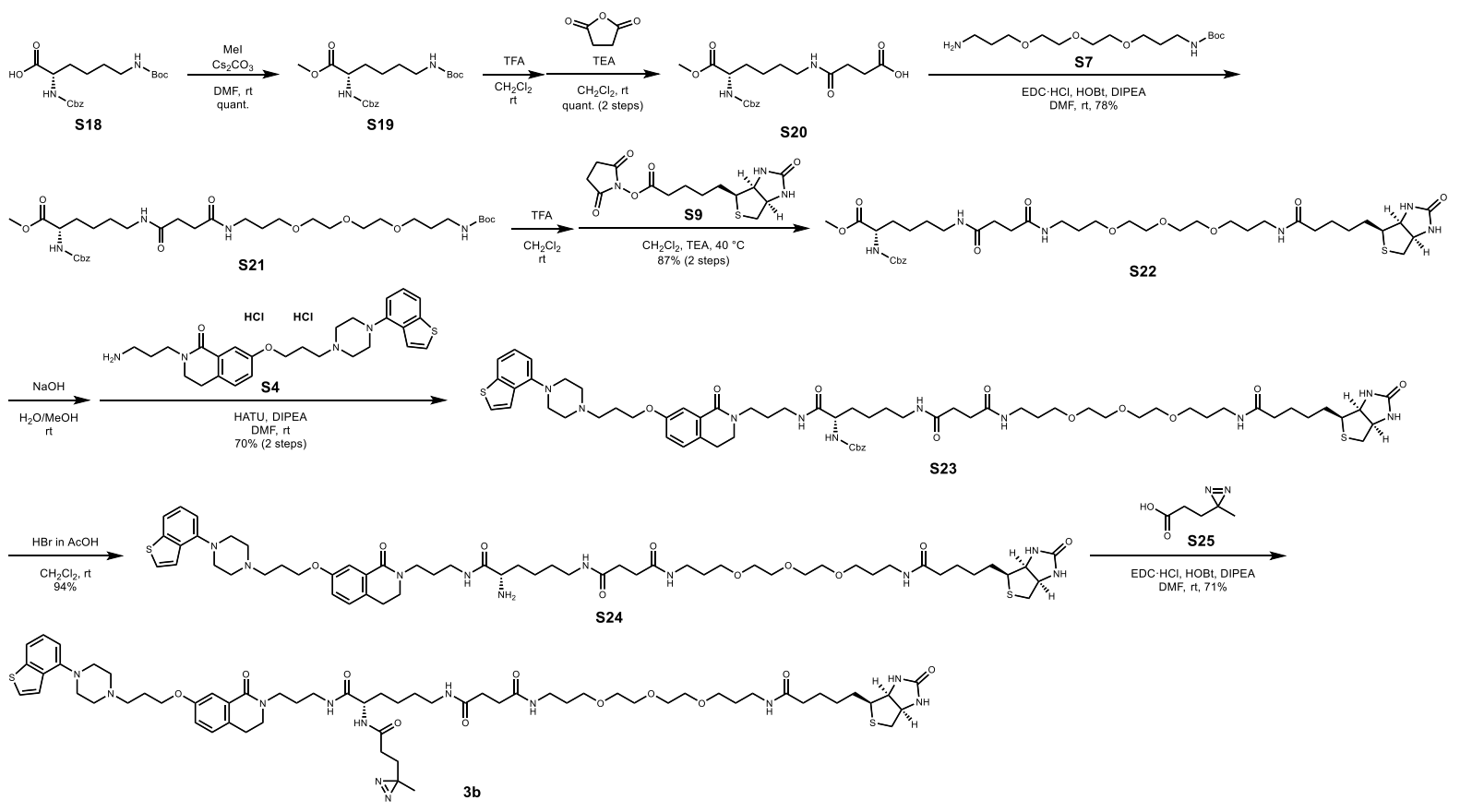

Synthesis of $\mathbf{S 2 1}$ (S19 and $\mathbf{S 2 0}$ were prepared according to a known procedure. ${ }^{\text {ref.12) }}$

A solution of $\mathbf{S 2 0}$ (1.23 g, $3.12 \mathrm{mmol}$ ), $N$-Boc-4,7,10-trioxa-1,13-tridecanediamine $\mathbf{S 7}$ (1.00 g, $3.12 \mathrm{mmol}), \mathrm{EDC} \cdot \mathrm{HCl}(778 \mathrm{mg}, 4.06 \mathrm{mmol}), \mathrm{HOBt}(621 \mathrm{mg}, 4.06 \mathrm{mmol})$, and DIPEA (1.64 $\mathrm{mL}, 9.36 \mathrm{mmol})$ in DMF (30 mL) was stirred at r.t. for $16 \mathrm{~h}$. After removal of the solvent by evaporation, the residue was dissolved in EtOAc, and the organic layer was washed with 5\% (w/v) citric acid aq. $(30 \mathrm{~mL})$, sat. $\mathrm{NaHCO}_{3}(30 \mathrm{~mL})$, water $(30 \mathrm{~mL})$, and brine $(30 \mathrm{~mL})$ and then dried over $\mathrm{Na}_{2} \mathrm{SO}_{4}$. The solvent was removed by evaporation to give $\mathbf{S 2 1}$ as a pale yellow oil (1.70 g, 78\%) ; ${ }^{1} \mathrm{H}$ NMR (400 MHz, $\left.\mathrm{CDCl}_{3}\right) \delta 7.36-7.31$ (m, 5H), 6.59 (br, 1H), 6.48 (br, $1 \mathrm{H}), 5.66(\mathrm{~d}, J=7.5 \mathrm{~Hz}, 1 \mathrm{H}), 5.11-5.08(\mathrm{~m}, 3 \mathrm{H}), 4.36-4.30(\mathrm{~m}, 1 \mathrm{H}), 3.74(\mathrm{~s}, 3 \mathrm{H}), 3.65-$ $3.63(\mathrm{~m}, 4 \mathrm{H}), 3.60-3.57(\mathrm{~m}, 4 \mathrm{H}), 3.55-3.51(\mathrm{~m}, 4 \mathrm{H}), 3.32(\mathrm{q}, 6.1 \mathrm{~Hz}, 2 \mathrm{H}), 3.26-3.16(\mathrm{~m}$, $4 \mathrm{H}), 2.47$ (s, 4H), $1.81-1.65(\mathrm{~m}, 6 \mathrm{H}), 1.55-1.48(\mathrm{~m}, 2 \mathrm{H}), 1.43(\mathrm{~s}, 9 \mathrm{H}), 1.40-1.32(\mathrm{~m}, 2 \mathrm{H})$; ${ }^{13} \mathrm{C}$ NMR $\left(100 \mathrm{MHz}, \mathrm{CDCl}_{3}\right) \delta 172.9,172.4,172.1,156.1,136.3,128.5,128.1,128.1,78.9$, 70.4, 70.1, 70.0, 69.9, 69.4, 66.9, 53.7, 52.3, 38.7, 38.4, 37.9, 31.8, 31.7, 29.6, 28.8, 28.8, 28.4, 22.3; HRMS (ESI) calcd for $\mathrm{C}_{34} \mathrm{H}_{56} \mathrm{~N}_{4} \mathrm{O}_{11} \mathrm{Na} 719.3843[\mathrm{M}+\mathrm{Na}]^{+}$, found 719.3849 .

\section{Synthesis of $\mathbf{S 2 2}$}

To a solution of $\mathbf{S 2 1}$ (417 mg, $0.598 \mathrm{mmol})$ in $\mathrm{CH}_{2} \mathrm{Cl}_{2}(5 \mathrm{~mL})$ was added TFA (1.00 mL, 13.0 $\mathrm{mmol}$ ), and the mixture was stirred at r.t. overnight. After removal of the solvent by evaporation, the residual TFA was further removed azeotropically with toluene $(\times 2)$ to give deprotected $\mathbf{S 2 1}$. Then, a solution of deprotected S21, TEA $(522 \mu \mathrm{L}, 3.74 \mathrm{mmol})$, and S9 (245 mg, $0.718 \mathrm{mmol})$ in $7 \mathrm{~mL} \mathrm{DMF}$ was stirred at $40{ }^{\circ} \mathrm{C}$ for $2 \mathrm{~h}$. After removal of the solvent by evaporation, the residue was purified by medium-pressure reverse phase flash chromatography (column; SNAP 
Ultra C18 (30 g), mobile phase; $\mathrm{H}_{2} \mathrm{O} / \mathrm{MeCN}$ (100:0 $\left.\rightarrow 0: 100\right)$, detection; UV ( $\lambda$-all)). The suitable fractions were pooled and lyophilized to give $\mathbf{S 2 2}$ as a colorless oil (427 $\mathrm{mg}, 2$ steps 87\%); ${ }^{1} \mathrm{H}$ NMR (400 MHz, DMSO- $\left.d_{6}\right) \delta 7.79-7.70(\mathrm{~m}, 4 \mathrm{H}), 7.39-7.26(\mathrm{~m}, 5 \mathrm{H}), 6.43(\mathrm{~s}, 1 \mathrm{H})$, $6.36(\mathrm{~s}, 1 \mathrm{H}), 5.03(\mathrm{~s}, 2 \mathrm{H}), 4.32-4.28(\mathrm{~m}, 1 \mathrm{H}), 4.12(\mathrm{td}, J=4.4,1.7 \mathrm{~Hz}, 1 \mathrm{H}), 4.02-3.96(\mathrm{~m}$, 1H), $3.62(\mathrm{~s}, 3 \mathrm{H}), 3.52-3.45(\mathrm{~m}, 8 \mathrm{H}), 3.37(\mathrm{td}, J=6.4,2.4 \mathrm{~Hz}, 4 \mathrm{H}), 3.11-3.03(\mathrm{~m}, 5 \mathrm{H}), 2.99$ $(\mathrm{q}, J=6.1 \mathrm{~Hz}, 2 \mathrm{H}), 2.82(\mathrm{dd}, J=12.5,5.1 \mathrm{~Hz}, 1 \mathrm{H}), 2.57(\mathrm{~d}, J=12.5 \mathrm{~Hz}, 1 \mathrm{H}), 2.27(\mathrm{~s}, 4 \mathrm{H})$, $2.04(\mathrm{t}, J=7.4 \mathrm{~Hz}, 2 \mathrm{H}), 1.67-1.22(\mathrm{~m}, 16 \mathrm{H}) ;{ }^{13} \mathrm{C}$ NMR $\left(100 \mathrm{MHz}, \mathrm{DMSO}-d_{6}\right) \delta 173.0,172.0$, 171.3, 171.2, 162.8, 156.2, 137.0, 128.4, 127.9, 127.8, 69.8, 69.6, 68.2, 68.1, 65.6, 61.1, 59.3, 55.5, 53.9, 51.9, 39.9, 38.2, 35.9 35.8, 35.3, 31.0, 30.4, 29.5, 29.4, 28.7, 28.3, 28.1, 25.4, 22.9; HRMS (ESI) calcd for $\mathrm{C}_{39} \mathrm{H}_{62} \mathrm{~N}_{6} \mathrm{O}_{11} \mathrm{NaS} 845.4095[\mathrm{M}+\mathrm{Na}]^{+}$, found 845.4092.

\section{Synthesis of $\mathbf{S} 23$}

To a solution of $\mathbf{S 2 2}$ (40 mg, $0.049 \mathrm{mmol})$ in $\mathrm{MeOH}(1 \mathrm{~mL})$ was added $1 \mathrm{M} \mathrm{NaOH}$ aq. (0.19 $\mathrm{mL}, 0.19 \mathrm{mmol}$ ), and the mixture was stirred at r.t. for $15 \mathrm{~h}$. After removal of the solvent by evaporation, $1 \mathrm{M} \mathrm{HCl}$ aq. was added to the residue for neutralization, and the solvent was removed by evaporation. Then, a solution of hydrolyzed S22, DIPEA (0.042 $\mathrm{mL}, 0.24 \mathrm{mmol})$, HATU (24 mg, $0.063 \mathrm{mmol}$ ), and $\mathbf{S 4}(27 \mathrm{mg}, 0.049 \mathrm{mmol})$ in $1 \mathrm{~mL}$ DMF was stirred at r.t. for $2 \mathrm{~h}$. After removal of the solvent by evaporation, the residue was purified by medium-pressure reverse phase flash chromatography (column; SNAP Ultra C18 (12 g), mobile phase; $\mathrm{H}_{2} \mathrm{O} / \mathrm{MeCN}(70: 30 \rightarrow 20: 80)$, detection; UV $(\lambda$-all)). The suitable fractions were pooled and lyophilized to give $\mathbf{S 2 3}$ as a colorless oil (43 mg, 2 steps 70\%); ${ }^{1} \mathrm{H}$ NMR (400 MHz, CD $3 \mathrm{OD}$ ) $\delta 7.66(\mathrm{~d}, J=8.1 \mathrm{~Hz}, 1 \mathrm{H}), 7.59(\mathrm{~d}, J=5.5 \mathrm{~Hz}, 1 \mathrm{H}), 7.52(\mathrm{~d}, J=2.7 \mathrm{~Hz}, 1 \mathrm{H}), 7.50(\mathrm{dd}, J=5.5$, $0.7 \mathrm{~Hz}, 1 \mathrm{H}), 7.37-7.24(\mathrm{~m}, 6 \mathrm{H}), 7.22(\mathrm{~d}, J=8.4 \mathrm{~Hz}, 1 \mathrm{H}), 7.10(\mathrm{dd}, J=8.3,2.7 \mathrm{~Hz}, 1 \mathrm{H}), 7.02$ $(\mathrm{d}, J=7.2 \mathrm{~Hz}, 1 \mathrm{H}), 5.13-5.06(\mathrm{~m}, 2 \mathrm{H}), 4.46(\mathrm{dd}, J=7.8,4.4 \mathrm{~Hz}, 1 \mathrm{H}), 4.27(\mathrm{dd}, J=7.8,4.4$ $\mathrm{Hz}, 1 \mathrm{H}), 4.18(\mathrm{t}, J=5.5 \mathrm{~Hz}, 2 \mathrm{H}), 4.02(\mathrm{dd}, J=9.1,5.2 \mathrm{~Hz}, 1 \mathrm{H}), 3.72-3.47(\mathrm{~m}, 24 \mathrm{H}), 3.26-$ $3.14(\mathrm{~m}, 11 \mathrm{H}), 2.95-2.88(\mathrm{~m}, 3 \mathrm{H}), 2.68(\mathrm{~d}, J=12.7 \mathrm{~Hz}, 1 \mathrm{H}), 2.44(\mathrm{~s}, 4 \mathrm{H}), 2.35-2.29(\mathrm{~m}$, $2 \mathrm{H}$ ), $2.18(\mathrm{t}, J=7.4 \mathrm{~Hz}, 2 \mathrm{H}), 1.82$ (quin, $J=6.5 \mathrm{~Hz}, 2 \mathrm{H}), 1.77-1.33(\mathrm{~m}, 16 \mathrm{H}) ;{ }^{13} \mathrm{C} \mathrm{NMR}(100$ $\left.\mathrm{MHz}, \mathrm{CD}_{3} \mathrm{OD}\right) \delta 175.9,175.0,174.5,174.5,166.4,166.1,158.9,158.4,147.6,142.8,138.2$, $135.4,132.9,131.2$, 129.7, 129.5, 129.0, 128.8, 127.2, 126.1, 122.4, 120.1, 119.4, 113.8, 113.7 , 71.5, 71.2, 69.9, 69.9, 67.7, 66.2, 63.4, 61.6, 57.0, 56.9, 55.8, 54.7, 53.9, 50.6, 47.7, 46.1, 41.0, 40.0, 37.9, 37.8, 37.7, 36.8, 32.7, 32.4, 30.4, 30.4, 30.0, 29.8, 29.5, 28.4, 28.0, 26.9, 25.3, 24.3; HRMS (ESI) calcd for $\mathrm{C}_{65} \mathrm{H}_{93} \mathrm{~N}_{10} \mathrm{O}_{12} \mathrm{~S}_{2} 1269.6416[\mathrm{M}+\mathrm{H}]^{+}$, found 1269.6416.

\section{Synthesis of $\mathbf{S 2 4}$}

To a solution of $\mathbf{S 2 3}$ (19 mg, $0.015 \mathrm{mmol})$ in $\mathrm{CH}_{2} \mathrm{Cl}_{2}(5 \mathrm{~mL})$ was added $\mathrm{HBr}$ in $\mathrm{AcOH}(30 \mu \mathrm{L}$, $0.15 \mathrm{mmol}$ ), and the mixture was stirred at r.t. for $15 \mathrm{~h}$. After removal of the solvent by evaporation, the residue was purified by medium-pressure reverse phase flash chromatography (column; SNAP Ultra C18 (12 g), mobile phase; 0.1\% (v/v) AcOH aqueous solution/0.1\% (v/v) 
$\mathrm{AcOH}$ in $\mathrm{MeCN}(100: 0 \rightarrow 0: 100)$, detection; UV $(\lambda$-all)). The suitable fractions were pooled and lyophilized to give $\mathbf{S 2 4}$ as a colorless oil (16 mg, 94\%); ${ }^{1} \mathrm{H}$ NMR (400 MHz, $\left.\mathrm{CD}_{3} \mathrm{OD}\right) \delta$ $7.55(\mathrm{~d}, J=8.0 \mathrm{~Hz}, 1 \mathrm{H}), 7.52-7.50(\mathrm{~m}, 2 \mathrm{H}), 7.43(\mathrm{dd}, J=5.5,0.6 \mathrm{~Hz}, 1 \mathrm{H}), 7.27(\mathrm{t}, J=7.8$ $\mathrm{Hz}, 1 \mathrm{H}), 7.20(\mathrm{~d}, J=8.4 \mathrm{~Hz}, 1 \mathrm{H}), 7.07(\mathrm{dd}, J=8.3,2.7 \mathrm{~Hz}, 1 \mathrm{H}), 6.94(\mathrm{~d}, J=7.3 \mathrm{~Hz}, 1 \mathrm{H}), 4.47$ $(\mathrm{dd}, J=7.8,4.4 \mathrm{~Hz}, 1 \mathrm{H}), 4.27(\mathrm{dd}, J=7.8,4.4 \mathrm{~Hz}, 1 \mathrm{H}), 4.11(\mathrm{t}, J=6.0 \mathrm{~Hz}, 2 \mathrm{H}), 3.69-3.56$ $(\mathrm{m}, 13 \mathrm{H}), 3.50(\mathrm{td}, J=6.2,2.7 \mathrm{~Hz}, 4 \mathrm{H}), 3.29-3.16(\mathrm{~m}, 13 \mathrm{H}), 2.96(\mathrm{t}, J=6.7 \mathrm{~Hz}, 2 \mathrm{H}), 2.91$ (dd, $J=12.5,5.0 \mathrm{~Hz}, 1 \mathrm{H}), 2.81(\mathrm{br}, 4 \mathrm{H}), 2.73-2.68(\mathrm{~m}, 3 \mathrm{H}), 2.45$ (t, $J=3.8 \mathrm{~Hz}, 4 \mathrm{H}), 2.19$ (t, $J=7.4 \mathrm{~Hz}, 2 \mathrm{H}$ ), $2.11-2.03(\mathrm{~m}, 2 \mathrm{H}), 1.87$ (quin, $J=6.9 \mathrm{~Hz}, 2 \mathrm{H}), 1.78-1.50(\mathrm{~m}, 12 \mathrm{H}), 1.42$ (quin, $J=7.5 \mathrm{~Hz}, 4 \mathrm{H}) ;{ }^{13} \mathrm{C} \mathrm{NMR}\left(100 \mathrm{MHz}, \mathrm{CD}_{3} \mathrm{OD}\right) \delta 175.9,174.6,174.5,174.4,166.6$, 166.1, 159.5, 149.5, 142.5, 135.4, 132.3, 131.1, 129.6, 126.2 , 126.1, 122.8, 120.3, 118.2, 113.6, 113.2, 71.5, 71.2, 71.2, 69.9, 69.9, 67.5, 63.4, 61.6, 57.0, 56.4, 55.5, 54.6, 52.9, 47.6, 46.1, 41.0, 39.9, 37.9, 37.8, 36.8, 34.4, 32.2, 32.2, 30.4, 30.1, 29.8, 29.5, 28.4, 28.0, 27.4, 26.9, 23.7; HRMS (ESI) calcd for $\mathrm{C}_{57} \mathrm{H}_{87} \mathrm{~N}_{10} \mathrm{O}_{10} \mathrm{~S}_{2} 1135.6048[\mathrm{M}+\mathrm{H}]^{+}$, found 1135.6057 .

Synthesis of probe $\mathbf{3 b}$ (S25 was prepared according to a known procedure. ${ }^{\text {ref.13 }}$ )

A solution of S24 (142 mg, $0.125 \mathrm{mmol}$ ), 3-methyl-3H-diazirine-3-propanoic acid S25 (19.2 $\mathrm{mg}, 0.150 \mathrm{mmol})$, EDC $\cdot \mathrm{HCl}(28.8 \mathrm{mg}, 0.150 \mathrm{mmol})$, and $\mathrm{HOBt} \cdot \mathrm{H}_{2} \mathrm{O}(23.0 \mathrm{mg}, 0.150 \mathrm{mmol})$ in DMF (3 mL) was stirred at r.t. for $20 \mathrm{~h}$. After removal of the solvent by evaporation, the residue was purified by medium-pressure reverse phase flash chromatography (column; SNAP Ultra C18 (12 g), mobile phase; 0.1\% (v/v) TFA aqueous solution/0.1\% (v/v) TFA in MeCN $(95: 5 \rightarrow 45: 55)$, detection; UV $(\lambda$-all)). The suitable fractions were pooled and lyophilized to give probe $3 \mathbf{b}$ as a white powder $(111 \mathrm{mg}, 71 \%)$; ${ }^{1} \mathrm{H}$ NMR $\left(500 \mathrm{MHz}, \mathrm{DMSO}-d_{6}\right) \delta 9.60$ (s, $1 \mathrm{H}), 8.00(\mathrm{~d}, J=8.0 \mathrm{~Hz}, 1 \mathrm{H}), 7.90(\mathrm{t}, J=5.7 \mathrm{~Hz}, 1 \mathrm{H}), 7.79-7.71(\mathrm{~m}, 5 \mathrm{H}), 7.51(\mathrm{~d}, J=5.5 \mathrm{~Hz}$, $1 \mathrm{H}), 7.43(\mathrm{~d}, J=2.8 \mathrm{~Hz}, 1 \mathrm{H}), 7.33(\mathrm{t}, J=7.9 \mathrm{~Hz}, 1 \mathrm{H}), 7.24(\mathrm{~d}, J=8.4 \mathrm{~Hz}, 1 \mathrm{H}), 7.08(\mathrm{dd}, J=$ 8.3, $2.8 \mathrm{~Hz}, 1 \mathrm{H}), 6.99$ (d, $J=7.4 \mathrm{~Hz}, 1 \mathrm{H}), 6.42$ (br, 1H), 6.36 (br, 1H), 4.30 (dd, $J=7.8,4.6$ $\mathrm{Hz}, 1 \mathrm{H}), 4.15-4.10$ (m, 4H), 3.70 (br, 2H), 3.60 (br, 2H), $3.52-3.44$ (m, 12H), 3.41 (br, 2H), $3.38(\mathrm{td}, J=6.3,2.9 \mathrm{~Hz}, 6 \mathrm{H}), 3.11-3.02(\mathrm{~m}, 9 \mathrm{H}), 2.99(\mathrm{q}, J=6.5 \mathrm{~Hz}, 2 \mathrm{H}), 2.89(\mathrm{t}, J=6.4 \mathrm{~Hz}$, 2H), $2.81(\mathrm{dd}, J=12.4,5.2 \mathrm{~Hz}, 1 \mathrm{H}), 2.57(\mathrm{~d}, J=12.4 \mathrm{~Hz}, 1 \mathrm{H}), 2.26(\mathrm{~s}, 4 \mathrm{H}), 2.23-2.18$ (m, 2H), $2.08-2.03(\mathrm{~m}, 4 \mathrm{H}), 1.67$ (quin, $J=6.9 \mathrm{~Hz}, 2 \mathrm{H}), 1.63-1.54(\mathrm{~m}, 8 \mathrm{H}), 1.53-1.43(\mathrm{~m}, 4 \mathrm{H})$, $1.39-1.21(\mathrm{~m}, 6 \mathrm{H}), 0.98(\mathrm{~s}, 3 \mathrm{H}) ;{ }^{13} \mathrm{C}$ NMR $\left(125 \mathrm{MHz}, \mathrm{DMSO}-d_{6}\right) \delta 172.0,171.7,171.3,171.2$, $170.9,163.2$, 162.8, 158.3, 158.0, 157.1, 146.5, 140.8, 133.4, 131.2, 130.3, 128.6, 126.8, 125.2, 121.8, 118.6, 117.9, 112.7, 112.3, 69.8, 69.6, 68.2, 68.1, 65.0, 61.1, 59.3, 55.5, 53.3, 52.8, 51.7, 48.8, 45.9, 44.6, 38.4, 36.2, 35.9, 35.8, 35.3, 31.7, 31.0, 29.9, 29.7, 29.5, 29.5, 28.9, 28.3, 28.1, 27.4, 26.6, 25.9, 25.4, 23.6, 22.9, 19.4; HRMS (ESI) calcd for $\mathrm{C}_{62} \mathrm{H}_{92} \mathrm{~N}_{12} \mathrm{O}_{11} \mathrm{NaS}_{2} 1267.6348$ $[\mathrm{M}+\mathrm{Na}]^{+}$, found 1267.6357 . 
Scheme S7. Synthesis of compound S27 and probe 4
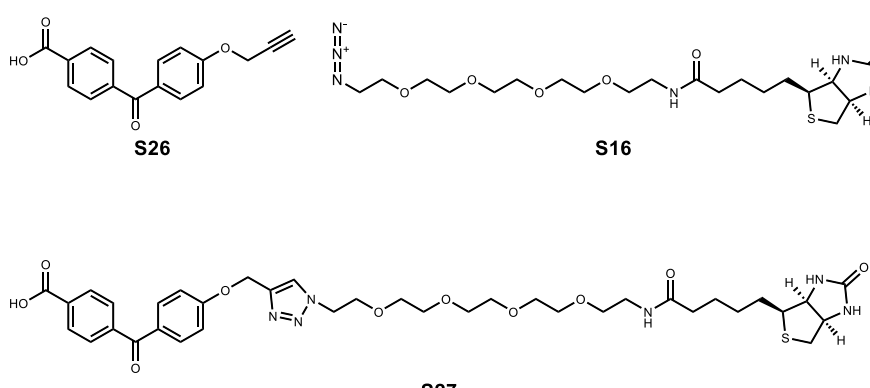

S27

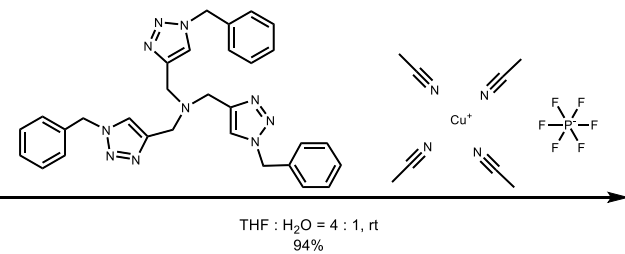

$94 \%$

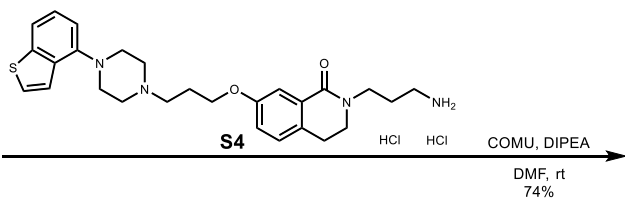

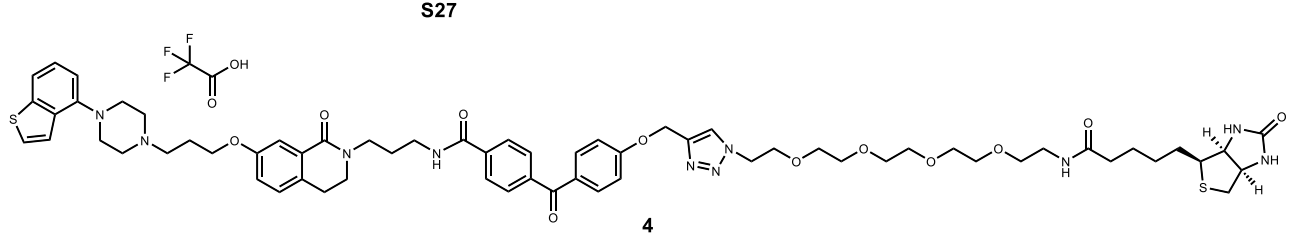

Synthesis of $\mathbf{S 2 7}$ (S26 was prepared according to a known procedure. ${ }^{\text {ref.14 }}$ )

A solution of S26 (20 mg, $71 \mu \mathrm{mol})$, azide-PEG4-biotin S16 (35 mg, $71 \mu \mathrm{mol})$, tetrakis(acetonitrile)copper(I) hexafluorophosphate $(2.7 \mathrm{mg}, 7.2 \mu \mathrm{mol})$, and TBTA $(3.8 \mathrm{mg}$, $7.2 \mu \mathrm{mol})$ in $1 \mathrm{~mL} \mathrm{THF} / \mathrm{H}_{2} \mathrm{O}(4 / 1)$ was stirred at r.t. for $3 \mathrm{~h}$. After removal of the solvent by evaporation, the residue was purified by medium-pressure reverse phase flash chromatography (column; SNAP Ultra C18 (12 g), mobile phase; 0.1\% (v/v) TFA aqueous solution/0.1\% (v/v) TFA in MeCN (95:5 $\rightarrow 45: 55)$, detection; UV ( $\lambda$-all)). The suitable fractions were pooled and lyophilized to give $\mathbf{S 2 7}$ as a white powder (52 mg, 94\%); ${ }^{1} \mathrm{H}$ NMR (500 MHz, DMSO- $\left.d_{6}\right) \delta$ $8.25(\mathrm{~s}, 1 \mathrm{H}), 8.09(\mathrm{~d}, J=8.1 \mathrm{~Hz}, 2 \mathrm{H}), 7.81(\mathrm{t}, J=5.6 \mathrm{~Hz}, 1 \mathrm{H}), 7.78-7.77(\mathrm{~m}, 4 \mathrm{H}), 7.22(\mathrm{~d}, J$ $=8.9 \mathrm{~Hz}, 2 \mathrm{H}), 6.40(\mathrm{br}, 1 \mathrm{H}), 6.35(\mathrm{br}, 1 \mathrm{H}), 5.28(\mathrm{~s}, 2 \mathrm{H}), 4.55(\mathrm{t}, J=5.2 \mathrm{~Hz}, 2 \mathrm{H}), 4.29(\mathrm{dd}, J=$ $7.8,5.1 \mathrm{~Hz}, 1 \mathrm{H}), 4.13-4.10(\mathrm{~m}, 1 \mathrm{H}), 3.83(\mathrm{t}, J=5.2 \mathrm{~Hz}, 2 \mathrm{H}), 3.54-3.51(\mathrm{~m}, 2 \mathrm{H}), 3.48-3.45$ $(\mathrm{m}, 10 \mathrm{H}), 3.37(\mathrm{t}, J=6.0 \mathrm{~Hz}, 2 \mathrm{H}), 3.16(\mathrm{q}, J=5.8 \mathrm{~Hz}, 2 \mathrm{H}), 3.08(\mathrm{td}, J=6.3,4.6 \mathrm{~Hz}, 1 \mathrm{H}), 2.81$ $(\mathrm{dd}, J=12.3,5.1 \mathrm{~Hz}, 1 \mathrm{H}), 2.57(\mathrm{~d}, J=12.4 \mathrm{~Hz}, 1 \mathrm{H}), 2.05(\mathrm{t}, J=7.5 \mathrm{~Hz}, 2 \mathrm{H}), 1.63-1.56(\mathrm{~m}$, $1 \mathrm{H}), 1.53-1.41(\mathrm{~m}, 3 \mathrm{H}), 1.35-1.22(\mathrm{~m}, 2 \mathrm{H}) ;{ }^{13} \mathrm{C}$ NMR (125 MHz, DMSO-d $) \delta 194.0,172.2$, $166.8,162.8,162.1,142.0,141.4,133.8,132.4,129.4,129.3,129.3,125.3,114.8,69.8,69.8$, $69.8,69.7,69.6,69.2,68.7,61.5,61.1,59.3,55.5,49.5,38.5,35.2,28.3,28.1,25.3$; HRMS (ESI) calcd for $\mathrm{C}_{37} \mathrm{H}_{49} \mathrm{~N}_{6} \mathrm{O}_{10} \mathrm{~S} 769.3231[\mathrm{M}+\mathrm{H}]^{+}$, found 769.3237 .

\section{Synthesis of probe 4}

A solution of $\mathbf{S 2 7}(15 \mathrm{mg}, 20 \mu \mathrm{mol}), \mathbf{S 4}(11 \mathrm{mg}, 20 \mu \mathrm{mol})$, COMU (9.2 mg, $21 \mu \mathrm{mol})$, and DIPEA $(11 \mu \mathrm{L}, 64 \mu \mathrm{mol})$ in $1 \mathrm{~mL}$ DMF was stirred at r.t. for $2 \mathrm{~h}$. After removal of the solvent by evaporation, the residue was purified by medium-pressure reverse phase flash chromatography (column; SNAP Ultra C18 (12 g), mobile phase; 0.1\% (v/v) TFA aqueous solution/0.1\% (v/v) TFA in MeCN (95:5 $\rightarrow 40: 60)$, detection; UV ( $\lambda$-all)). The suitable fractions 
were pooled and lyophilized to give probe 4 as a white powder $(20 \mathrm{mg}, 74 \%) ;{ }^{1} \mathrm{H}$ NMR (400 MHz, DMSO-d6) $\delta 9.59(\mathrm{br}, 1 \mathrm{H}), 8.68(\mathrm{t}, J=5.7 \mathrm{~Hz}, 1 \mathrm{H}), 8.24(\mathrm{~s}, 1 \mathrm{H}), 7.99(\mathrm{~d}, J=8.4 \mathrm{~Hz}$, 2H), $7.81-7.75(\mathrm{~m}, 6 \mathrm{H}), 7.72(\mathrm{~d}, J=8.0 \mathrm{~Hz}, 1 \mathrm{H}), 7.51(\mathrm{dd}, J=5.6,0.7 \mathrm{~Hz}, 1 \mathrm{H}), 7.45(\mathrm{~d}, J=$ $2.8 \mathrm{~Hz}, 1 \mathrm{H}), 7.33(\mathrm{t}, J=7.8 \mathrm{~Hz}, 1 \mathrm{H}), 7.25(\mathrm{~d}, J=8.4 \mathrm{~Hz}, 1 \mathrm{H}), 7.22(\mathrm{~d}, J=8.9 \mathrm{~Hz}, 2 \mathrm{H}), 7.08$ $(\mathrm{dd}, J=8.0,2.8 \mathrm{~Hz}, 1 \mathrm{H}), 6.99(\mathrm{~d}, J=7.3 \mathrm{~Hz}, 1 \mathrm{H}), 6.40$ (br, 1H), 6.34 (br, 1H), 5.28 (s, 2H), $4.55(\mathrm{t}, J=5.2 \mathrm{~Hz}, 2 \mathrm{H}), 4.29(\mathrm{dd}, J=7.9,4.5 \mathrm{~Hz}, 1 \mathrm{H}), 4.15-4.10(\mathrm{~m}, 3 \mathrm{H}), 3.83(\mathrm{t}, J=5.3 \mathrm{~Hz}$, 2H), $3.70(\mathrm{br}, 2 \mathrm{H}), 3.61-3.51(\mathrm{~m}, 8 \mathrm{H}), 3.48-3.46(\mathrm{~m}, 10 \mathrm{H}), 3.41-3.31(\mathrm{~m}, 8 \mathrm{H}), 3.16(\mathrm{q}, J$ $=5.8 \mathrm{~Hz}, 2 \mathrm{H}), 3.12-3.05(\mathrm{~m}, 3 \mathrm{H}), 2.92(\mathrm{t}, J=6.4 \mathrm{~Hz}, 2 \mathrm{H}), 2.80(\mathrm{dd}, J=12.4,5.1 \mathrm{~Hz}, 1 \mathrm{H})$, $2.57(\mathrm{~d}, J=12.4 \mathrm{~Hz}, 1 \mathrm{H}), 2.23-2.18(\mathrm{~m}, 2 \mathrm{H}), 2.05(\mathrm{t}, J=7.4 \mathrm{~Hz}, 2 \mathrm{H}), 1.85$ (quin, $J=7.0 \mathrm{~Hz}$, $2 \mathrm{H}), 1.64-1.55(\mathrm{~m}, 1 \mathrm{H}), 1.53-1.40(\mathrm{~m}, 3 \mathrm{H}), 1.36-1.24(\mathrm{~m}, 2 \mathrm{H}) ;{ }^{13} \mathrm{C}$ NMR $(125 \mathrm{MHz}$, DMSO- $\left.d_{6}\right) \delta 194.0,172.2,165.5,163.2,162.8,162.1,158.2,157.9,157.1,146.5,142.0,140.7$, $139.9,137.5,133.4,132.3,131.1,130.3,129.4,129.2$, 128.6, 127.3, 126.7 , 125.3, 125.1, 121.8, $118.6,117.9,114.8,112.7,112.4,69.8,69.8,69.8,69.7,69.6,69.2,68.7,65.0,61.5,61.1,59.2$, 55.5, 53.3, 51.6, 49.5, 48.8, 45.9, 44.6, 38.5, 37.1, 35.2, 28.3, 28.1, 27.4, 26.6, 25.3, 23.6; HRMS (ESI) calcd for $\mathrm{C}_{64} \mathrm{H}_{81} \mathrm{~N}_{10} \mathrm{O}_{11} \mathrm{~S}_{2} 1229.5528[\mathrm{M}+\mathrm{H}]^{+}$, found 1229.5527 .

Scheme S8. Synthesis of compounds S29-S31 for preparation of probe 5

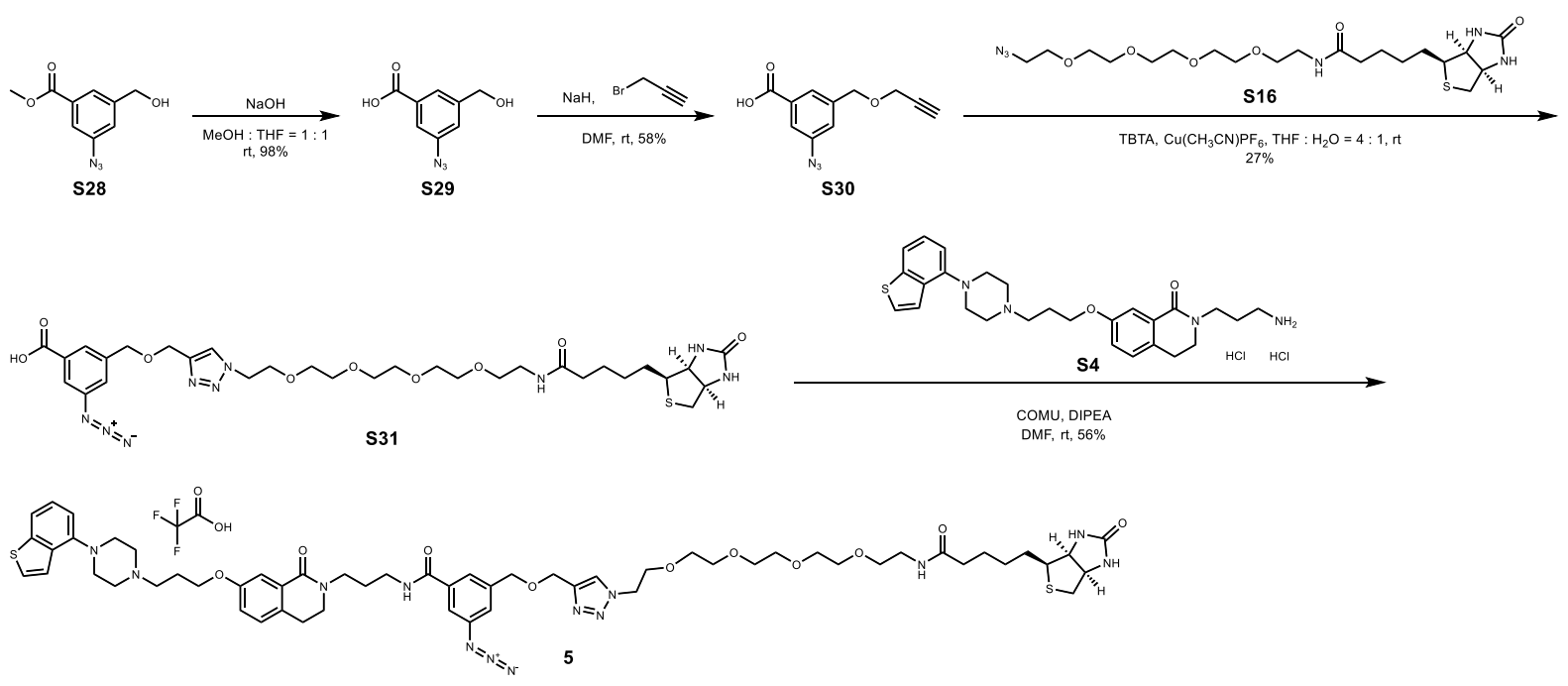

Synthesis of $\mathbf{S 2 9}$ ( $\mathbf{S 2 8}$ was prepared according to a known procedure. ${ }^{\text {ref. }}{ }^{15}$ )

To a solution of $\mathbf{S 2 8}(200 \mathrm{mg}, 0.965 \mathrm{mmol})$ in $4 \mathrm{~mL} \mathrm{MeOH} / \mathrm{THF}(1 / 1)$ at $0{ }^{\circ} \mathrm{C}$ was added 579 $\mu \mathrm{L} 5 \mathrm{M} \mathrm{NaOH}$ aq., and the mixture was warmed up to r.t. and stirred for $4 \mathrm{~h}$. After addition of $600 \mu \mathrm{L} 5 \mathrm{M} \mathrm{HCl}$ to acidify the solution, the solvent was extracted with EtOAc. The organic layers were collected and washed with brine. After drying over $\mathrm{Na}_{2} \mathrm{SO}_{4}$, the solvent was removed by evaporation to give $\mathbf{S 2 9}$ as a pale yellow solid (183 $\mathrm{mg}, 98 \%) ;{ }^{1} \mathrm{H}$ NMR (500 MHz, DMSO- $\left.d_{6}\right) \delta 13.20$ (br, 1H), $7.72(\mathrm{~s}, 1 \mathrm{H}), 7.44-7.43(\mathrm{~m} \mathrm{1H}), 7.30-7.29(\mathrm{~m} \mathrm{1H}), 5.42$ (br, 1H), 3.32 (s, 2H); ${ }^{13} \mathrm{C}$ NMR (125 MHz, DMSO- $\left.d_{6}\right) \delta 166.6,145.6,139.8,132.5,123.8$, 
120.9, 117.8, 62.0; HRMS (ESI) calcd for $\mathrm{C}_{8} \mathrm{H}_{7} \mathrm{~N}_{3} \mathrm{O}_{3} \mathrm{Na} 216.0385[\mathrm{M}+\mathrm{Na}]^{+}$, found 216.0384.

\section{Synthesis of $\mathbf{S 3 0}$}

To a solution of $\mathbf{S 2 9}(162 \mathrm{mg}, 0.839 \mathrm{mmol})$ in $5 \mathrm{~mL}$ DMF at $0{ }^{\circ} \mathrm{C}$ was added $60 \% \mathrm{NaH}(345$ $\mathrm{mg}, 1.85 \mathrm{mmol}$ ), and the mixture was stirred for $30 \mathrm{~min}$ before 3-bromopropyne (139 $\mu \mathrm{L}, 1.85$ mmol) was added. The mixture was warmed up to r.t. and stirred for $1 \mathrm{~h}$. Then $30 \mathrm{~mL}$ water was added to the mixture, and the aqueous layer was washed with EtOAc and acidified with 8 $\mathrm{mL} 1 \mathrm{M} \mathrm{HCl}$ in water. The solvent was extracted with EtOAc, and the organic layers were combined, washed with brine and dried over $\mathrm{Na}_{2} \mathrm{SO}_{4}$. After removal of the solvent by evaporation, the residue was purified by medium-pressure reverse phase flash chromatography (column; SNAP Ultra C18 (12 g), mobile phase; 0.1\% (v/v) TFA aqueous solution/0.1\% (v/v) TFA in MeCN (95:5 $\rightarrow 45: 55)$, detection; UV ( $\lambda$-all)). The suitable fractions were pooled and extracted with EtOAc. The organic layers were combined, washed with brine dried over $\mathrm{Na}_{2} \mathrm{SO}_{4}$. The solvent was removed by evaporation to give $\mathbf{S 3 0}$ as a pale yellow solid (112 $\mathrm{mg}$, $58 \%$ ) ; ${ }^{1} \mathrm{H}$ NMR (500 MHz, DMSO- $\left.d_{6}\right) \delta 13.29(\mathrm{br}, 1 \mathrm{H}), 7.71(\mathrm{~s}, 1 \mathrm{H}), 7.50-7.49(\mathrm{~m}, 1 \mathrm{H})$, $7.31-7.30(\mathrm{~m}, 1 \mathrm{H}), 4.60(\mathrm{~s}, 2 \mathrm{H}), 4.23(\mathrm{~d}, J=2.4 \mathrm{~Hz}, 2 \mathrm{H}), 3.52(\mathrm{t}, J=2.4 \mathrm{~Hz}, 1 \mathrm{H}) ;{ }^{13} \mathrm{C} \mathrm{NMR}$ (125 MHz, DMSO- $\left.d_{6}\right) \delta 166.5,140.6,140.0,132.9,124.8,122.1,118.7,80.1,77.8,69.8,57.3$; HRMS (ESI) calcd for $\mathrm{C}_{11} \mathrm{H}_{9} \mathrm{~N}_{3} \mathrm{O}_{3} \mathrm{Na} 254.0542[\mathrm{M}+\mathrm{Na}]^{+}$, found 254.0543.

\section{Synthesis of $\mathbf{S 3 1}$}

A solution of S30 (41 mg, $0.14 \mathrm{mmol}$ ), azide-PEG4-biotin $\mathbf{S 1 6}$ (35 mg, $72 \mathrm{mmol}$ ), TBTA (3.8 $\mathrm{mg}, 0.072 \mathrm{mmol}$ ), and tetrakis(acetonitrile)copper(I) hexafluorophosphate (2.7 $\mathrm{mg}, 0.072$ $\mathrm{mmol}$ ) in $1 \mathrm{~mL} \mathrm{THF} / \mathrm{H}_{2} \mathrm{O}(4 / 1)$ was stirred at r.t. for $4 \mathrm{~h}$. After removal of the solvent by evaporation, the residue was purified by medium-pressure reverse phase flash chromatography (column; SNAP Ultra C18 (12 g), mobile phase; 0.1\% (v/v) TFA aqueous solution/0.1\% (v/v) TFA in MeCN (95:5 $\rightarrow 45: 55)$, detection; UV $(\lambda$-all)). The suitable fractions were pooled and lyophilized to give S31 as a white powder (14 mg, 27\%); ${ }^{1} \mathrm{H}$ NMR (500 MHz, DMSO- $\left.d_{6}\right) \delta$ $13.28(\mathrm{br}, 1 \mathrm{H}), 8.12(\mathrm{~s}, 1 \mathrm{H}), 7.81(\mathrm{t}, J=5.5 \mathrm{~Hz}, 1 \mathrm{H}), 7.71(\mathrm{~s}, 1 \mathrm{H}), 7.49-7.48(\mathrm{~m}, 1 \mathrm{H}), 7.32-$ $7.31(\mathrm{~m}, 1 \mathrm{H}), 6.41(\mathrm{br}, 2 \mathrm{H}), 4.61(\mathrm{~s}, 4 \mathrm{H}), 4.52(\mathrm{t}, J=5.2 \mathrm{~Hz}, 2 \mathrm{H}), 4.30$ (dd, $J=7.8,4.5 \mathrm{~Hz}$, $1 \mathrm{H}), 4.12(\mathrm{dd}, J=7.8,4.5 \mathrm{~Hz}, 1 \mathrm{H}), 3.82(\mathrm{t}, J=5.2 \mathrm{~Hz}, 2 \mathrm{H}), 3.53-3.51(\mathrm{~m}, 2 \mathrm{H}), 3.48-3.45$ $(\mathrm{m}, 10 \mathrm{H}), 3.37(\mathrm{t}, J=6.0 \mathrm{~Hz}, 2 \mathrm{H}), 3.17(\mathrm{q}, J=5.8 \mathrm{~Hz}, 2 \mathrm{H}), 3.10-3.07(\mathrm{~m}, 1 \mathrm{H}), 2.81(\mathrm{dd}, J=$ $12.3,5.1 \mathrm{~Hz}, 1 \mathrm{H}), 2.57(\mathrm{~d}, J=12.3 \mathrm{~Hz}, 1 \mathrm{H}), 2.05(\mathrm{t}, J=7.4 \mathrm{~Hz}, 2 \mathrm{H}), 1.64-1.57(\mathrm{~m}, 1 \mathrm{H}), 1.54$ $-1.41(\mathrm{~m}, 3 \mathrm{H}), 1.35-1.24(\mathrm{~m}, 2 \mathrm{H}) ;{ }^{13} \mathrm{C}$ NMR (125 MHz, DMSO-d $) \delta 172.2,166.5,162.8$, 143.6, 141.2, 140.0, 132.6, 124.8, 124.5, 122.1, 118.5, 70.1, 69.8, 69.8, 69.8, 69.7, 69.6, 69.2, $68.7,63.2,61.1,59.3,55.5,49.4,38.5,35.2,28.3,28.1,25.3$; HRMS (ESI) calcd for $\mathrm{C}_{31} \mathrm{H}_{46} \mathrm{~N}_{9} \mathrm{O}_{9} \mathrm{~S} 720.3139[\mathrm{M}+\mathrm{H}]^{+}$, found 720.3142 . 
Synthesis of probe 5

A solution of $\mathbf{S 3 1}(9.1 \mathrm{mg}, 0.013 \mathrm{mmol}), \mathbf{S 4}(7.0 \mathrm{mg}, 0.013 \mathrm{mmol})$, COMU (6.0 mg, 0.014 mmol), and DIPEA ( $7.3 \mu \mathrm{L}, 0.042 \mathrm{mmol})$ in $1 \mathrm{~mL} \mathrm{DMF}$ was stirred at r.t. for $2 \mathrm{~h}$. After removal of the solvent by evaporation, the residue was purified by medium-pressure reverse phase flash chromatography (column; SNAP Ultra C18 (12 g), mobile phase; 0.1\% (v/v) TFA aqueous solution/0.1\% (v/v) TFA in MeCN (95:5 $\rightarrow 40: 60)$, detection; UV ( $\lambda$-all)). The suitable fractions were pooled and lyophilized to give probe 5 as a white powder $(9.1 \mathrm{mg}, 56 \%) ;{ }^{1} \mathrm{H}$ NMR (500 MHz, DMSO-d $d_{6} \delta 9.58(\mathrm{br}, 1 \mathrm{H}), 8.62(\mathrm{t}, J=5.7 \mathrm{~Hz}, 1 \mathrm{H}), 8.12(\mathrm{~s}, 1 \mathrm{H}), 7.81(\mathrm{t}, J=5.7 \mathrm{~Hz}, 1 \mathrm{H})$, $7.78(\mathrm{~d}, J=5.6 \mathrm{~Hz}, 1 \mathrm{H}), 7.72(\mathrm{~d}, J=8.1 \mathrm{~Hz}, 1 \mathrm{H}), 7.63(\mathrm{br}, 1 \mathrm{H}), 7.51(\mathrm{~d}, J=5.7 \mathrm{~Hz}, 1 \mathrm{H}), 7.49$ $-7.48(\mathrm{~m}, 1 \mathrm{H}), 7.44(\mathrm{~d}, J=2.8 \mathrm{~Hz}, 1 \mathrm{H}), 7.33(\mathrm{t}, J=7.8 \mathrm{~Hz}, 1 \mathrm{H}), 7.25(\mathrm{~d}, J=8.4 \mathrm{~Hz}, 1 \mathrm{H}), 7.22$ $-7.21(\mathrm{~m}, 1 \mathrm{H}), 7.08(\mathrm{dd}, J=8.2,2.8 \mathrm{~Hz}, 1 \mathrm{H}), 6.99$ (d, $J=7.3 \mathrm{~Hz}, 1 \mathrm{H}), 6.40-6.35(\mathrm{br}, 2 \mathrm{H})$, $4.61(\mathrm{~s}, 2 \mathrm{H}), 4.58(\mathrm{~s}, 2 \mathrm{H}), 4.52(\mathrm{t}, J=5.3 \mathrm{~Hz}, 2 \mathrm{H}), 4.31-4.28(\mathrm{~m}, 1 \mathrm{H}), 4.14-4.10(\mathrm{~m}, 3 \mathrm{H})$, $3.81(\mathrm{t}, J=5.3 \mathrm{~Hz}, 2 \mathrm{H}), 3.70(\mathrm{br}, 2 \mathrm{H}), 3.59$ (br, $2 \mathrm{H}), 3.56-3.53(\mathrm{~m}, 4 \mathrm{H}), 3.52-3.51(\mathrm{~m}, 2 \mathrm{H})$, $3.48-3.45$ (m, under the water signal), $3.43-3.39(\mathrm{~m}, 4 \mathrm{H}), 3.37(\mathrm{t}, J=5.9 \mathrm{~Hz}, 2 \mathrm{H}), 3.29(\mathrm{q}$, $J=6.7 \mathrm{~Hz}, 2 \mathrm{H}), 3.16(\mathrm{q}, J=5.8 \mathrm{~Hz}, 2 \mathrm{H}), 3.11-3.06(\mathrm{~m}, 3 \mathrm{H}), 2.91(\mathrm{t}, J=6.4 \mathrm{~Hz}, 2 \mathrm{H}), 2.81$ $(\mathrm{dd}, J=12.5,5.1 \mathrm{~Hz}, 1 \mathrm{H}), 2.57(\mathrm{~d}, J=12.5 \mathrm{~Hz}, 1 \mathrm{H}), 2.23-2.17(\mathrm{~m}, 2 \mathrm{H}), 2.05(\mathrm{t}, J=7.4 \mathrm{~Hz}$, $2 \mathrm{H}$ ), 1.82 (quin, $J=7.2 \mathrm{~Hz}, 2 \mathrm{H}), 1.62-1.56(\mathrm{~m}, 1 \mathrm{H}), 1.52-1.41(\mathrm{~m}, 3 \mathrm{H}), 1.32-1.24(\mathrm{~m}$, $2 \mathrm{H}) ;{ }^{13} \mathrm{C}$ NMR (125 MHz, DMSO- $\left.d_{6}\right) \delta 172.2,165.1,163.2,162.8,158.3,158.0,157.1,146.5$, 143.6, 140.8, 140.7, 136.4, 133.4, 131.1, 130.3, 126.7, 125.1, 124.5, 123.1, 121.8, 120.5, 117.9, $117.1,116.8,114.8,112.7,112.4,70.4,69.8,69.8,69.7,69.6,69.2,68.7,65.0,63.2,61.1,59.3$, 55.5, 53.3, 51.6, 49.4, 48.8, 45.8, 38.5, 35.2, 28.3, 28.1, 27.4, 26.6, 25.3, 23.6; HRMS (ESI) calcd for $\mathrm{C}_{58} \mathrm{H}_{78} \mathrm{~N}_{13} \mathrm{O}_{10} \mathrm{~S}_{2} 1180.5436[\mathrm{M}+\mathrm{H}]^{+}$, found 1180.5431 .

Scheme S9. Synthesis of compounds S32-S34 for preparation of probe $6 \mathbf{a}$
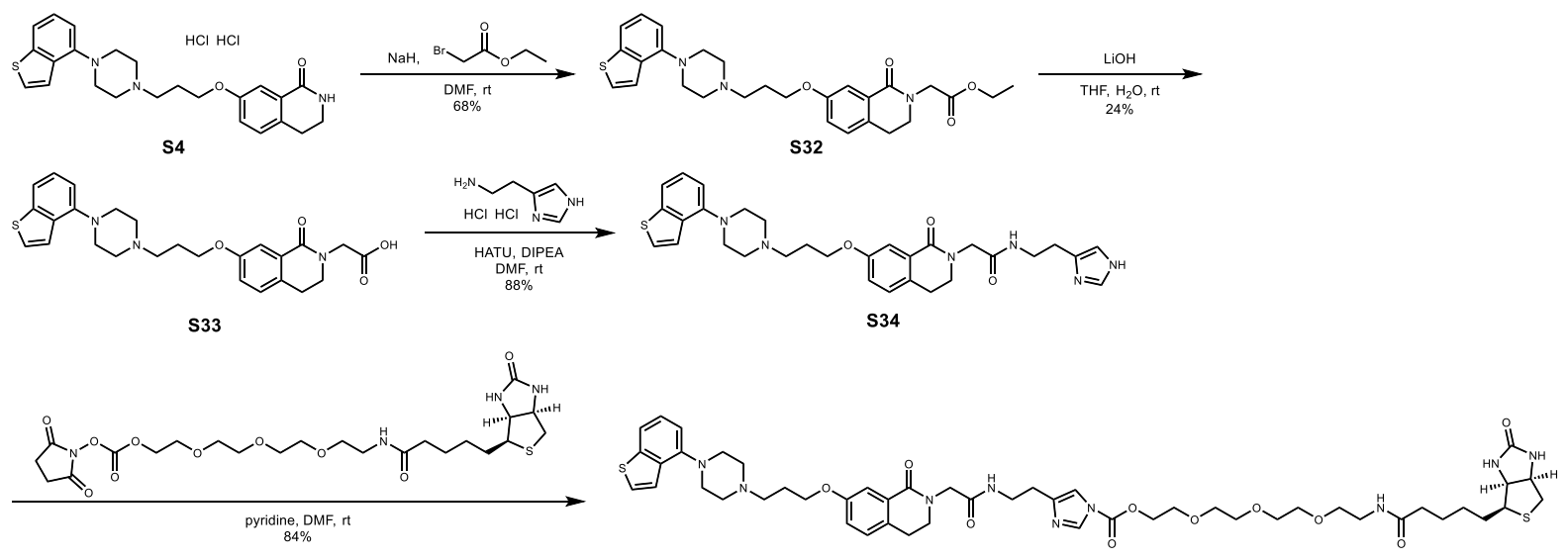

$6 a$

Synthesis of $\mathbf{S 3 2}$

To a solution of $\mathbf{S 4}(500 \mathrm{mg}, 1.19 \mathrm{mmol})$ in $18 \mathrm{~mL}$ DMF was added 60\% NaH (66.4 mg, 1.66 $\mathrm{mmol})$ at $0{ }^{\circ} \mathrm{C}$ for $30 \mathrm{~min}$. Then, ethyl bromoacetate $(190 \mu \mathrm{L}, 1.66 \mathrm{mmol})$ was to the solution, 
and the mixture was stirred at r.t. for $3 \mathrm{~h}$. After removal of the solvent by evaporation, the residue was dissolved in $\mathrm{EtOAc} / \mathrm{Et}_{2} \mathrm{O}(1 / 1,110 \mathrm{~mL})$, washed by water $(100 \mathrm{~mL})$ twice and dried over $\mathrm{Na}_{2} \mathrm{SO}_{4}$. After removal of the solvent by evaporation, the residue was purified by medium-pressure flash chromatography (column; SNAP Ultra (25 g), mobile phase; Hexane/EtOAc/MeOH (80:20:0 $\rightarrow 0: 100: 0 \rightarrow 0: 80: 20)$, detection; UV ( $\lambda$-all)). The suitable fractions were combined, and the solvent was removed by evaporation to give $\mathbf{S 3 2}$ as a pale yellow oil (411 mg, 68\%); ${ }^{1} \mathrm{H}$ NMR $\left(500 \mathrm{MHz}, \mathrm{CDCl}_{3}\right) \delta 7.63(\mathrm{~d}, J=2.7 \mathrm{~Hz}, 1 \mathrm{H}), 7.55(\mathrm{~d}, J$ $=8.1 \mathrm{~Hz}, 1 \mathrm{H}), 7.42(\mathrm{dd}, J=5.5,0.5 \mathrm{~Hz}, 1 \mathrm{H}), 7.39(\mathrm{~d}, J=5.5 \mathrm{~Hz}, 1 \mathrm{H}), 7.27(\mathrm{t}, J=7.8 \mathrm{~Hz}, 1 \mathrm{H})$, $7.10(\mathrm{~d}, J=8.4 \mathrm{~Hz}, 1 \mathrm{H}), 7.01(\mathrm{dd}, J=8.4,2.8 \mathrm{~Hz}, 1 \mathrm{H}), 6.91(\mathrm{dd}, J=7.7,0.5 \mathrm{~Hz}, 1 \mathrm{H}), 4.33$ (s, 2H), 4.22 (q, $J=7.1 \mathrm{~Hz}, 2 \mathrm{H}), 4.11(\mathrm{t}, J=6.4 \mathrm{~Hz}, 2 \mathrm{H}), 3.64(\mathrm{t}, J=6.6 \mathrm{~Hz}, 2 \mathrm{H}), .321(\mathrm{br}, 4 \mathrm{H})$, $2.99(\mathrm{t}, J=6.6 \mathrm{~Hz}, 2 \mathrm{H}), 2.75(\mathrm{br}, 4 \mathrm{H}), 2.65$ (br, 2H), 2.05 (quin, $J=6.9 \mathrm{~Hz}, 2 \mathrm{H}), 1.29$ (t, $J=$ $7.1 \mathrm{~Hz}, 3 \mathrm{H}) ;{ }^{13} \mathrm{C}$ NMR $\left(125 \mathrm{MHz}, \mathrm{CDCl}_{3}\right) \delta 169.3,165.0,158.1,148.5,141.1,134.1,130.6$, 129.7, 128.2, 125.0, 124.9, 121.9, 119.9, 117.0, 112.4, 112.2, 66.5, 61.3, 55.2, 53.6, 52.0, 49.3, 47.7, 27.2, 26.7, 14.2; HRMS (ESI) calcd for $\mathrm{C}_{28} \mathrm{H}_{34} \mathrm{~N}_{3} \mathrm{O}_{4} \mathrm{~S} 508.2270[\mathrm{M}+\mathrm{H}]^{+}$, found 508.2268.

\section{Synthesis of $\mathbf{S 3 3}$}

To a solution of $\mathbf{S 3 2}(411 \mathrm{mg}, 0.809 \mathrm{mmol})$ in $\mathrm{THF} / \mathrm{H}_{2} \mathrm{O}(7 / 1,24 \mathrm{~mL})$ was added $1 \mathrm{M} \mathrm{LiOH}$ aq. $(1.05 \mathrm{~mL}, 1.05 \mathrm{mmol})$ at $0{ }^{\circ} \mathrm{C}$, and the mixture was stirred at r.t. for $19 \mathrm{~h}$. After removal of the solvent by evaporation, the residual solvent was acidified by $5 \mathrm{M} \mathrm{HCl} \mathrm{aq.,} \mathrm{extracted} \mathrm{with}$ $\mathrm{CH}_{2} \mathrm{Cl}_{2}$ three times, and the organic layer was dried over $\mathrm{Na}_{2} \mathrm{SO}_{4}$. After removal of the solvent by evaporation, the residue was purified by medium-pressure flash chromatography (column; SNAP Ultra (25 g), mobile phase; $\mathrm{CH}_{2} \mathrm{Cl}_{2} / \mathrm{MeOH}(100: 0 \rightarrow 0: 100)$, detection; $\mathrm{UV}(\lambda$-all)). The suitable fractions were pooled, and the solvent was removed by evaporation to give $\mathbf{S 3 3}$ as a colorless solid (94.5 mg, 24\%); ${ }^{1} \mathrm{H}$ NMR (500 MHz, DMSO-d6) $\delta 7.69(\mathrm{~d}, J=5.5 \mathrm{~Hz}, 1 \mathrm{H})$, $7.61(\mathrm{~d}, J=8.1 \mathrm{~Hz}, 1 \mathrm{H}), 7.40(\mathrm{~d}, J=5.5 \mathrm{~Hz}, 1 \mathrm{H}), 7.38(\mathrm{~d}, J=2.8 \mathrm{~Hz}, 1 \mathrm{H}), 7.27(\mathrm{t}, J=7.9 \mathrm{~Hz}$, $1 \mathrm{H}), 7.20(\mathrm{~d}, J=8.4 \mathrm{~Hz}, 1 \mathrm{H}), 7.05(\mathrm{dd}, J=8.3,2.7 \mathrm{~Hz}, 1 \mathrm{H}), 6.90(\mathrm{~d}, J=7.6 \mathrm{~Hz}, 1 \mathrm{H}), 4.07-$ $4.05(\mathrm{~m}, 4 \mathrm{H}), 3.56(\mathrm{t}, J=6.6 \mathrm{~Hz}, 2 \mathrm{H}), 3.08(\mathrm{br}, 4 \mathrm{H}), 2.89$ (t, $J=6.6 \mathrm{~Hz}, 2 \mathrm{H}), 2.64(\mathrm{br}, 4 \mathrm{H})$, $2.55(\mathrm{t}, J=7.0 \mathrm{~Hz}, 2 \mathrm{H}), 1.94$ (quin, $J=6.8 \mathrm{~Hz}, 2 \mathrm{H}) ;{ }^{13} \mathrm{C}$ NMR (100 MHz, DMSO-d6) $\delta 170.9$, $163.4,157.5,148.3,140.5,133.5,130.9,130.2$, 128.5, 125.9, 125.2, 122.0, 118.7, 116.7, 112.1, 112.0, 66.1, 54.4, 53.1, 51.8, 50.2, 47.0, 26.5, 26.2; HRMS (ESI) calcd for $\mathrm{C}_{26} \mathrm{H}_{30} \mathrm{~N}_{3} \mathrm{O}_{4} \mathrm{~S}$ $480.1957[\mathrm{M}+\mathrm{H}]^{+}$, found 480.1958 .

\section{Synthesis of $\mathbf{S 3 4}$}

A solution of $\mathbf{S 3 3}$ (83 mg, $0.17 \mathrm{mmol}$ ), histamine $2 \mathrm{HCl}$ (31 mg, $0.17 \mathrm{mmol}$ ), HATU (76 mg, $0.17 \mathrm{mmol})$, and DIPEA $(0.12 \mathrm{~mL}, 0.67 \mathrm{mmol})$ in dry DMF $(5 \mathrm{~mL})$ was stirred at r.t. for $15 \mathrm{~h}$. After removal of the solvent by evaporation, the residue was purified by medium-pressure reverse phase flash chromatography (column; SNAP ISOLUTE Flash-NH2 (28 g), mobile phase; $\mathrm{CH}_{2} \mathrm{Cl}_{2} / \mathrm{MeOH}(100: 0 \rightarrow 93: 7)$, detection; UV $(\lambda$-all)). The suitable fractions were 
pooled, and the solvent was removed by evaporation to give $\mathbf{S 3 4}$ as a white solid (84 $\mathrm{mg}, 88 \%$ ); ${ }^{1} \mathrm{H}$ NMR $\left(500 \mathrm{MHz}, \mathrm{CDCl}_{3}\right) \delta 7.58(\mathrm{~d}, J=2.7 \mathrm{~Hz}, 1 \mathrm{H}), 7.55(\mathrm{~d}, J=8.0 \mathrm{~Hz}, 1 \mathrm{H}), 7.42-7.39$ (m, 2H), 7.27 (t, $J=7.9 \mathrm{~Hz}, 1 \mathrm{H}), 7.14(\mathrm{br}, 2 \mathrm{H}), 7.04(\mathrm{dd}, J=8.4,2.8 \mathrm{~Hz}, 1 \mathrm{H}), 6.89$ (d, $J=7.6$ $\mathrm{Hz}, 1 \mathrm{H}), 6.75(\mathrm{br}, 1 \mathrm{H}), 4.17(\mathrm{~s}, 2 \mathrm{H}), 4.14(\mathrm{t}, J=6.3 \mathrm{~Hz}, 2 \mathrm{H}), 3.71(\mathrm{t}, J=6.8 \mathrm{~Hz}, 2 \mathrm{H}), 3.51$ (q, $J=5.8 \mathrm{~Hz}, 2 \mathrm{H}), 3.20(\mathrm{br}, 4 \mathrm{H}), 3.02(\mathrm{t}, J=6.7 \mathrm{~Hz}, 2 \mathrm{H}), 2.80-2.77(\mathrm{~m}, 6 \mathrm{H}), 2.67(\mathrm{t}, J=7.5 \mathrm{~Hz}$, 2H), $2.08-2.02$ (m, 2H); ${ }^{13} \mathrm{C}$ NMR (125 MHz, DMSO- $\left.d_{6}\right) \delta 172.1,167.9,163.8,157.5,148.3$, 140.5, 134.7, 133.5, 131.1, 130.0, 128.6, 125.9, 125.2, 122.0, 118.9, 116.7, 112.2, 112.1, 66.1, 54.4, 53.2, 51.8, 50.3, 47.3, 38.9, 26.5, 26.2, 21.2; HRMS (ESI) calcd for $\mathrm{C}_{31} \mathrm{H}_{37} \mathrm{~N}_{6} \mathrm{O}_{3} \mathrm{~S}$ $573.2648[\mathrm{M}+\mathrm{H}]^{+}$, found 573.2646 .

\section{Synthesis of probe $\mathbf{6 a}$}

A solution of $\mathbf{S 3 4}(96.2 \mathrm{mg}, 0.168 \mathrm{mmol})$, NHS-PEG4-biotin (141 mg, $0.252 \mathrm{mmol})$, and pyridine $(40.8 \mu \mathrm{L}, 0.504 \mathrm{mmol})$ in $1 \mathrm{~mL} \mathrm{DMF}$ was stirred at r.t. for $14 \mathrm{~h}$. After removal of the solvent by evaporation, the residue was purified by medium-pressure reverse phase flash chromatography (column; SNAP Ultra C18 (12 g), mobile phase; $\mathrm{H}_{2} \mathrm{O} / \mathrm{MeCN}(95: 5 \rightarrow 30: 70)$, detection; UV ( $\lambda$-all)). The suitable fractions were pooled and lyophilized to give probe $\mathbf{6 a}$ as a white powder (143 mg, 84\%) ; ${ }^{1} \mathrm{H}$ NMR $\left(500 \mathrm{MHz}, \mathrm{DMSO}-d_{6}\right) \delta 8.14(\mathrm{~d}, J=1.1 \mathrm{~Hz}, 1 \mathrm{H})$, $8.04(\mathrm{t}, J=5.7 \mathrm{~Hz}, 1 \mathrm{H}), 7.81(\mathrm{t}, J=5.6 \mathrm{~Hz}, 1 \mathrm{H}), 7.69(\mathrm{~d}, J=5.5 \mathrm{~Hz}, 1 \mathrm{H}), 7.61(\mathrm{~d}, J=8.1 \mathrm{~Hz}$, $1 \mathrm{H}), 7.40(\mathrm{~d}, J=5.9 \mathrm{~Hz}, 1 \mathrm{H}), 7.39(\mathrm{~d}, J=7.8 \mathrm{~Hz}, 1 \mathrm{H}), 7.37(\mathrm{br}, 1 \mathrm{H}), 7.27(\mathrm{t}, J=7.8 \mathrm{~Hz}, 1 \mathrm{H})$, $7.22(\mathrm{~d}, J=8.4 \mathrm{~Hz}, 1 \mathrm{H}), 7.07$ (dd, $J=8.4,2.7 \mathrm{~Hz}, 1 \mathrm{H}), 6.90$ (d, $J=7.5 \mathrm{~Hz}, 1 \mathrm{H}), 6.41$ (s, 1H), 6.35 (s, 1H), $4.49-4.47(\mathrm{~m}, 2 \mathrm{H}), 4.29$ (dd, $J=7.7,5.2 \mathrm{~Hz}, 1 \mathrm{H}), 4.13-4.06$ (m, 5H), $3.76-$ $3.74(\mathrm{~m}, 2 \mathrm{H}), 3.59-3.45(\mathrm{~m}, 10 \mathrm{H}), 3.37(\mathrm{t}, J=6.0 \mathrm{~Hz}, 2 \mathrm{H}), 3.39$ (br, overlapped with the water signal), 3.17 (q, $J=5.8 \mathrm{~Hz}, 2 \mathrm{H}), 3.08(\mathrm{br}, 5 \mathrm{H}), 2.91(\mathrm{t}, J=6.5 \mathrm{~Hz}, 2 \mathrm{H}), 2.81(\mathrm{dd}, J=12.4,5.1$ $\mathrm{Hz}, 1 \mathrm{H}), 2.64(\mathrm{br}, 6 \mathrm{H}), 2.58-2.53(\mathrm{~m}, 3 \mathrm{H}), 2.05(\mathrm{t}, J=7.4 \mathrm{~Hz}, 2 \mathrm{H}), 1.94$ (quin, $J=6.7 \mathrm{~Hz}$, $2 \mathrm{H}), 1.63-1.56(\mathrm{~m}, 1 \mathrm{H}), 1.53-1.41(\mathrm{~m}, 3 \mathrm{H}), 1.35-1.24(\mathrm{~m}, 2 \mathrm{H}) ;{ }^{13} \mathrm{C}$ NMR $(125 \mathrm{MHz}$, DMSO- $\left.d_{6}\right) \delta 172.2,168.0,163.7,162.8,157.5,148.3,141.2,140.5,136.9,133.5,131.1,130.0$, 128.6, 125.9, 125.2, 122.0, 118.9, 116.7, 113.7, 112.2, 112.1, 69.9, 69.8, 69.8, 69.6, 69.2, 68.0, 67.1, 66.1, 61.1, 59.2, 55.5, 54.4, 53.2, 51.8, 50.2, 47.3, 38.5, 38.1, 35.2, 28.3, 28.1, 27.9, 26.4, 26.2, 25.3; HRMS (ESI) calcd for $\mathrm{C}_{50} \mathrm{H}_{68} \mathrm{~N}_{9} \mathrm{O}_{10} \mathrm{~S}_{2} 1018.4531[\mathrm{M}+\mathrm{H}]^{+}$, found 1018.4529. 
Scheme S10. Synthesis of compounds S35 and S36 for preparation of probe $6 \mathbf{b}$
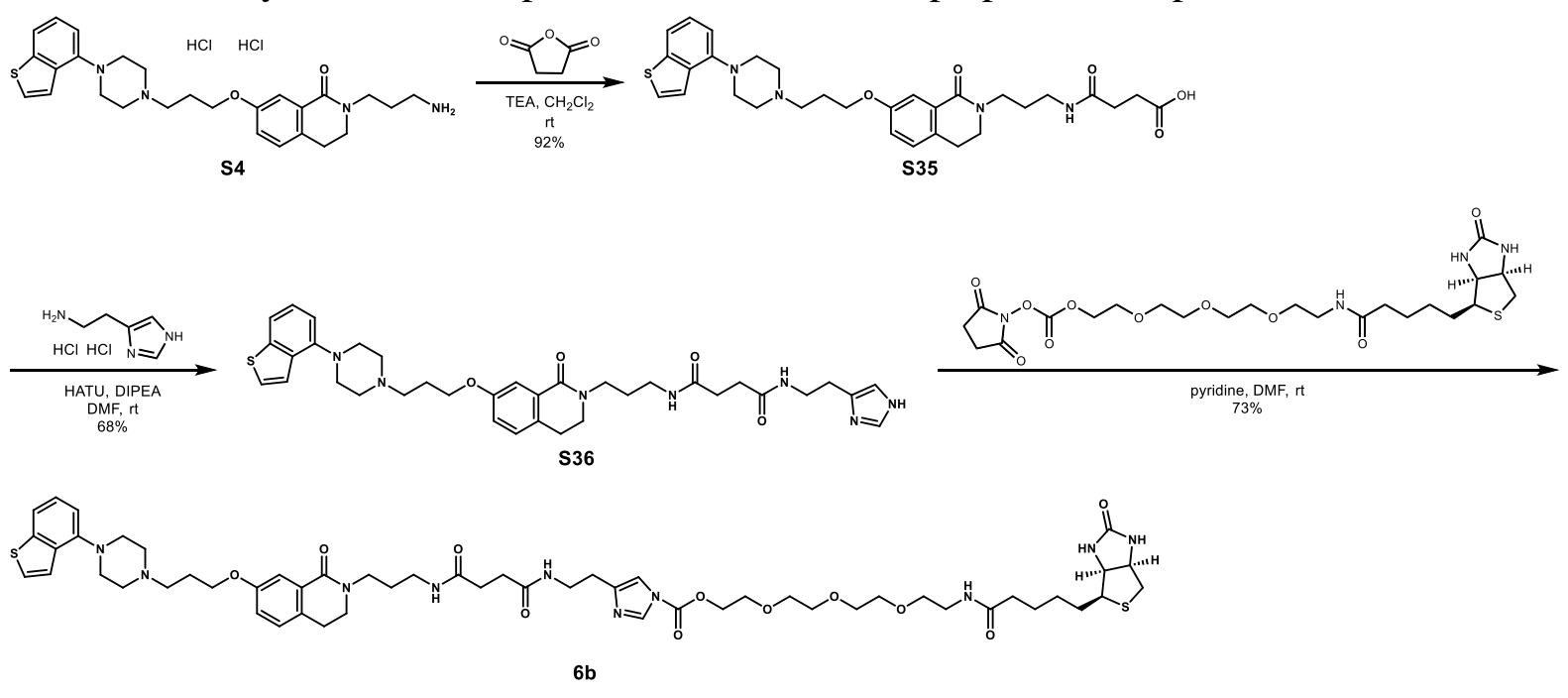

\section{Synthesis of $\mathbf{S 3 5}$}

To a solution of $\mathbf{S 4}(225 \mathrm{mg}, 0.470 \mathrm{mmol})$ and TEA $(131 \mu \mathrm{L}, 0.940 \mathrm{mmol})$ in $\mathrm{CH}_{2} \mathrm{Cl}_{2}(4 \mathrm{~mL})$ was added succinic anhydride $(52.8 \mathrm{mg}, 0.517 \mathrm{mmol})$, and the mixture was stirred at r.t. for 18 h. Then $30 \mathrm{~mL}$ sat. $\mathrm{NH}_{4} \mathrm{Cl}$ aq. was added to the mixture, and the solvent was extracted with $\mathrm{CH}_{2} \mathrm{Cl}_{2}$, and the organic layer was dried over $\mathrm{Na}_{2} \mathrm{SO}_{4}$. The solvent was removed by evaporation to give $\mathbf{S 3 5}$ as a brown amorphous (250 mg, 92\%); ${ }^{1} \mathrm{H}$ NMR $\left(500 \mathrm{MHz}, \mathrm{CDCl}_{3}\right) \delta 12.45$ (br, $1 \mathrm{H}), 7.65(\mathrm{~d}, J=8.1 \mathrm{~Hz}, 1 \mathrm{H}), 7.53-7.48(\mathrm{~m}, 2 \mathrm{H}), 7.46(\mathrm{~d}, J=5.6 \mathrm{~Hz}, 1 \mathrm{H}), 7.32-7.29$ (m, 2H), $7.13(\mathrm{~d}, J=8.3 \mathrm{~Hz}, 1 \mathrm{H}), 6.98(\mathrm{dd}, J=8.1,1.4 \mathrm{~Hz}, 1 \mathrm{H}), 6.95(\mathrm{~d}, J=7.7 \mathrm{~Hz}, 1 \mathrm{H}), 4.16(\mathrm{t}$, $J=5.2 \mathrm{~Hz}, 2 \mathrm{H}), 3.86(\mathrm{br}, 2 \mathrm{H}), 3.67(\mathrm{t}, J=5.6 \mathrm{~Hz}, 2 \mathrm{H}), 3.56-3.51(\mathrm{~m}, 4 \mathrm{H}), 3.43-3.36(\mathrm{~m}$, overlapped with the water signal), $3.27(\mathrm{br}, 2 \mathrm{H}), 3.18(\mathrm{t}, J=10.8 \mathrm{~Hz}, 2 \mathrm{H}), 2.93$ (t, $J=6.5 \mathrm{~Hz}$, 2H), 2.63 (t, $J=5.8 \mathrm{~Hz}, 2 \mathrm{H}), 2.53$ (t, $J=6.4 \mathrm{~Hz}, 2 \mathrm{H}), 2.33$ (br, 2H), 1.78 (br, 2H); ${ }^{13} \mathrm{C}$ NMR (125 MHz, DMSO- $\left.d_{6}\right) \delta 173.9,170.9,163.1,157.1,146.5,140.7,133.4,131.1,130.4,128.6$, 126.7, 125.1, 121.8, 118.6, 117.9, 112.7, 112.3, 65.0, 53.3, 51.6, 48.8, 45.9, 44.6, 36.4, 30.1, 29.2, 27.5, 26.6, 23.6; HRMS (ESI) calcd for $\mathrm{C}_{31} \mathrm{H}_{39} \mathrm{~N}_{4} \mathrm{O}_{5} \mathrm{~S} 579.2641[\mathrm{M}+\mathrm{H}]^{+}$, found 579.2643.

\section{Synthesis of $\mathbf{S 3 6}$}

A solution of $\mathbf{S 3 5}$ (100 mg, $0.173 \mathrm{mmol}$ ), histamine $2 \mathrm{HCl}$ (32.5 mg, $0.173 \mathrm{mmol}$ ), HATU (78.7 $\mathrm{mg}, 0.207 \mathrm{mmol})$, and DIPEA $(120 \mu \mathrm{L}, 0.691 \mathrm{mmol})$ in dry DMF $(5 \mathrm{~mL})$ was stirred at r.t. for $3 \mathrm{~h}$. After removal of the solvent by evaporation, the residue was purified by medium-pressure flash chromatography (column; SNAP ISOLUTE Flash-NH2 (28 g), mobile phase; $\mathrm{CH}_{2} \mathrm{Cl}_{2} / \mathrm{MeOH}(100: 0 \rightarrow 90: 10)$, detection; $\mathrm{UV}(\lambda$-all)). The suitable fractions were pooled, and the solvent was removed by evaporation to give $\mathbf{S 3 6}$ as a white solid (79.2 $\mathrm{mg}, 68 \%)$; ${ }^{1} \mathrm{H}$ NMR $\left(500 \mathrm{MHz} \mathrm{CDCl}_{3}\right) \delta 7.67$ (br, $\left.1 \mathrm{H}\right), 7.57$ (d, $\left.J=2.6 \mathrm{~Hz}, 1 \mathrm{H}\right), 7.55$ (d, $\left.J=8.1 \mathrm{~Hz}, 1 \mathrm{H}\right), 7.42-$ $7.38(\mathrm{~m}, 2 \mathrm{H}), 7.27(\mathrm{t}, J=7.8 \mathrm{~Hz}, 1 \mathrm{H}), 7.24(\mathrm{t}, J=6.0 \mathrm{~Hz}, 1 \mathrm{H}), 7.11(\mathrm{~d}, J=8.4 \mathrm{~Hz}, 1 \mathrm{H}), 7.01$ $(\mathrm{dd}, J=8.3,2.6 \mathrm{~Hz}, 1 \mathrm{H}), 6.90(\mathrm{~d}, J=7.6 \mathrm{~Hz}, 1 \mathrm{H}), 6.83(\mathrm{br}, 1 \mathrm{H}), 6.58(\mathrm{t}, J=5.7 \mathrm{~Hz}, 1 \mathrm{H}), 4.11$ 
$(\mathrm{t}, J=6.2 \mathrm{~Hz}, 2 \mathrm{H}), 3.63(\mathrm{t}, J=6.1 \mathrm{~Hz}, 2 \mathrm{H}), 3.52(\mathrm{t}, J=6.7 \mathrm{~Hz}, 2 \mathrm{H}), 3.45(\mathrm{q}, J=6.0 \mathrm{~Hz}, 2 \mathrm{H})$, $3.25-3.21(\mathrm{~m}, 6 \mathrm{H}), 2.93(\mathrm{t}, J=6.6 \mathrm{~Hz}, 2 \mathrm{H}), 2.83(\mathrm{t}, J=5.9 \mathrm{~Hz}, 2 \mathrm{H}), 2.76(\mathrm{br}, 4 \mathrm{H}), 2.67(\mathrm{t}, J$ $=7.4 \mathrm{~Hz}, 2 \mathrm{H}$ ), $2.64-2.61(\mathrm{~m}, 2 \mathrm{H}), 2.46-2.43(\mathrm{~m}, 2 \mathrm{H}), 2.06$ (quin, $J=6.9 \mathrm{~Hz}, 2 \mathrm{H}$ ), 1.75 (quin, $J=5.8 \mathrm{~Hz}, 2 \mathrm{H}) ;{ }^{13} \mathrm{C} \mathrm{NMR}\left(125 \mathrm{MHz}, \mathrm{CDCl}_{3}\right) \delta 172.5,165.4,158.2,148.3,141.1,134.7,134.0$, 132.3, 130.1, 129.8, 128.2, 125.0, 125.0, 121.8, 120.1, 119.7, 117.0, 112.4, 112.2, 66.5, 55.1, 53.6, 52.0, 46.3, 44.3, 39.9, 35.6, 31.7, 31.5, 29.7, 27.2, 27.1, 26.6, 25.5; HRMS (ESI) calcd for $\mathrm{C}_{36} \mathrm{H}_{46} \mathrm{~N}_{7} \mathrm{O}_{4} \mathrm{~S} 672.3332[\mathrm{M}+\mathrm{H}]^{+}$, found 672.3333 .

\section{Synthesis of probe $\boldsymbol{6} \boldsymbol{b}$}

A solution of S36 (79 mg, $0.12 \mathrm{mmol}$ ), NHS-PEG4-biotin (99 mg, $0.18 \mathrm{mmol}$ ), and pyridine $(29 \mu \mathrm{L}, 0.35 \mathrm{mmol}$ ) in $4 \mathrm{~mL}$ DMF was stirred at r.t. for $18 \mathrm{~h}$. After removal of the solvent by evaporation, the residue was purified by medium-pressure reverse phase flash chromatography (column; SNAP Ultra C18 (12 g), mobile phase; $\mathrm{H}_{2} \mathrm{O} / \mathrm{MeCN}(95: 5 \rightarrow 25: 75)$, detection; $\mathrm{UV}$ ( $\lambda$ all)). The suitable fractions were pooled and lyophilized to give probe $\mathbf{6 b}$ as a white powder (96 mg, 73\%) ; ${ }^{1} \mathrm{H}$ NMR (500 MHz, DMSO- $\left.d_{6}\right) \delta 8.16(\mathrm{~d}, J=1.1 \mathrm{~Hz}, 1 \mathrm{H}), 7.90(\mathrm{t}, J=5.6 \mathrm{~Hz}$, $1 \mathrm{H}), 7.82(\mathrm{q}, J=6.1 \mathrm{~Hz}, 1 \mathrm{H}), 7.70(\mathrm{~d}, J=5.5 \mathrm{~Hz}, 1 \mathrm{H}), 7.62(\mathrm{~d}, J=8.1 \mathrm{~Hz}, 1 \mathrm{H}), 7.41(\mathrm{~d}, J=$ $5.5 \mathrm{~Hz}, 1 \mathrm{H}), 7.39$ (d, $J=2.6 \mathrm{~Hz}, 1 \mathrm{H}), 7.34(\mathrm{~d}, J=0.9 \mathrm{~Hz}, 1 \mathrm{H}), 7.28(\mathrm{t}, J=7.9 \mathrm{~Hz}, 1 \mathrm{H}), 7.20$ $(\mathrm{d}, J=8.4 \mathrm{~Hz}, 1 \mathrm{H}), 7.05(\mathrm{dd}, J=8.4,2.7 \mathrm{~Hz}, 1 \mathrm{H}), 6.91(\mathrm{~d}, J=7.6 \mathrm{~Hz}, 1 \mathrm{H}), 6.41(\mathrm{br}, 1 \mathrm{H}), 6.35$ (br, 1H), $4.48-4.46(\mathrm{~m}, 2 \mathrm{H}), 4.29(\mathrm{dd}, J=7.9,5.2 \mathrm{~Hz}, 1 \mathrm{H}), 4.13-4.10(\mathrm{~m}, 1 \mathrm{H}), 4.07$ (t, $J=$ $6.3 \mathrm{~Hz}, 2 \mathrm{H}), 3.75-3.73(\mathrm{~m}, 2 \mathrm{H}), 3.58-3.57(\mathrm{~m}, 2 \mathrm{H}), 3.52-3.45(\mathrm{~m}, 10 \mathrm{H}), 3.37(\mathrm{t}, J=5.9$ $\mathrm{Hz}, 2 \mathrm{H}), 3.27(\mathrm{q}, J=7.1 \mathrm{~Hz}, 2 \mathrm{H}), 3.17(\mathrm{q}, J=5.8 \mathrm{~Hz}, 2 \mathrm{H}), 3.10-3.03(\mathrm{~m}, 7 \mathrm{H}), 2.87(\mathrm{t}, J=$ $6.5 \mathrm{~Hz}, 2 \mathrm{H}), 2.81(\mathrm{dd}, J=12.5,5.1 \mathrm{~Hz}, 1 \mathrm{H}), 2.68(\mathrm{br}, 4 \mathrm{H}), 2.61-2.56(\mathrm{~m}, 5 \mathrm{H}), 2.29$ (br, 4H), 2.05 (t, $J=7.4 \mathrm{~Hz}, 2 \mathrm{H}$ ), 1.95 (br, 2H), 1.67 (quin, $J=7.0 \mathrm{~Hz}, 2 \mathrm{H}), 1.62-1.56(\mathrm{~m}, 1 \mathrm{H}), 1.53-$ $1.41(\mathrm{~m}, 3 \mathrm{H}), 1.35-1.22(\mathrm{~m}, 2 \mathrm{H}) ;{ }^{13} \mathrm{C}$ NMR (125 MHz, DMSO- $\left.d_{6}\right) \delta 172.2,171.3,171.3$, $163.2,162.8,157.5,148.4,141.3,140.5,136.9,133.5,130.7,130.3,128.5,126.0,125.2$, 122.0 , $118.7,116.8,113.6,112.2,112.0,69.9,69.8,69.8,69.6,69.2,68.0,67.1,66.0,61.1,59.3,55.5$, 54.4, 53.1, 51.6, 46.0, 44.7, 38.5, 38.0, 36.3, 35.2, 31.0, 30.9, 28.3, 28.1, 28.0, 27.5, 26.6, 25.3; HRMS (ESI) calcd for $\mathrm{C}_{55} \mathrm{H}_{77} \mathrm{~N}_{10} \mathrm{O}_{11} \mathrm{~S}_{2}$ 1117.5215 [M+H] $]^{+}$, found 1117.5211. 
Scheme S11. Synthesis of compound S38
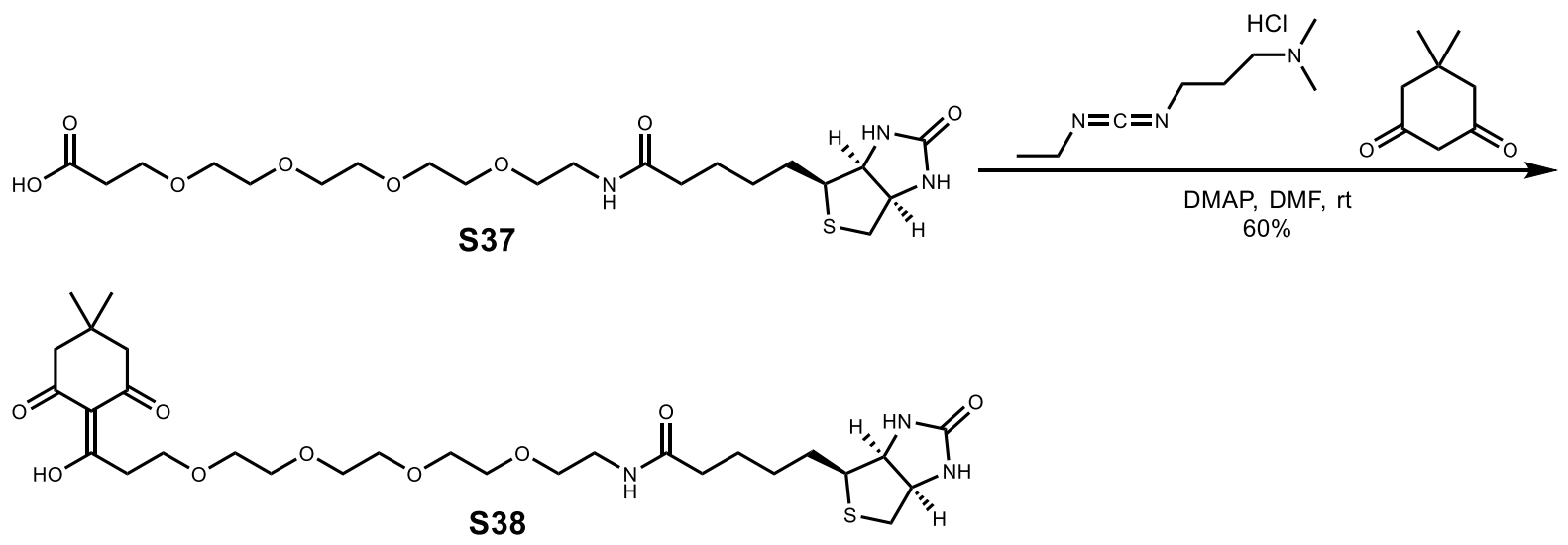

Synthesis of $\mathbf{S 3 8}$

A solution of 5,5-dimethyl-1,3-cyclohexanedione $(73.7 \mathrm{mg}, 0.526 \mathrm{mmol})$, biotin-PEG4-acid S37 (235 mg, $0.478 \mathrm{mmol}), \mathrm{EDC} \cdot \mathrm{HCl}(96.2 \mathrm{mg}, 0.502 \mathrm{mmol})$, and 4-dimethylaminopyridine (58.4 mg, $0.478 \mathrm{mmol}$ ) in $4 \mathrm{~mL}$ DMF was stirred at r.t. for $14 \mathrm{~h}$. After removal of the solvent by evaporation, the residue was purified by medium-pressure reverse phase flash chromatography (column; SNAP Ultra C18 (12 g), mobile phase; 0.1\% (v/v) TFA aqueous solution/0.1\% (v/v) TFA in MeCN (95:5 $\rightarrow 45: 55)$, detection; UV ( $\lambda$-all)). The suitable fractions were pooled and lyophilized to give $\mathbf{S 3 8}$ as a white solid (177 mg, 60\%); ${ }^{1} \mathrm{H}$ NMR (500 MHz, DMSO- $\left.d_{6}\right) \delta 7.82(\mathrm{t}, J=5.6 \mathrm{~Hz}, 1 \mathrm{H}), 6.41(\mathrm{br}, 1 \mathrm{H}), 6.35$ (br, $\left.1 \mathrm{H}\right), 4.30$ (dd, $J=7.9,5.0 \mathrm{~Hz}$, $1 \mathrm{H}), 4.14-4.11(\mathrm{~m}, 1 \mathrm{H}), 3.68(\mathrm{t}, J=6.4 \mathrm{~Hz}, 2 \mathrm{H}), 3.52-3.49(\mathrm{~m}, 12 \mathrm{H}), 3.39(\mathrm{t}, J=5.9 \mathrm{~Hz}$, $2 \mathrm{H}), 3.23(\mathrm{t}, J=6.4 \mathrm{~Hz}, 2 \mathrm{H}), 3.18(\mathrm{q}, J=5.7 \mathrm{~Hz}, 2 \mathrm{H}), 3.11-3.07(\mathrm{~m}, 1 \mathrm{H}), 2.82(\mathrm{dd}, J=12.5$, $5.1 \mathrm{~Hz}, 1 \mathrm{H}), 2.63(\mathrm{~s}, 2 \mathrm{H}), 2.57(\mathrm{~d}, J=12.5 \mathrm{~Hz}, 1 \mathrm{H}), 2.33(\mathrm{~s}, 2 \mathrm{H}), 2.06(\mathrm{t}, J=7.5 \mathrm{~Hz}, 2 \mathrm{H}), 1.64$ - $1.57(\mathrm{~m}, 1 \mathrm{H}), 1.54-1.42(\mathrm{~m}, 3 \mathrm{H}), 1.36-1.24(\mathrm{~m}, 2 \mathrm{H}), 1.00(\mathrm{~s}, 6 \mathrm{H}) ;{ }^{13} \mathrm{C}$ NMR $(125 \mathrm{MHz}$, DMSO- $\left.d_{6}\right) \delta 202.8,197.5,194.9,172.2,162.8,112.0,69.8,69.8,69.7,69.7,69.6,69.2,65.6$, 61.1, 59.3, 55.5, 51.8, 45.6, 40.2, 38.5, 35.2, 30.5, 28.3, 28.1, 27.6, 25.3; HRMS (ESI) calcd for $\mathrm{C}_{29} \mathrm{H}_{48} \mathrm{~N}_{3} \mathrm{O} 9 \mathrm{~S} 614.3111[\mathrm{M}+\mathrm{H}]^{+}$, found 614.3112 .

Scheme S12. Synthesis of compounds S39 and S40

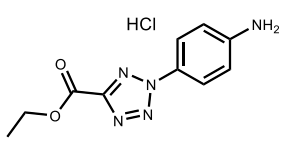

S5

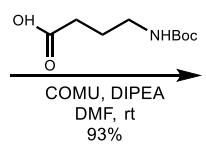

$93 \%$

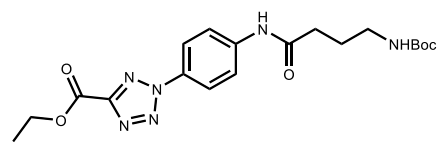

S39

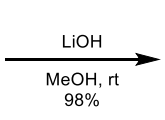

$8 \%$

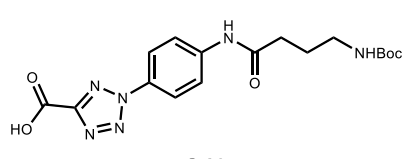

S40

Synthesis of $\mathbf{S 3 9}$

A solution of $N$-Boc-4-aminobutyric acid (236 mg, $1.16 \mathrm{mmol}), \mathbf{S 5}$ (313 $\mathrm{mg}, 1.16 \mathrm{mmol}$ ), COMU (546 mg, $1.28 \mathrm{mmol})$, and DIPEA (444 $\mathrm{L}, 2.55 \mathrm{mmol})$ in $2 \mathrm{~mL}$ DMF was stirred at r.t. for $17 \mathrm{~h}$. After removal of the solvent by evaporation, the residue was purified by mediumpressure reverse phase flash chromatography (column; SNAP Ultra C18 (30 g), mobile phase; 
$0.1 \%$ (v/v) AcOH aqueous solution/0.1\% (v/v) AcOH in $\mathrm{MeCN}(90: 10 \rightarrow 30: 70)$, detection; UV $(\lambda$-all)). The suitable fractions were pooled and lyophilized to give $\mathbf{S 3 9}$ as a white solid (453 $\mathrm{mg}, 93 \%) ;{ }^{1} \mathrm{H}$ NMR (500 MHz, DMSO- $\left.d_{6}\right) \delta 10.31(\mathrm{~s}, 1 \mathrm{H}), 8.08(\mathrm{~d}, J=9.0 \mathrm{~Hz}, 2 \mathrm{H}), 7.89$ (d, $J=9.0 \mathrm{~Hz}, 2 \mathrm{H}), 6.86(\mathrm{t}, J=5.5 \mathrm{~Hz}, 1 \mathrm{H}), 4.47(\mathrm{q}, J=7.0 \mathrm{~Hz}, 2 \mathrm{H}), 2.98(\mathrm{q}, J=6.5 \mathrm{~Hz}, 2 \mathrm{H})$, $2.36(\mathrm{t}, J=7.5 \mathrm{~Hz}, 2 \mathrm{H}), 1.71$ (quin, $J=7.2 \mathrm{~Hz}, 2 \mathrm{H}), 1.38(\mathrm{t}, J=7.1 \mathrm{~Hz}, 12 \mathrm{H}) ;{ }^{13} \mathrm{C} \mathrm{NMR}(125$ MHz, DMSO- $\left.d_{6}\right) \delta 171.6,157.4,157.2$, 155.7, 141.6, 130.7, 121.3, 119.8, 77.6, 62.4, 34.0, 28.4, 25.5, 14.1; HRMS (ESI) calcd for $\mathrm{C}_{19} \mathrm{H}_{27} \mathrm{~N}_{6} \mathrm{O}_{5} 419.2043[\mathrm{M}+\mathrm{H}]^{+}$, found 419.2054.

\section{Synthesis of $\mathbf{S 4 0}$}

To a solution of $\mathbf{S 3 9}$ (450 mg, $1.08 \mathrm{mmol}$ ) in $15 \mathrm{~mL} \mathrm{MeOH}$ was added $1.29 \mathrm{~mL} 1 \mathrm{M} \mathrm{LiOH}$ aq. and $4.55 \mathrm{~mL}$ water, and the mixture was stirred at r.t. for $30 \mathrm{~min}$. After addition of $0.1 \%(\mathrm{v} / \mathrm{v})$ $\mathrm{AcOH}$ aqueous solution to acidify the solution, the solvent was removed by evaporation. The residue was purified by medium-pressure reverse phase flash chromatography (column; SNAP Ultra C18 (12 g), mobile phase; $0.1 \%$ (v/v) $\mathrm{AcOH}$ aqueous solution/0.1\% (v/v) $\mathrm{AcOH}$ in $\operatorname{MeCN}(100: 0 \rightarrow 45: 55)$, detection; UV $(\lambda$-all)). The suitable fractions were pooled and extracted with EtOAc three times. The organic layers were combined, washed with brine and then dried over $\mathrm{Na}_{2} \mathrm{SO}_{4}$. The solvent was removed by evaporation to give $\mathbf{S 4 0}$ as a white amorphous (410 mg, 98\%); ${ }^{1} \mathrm{H}$ NMR (500 MHz, DMSO- $\left.d_{6}\right) \delta 10.30(\mathrm{~s}, 1 \mathrm{H}), 8.06(\mathrm{~d}, J=9.1 \mathrm{~Hz}, 2 \mathrm{H}), 7.89$ (d, $J=9.1 \mathrm{~Hz}, 2 \mathrm{H}), 6.86(\mathrm{t}, J=5.5 \mathrm{~Hz}, 1 \mathrm{H}), 2.98(\mathrm{q}, J=6.6 \mathrm{~Hz}, 2 \mathrm{H}), 2.36(\mathrm{t}, J=7.4 \mathrm{~Hz}, 2 \mathrm{H}), 1.71$ (quin, $J=7.2 \mathrm{~Hz}, 2 \mathrm{H}), 1.38(\mathrm{~s}, 9 \mathrm{H}) ;{ }^{13} \mathrm{C}$ NMR (125 MHz, DMSO- $\left.d_{6}\right) \delta 171.6,158.7,158.2$, 155.7, 141.5, 130.8, 121.1, 119.8, 77.5, 33.9, 28.3, 25.4; HRMS (ESI) calcd for $\mathrm{C}_{17} \mathrm{H}_{23} \mathrm{~N}_{6} \mathrm{O}_{5}$ $391.1730[\mathrm{M}+\mathrm{H}]^{+}$, found 391.1724 . 
Scheme S13. Synthesis of compounds S41 and S42 for preparation of probe 7

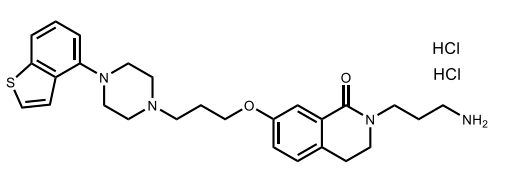

s4
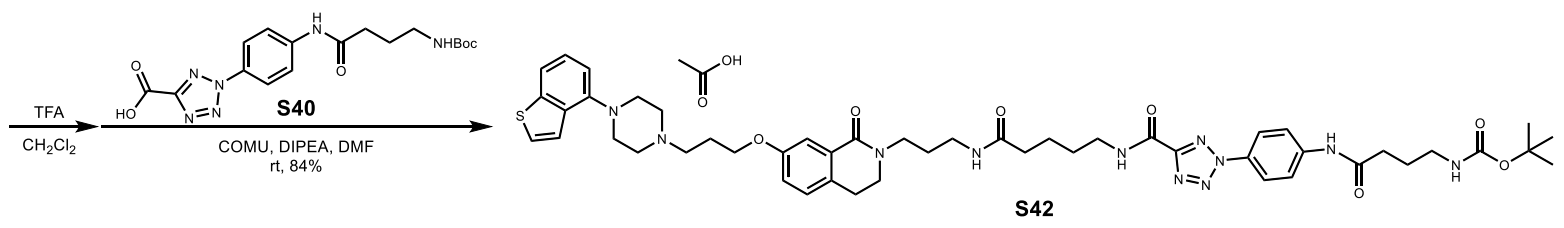

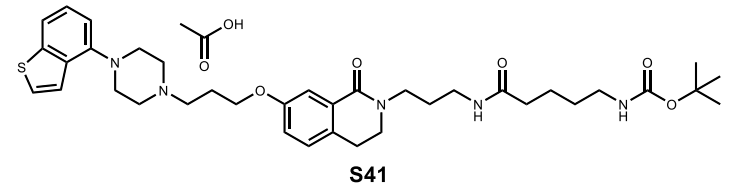

S41
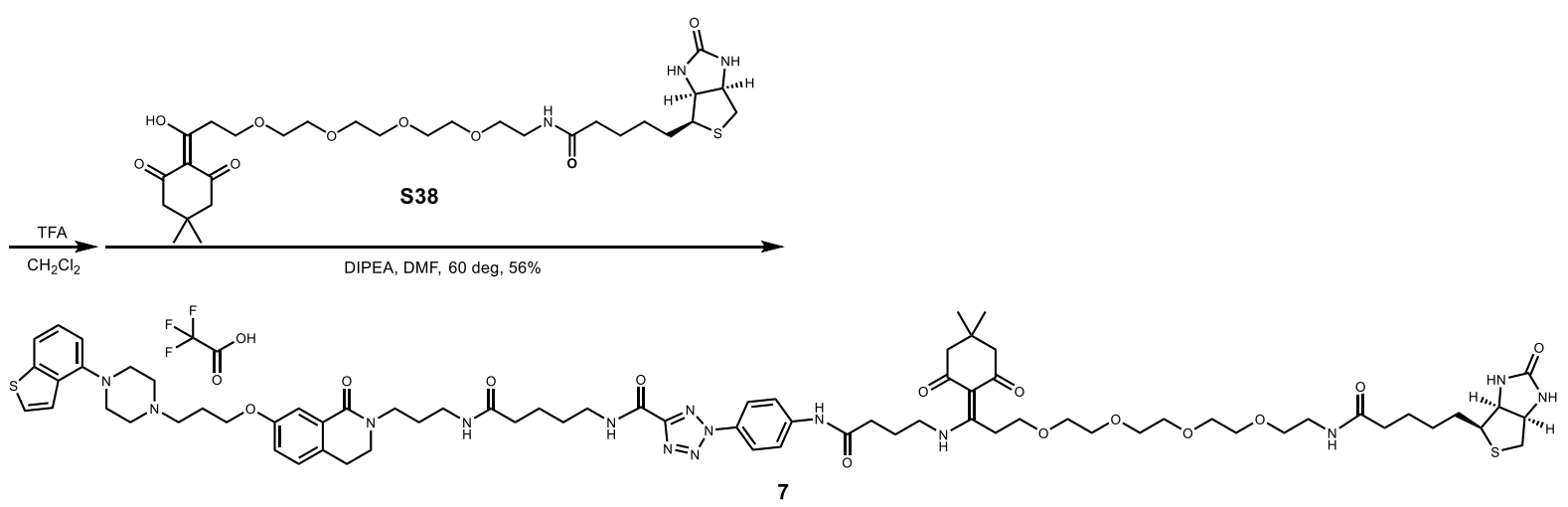

Synthesis of $\mathbf{S 4 1}$

A solution of $\mathbf{S 4}$ (20 mg, $0.036 \mathrm{mmol})$, Boc-5-aminovaleric acid (7.9 mg, $0.036 \mathrm{mmol})$, COMU (17 mg, $0.040 \mathrm{mmol}$ ), and DIPEA $(27 \mu \mathrm{l}, 0.15 \mathrm{mmol})$ in $1 \mathrm{~mL} \mathrm{DMF}$ was stirred at r.t. for $5 \mathrm{~h}$. After removal of the solvent by evaporation, the residue was purified by medium-pressure reverse phase flash chromatography (column; SNAP Ultra C18 (12 g), mobile phase; 0.1\% $(\mathrm{v} / \mathrm{v}) \mathrm{AcOH}$ aqueous solution/0.1\% (v/v) $\mathrm{AcOH}$ in $\mathrm{MeCN}(95: 5 \rightarrow 30: 70)$, detection; UV $(\lambda-$ all)). The suitable fractions were pooled and lyophilized to give $\mathbf{S 4 1}$ as a white powder (15 $\mathrm{mg}$, $61 \%) ;{ }^{1} \mathrm{H}$ NMR (500 MHz, DMSO- $\left.d_{6}\right) \delta 7.78(\mathrm{t}, J=5.5 \mathrm{~Hz}, 1 \mathrm{H}), 7.69(\mathrm{~d}, J=5.6 \mathrm{~Hz}, 1 \mathrm{H}), 7.61$ $(\mathrm{d}, J=7.9 \mathrm{~Hz}, 1 \mathrm{H}), 7.40(\mathrm{~d}, J=5.6 \mathrm{~Hz}, 1 \mathrm{H}), 7.39(\mathrm{~d}, J=2.7 \mathrm{~Hz}, 1 \mathrm{H}), 7.27(\mathrm{t}, J=7.8 \mathrm{~Hz}, 1 \mathrm{H})$, $7.20(\mathrm{~d}, J=8.4 \mathrm{~Hz}, 1 \mathrm{H}), 7.05(\mathrm{dd}, J=8.3,2.6 \mathrm{~Hz}, 1 \mathrm{H}), 6.90(\mathrm{~d}, J=7.7 \mathrm{~Hz}, 1 \mathrm{H}), 6.77(\mathrm{t}, J=$ $5.4 \mathrm{~Hz}, 1 \mathrm{H}), 4.06(\mathrm{t}, J=6.3 \mathrm{~Hz}, 2 \mathrm{H}), 3.50(\mathrm{t}, J=7.0 \mathrm{~Hz}$, under the water signal), $3.46(\mathrm{t}, J=$ $6.6 \mathrm{~Hz}$, under the water signal), $3.08-3.03(\mathrm{~m}, 6 \mathrm{H}), 2.91-2.87(\mathrm{~m}, 4 \mathrm{H}), 2.64(\mathrm{br}, 4 \mathrm{H}), 2.54$ (t, $J=7.1 \mathrm{~Hz}, 2 \mathrm{H}$ ), $2.04(\mathrm{t}, J=7.3 \mathrm{~Hz}, 2 \mathrm{H}$ ), 1.93 (quin, $J=6.7 \mathrm{~Hz}, 2 \mathrm{H}$ ), 1.82 (s, 3H), 1.67 (quin, $J=7.0 \mathrm{~Hz}, 2 \mathrm{H}), 1.46$ (quin, $J=7.5 \mathrm{~Hz}, 2 \mathrm{H}), 1.36-1.31(\mathrm{~m}, 11 \mathrm{H}) ;{ }^{13} \mathrm{C} \mathrm{NMR}(125 \mathrm{MHz}$, DMSO- $\left.d_{6}\right) \delta 173.0,172.0,163.2,157.6,155.6,148.4,140.5,133.5,130.7,130.3,128.6,125.9$, 125.2 , 122.0, 118.7, 116.7, 112.2, 112.1, 77.4, 66.1, 54.5, 53.2, 51.8, 45.9, 44.7, 36.3, 35.2, 29.2, 28.4, 27.6, 26.6, 26.3, 22.8, 22.4; HRMS (ESI) calcd for $\mathrm{C}_{37} \mathrm{H}_{52} \mathrm{~N}_{5} \mathrm{O}_{5} \mathrm{~S} 678.3689[\mathrm{M}+\mathrm{H}]^{+}$, found 678.3693 .

\section{Synthesis of $\mathbf{S 4 2}$}

To a solution of $\mathbf{S 4 1}(15 \mathrm{mg}, 0.020 \mathrm{mmol})$ in $\mathrm{CH}_{2} \mathrm{Cl}_{2}(3 \mathrm{~mL})$ was added TFA $(0.15 \mathrm{~mL}, 2.0$ 
$\mathrm{mmol}$ ), and the mixture was stirred at r.t. for $2 \mathrm{~h}$. After removal of the solvent by evaporation, the residual TFA was further removed azeotropically with toluene $(\times 2)$ to give deprotected $\mathbf{S 4 1}$. A solution of deprotected S41, S40 (9.1 mg, $0.022 \mathrm{mmol}$ ), COMU (9.4 mg, $0.022 \mathrm{mmol}$ ), and DIPEA $(15 \mu \mathrm{L}, 85 \mu \mathrm{mol})$ in $2 \mathrm{~mL}$ DMF was stirred at r.t. for $1 \mathrm{~h}$. After removal of the solvent by evaporation, the residue was purified by medium-pressure reverse phase flash chromatography (column; SNAP Ultra C18 (12 g), mobile phase; 0.1\% (v/v) AcOH aqueous solution/0.1\% (v/v) $\mathrm{AcOH}$ in $\mathrm{MeCN}(95: 5 \rightarrow 35: 65)$, detection; UV ( $\lambda$-all)). The suitable fractions were pooled and lyophilized to give $\mathbf{S 4 2}$ as a white powder $(16 \mathrm{mg}, 2$ steps $84 \%) ;{ }^{1} \mathrm{H}$ NMR (500 MHz, DMSO-d $\left.d_{6}\right) \delta 11.93$ (br, 1H), 10.29 (s, 1H), 9.14 (t, $\left.J=5.8 \mathrm{~Hz}, 1 \mathrm{H}\right), 8.04$ (d, $J=9.1 \mathrm{~Hz}, 2 \mathrm{H}), 7.88(\mathrm{~d}, J=9.1 \mathrm{~Hz}, 2 \mathrm{H}), 7.82(\mathrm{t}, J=5.6 \mathrm{~Hz}, 1 \mathrm{H}), 7.71$ (br, 1H), $7.63(\mathrm{br}, 1 \mathrm{H})$, 7.42 (br, 1H), 7.39 (br, 1H), 7.28 (t, $J=7.6 \mathrm{~Hz}, 1 \mathrm{H}), 7.19$ (d, $J=8.4 \mathrm{~Hz}, 1 \mathrm{H}), 7.04$ (dd, $J=8.4$, $2.5 \mathrm{~Hz}, 1 \mathrm{H}), 6.92(\mathrm{br}, 1 \mathrm{H}), 6.86(\mathrm{t}, J=5.4 \mathrm{~Hz}, 1 \mathrm{H}), 4.06(\mathrm{br}, 2 \mathrm{H}), 3.50(\mathrm{t}, J=6.5 \mathrm{~Hz}, 2 \mathrm{H}), 3.47$ $(\mathrm{t}, J=7.1 \mathrm{~Hz}, 2 \mathrm{H}), 3.08-3.04(\mathrm{~m}, 6 \mathrm{H}), 2.98(\mathrm{q}, J=6.5 \mathrm{~Hz}, 2 \mathrm{H}), 2.87(\mathrm{t}, J=6.4 \mathrm{~Hz}, 2 \mathrm{H}), 2.64$ (br, 4H), $2.36(\mathrm{t}, J=7.3 \mathrm{~Hz}, 2 \mathrm{H}), 2.10$ (br, 2H), 1.95 (br, 2H), 1.91 (s, 3H), 1.71 (quin, $J=7.2$ $\mathrm{Hz}, 2 \mathrm{H}$ ), 1.67 (quin, $J=6.9 \mathrm{~Hz}, 2 \mathrm{H}$ ), 1.55 (br, 4H), 1.37 (s, 9H); ${ }^{13} \mathrm{C}$ NMR (125 MHz, DMSO$\left.d_{6}\right) \delta 172.1,171.9,171.6,163.1,160.0,156.2,155.7,141.4,140.5,133.5,130.8,130.8,130.3$, $128.5,126.5,126.1,125.2,121.9,121.1,119.8,118.6,112.3,112.1,77.6,54.5,53.2,51.9,45.9$, 44.7, 38.8, 36.3, 35.2, 33.9, 28.6, 28.3, 27.5, 26.6, 25.4, 22.8, 21.1; HRMS (ESI) calcd for $\mathrm{C}_{49} \mathrm{H}_{64} \mathrm{~N}_{11} \mathrm{O}_{7} \mathrm{~S} 950.4711[\mathrm{M}+\mathrm{H}]^{+}$, found 950.4713 .

\section{Synthesis of probe 7}

To a solution of $\mathbf{S 4 2}(14 \mathrm{mg}, 0.015 \mathrm{mmol})$ in $\mathrm{CH}_{2} \mathrm{Cl}_{2}(5 \mathrm{~mL})$ was added TFA (0.23 mL, 3.0 $\mathrm{mmol}$ ), and the mixture was stirred at r.t. for $12 \mathrm{~h}$. After removal of the solvent by evaporation, the residual TFA was further removed azeotropically with toluene $(\times 2)$ to give deprotected $\mathbf{S 4 2}$. A solution of deprotected S42, S38 (10 mg, $0.016 \mathrm{mmol})$, and DIPEA (12 $\mu \mathrm{L}, 0.068 \mathrm{mmol})$ in $2 \mathrm{~mL}$ DMF was stirred at $60{ }^{\circ} \mathrm{C}$ for $2 \mathrm{~h}$. After removal of the solvent by evaporation, the residue was purified by medium-pressure reverse phase flash chromatography (column; SNAP Ultra C18 (12 g), mobile phase; $0.1 \%$ (v/v) TFA aqueous solution/0.1\% (v/v) TFA in MeCN $(95: 5 \rightarrow 40: 60)$, detection; UV $(\lambda$-all)). The suitable fractions were pooled and lyophilized to give probe 7 as a white powder (13 mg, 2 steps $56 \%$ ); ${ }^{1} \mathrm{H}$ NMR (500 MHz, DMSO- $\left.d_{6}\right) \delta 13.53$ (t, $J=5.4 \mathrm{~Hz}, 1 \mathrm{H}), 10.38(\mathrm{~s}, 1 \mathrm{H}), 9.63(\mathrm{br}, 1 \mathrm{H}), 9.15$ (t, $J=5.9 \mathrm{~Hz}, 1 \mathrm{H}), 8.05$ (d, $J=9.1 \mathrm{~Hz}$, 2H), $7.88(\mathrm{~d}, J=9.1 \mathrm{~Hz}, 2 \mathrm{H}), 7.84-7.81(\mathrm{~m}, 2 \mathrm{H}), 7.78(\mathrm{~d}, J=5.6 \mathrm{~Hz}, 1 \mathrm{H}), 7.72(\mathrm{~d}, J=8.1$ $\mathrm{Hz}, 1 \mathrm{H}), 7.51(\mathrm{~d}, J=5.5 \mathrm{~Hz}, 1 \mathrm{H}), 7.43(\mathrm{~d}, J=2.8 \mathrm{~Hz}, 1 \mathrm{H}), 7.33(\mathrm{t}, J=7.9 \mathrm{~Hz}, 1 \mathrm{H}), 7.22(\mathrm{~d}, J$ $=8.4 \mathrm{~Hz}, 1 \mathrm{H}), 7.06(\mathrm{dd}, J=8.4,2.8 \mathrm{~Hz}, 1 \mathrm{H}), 6.99(\mathrm{~d}, J=7.3 \mathrm{~Hz}, 1 \mathrm{H}), 6.41$ (br, 1H), 6.36 (br, $1 \mathrm{H}), 4.29$ (dd, $J=7.9,4.9 \mathrm{~Hz}, 1 \mathrm{H}), 4.13-4.10$ (m, under the water signal), 3.70 (br, $2 \mathrm{H}), 3.62$ $-3.58(\mathrm{~m}, 6 \mathrm{H}), 3.52-3.49(\mathrm{~m}, 4 \mathrm{H}), 3.47-3.46(\mathrm{~m}, 12 \mathrm{H}), 3.41(\mathrm{br}, 4 \mathrm{H}), 3.37(\mathrm{t}, J=5.9 \mathrm{~Hz}$, 2H), $3.32(\mathrm{br}, 2 \mathrm{H}), 3.27(\mathrm{t}, J=6.1 \mathrm{~Hz}, 2 \mathrm{H}), 3.17(\mathrm{q}, J=5.8 \mathrm{~Hz}, 2 \mathrm{H}), 3.11-3.04(\mathrm{~m}, 5 \mathrm{H}), 2.88$ $(\mathrm{t}, J=6.4 \mathrm{~Hz}, 2 \mathrm{H}), 2.81(\mathrm{dd}, J=12.4,5.1 \mathrm{~Hz}, 1 \mathrm{H}), 2.57$ (d, $J=12.3 \mathrm{~Hz}, 1 \mathrm{H}), 2.48$ (d, overlapped 
with the DMSO signal), $2.28(\mathrm{~s}, 4 \mathrm{H}), 2.22-2.17(\mathrm{~m}, 2 \mathrm{H}), 2.11(\mathrm{br}, 2 \mathrm{H}), 2.05(\mathrm{t}, J=7.3 \mathrm{~Hz}$, $2 \mathrm{H}$ ), 1.93 (quin, $J=7.0 \mathrm{~Hz}, 2 \mathrm{H}$ ), 1.68 (quin, $J=6.9 \mathrm{~Hz}, 2 \mathrm{H}$ ), $1.62-1.41(\mathrm{~m}, 8 \mathrm{H}$ ), $1.33-1.23$ $(\mathrm{m}, 2 \mathrm{H}), 0.94(\mathrm{~s}, 6 \mathrm{H}) ;{ }^{13} \mathrm{C}$ NMR $\left(125 \mathrm{MHz}, \mathrm{DMSO}-d_{6}\right) \delta 173.3,172.2,171.9,170.9,163.1$, 162.8, 160.0, 158.2, 157.9, 157.1, 156.2, 146.5, 141.3, 140.7, 133.4, 131.1, 130.9, 130.3, 128.6, $126.7,125.1,121.8,121.1,119.9,118.6,118.0,117.9,112.7,112.4,112.4,106.2,69.8,69.8$, $69.8,69.6,69.2,68.8,65.0,61.1,59.3,56.6,55.5,53.3,52.4,51.6,48.8,45.9,44.7,44.6,42.5$, $38.8,38.5,36.3,35.2,33.4,30.0,29.7,28.6,28.3,28.1,27.9,27.5,26.6,25.3,24.6,23.6,22.8$; HRMS (ESI) calcd for $\mathrm{C}_{73} \mathrm{H}_{101} \mathrm{~N}_{14} \mathrm{O}_{13} \mathrm{~S}_{2} 1445.7114[\mathrm{M}+\mathrm{H}]^{+}$, found 1445.7126.

Scheme S14. Synthesis of compounds S44 and S45 for preparation of probe 8
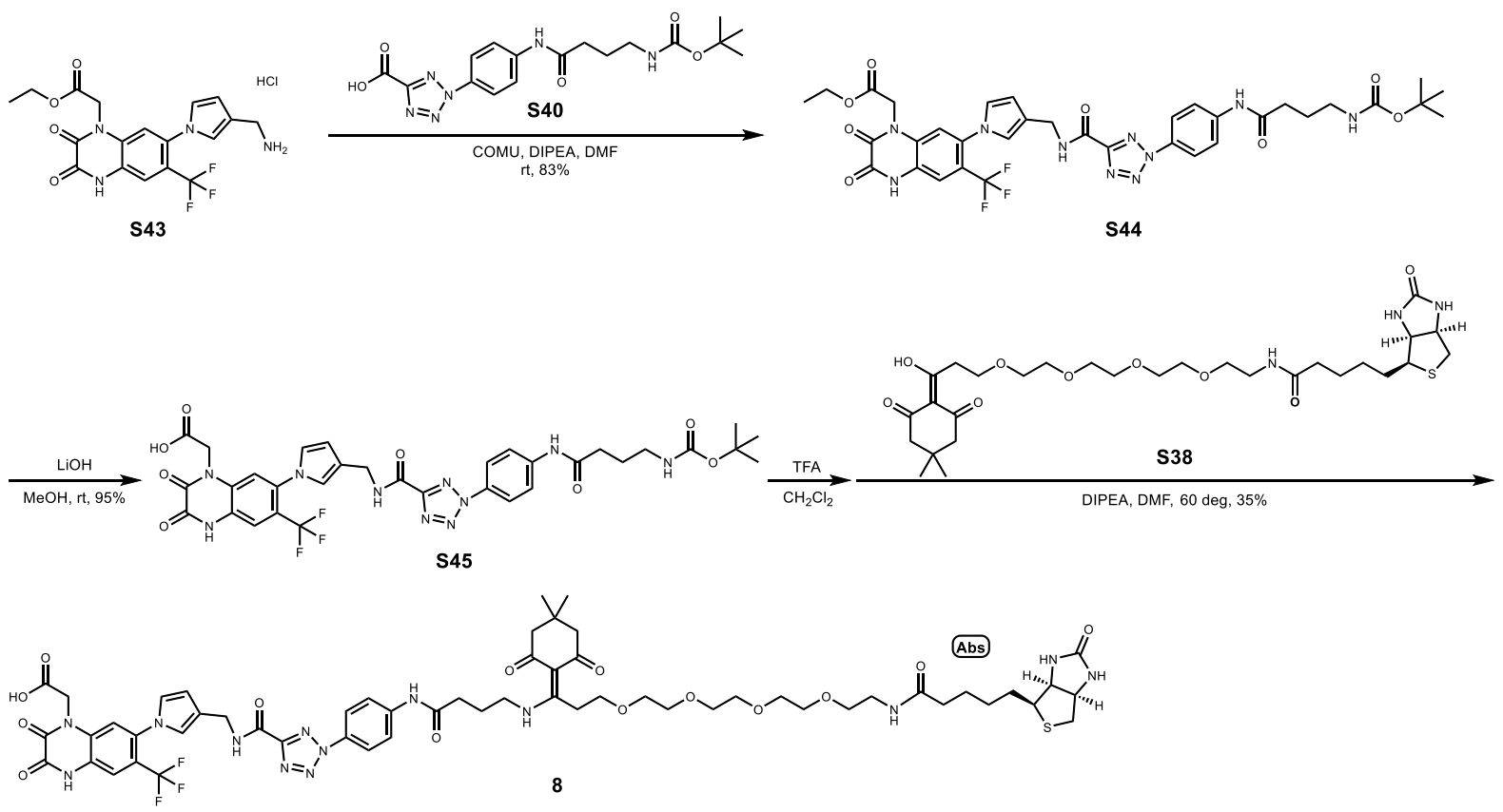

Synthesis of $\mathbf{S 4 4}$ ( $\mathbf{S 4 3}$ was prepared according to a known procedure. ${ }^{\text {ref.16) }}$

A solution of $\mathbf{S 4 3}(23 \mathrm{mg}, 0.051 \mathrm{mmol}), \mathbf{S 4 0}$ (20 mg, $0.051 \mathrm{mmol})$, COMU (24 mg, 0.057 mmol), and DIPEA ( $20 \mu \mathrm{L}, 0.11 \mathrm{mmol})$ in $2 \mathrm{~mL} \mathrm{DMF}$ was stirred at r.t. for $1 \mathrm{~h}$. After removal of the solvent by evaporation, the residue was purified by medium-pressure reverse phase flash chromatography (column; SNAP Ultra C18 (12 g), mobile phase; 0.1\% (v/v) AcOH aqueous solution/0.1\% (v/v) $\mathrm{AcOH}$ in $\mathrm{MeCN}(90: 10 \rightarrow 30: 70)$, detection; UV ( $\lambda$-all)). The suitable fractions were pooled and lyophilized to give $\mathbf{S 4 4}$ as a white powder (33 $\mathrm{mg}, 83 \%) ;{ }^{1} \mathrm{H}$ NMR (500 MHz, DMSO-d6) $\delta 12.46$ (br, 1H), 10.29 (s, 1H), 9.43 (t, $J=6.1 \mathrm{~Hz}, 1 \mathrm{H}), 8.06$ (d, $J=9.1$ $\mathrm{Hz}, 2 \mathrm{H}), 7.89$ (d, J=9.1 Hz, 2H), $7.61(\mathrm{~s}, 1 \mathrm{H}), 7.54$ (s, 1H), 6.88 (br, 1H), 6.86 (t, $J=5.7 \mathrm{~Hz}$, $1 \mathrm{H}), 6.83(\mathrm{t}, J=2.5 \mathrm{~Hz}, 1 \mathrm{H}), 6.28(\mathrm{dd}, J=2.9,1.7 \mathrm{~Hz}, 1 \mathrm{H}), 5.01(\mathrm{~s}, 2 \mathrm{H}), 4.41(\mathrm{~d}, J=6.0 \mathrm{~Hz}$, 2H), $4.13(\mathrm{q}, J=7.1 \mathrm{~Hz}, 2 \mathrm{H}), 2.98(\mathrm{q}, J=6.5 \mathrm{~Hz}, 2 \mathrm{H}), 2.36(\mathrm{t}, J=7.3 \mathrm{~Hz}, 2 \mathrm{H}), 1.71$ (quin, $J=$ $7.2 \mathrm{~Hz}, 2 \mathrm{H}), 1.38(\mathrm{~s}, 9 \mathrm{H}), 1.17(\mathrm{t}, J=7.1 \mathrm{~Hz}, 3 \mathrm{H}) ;{ }^{13} \mathrm{C}$ NMR (125 MHz, DMSO- $\left.d_{6}\right) \delta 171.6$, $167.4,160.0,156.1$, 155.7, 155.4, 153.0, 141.4, 133.7, 130.8, 130.0, 125.5, 124.1, 123.9, 121.9, 
121.8, 121.8, 121.1, 119.8, 116.5, 114.2, 109.6, 77.6, 61.4, 44.8, 35.7, 33.9, 28.3, 25.4, 14.0; HRMS (ESI) calcd for $\mathrm{C}_{35} \mathrm{H}_{37} \mathrm{~N}_{10} \mathrm{O}_{8} \mathrm{~F}_{3} \mathrm{Na} 805.2646[\mathrm{M}+\mathrm{Na}]^{+}$, found 805.2641.

\section{Synthesis of $\mathbf{S 4 5}$}

To a solution of $\mathbf{S 4 4}$ (33 mg, $0.042 \mathrm{mmol}$ ) in $2 \mathrm{~mL} \mathrm{MeOH}$ was added $0.084 \mathrm{~mL} 1 \mathrm{M} \mathrm{LiOH}$ aq. and $0.18 \mathrm{~mL}$ water, and the mixture was stirred at r.t. for $21 \mathrm{~h}$. After addition of $0.1 \%(\mathrm{v} / \mathrm{v})$ $\mathrm{AcOH}$ aqueous solution to acidify the solution, the solvent was removed by evaporation. The residue was purified by medium-pressure reverse phase flash chromatography (column; SNAP Ultra C18 (12 g), mobile phase; 0.1\% (v/v) AcOH aqueous solution/0.1\% (v/v) $\mathrm{AcOH}$ in $\mathrm{MeCN}(95: 5 \rightarrow 30: 70)$, detection; UV $(\lambda$-all)). The suitable fractions were pooled and lyophilized to give $\mathbf{S 4 5}$ as a white powder (30 mg, 95\%) ; ${ }^{1} \mathrm{H}$ NMR (500 MHz, DMSO- $\left.d_{6}\right) \delta$ 12.46 (s, 1H), $10.30(\mathrm{~s}, 1 \mathrm{H}), 9.43(\mathrm{t}, J=6.0 \mathrm{~Hz}, 1 \mathrm{H}), 8.06$ (d, $J=9.1 \mathrm{~Hz}, 2 \mathrm{H}), 7.89$ (d, $J=9.1$ $\mathrm{Hz}, 2 \mathrm{H}), 7.61(\mathrm{~s}, 1 \mathrm{H}), 7.46(\mathrm{~s}, 1 \mathrm{H}), 6.89(\mathrm{br}, 1 \mathrm{H}), 6.86(\mathrm{t}, J=5.6 \mathrm{~Hz}, 1 \mathrm{H}), 6.83(\mathrm{t}, J=2.4 \mathrm{~Hz}$, $1 \mathrm{H}), 6.28(\mathrm{dd}, J=2.9,1.7 \mathrm{~Hz}, 1 \mathrm{H}), 4.91(\mathrm{~s}, 2 \mathrm{H}), 4.41(\mathrm{~d}, J=6.0 \mathrm{~Hz}, 2 \mathrm{H}), 2.98(\mathrm{q}, J=6.4 \mathrm{~Hz}$, 2H), $2.36(\mathrm{t}, J=7.3 \mathrm{~Hz}, 2 \mathrm{H}), 1.71$ (quin, $J=7.2 \mathrm{~Hz}, 2 \mathrm{H}), 1.38(\mathrm{~s}, 9 \mathrm{H}) ;{ }^{13} \mathrm{C}$ NMR $(125 \mathrm{MHz}$, DMSO- $\left.d_{6}\right) \delta 171.6,168.6,160.0,156.1,155.7,155.3,153.0,141.4,133.8,130.9,130.1,125.2$, 124.1, 123.9, 121.9, 121.8, 121.8, 121.1, 119.8, 116.5, 114.0, 109.6, 77.6, 44.9, 35.7, 33.9, 28.3, 25.4; HRMS (ESI) calcd for $\mathrm{C}_{33} \mathrm{H}_{33} \mathrm{~N}_{10} \mathrm{O}_{8} \mathrm{~F}_{3} \mathrm{Na} 777.2333[\mathrm{M}+\mathrm{Na}]^{+}$, found 777.2339.

\section{Synthesis of probe 8}

To a solution of $\mathbf{S 4 5}(29 \mathrm{mg}, 0.038 \mathrm{mmol})$ in $\mathrm{CH}_{2} \mathrm{Cl}_{2}(3 \mathrm{~mL})$ was added TFA $(0.29 \mathrm{~mL}, 3.8$ $\mathrm{mmol}$ ), and the mixture was stirred at r.t. for $2 \mathrm{~h}$. After removal of the solvent by evaporation, the residual TFA was further removed azeotropically with toluene $(\times 2)$ to give deprotected $\mathbf{S 4 5}$. Then, a solution of deprotected S45, S38 (24 mg, $0.039 \mathrm{mmol}$ ), and DIPEA ( $27 \mu \mathrm{L}, 0.15 \mathrm{mmol}$ ) in $2 \mathrm{~mL}$ DMF was stirred at $60{ }^{\circ} \mathrm{C}$ for $5 \mathrm{~h}$. After removal of the solvent by evaporation, the residue was purified by medium-pressure reverse phase flash chromatography (column; SNAP Ultra C18 (12 g), mobile phase; 0.1\% (v/v) TFA aqueous solution/0.1\% (v/v) TFA in MeCN $(95: 5 \rightarrow 30: 70)$, detection; UV $(\lambda$-all $))$. The suitable fractions were pooled and lyophilized to give probe 8 as a white powder (17 mg, 2 steps 35\%); ${ }^{1} \mathrm{H}$ NMR (500 MHz, DMSO- $\left.d_{6}\right) \delta 13.53$ (t, $J=5.3 \mathrm{~Hz}, 1 \mathrm{H}), 12.46(\mathrm{~s}, 1 \mathrm{H}), 10.37(\mathrm{~s}, 1 \mathrm{H}), 9.43(\mathrm{t}, J=6.0 \mathrm{~Hz}, 1 \mathrm{H}), 8.08(\mathrm{~d}, J=9.1 \mathrm{~Hz}$, 2H), $7.89(\mathrm{~d}, J=9.1 \mathrm{~Hz}, 2 \mathrm{H}), 7.81(\mathrm{t}, J=5.6 \mathrm{~Hz}, 1 \mathrm{H}), 7.61(\mathrm{~s}, 1 \mathrm{H}), 7.49$ (s, 1H), $6.90(\mathrm{br}, 1 \mathrm{H})$, $6.84(\mathrm{t}, J=2.3 \mathrm{~Hz}, 1 \mathrm{H}), 6.41(\mathrm{br}, 1 \mathrm{H}), 6.35(\mathrm{br}, 1 \mathrm{H}), 6.28$ (dd, $J=2.9,1.7 \mathrm{~Hz}, 1 \mathrm{H}), 4.95$ (s, $2 \mathrm{H}), 4.41(\mathrm{~d}, J=5.9 \mathrm{~Hz}, 2 \mathrm{H}), 4.29(\mathrm{dd}, J=7.8,5.0 \mathrm{~Hz}, 1 \mathrm{H}), 4.13-4.10(\mathrm{~m}, 1 \mathrm{H}), 3.61(\mathrm{t}, J=$ $6.3 \mathrm{~Hz}, 4 \mathrm{H}), 3.51-3.46(\mathrm{~m}, 12 \mathrm{H}), 3.36(\mathrm{q}, J=6.0 \mathrm{~Hz}, 2 \mathrm{H}), 3.27(\mathrm{t}, J=6.1 \mathrm{~Hz}, 2 \mathrm{H}), 3.17$ (q, $J$ $=5.8 \mathrm{~Hz}, 2 \mathrm{H}), 3.10-3.06(\mathrm{~m}, 1 \mathrm{H}), 2.81(\mathrm{dd}, J=12.4,5.1 \mathrm{~Hz}, 1 \mathrm{H}), 2.57(\mathrm{~d}, J=12.4 \mathrm{~Hz}, 1 \mathrm{H})$, 2.48 (t, overlapped with the DMSO signal), 2.28 (s, 4H), $2.05(\mathrm{t}, J=7.4 \mathrm{~Hz}, 2 \mathrm{H}), 1.94$ (quin, $J$ $=7.0 \mathrm{~Hz}, 2 \mathrm{H}), 1.63-1.56(\mathrm{~m}, 1 \mathrm{H}), 1.53-1.41(\mathrm{~m}, 3 \mathrm{H}), 1.35-1.23(\mathrm{~m}, 2 \mathrm{H}), 0.94(\mathrm{~s}, 6 \mathrm{H}) ;{ }^{13} \mathrm{C}$ NMR (125 MHz, DMSO- $\left.d_{6}\right) \delta 173.4,172.2,170.9,168.7,162.8,160.0,156.1,155.3,153.0$, 
$141.3,133.8,130.9,130.0,125.2,124.0,123.9,121.9,121.8,121.8,121.2,119.9,116.5,114.0$, 109.6, 106.2, 69.8, 69.8, 69.6, 69.2, 68.8, 61.1, 59.3, 55.5, 52.4, 44.7, 42.5, 38.5, 35.7, 35.2, 33.4, 30.0, 29.7, 28.3, 28.1, 27.9, 25.3, 24.6; HRMS (ESI) calcd for $\mathrm{C}_{57} \mathrm{H}_{71} \mathrm{~N}_{13} \mathrm{O}_{14} \mathrm{~F}_{3} \mathrm{~S}$ $1250.4916[\mathrm{M}+\mathrm{H}]^{+}$, found 1250.4919 .

Scheme S15. Synthesis of S47 for preparation of probe 9

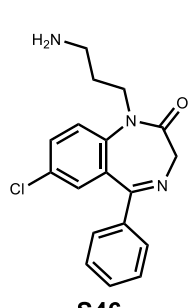

S46
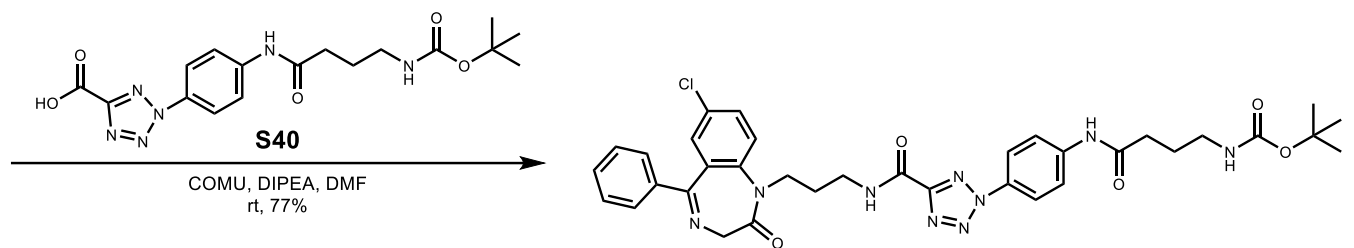
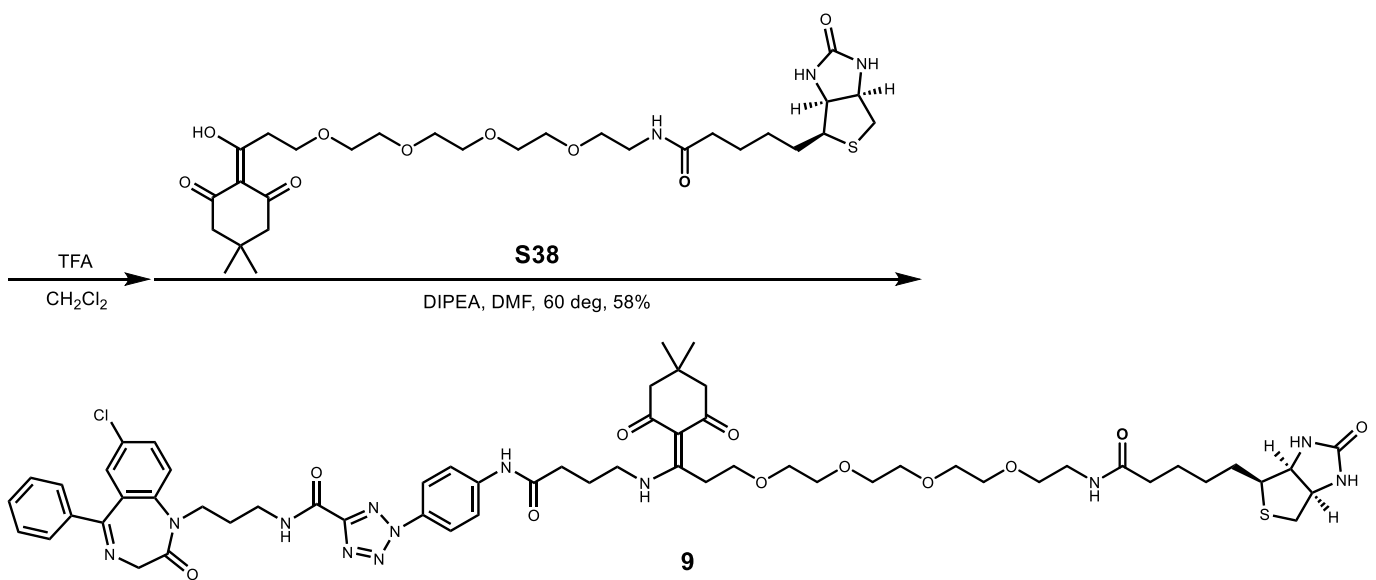

Synthesis of $\mathbf{S 4 7}$ ( $\mathbf{S 4 6}$ was prepared according to a known procedure. ${ }^{\text {ref.17) }}$

A solution of $\mathbf{S 4 6}$ (10 mg, $0.031 \mathrm{mmol}), \mathbf{S 4 0}$ (13 mg, $0.032 \mathrm{mmol})$, COMU (14 mg, 0.034 mmol), and DIPEA ( $17 \mu \mathrm{L}, 0.098 \mathrm{mmol})$ in $2 \mathrm{~mL} \mathrm{DMF}$ was stirred at r.t. for $3 \mathrm{~h}$. After removal of the solvent by evaporation, the residue was purified by medium-pressure reverse phase flash chromatography (column; SNAP Ultra C18 (12 g), mobile phase; 0.1\% (v/v) AcOH aqueous solution/0.1\% (v/v) $\mathrm{AcOH}$ in $\mathrm{MeCN}(95: 5 \rightarrow 30: 70)$, detection; UV ( $\lambda$-all)). The suitable fractions were pooled and lyophilized to give $\mathbf{S 4 7}$ as a white powder (16 $\mathrm{mg}, 77 \%)$; ${ }^{1} \mathrm{H}$ NMR $\left(500 \mathrm{MHz}, \mathrm{DMSO}-d_{6}\right) \delta 10.29(\mathrm{~s}, 1 \mathrm{H}), 9.05(\mathrm{t}, J=5.7 \mathrm{~Hz}, 1 \mathrm{H}), 8.05(\mathrm{~d}, J=9.1 \mathrm{~Hz}, 2 \mathrm{H}), 7.88$ $(\mathrm{d}, J=9.1 \mathrm{~Hz}, 2 \mathrm{H}), 7.72-7.67(\mathrm{~m}, 2 \mathrm{H}), 7.61-7.59(\mathrm{~m}, 2 \mathrm{H}), 7.53-7.50(\mathrm{~m}, 1 \mathrm{H}), 7.47-7.44$ $(\mathrm{m}, 2 \mathrm{H}), 7.22(\mathrm{~d}, J=2.0 \mathrm{~Hz}, 1 \mathrm{H}), 6.86(\mathrm{t}, J=5.5 \mathrm{~Hz}, 1 \mathrm{H}), 4.57(\mathrm{~d}, J=10.5 \mathrm{~Hz}, 1 \mathrm{H}), 4.33-$ $4.27(\mathrm{~m}, 1 \mathrm{H}), 3.80-3.73(\mathrm{~m}, 2 \mathrm{H}), 3.15(\mathrm{q}, J=7.0 \mathrm{~Hz}, 2 \mathrm{H}), 2.98(\mathrm{q}, J=6.6 \mathrm{~Hz}, 2 \mathrm{H}), 2.36(\mathrm{t}, J$ $=7.4 \mathrm{~Hz}, 2 \mathrm{H}), 1.74-1.61(\mathrm{~m}, 4 \mathrm{H}), 1.38(\mathrm{~s}, 9 \mathrm{H}) ;{ }^{13} \mathrm{C}$ NMR (125 MHz, DMSO- $\left.d_{6}\right) \delta 171.6$, 168.6, 168.2 , 159.7, 156.2, 155.7, 141.4, 140.9, 138.1, 131.6, 131.1, 130.8, 130.7, 129.2, 129.0, 128.6, 128.4, 124.9, 121.1, 119.8, 77.5, 56.9, 43.5, 36.5, 33.9, 28.3, 27.2, 25.4; HRMS (ESI) calcd for $\mathrm{C}_{35} \mathrm{H}_{38} \mathrm{~N}_{9} \mathrm{O}_{5} \mathrm{NaCl} 722.2582[\mathrm{M}+\mathrm{Na}]^{+}$, found 722.2590 . 


\section{Synthesis of probe 9}

To a solution of $\mathbf{S 4 7}(13 \mathrm{mg}, 0.019 \mathrm{mmol})$ in $\mathrm{CH}_{2} \mathrm{Cl}_{2}(1 \mathrm{~mL})$ was added TFA $(0.15 \mathrm{~mL}, 1.9$ $\mathrm{mmol}$ ), and the mixture was stirred at r.t. for $2 \mathrm{~h}$. After removal of the solvent by evaporation, the residual TFA was further removed azeotropically with toluene $(\times 2)$ to give deprotected $\mathbf{S 4 7}$. A solution of deprotected S47, S38 (12 mg, $0.020 \mathrm{mmol})$, and DIPEA (13 $\mu \mathrm{L}, 0.076 \mathrm{mmol})$ in $2 \mathrm{~mL} \mathrm{DMF}$ was stirred at $60{ }^{\circ} \mathrm{C}$ for $2 \mathrm{~h}$. After removal of the solvent by evaporation, the residue was purified by medium-pressure reverse phase flash chromatography (column; SNAP Ultra C18 (12 g), mobile phase; 0.1\% (v/v) AcOH aqueous solution/0.1\% (v/v) $\mathrm{AcOH}$ in $\mathrm{MeCN}$ $(95: 5 \rightarrow 25: 75)$, detection; UV $(\lambda$-all $))$. The suitable fractions were pooled and lyophilized to give probe 9 as a white powder (13 mg, 2 steps $58 \%$ ); ${ }^{1} \mathrm{H}$ NMR (500 MHz, DMSO- $\left.d_{6}\right) \delta 13.53$ $(\mathrm{t}, J=5.3 \mathrm{~Hz}, 1 \mathrm{H}), 10.37(\mathrm{~s}, 1 \mathrm{H}), 9.05(\mathrm{t}, J=5.7 \mathrm{~Hz}, 1 \mathrm{H}), 8.05(\mathrm{~d}, J=9.1 \mathrm{~Hz}, 2 \mathrm{H}), 7.88(\mathrm{~d}, J$ $=9.1 \mathrm{~Hz}, 2 \mathrm{H}), 7.81(\mathrm{t}, J=5.6 \mathrm{~Hz}, 1 \mathrm{H}), 7.72-7.68(\mathrm{~m}, 2 \mathrm{H}), 7.62-7.60(\mathrm{~m}, 2 \mathrm{H}), 7.54-7.51$ (m, 1H), $7.48-7.45(\mathrm{~m}, 2 \mathrm{H}), 7.22(\mathrm{dd}, J=2.0,0.7 \mathrm{~Hz}, 1 \mathrm{H}), 6.41(\mathrm{br}, 2 \mathrm{H}), 4.57$ (d, $J=10.7$ $\mathrm{Hz}, 1 \mathrm{H}), 4.33-4.27(\mathrm{~m}, 2 \mathrm{H}), 4.11(\mathrm{dd}, J=7.7,4.4 \mathrm{~Hz}, 1 \mathrm{H}), 3.81-3.73$ (m, overlapped with the water signal), $3.62-3.59(\mathrm{~m}, 4 \mathrm{H}), 3.47-3.46(\mathrm{~m}, 12 \mathrm{H}), 3.37(\mathrm{t}, J=5.9 \mathrm{~Hz}, 2 \mathrm{H}), 3.27(\mathrm{t}$, $J=6.2 \mathrm{~Hz}, 2 \mathrm{H}), 3.18-3.13(\mathrm{~m}, 4 \mathrm{H}), 3.10-3.06$ (m, 1H), 2.81 (dd, $J=12.4,5.1 \mathrm{~Hz}, 1 \mathrm{H}), 2.58$ (d, $J=12.4 \mathrm{~Hz}, 1 \mathrm{H}), 2.48$ (overlapped with the DMSO signal), $2.28(\mathrm{~s}, 4 \mathrm{H}), 2.05$ (t, $J=7.4$ $\mathrm{Hz}, 2 \mathrm{H}), 1.93$ (quin, $J=7.1 \mathrm{~Hz}, 2 \mathrm{H}), 1.76-1.56$ (m, 3H), $1.53-1.41$ (m, 3H), $1.34-1.24$ (m, $2 \mathrm{H}), 0.94(\mathrm{~s}, 6 \mathrm{H}) ;{ }^{13} \mathrm{C}$ NMR $\left(125 \mathrm{MHz}, \mathrm{DMSO}-d_{6}\right) \delta 173.4,172.2,170.9,168.5,168.4,162.8$, 159.8, 158.4, 158.1, 156.2, 141.3, 140.9, 137.9, 131.7, 131.0, 130.9, 130.8, 129.3, 129.1, 128.6, $128.4,124.9,121.2,119.9,116.8,114.5,106.2$, 69.8, 69.8, 69.6, 69.2, 68.8, 61.1, 59.3, 56.8, 55.5, 52.4, 43.5, 42.5, 38.5, 36.5, 35.2, 33.4, 30.1, 29.7, 28.3, 28.1, 27.9, 27.2, 25.3, 24.6; HRMS (ESI) calcd for $\mathrm{C}_{59} \mathrm{H}_{76} \mathrm{~N}_{12} \mathrm{O}_{11} \mathrm{SCl} 1195.5166[\mathrm{M}+\mathrm{H}]^{+}$, found 1195.5178.

Scheme S16. Synthesis of compound 10
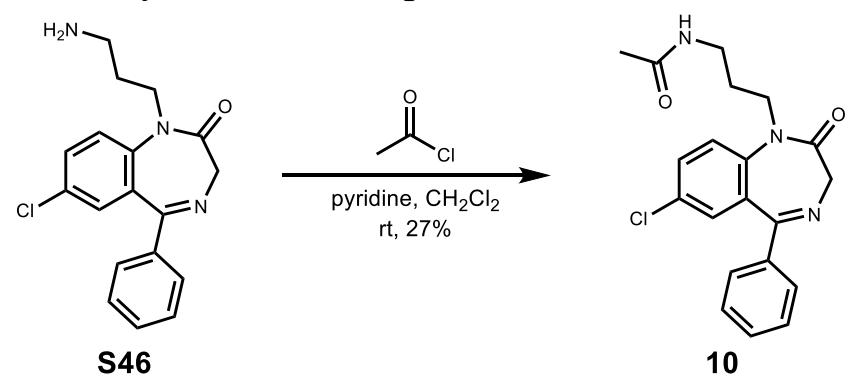

To a solution of $\mathbf{S 4 6}$ (36 $\mathrm{mg}, 0.11 \mathrm{mmol})$ in $\mathrm{CH}_{2} \mathrm{Cl}_{2}(2 \mathrm{~mL})$ was added pyridine $(0.044 \mathrm{~mL}, 0.55$ $\mathrm{mmol})$ and acethyl chloride $(0.039 \mathrm{~mL}, 0.55 \mathrm{mmol})$, and the mixture was stirred at r.t. for $1 \mathrm{~h}$. Then $5 \mathrm{~mL}$ water was added to the mixture, and the solvent was extracted with $\mathrm{CH}_{2} \mathrm{Cl}_{2}$, washed with brine and then dried over $\mathrm{Na}_{2} \mathrm{SO}_{4}$. After removal of the solvent by evaporation, the residue 
was purified by by medium-pressure flash chromatography (column; SNAP Ultra (10 g), mobile phase; Hex/EtOAc/MeOH (50:50:0 $\rightarrow 0: 100: 0 \rightarrow 0: 90: 10)$, detection; UV ( $\lambda$-all)). The suitable fractions were pooled, and the solvent was removed by evaporation to give compound 10 as a colorless oil $(11 \mathrm{mg}, 27 \%) ;{ }^{1} \mathrm{H}$ NMR $\left(500 \mathrm{MHz}, \mathrm{DMSO}-d_{6}\right) \delta 7.72(\mathrm{dd}, J=9.0,2.5 \mathrm{~Hz}$, 1H), $7.69-7.66(\mathrm{~m}, 2 \mathrm{H}), 7.58-7.56(\mathrm{~m}, 2 \mathrm{H}), 7.55-7.51(\mathrm{~m}, 1 \mathrm{H}), 7.48-7.45(\mathrm{~m}, 2 \mathrm{H}), 7.21$ $(\mathrm{d}, J=2.5 \mathrm{~Hz}, 1 \mathrm{H}), 4.56(\mathrm{~d}, J=10.5 \mathrm{~Hz}, 1 \mathrm{H}), 4.25-4.19(\mathrm{~m}, 1 \mathrm{H}), 3.77(\mathrm{~d}, J=10.5 \mathrm{~Hz}, 1 \mathrm{H})$, $3.69-3.64(\mathrm{~m}, 1 \mathrm{H}), 2.82(\mathrm{q}, J=6.5 \mathrm{~Hz}, 2 \mathrm{H}), 1.71(\mathrm{~s}, 3 \mathrm{H}), 1.58-1.39(\mathrm{~m}, 2 \mathrm{H}) ;{ }^{13} \mathrm{C} \mathrm{NMR}(125$ MHz, DMSO- $\left.d_{6}\right) \delta 169.0,168.5,168.2,140.9,138.0,131.5,131.1,130.7,129.2$, 129.0, 128.6, 128.4, 124.9, 56.9, 43.6, 36.0, 27.5, 22.6; HRMS (ESI) calcd for $\mathrm{C}_{20} \mathrm{H}_{21} \mathrm{~N}_{3} \mathrm{O}_{2} \mathrm{Cl} 370.1322$ $[\mathrm{M}+\mathrm{H}]^{+}$, found 370.1332 . 

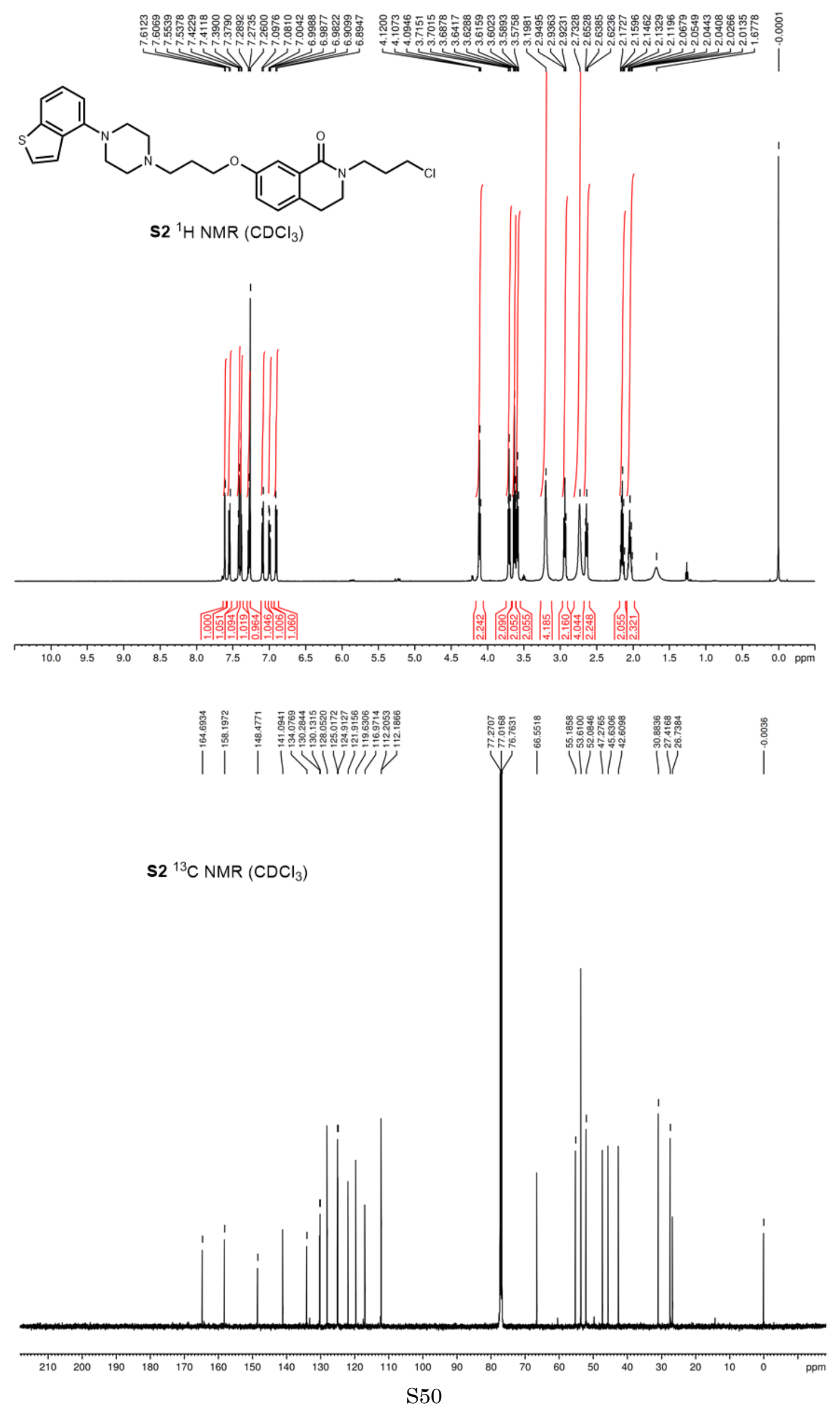

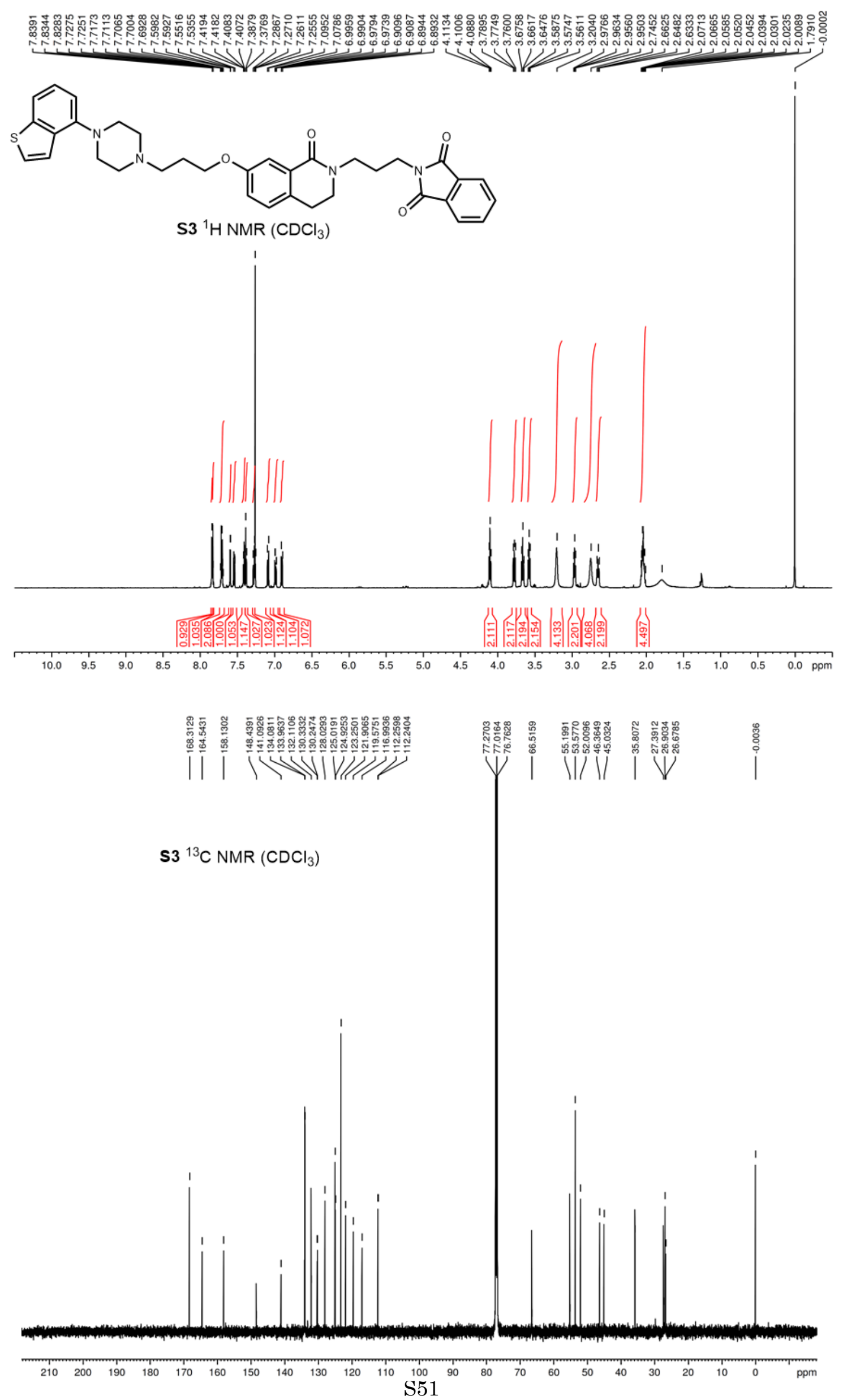

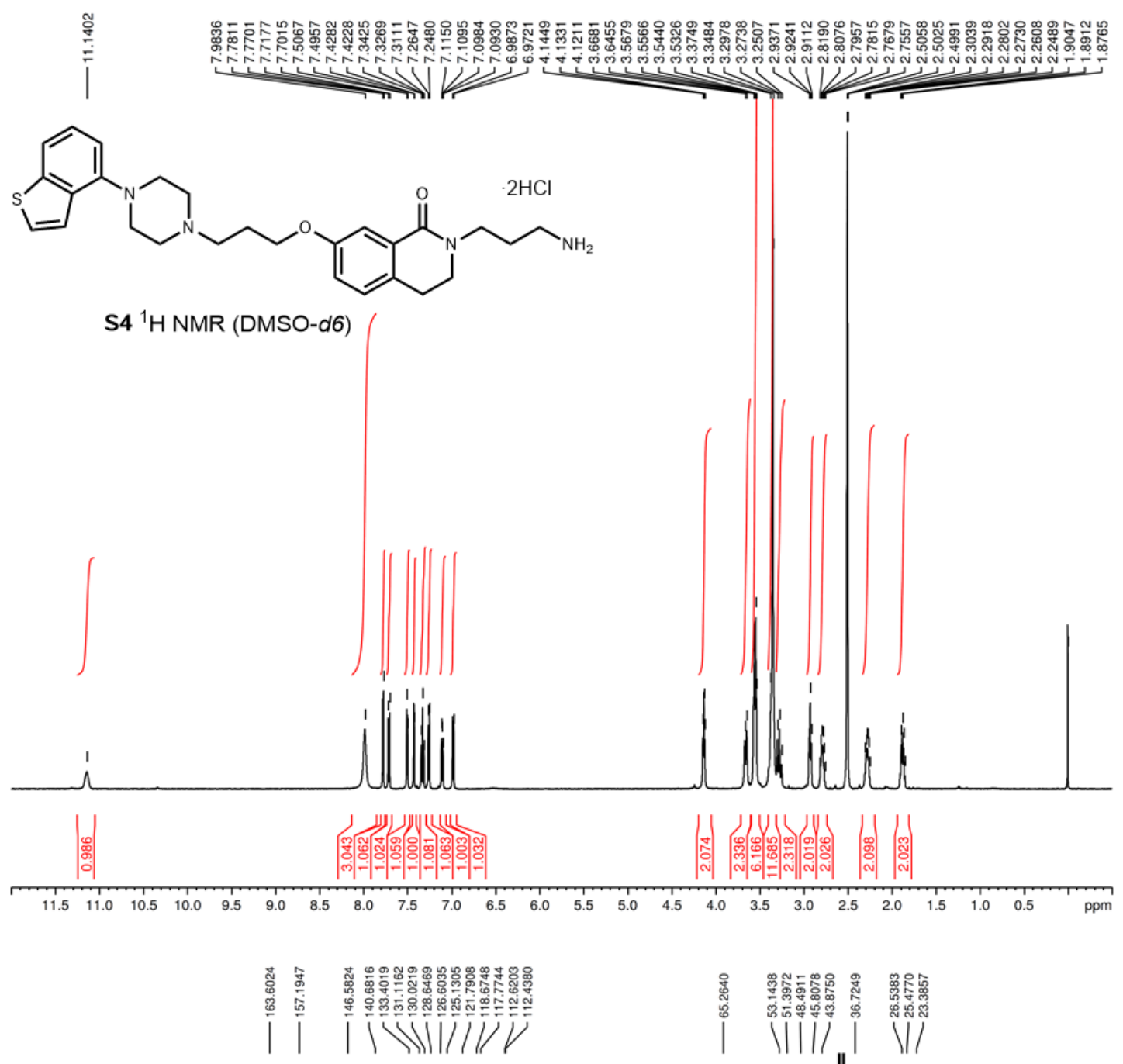

S4 ${ }^{13} \mathrm{C}$ NMR (DMSO-d6)

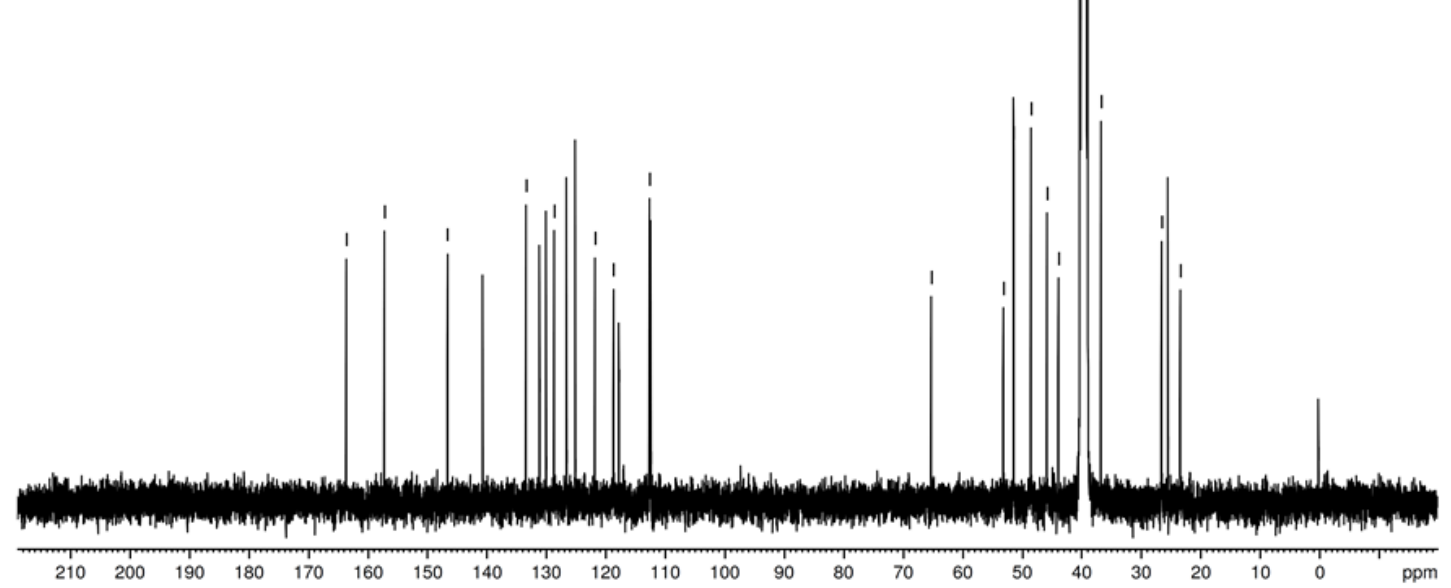



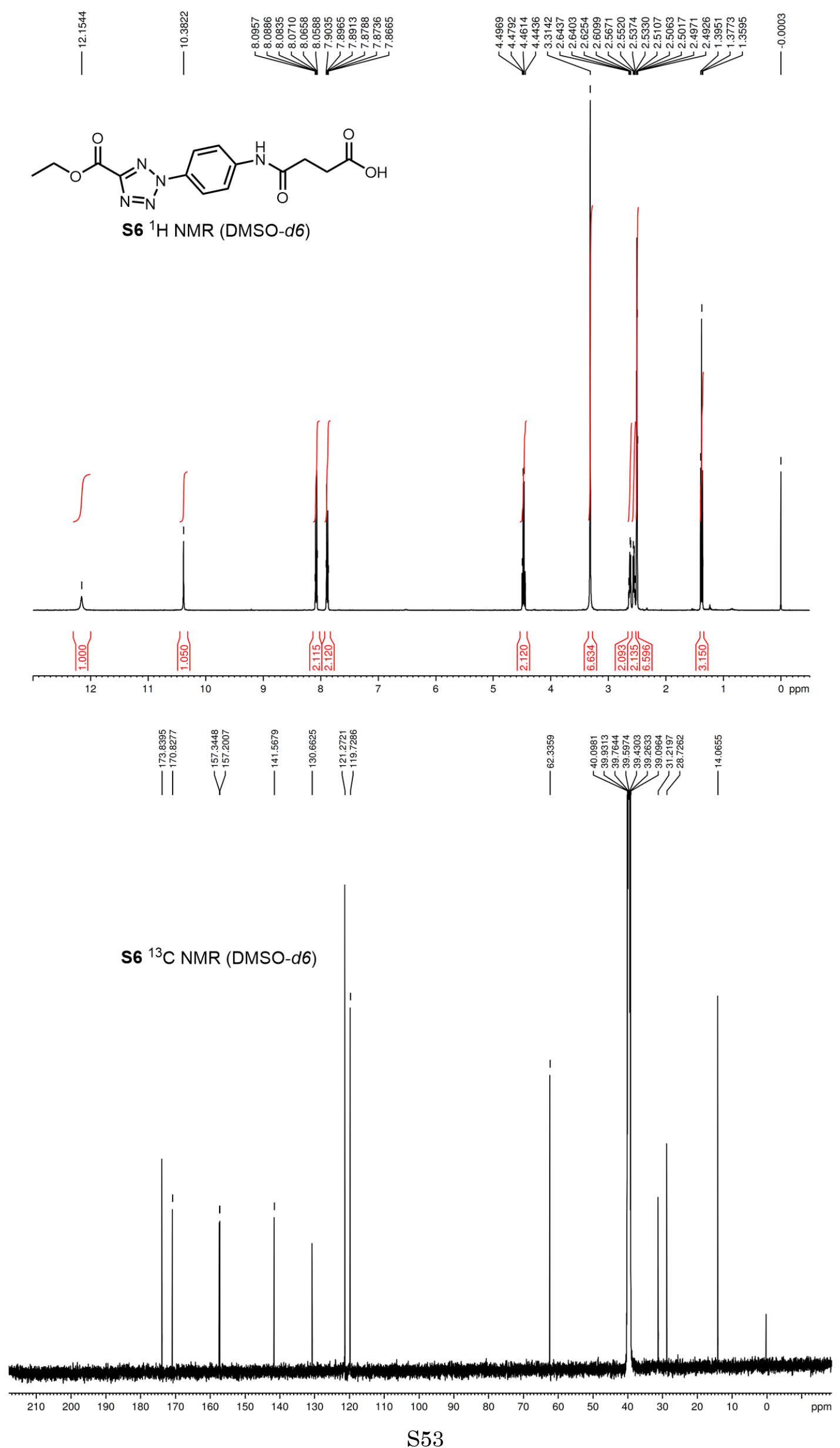


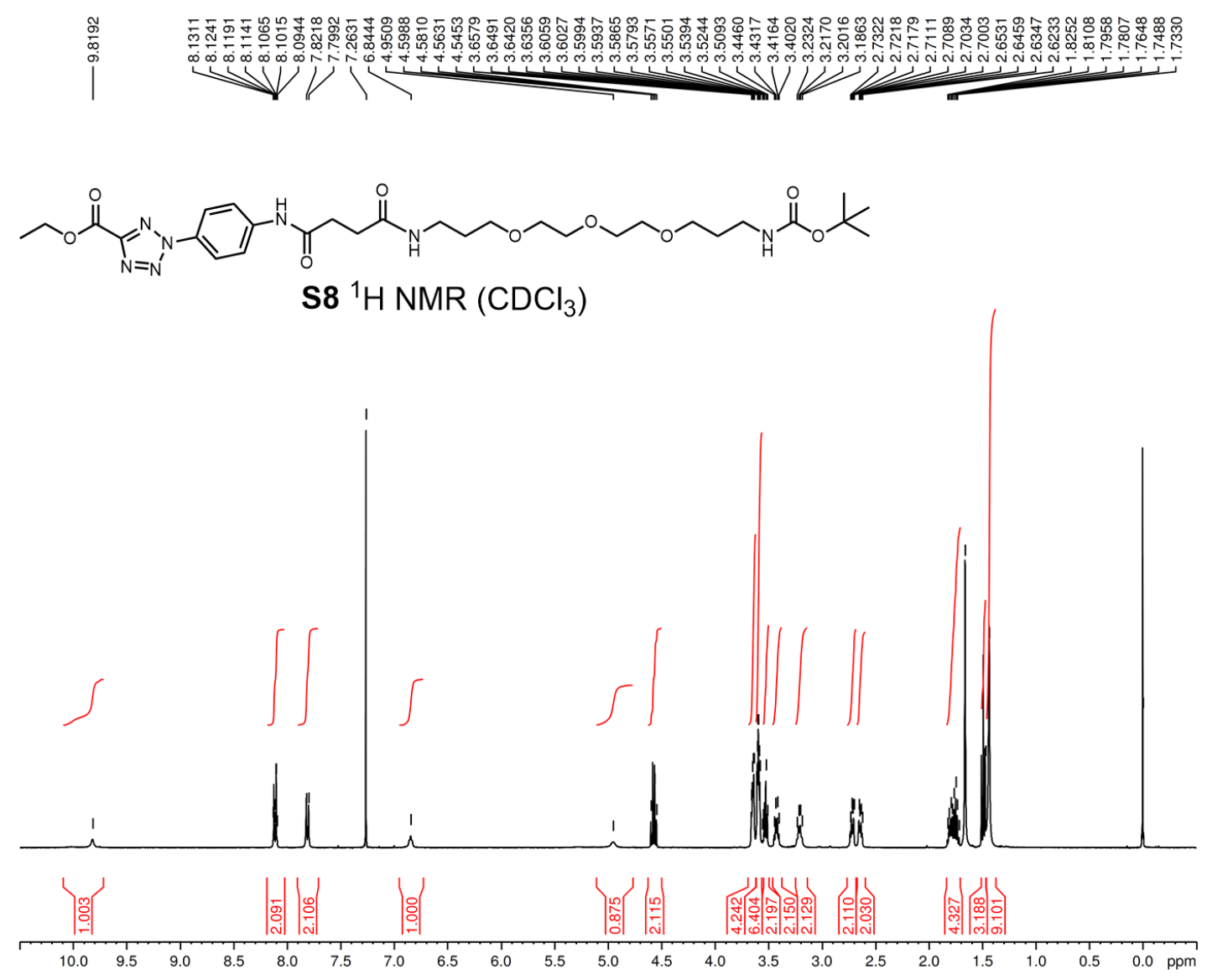

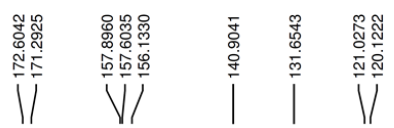

S8 ${ }^{13} \mathrm{C} \mathrm{NMR}\left(\mathrm{CDCl}_{3}\right)$
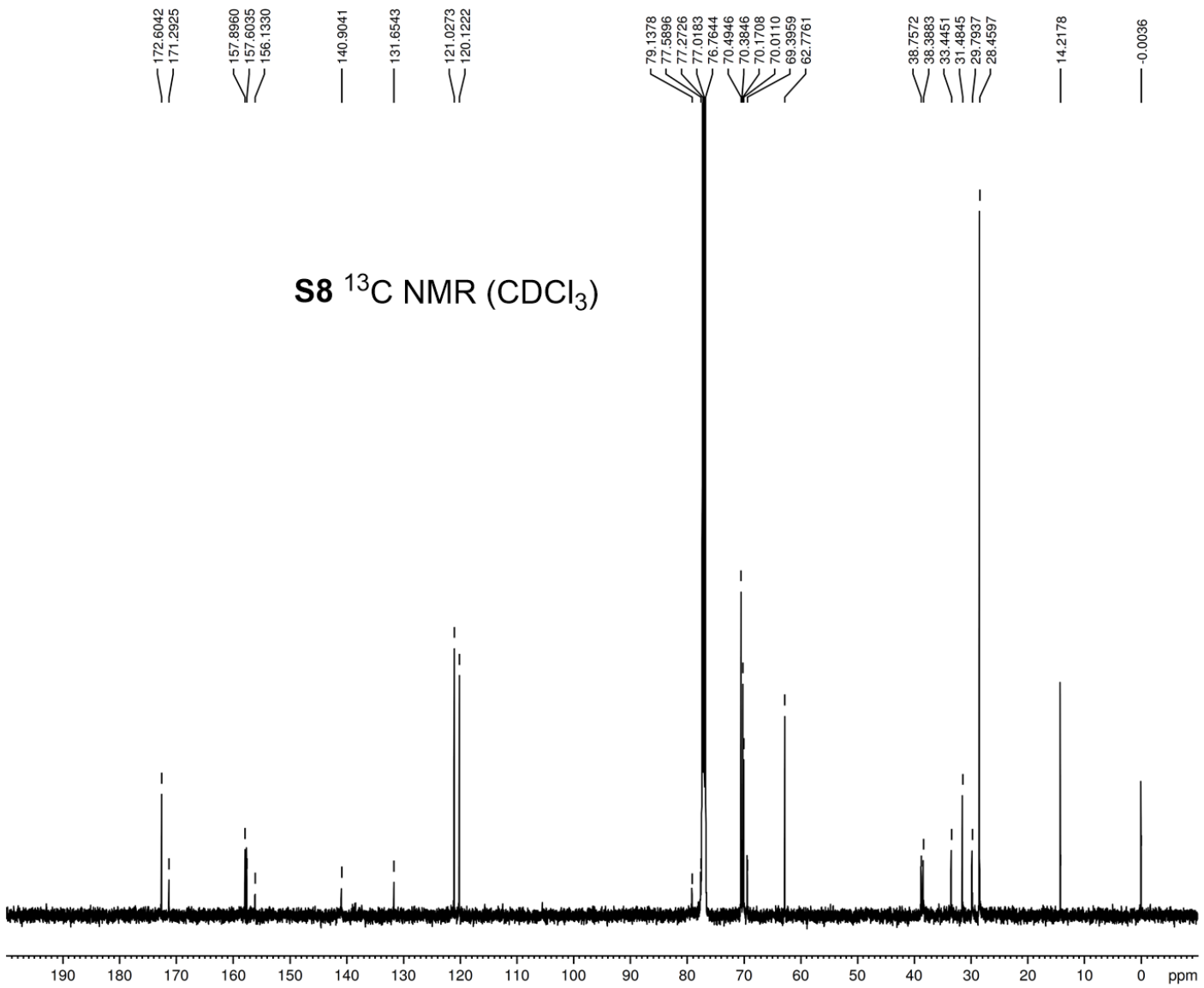

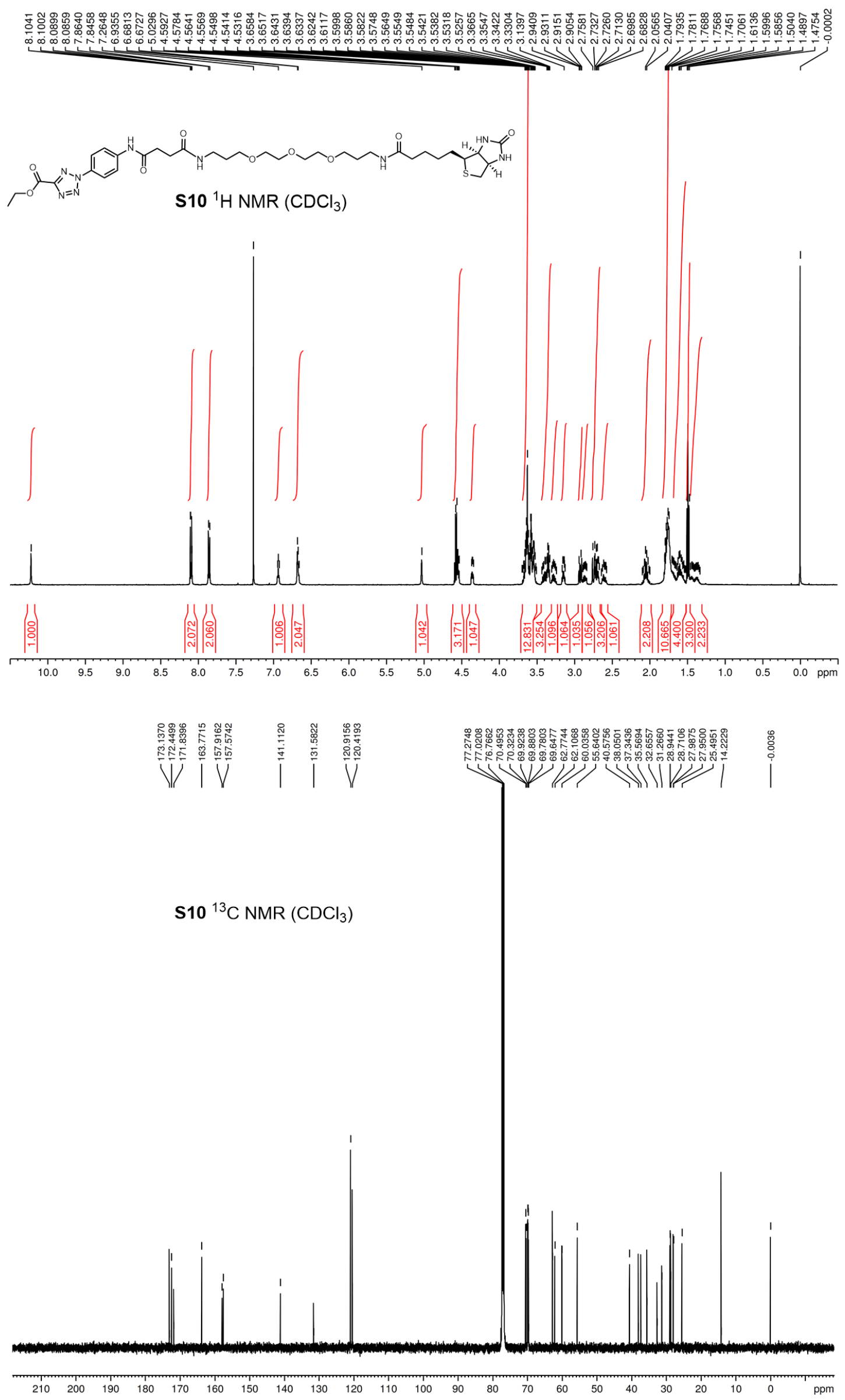


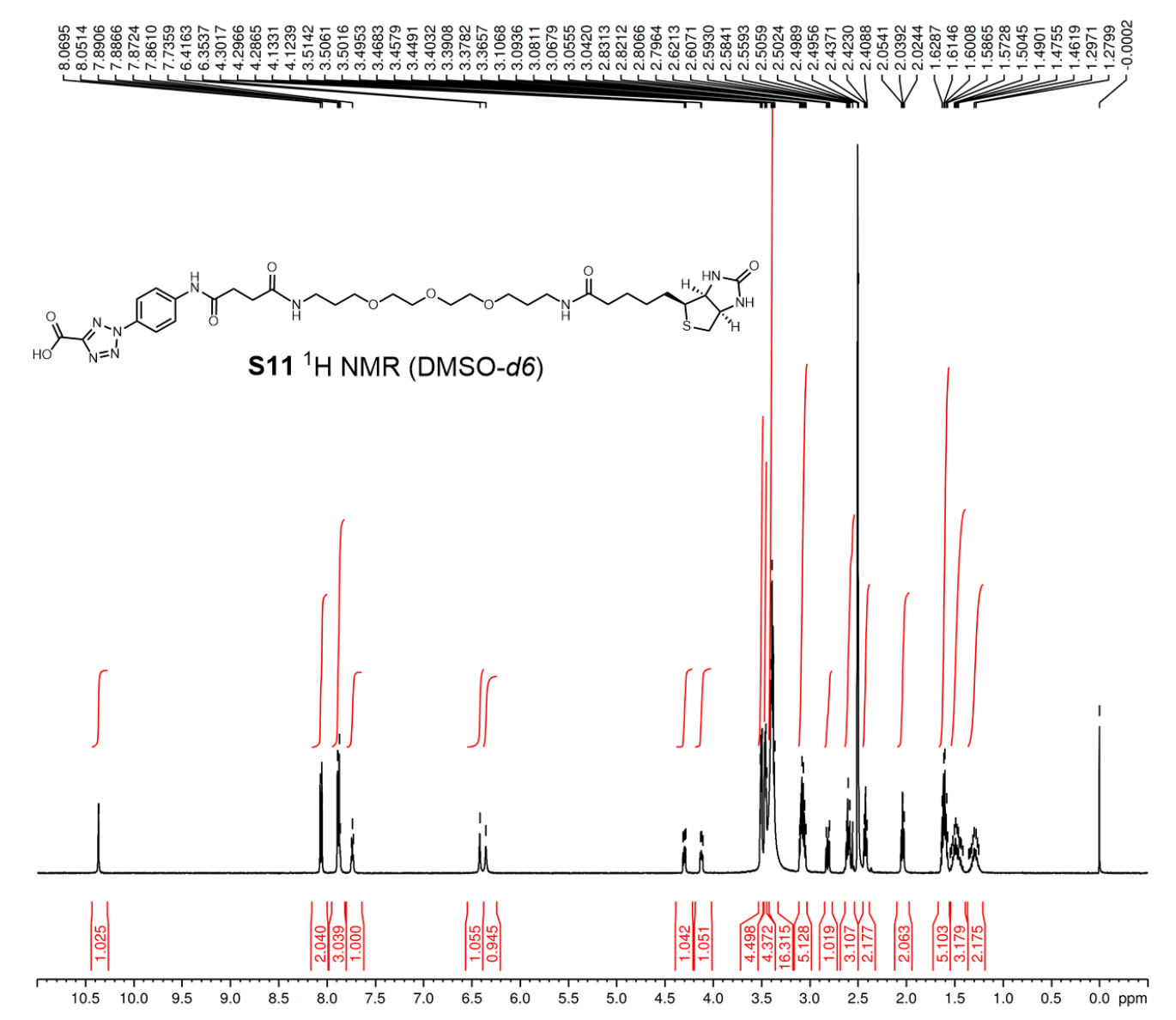

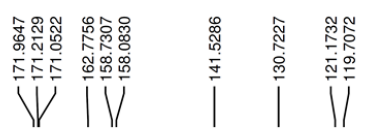

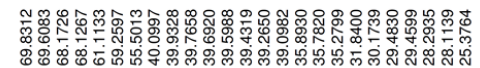

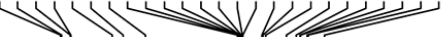

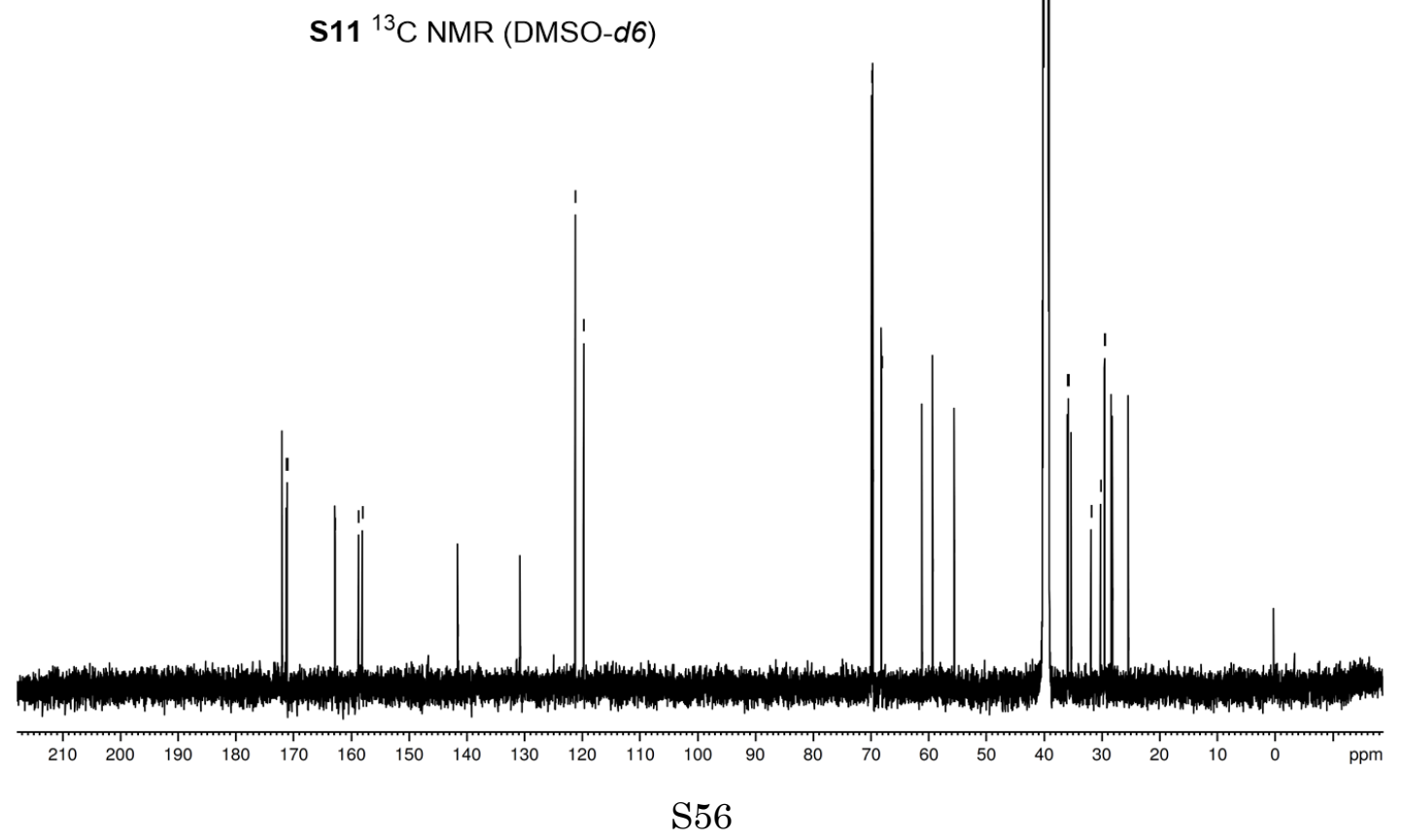




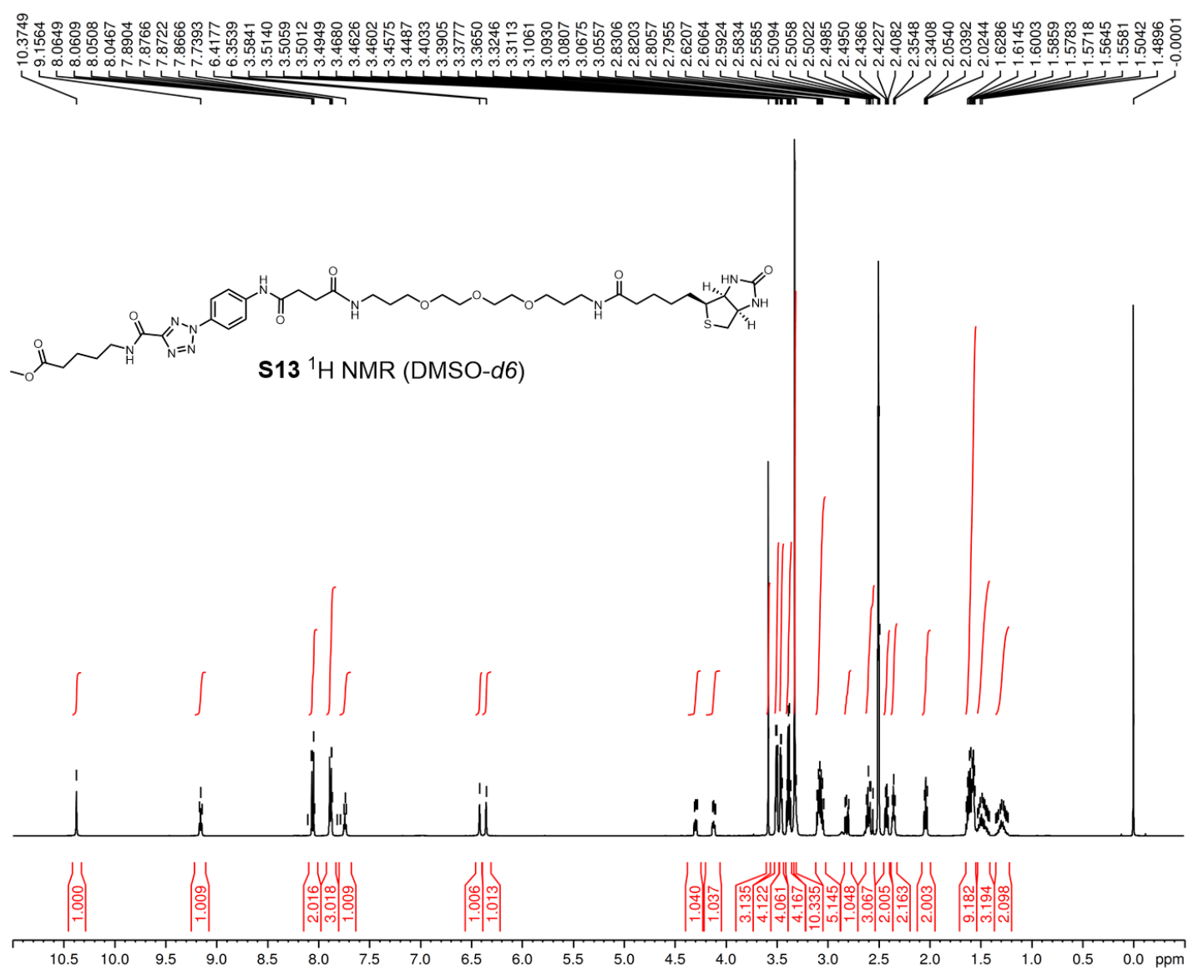

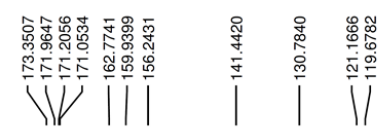

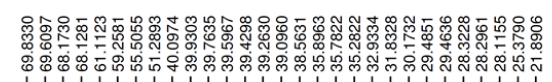

$N_{1}^{1}$

S13 ${ }^{13} \mathrm{C}$ NMR (DMSO-d6)

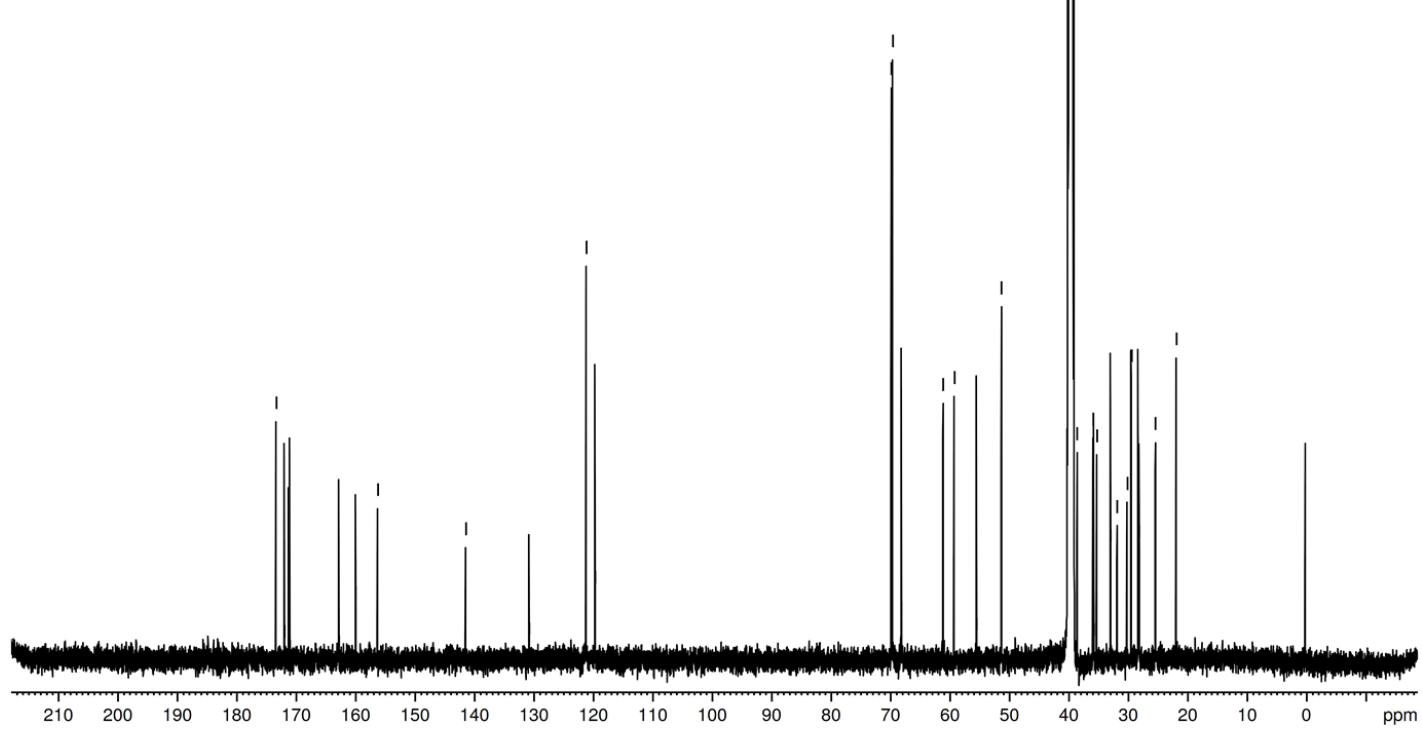




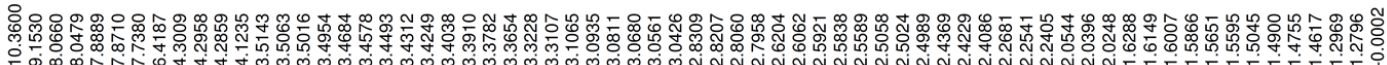
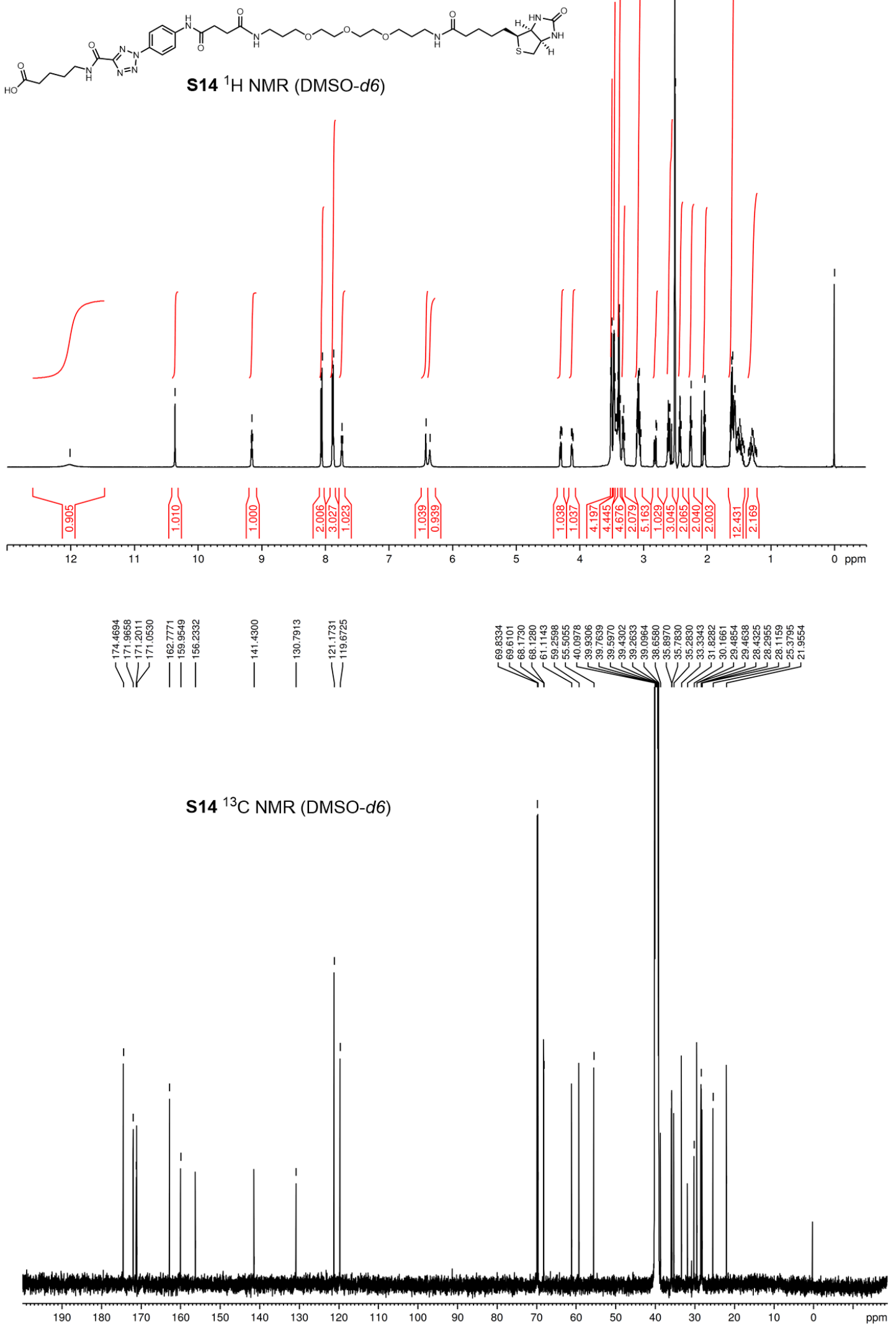

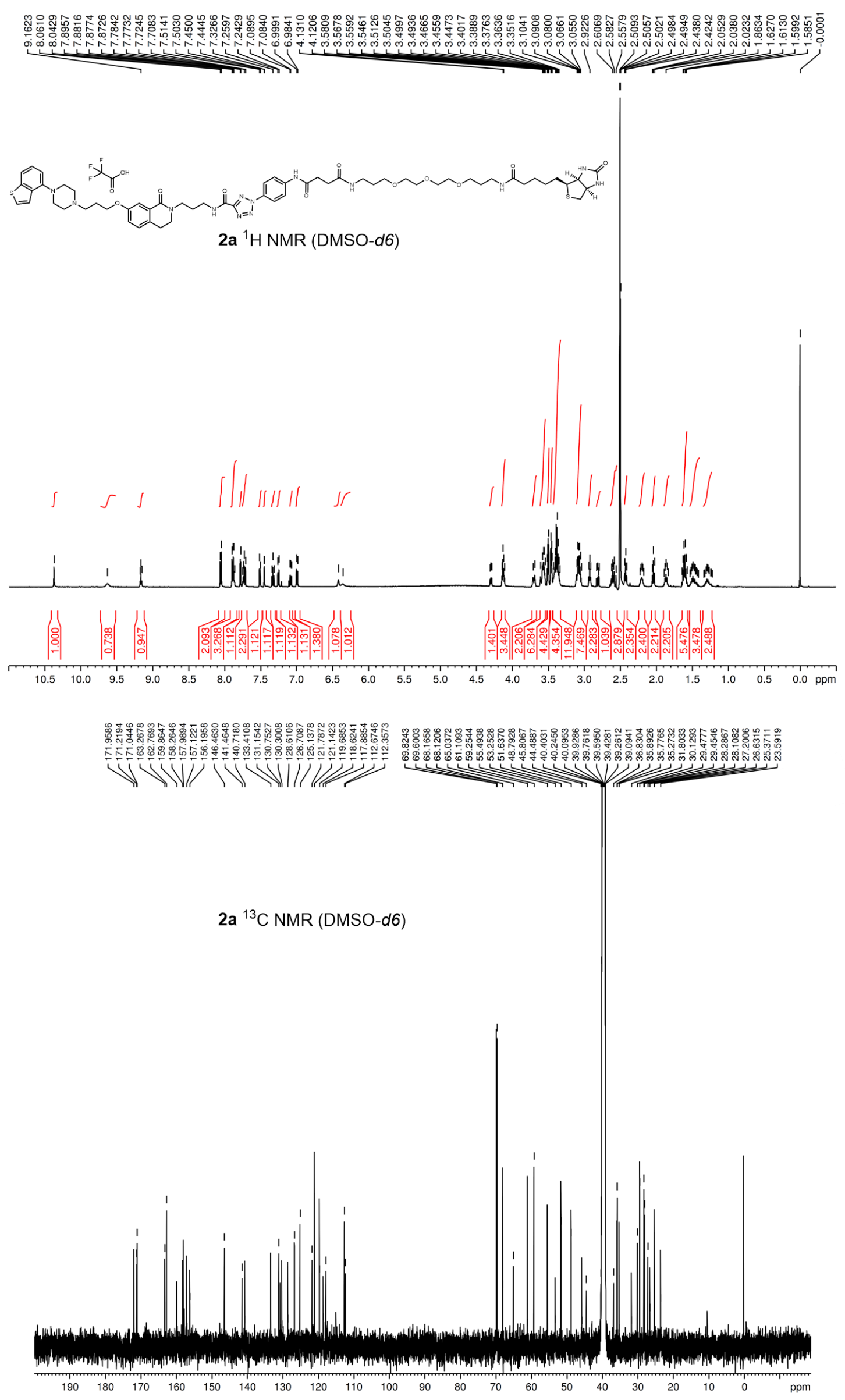


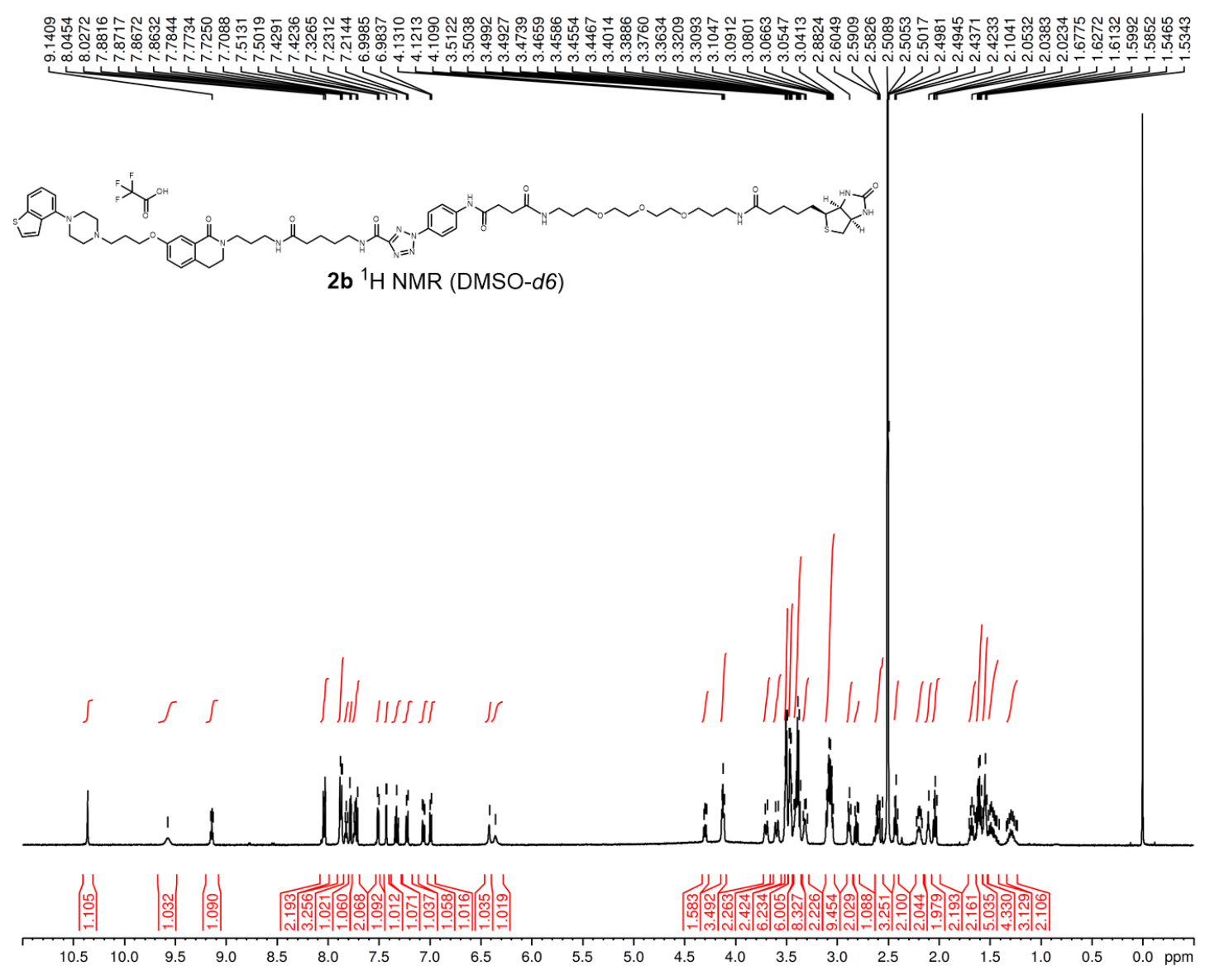

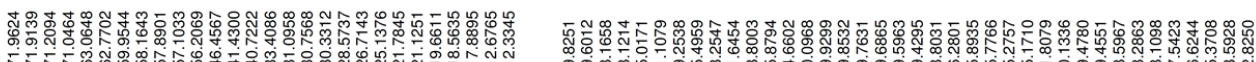

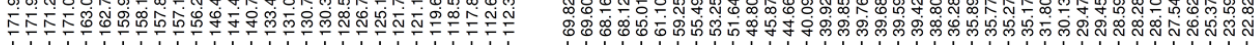
$4 \sqrt{1} \mid$

2b ${ }^{13} \mathrm{C}$ NMR (DMSO-d6)

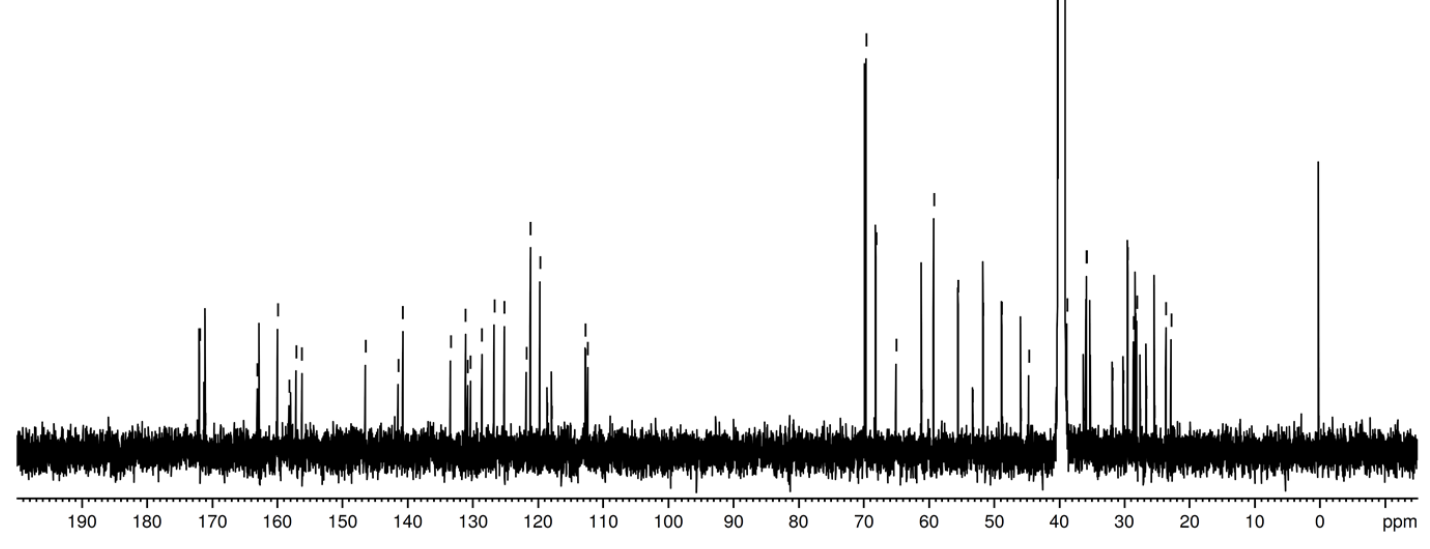




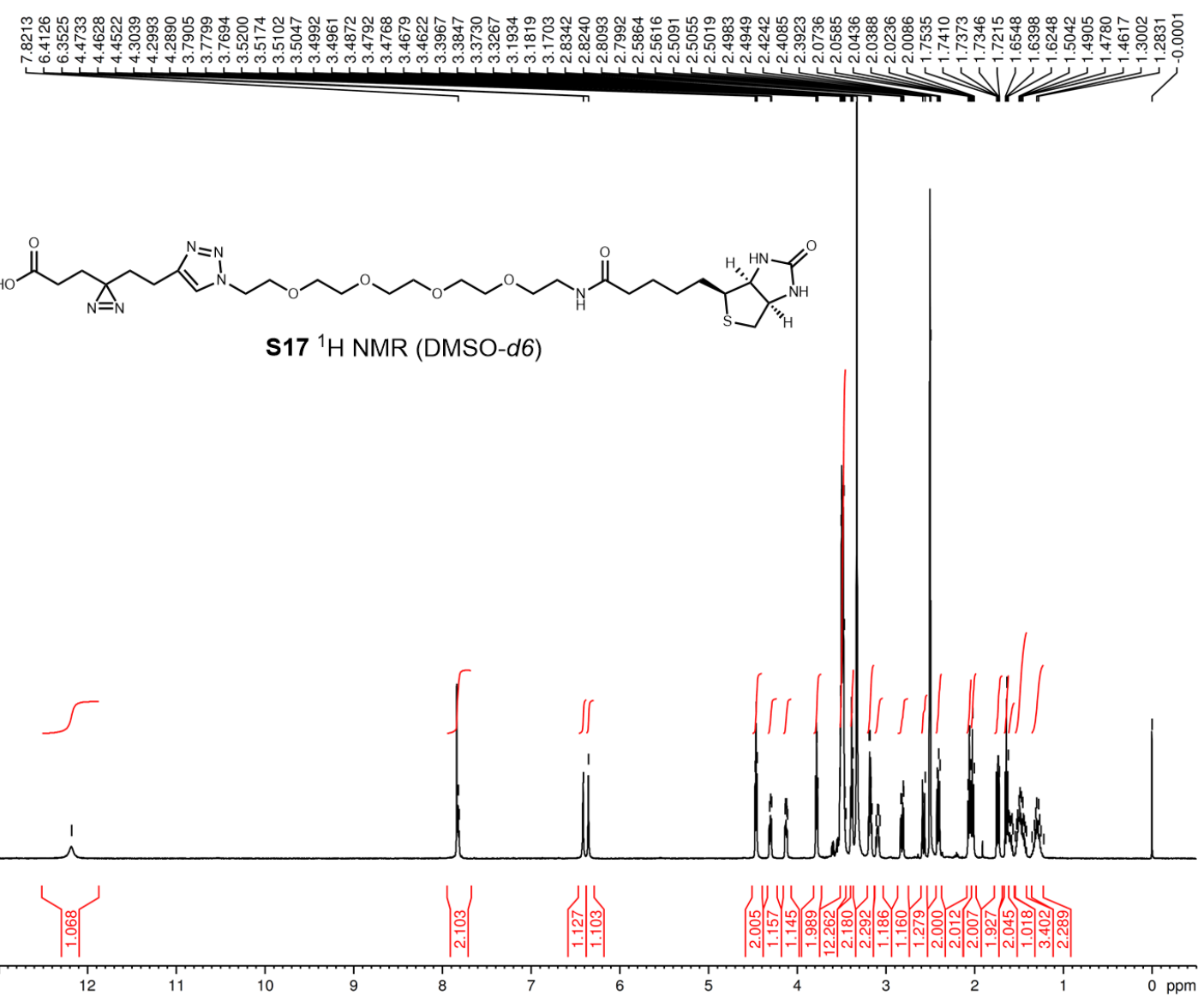

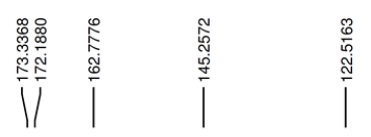

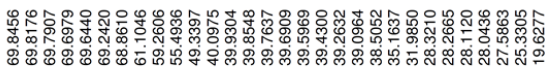

$+1$

$\mathbf{S 1 7}{ }^{13} \mathrm{C}$ NMR (DMSO-d6)

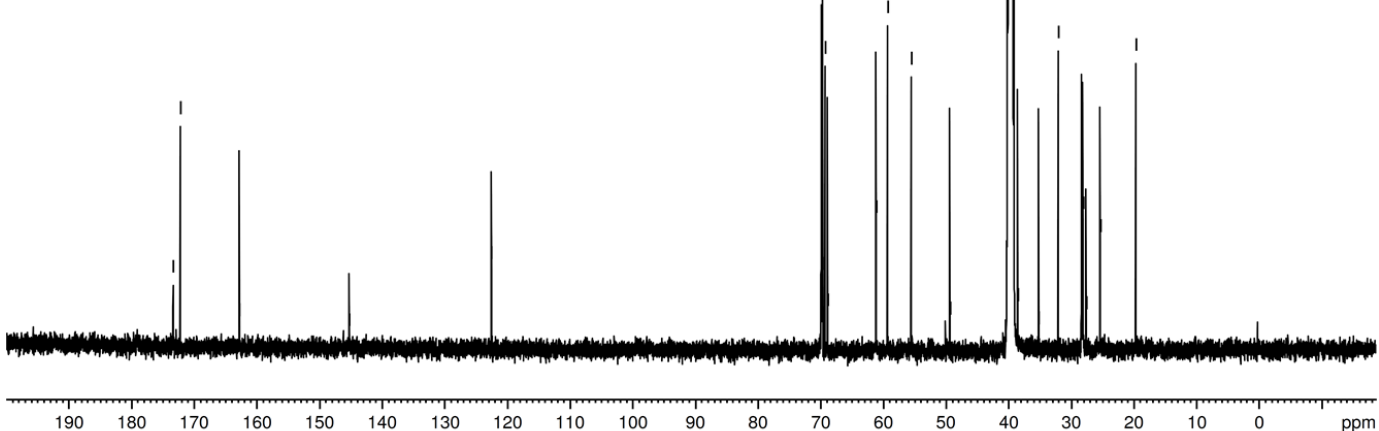




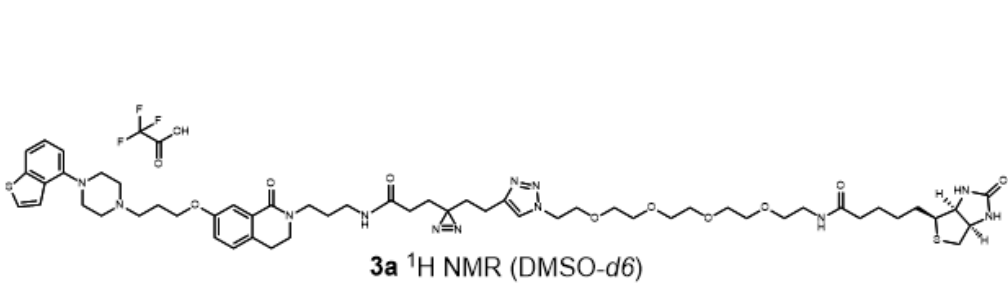

3a ${ }^{1}$ H NMR (DMSO-d6)

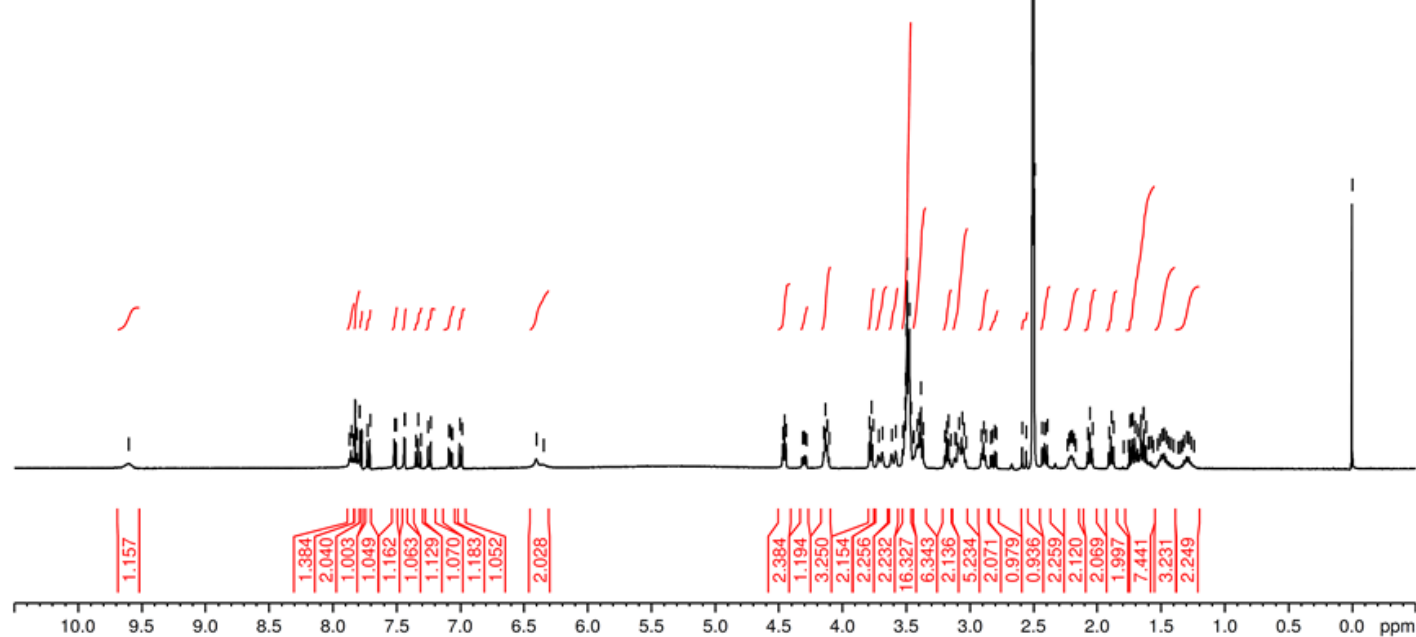

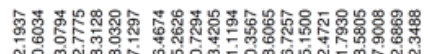

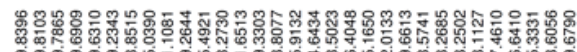

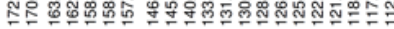

3.6\%

WVT TiNiVIV

W. W W

1

$3 a^{13}$ C NMR (DMSO-d6)

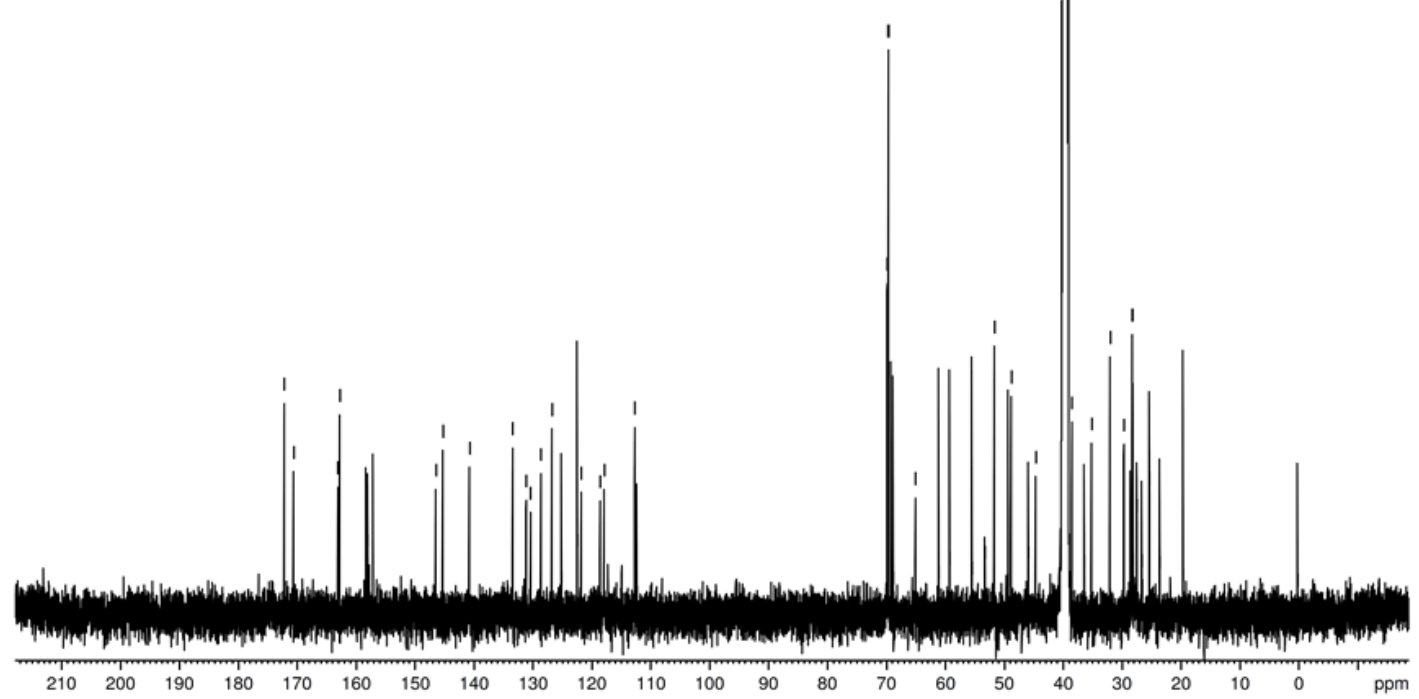




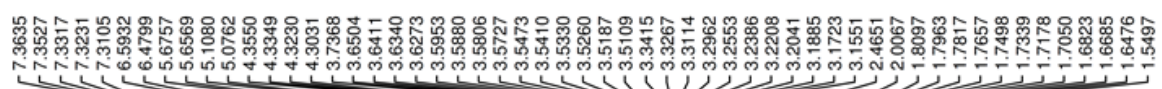

لـ

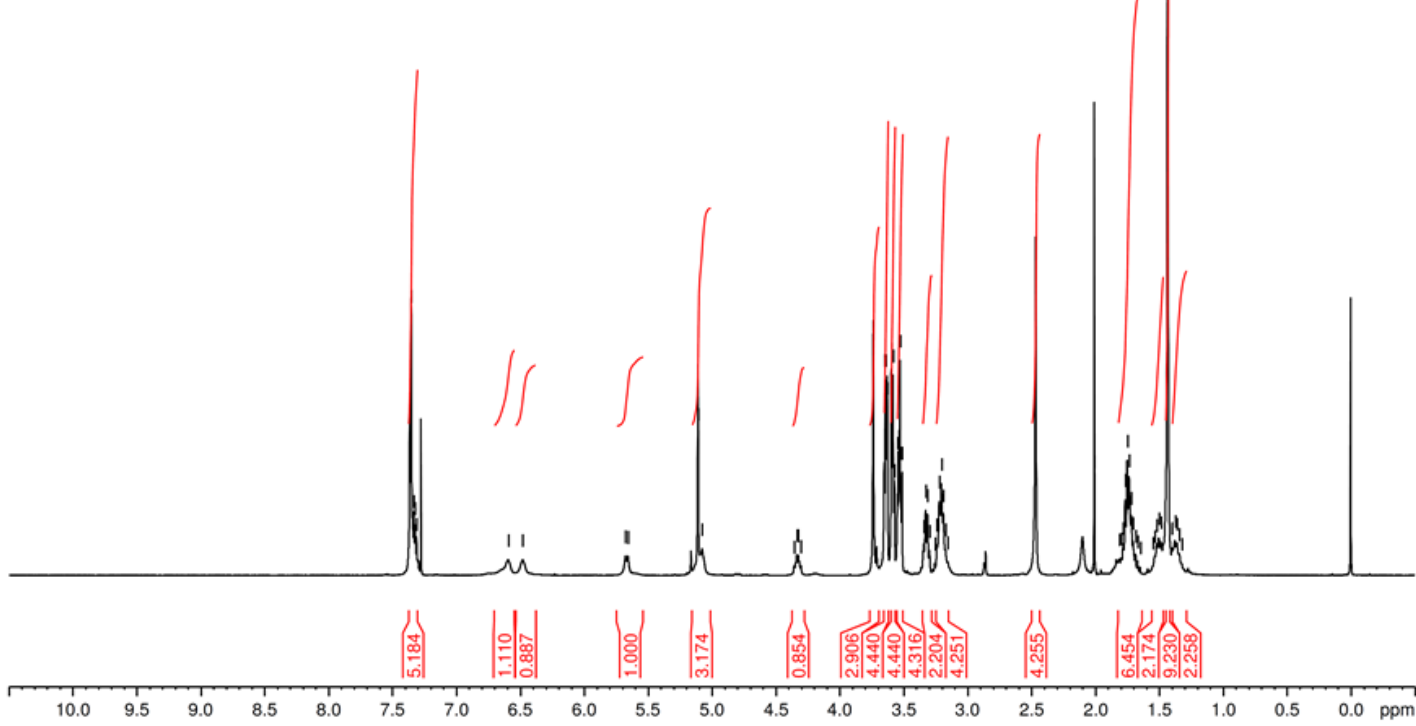

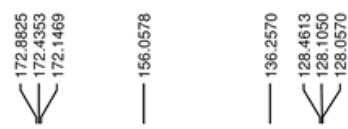

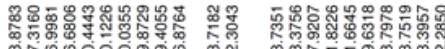

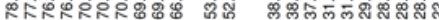

WVIJ II WVIVI

S21 ${ }^{13} \mathrm{C} \mathrm{NMR}\left(\mathrm{CDCl}_{3}\right)$

॥ 

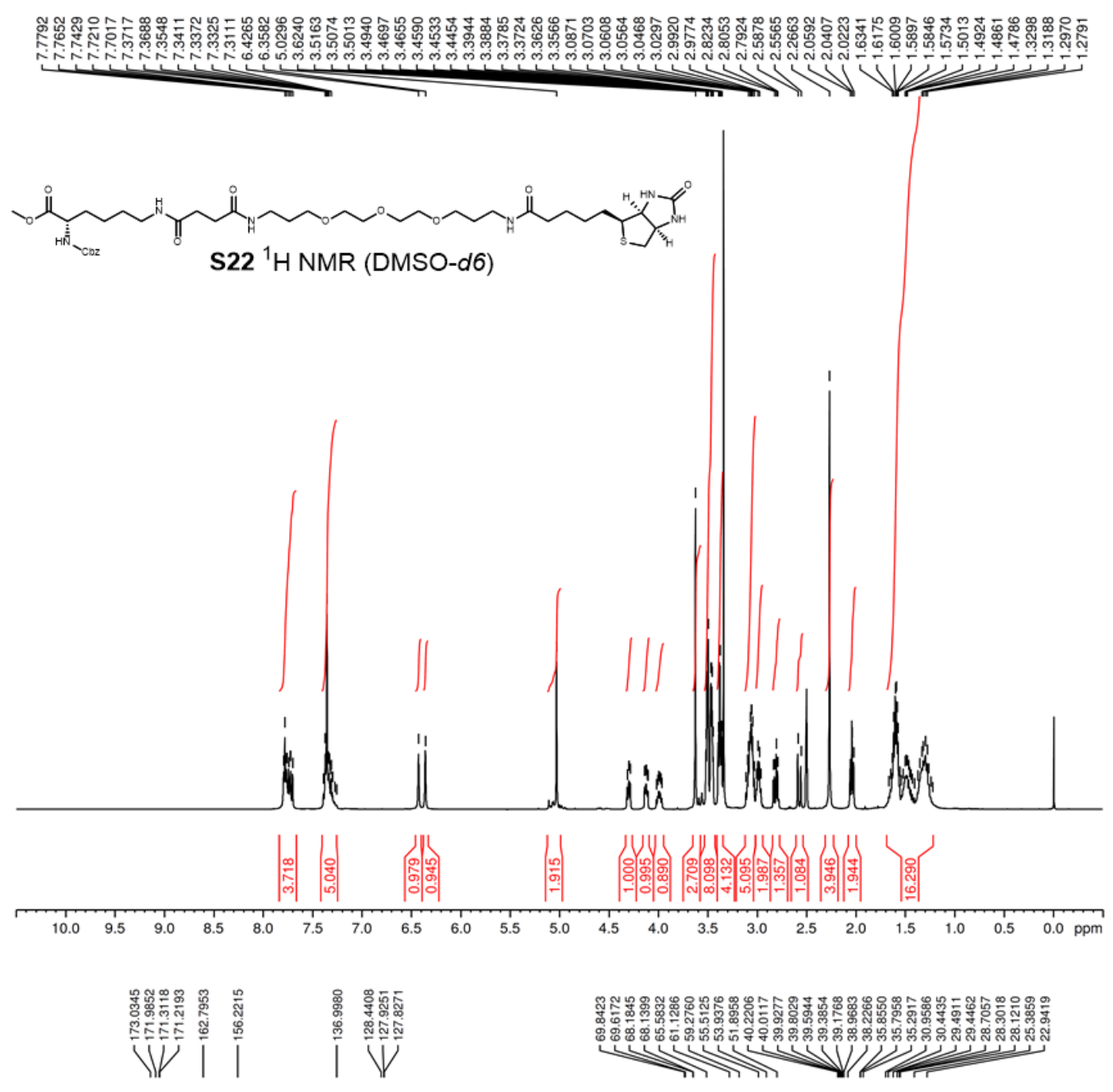

S22 ${ }^{13} \mathrm{C}$ NMR (DMSO-d6)

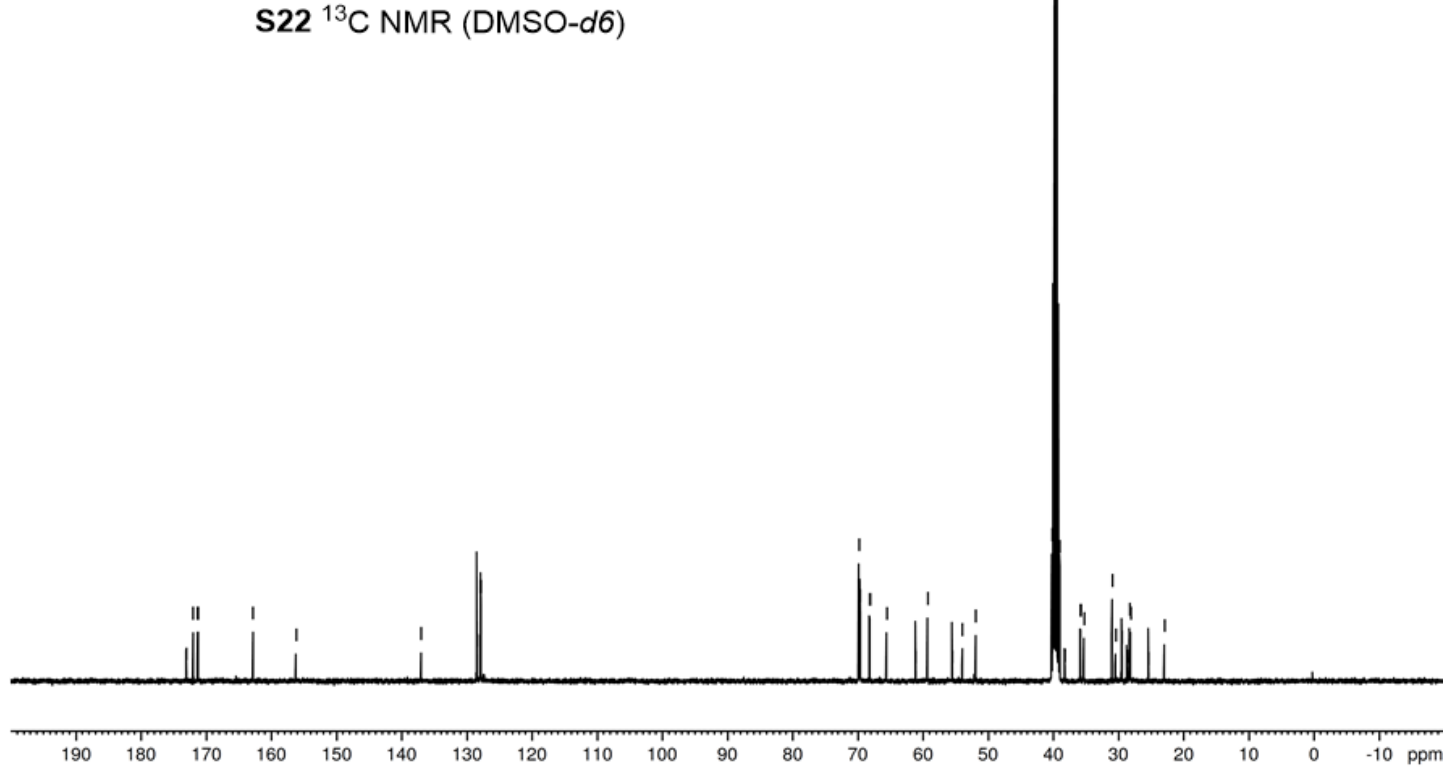




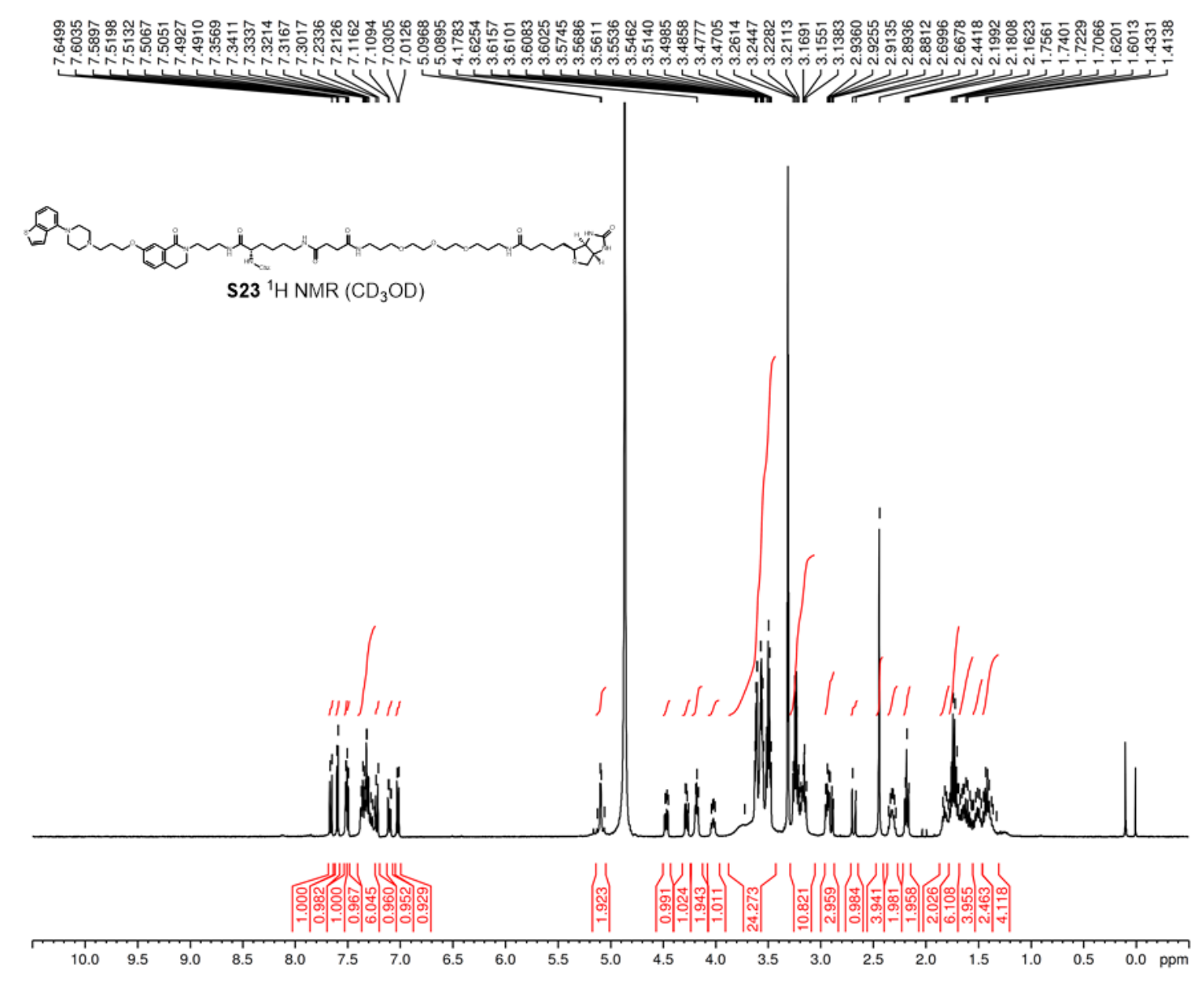

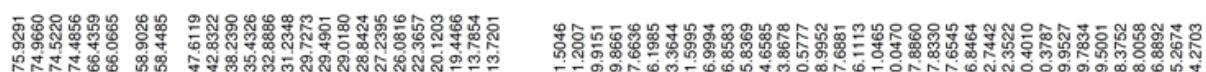

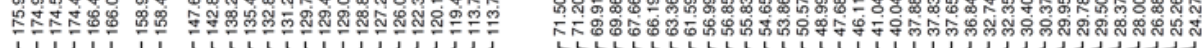

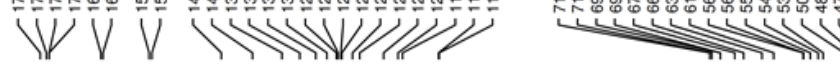

S23 ${ }^{13} \mathrm{C}$ NMR $\left(\mathrm{CD}_{3} \mathrm{OD}\right)$

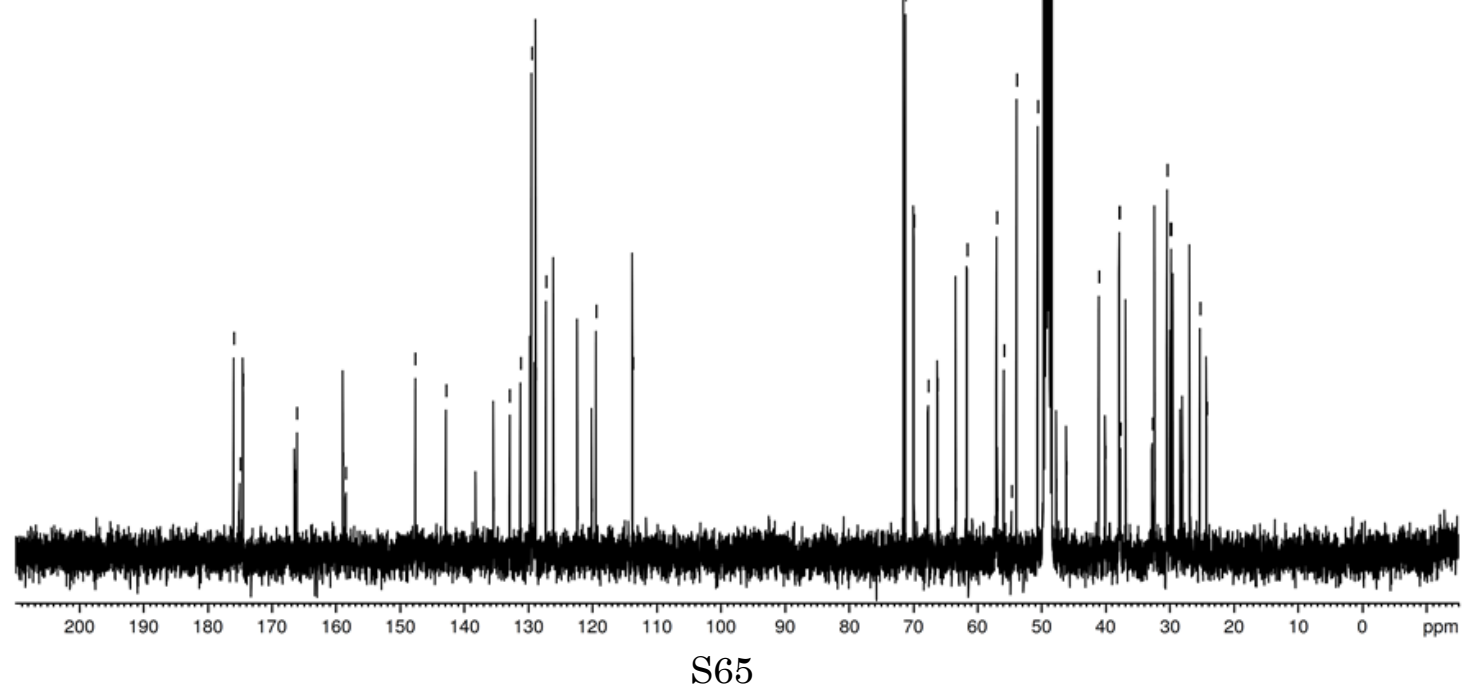




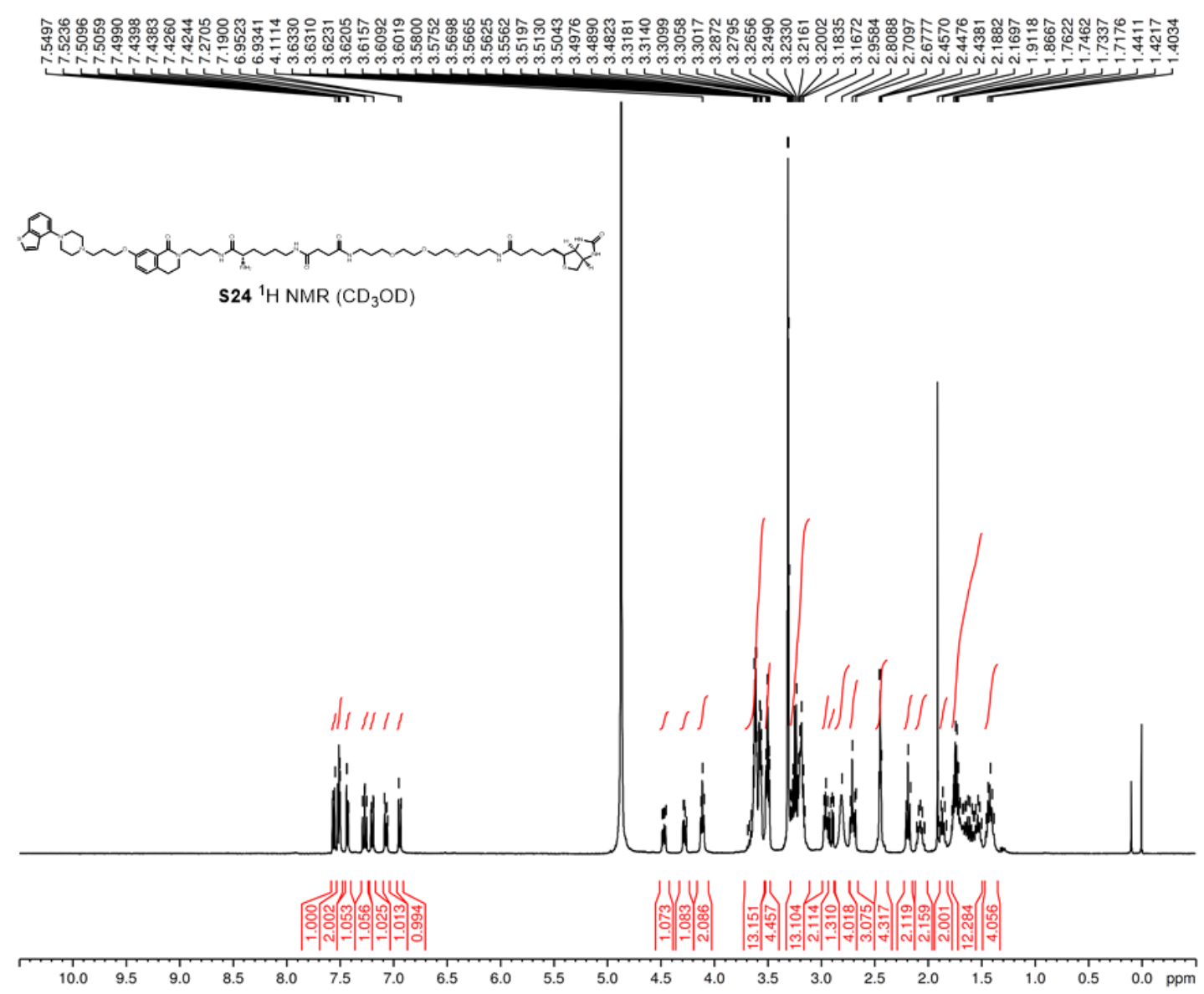

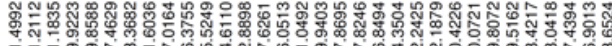

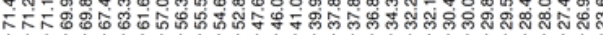

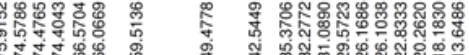

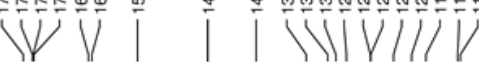

S24 ${ }^{13} \mathrm{C}$ NMR $\left(\mathrm{CD}_{3} \mathrm{OD}\right)$

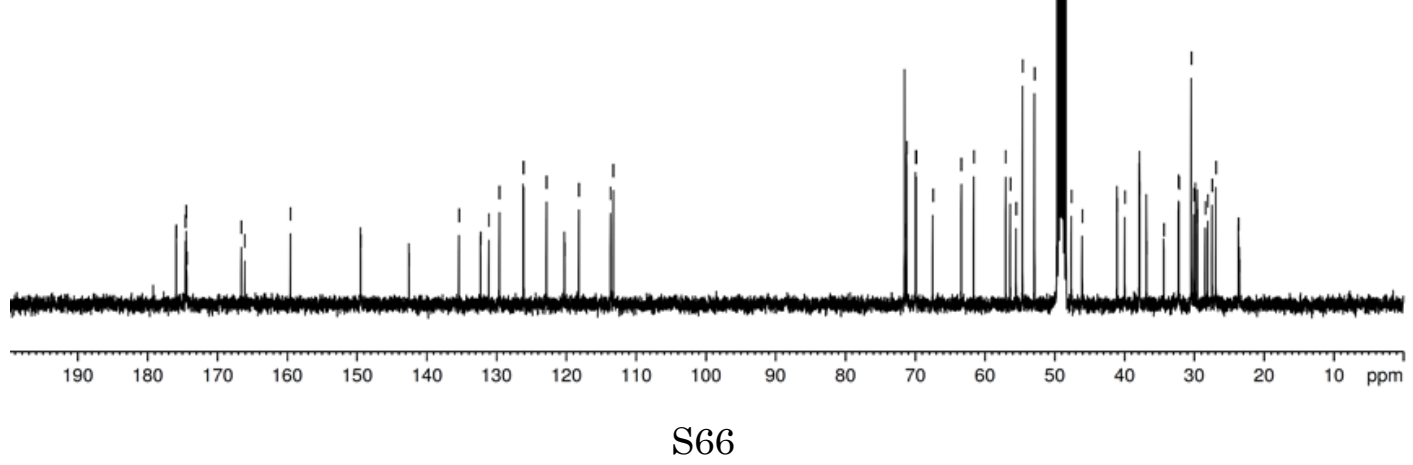




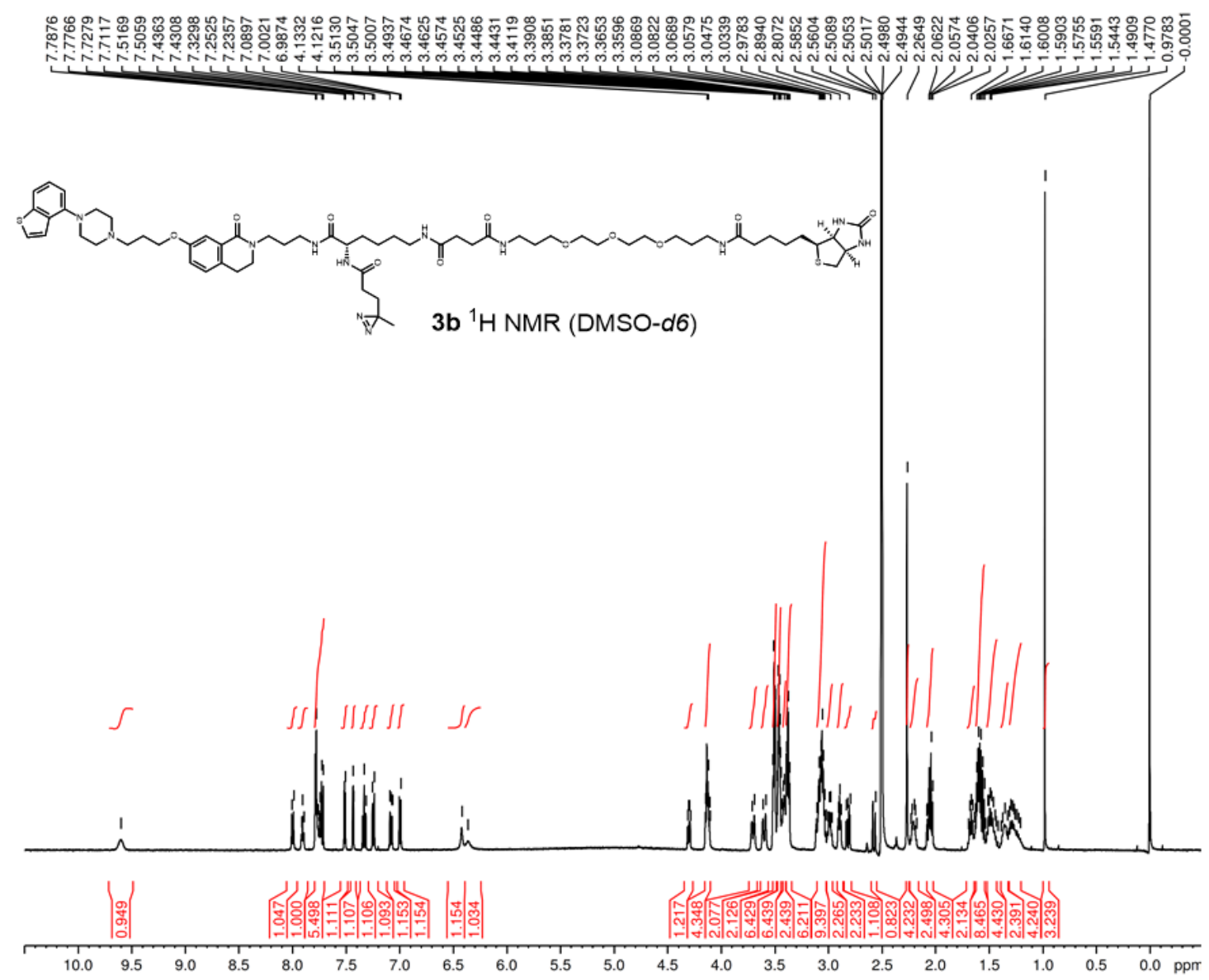

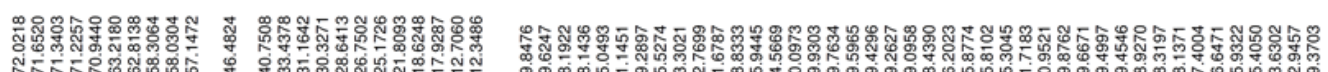

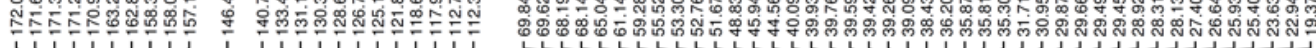
W VW I INIIIIV

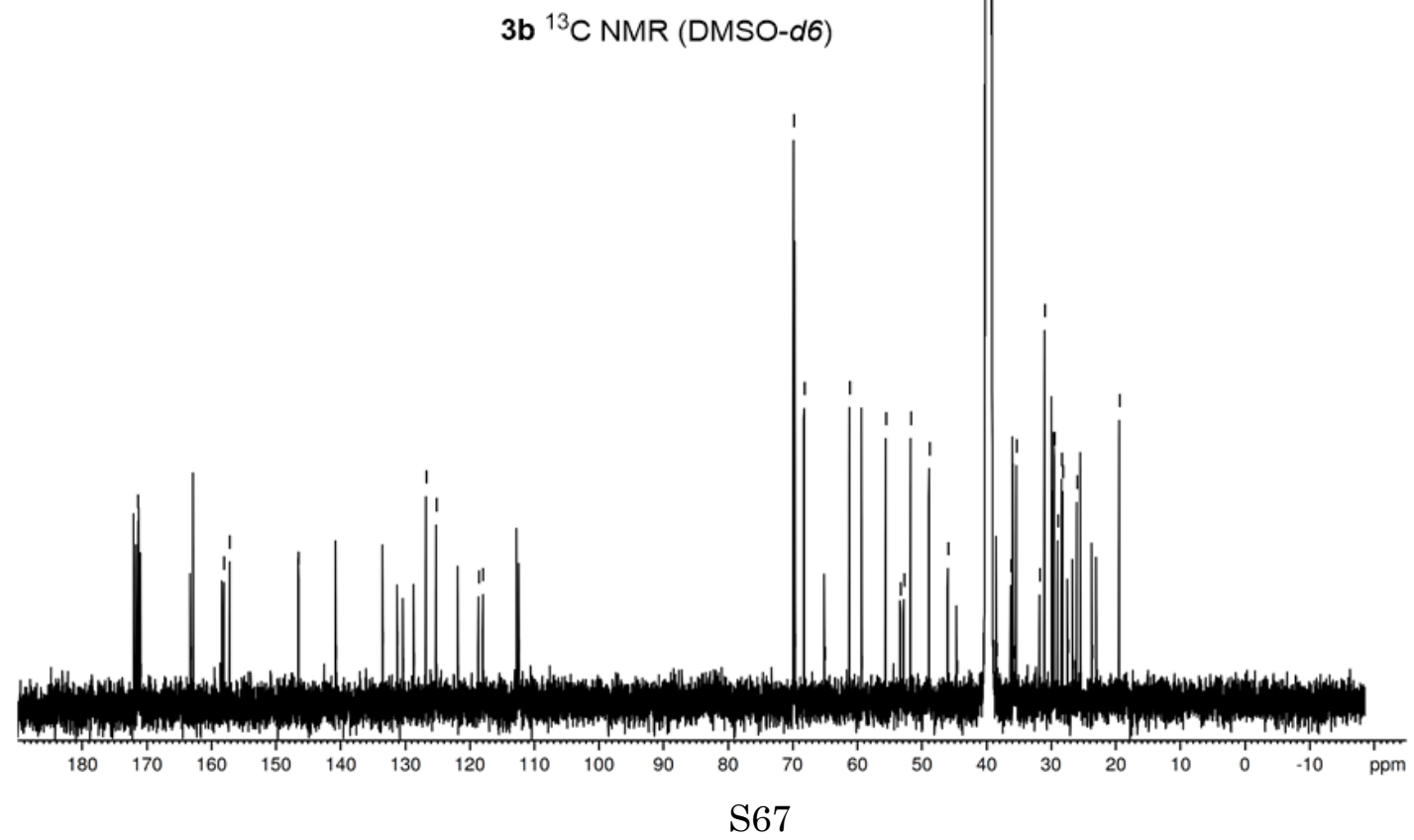




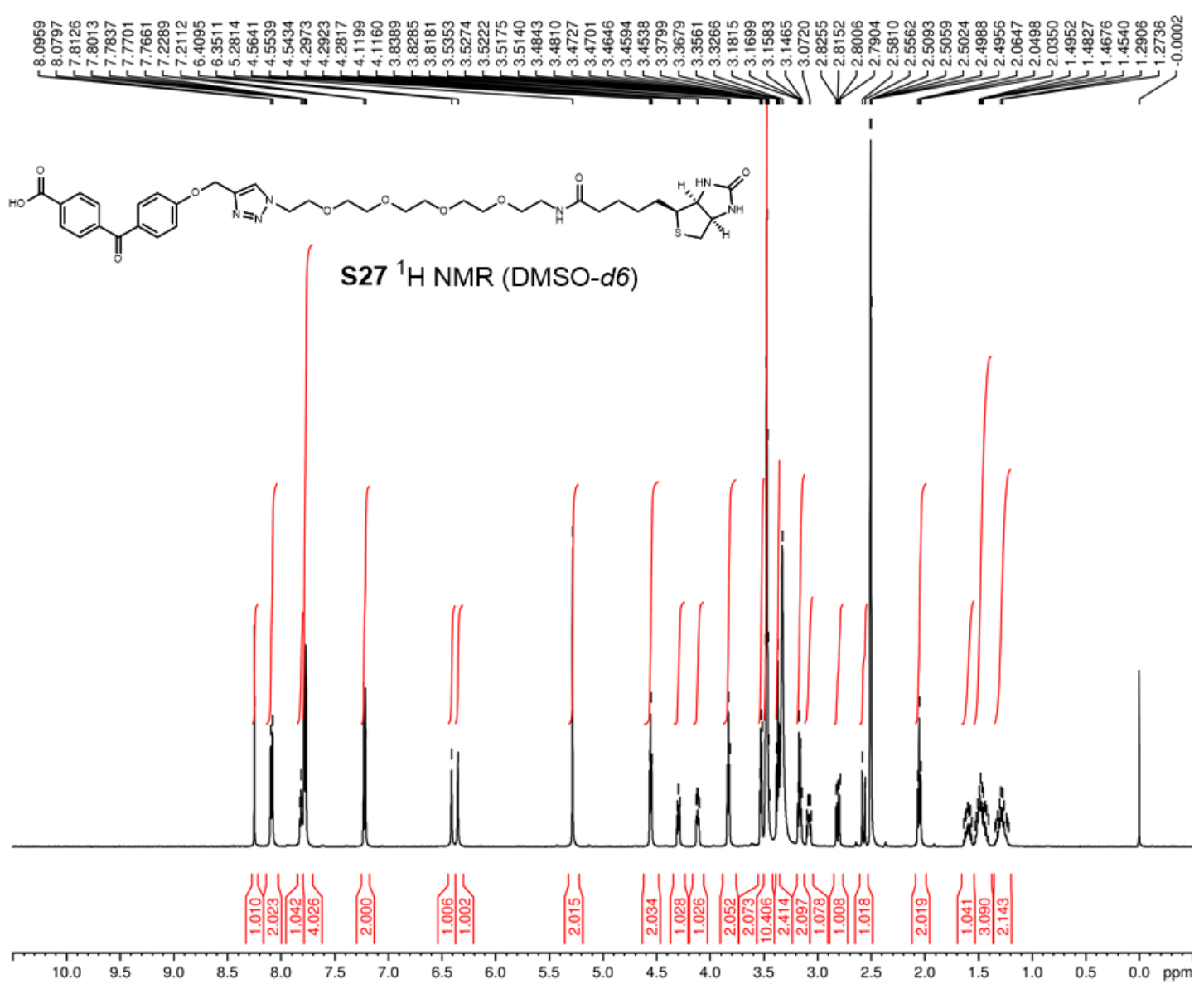

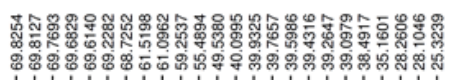

VVIVI |

$W V / 11 W=$

$\mathrm{S} 27{ }^{13} \mathrm{C}$ NMR (DMSO-d6)

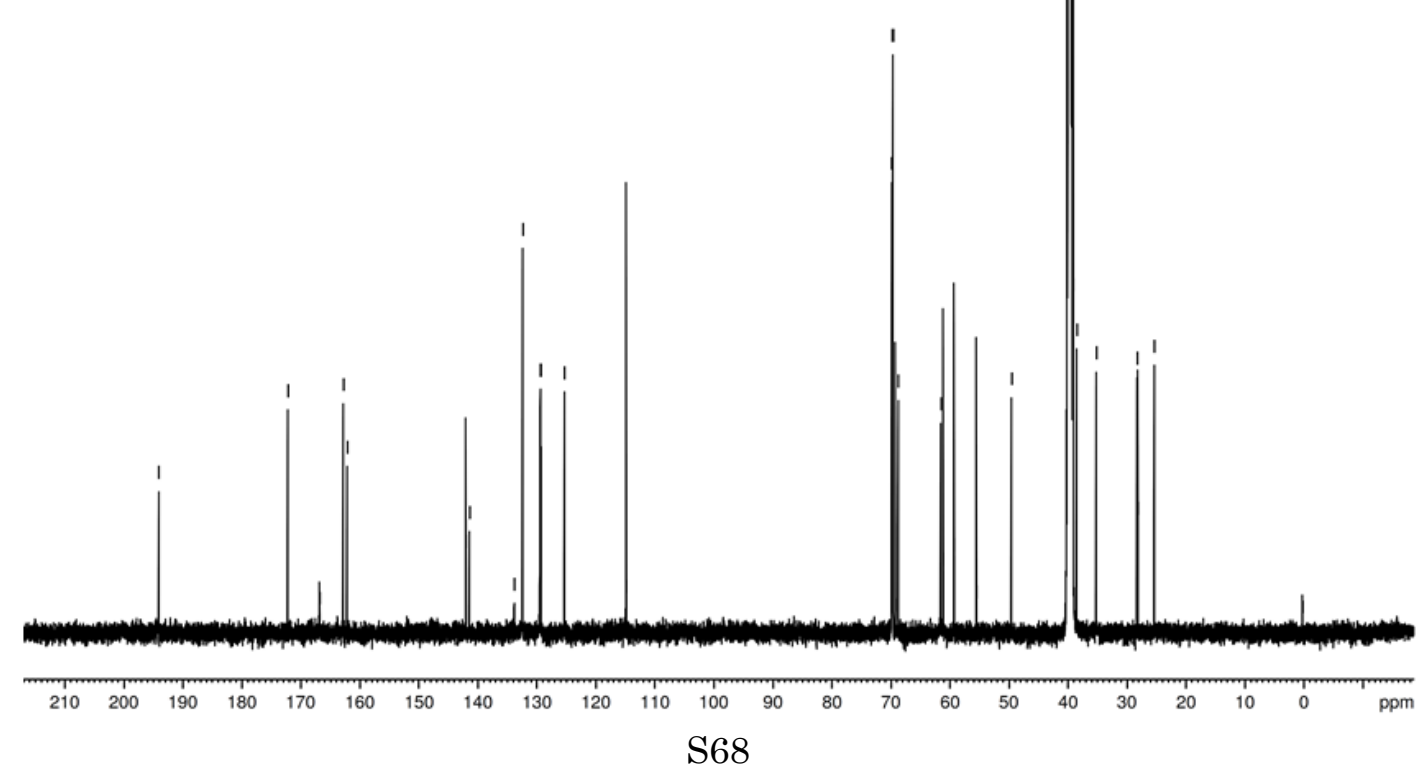




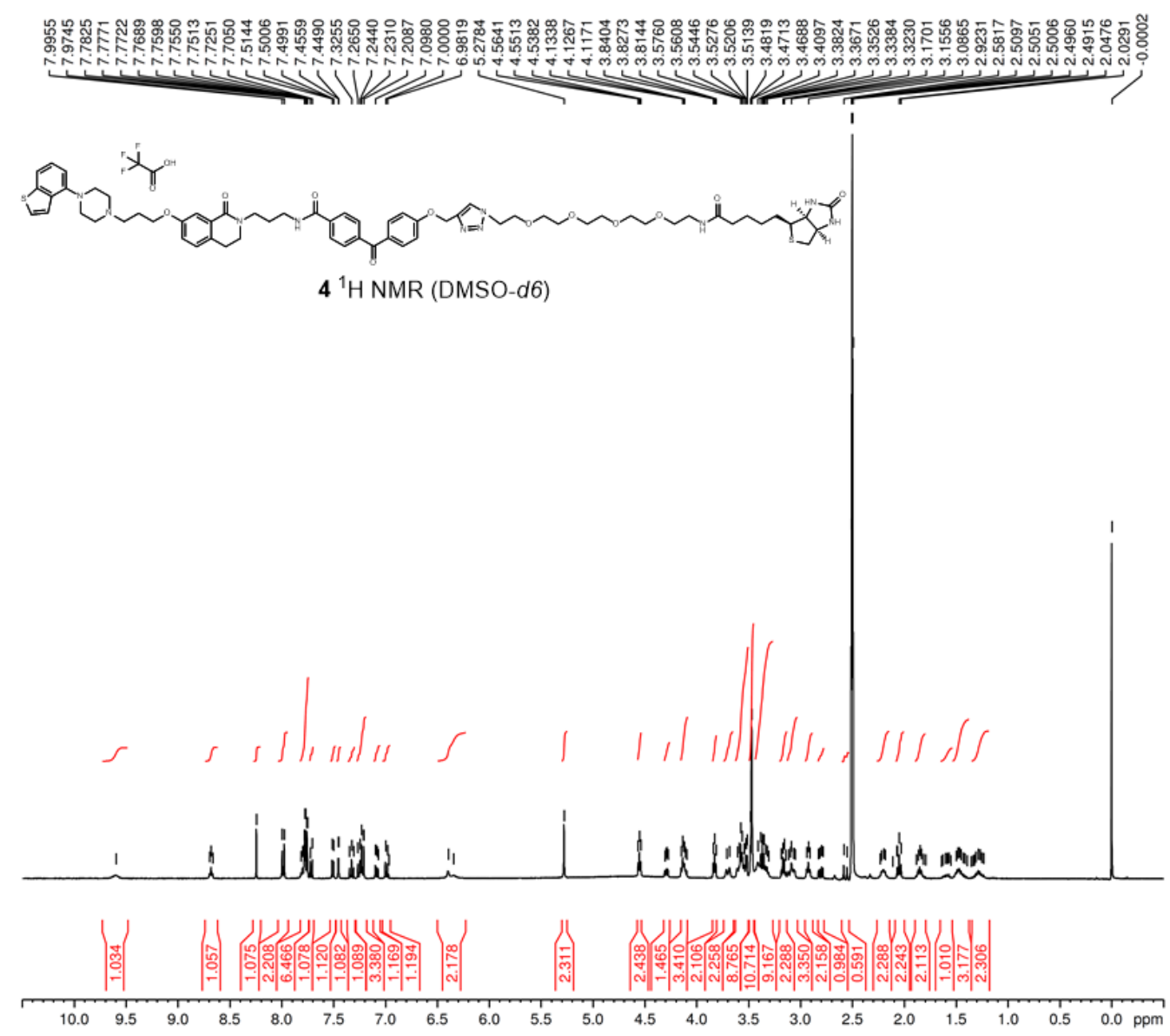

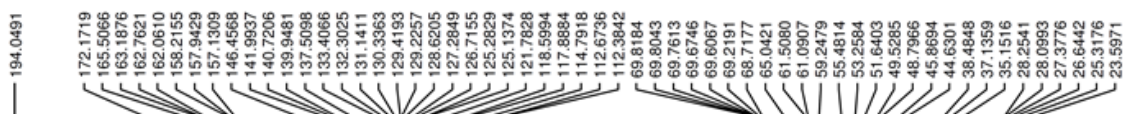

$4{ }^{13} \mathrm{C}$ NMR (DMSO-d6)

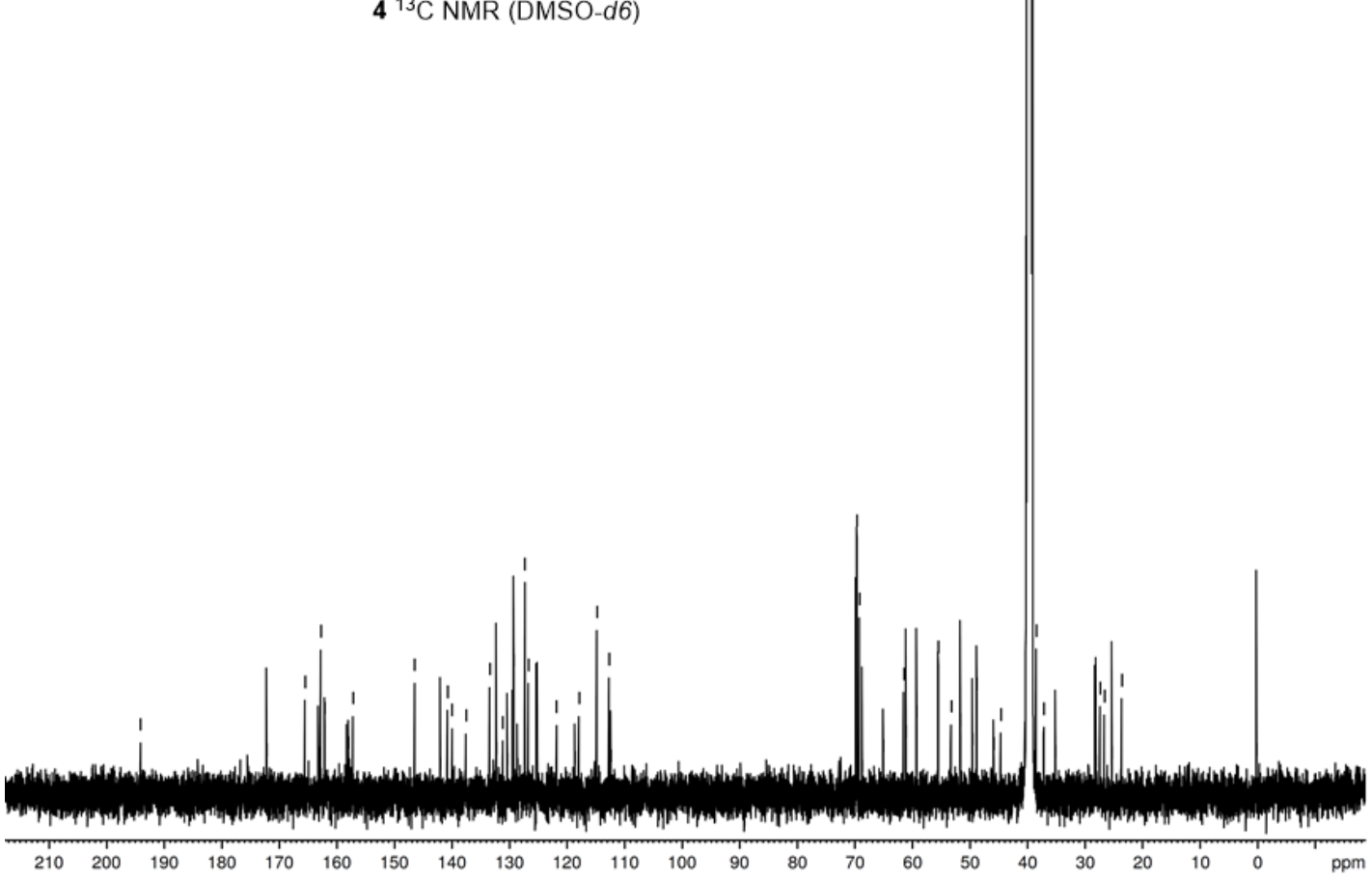




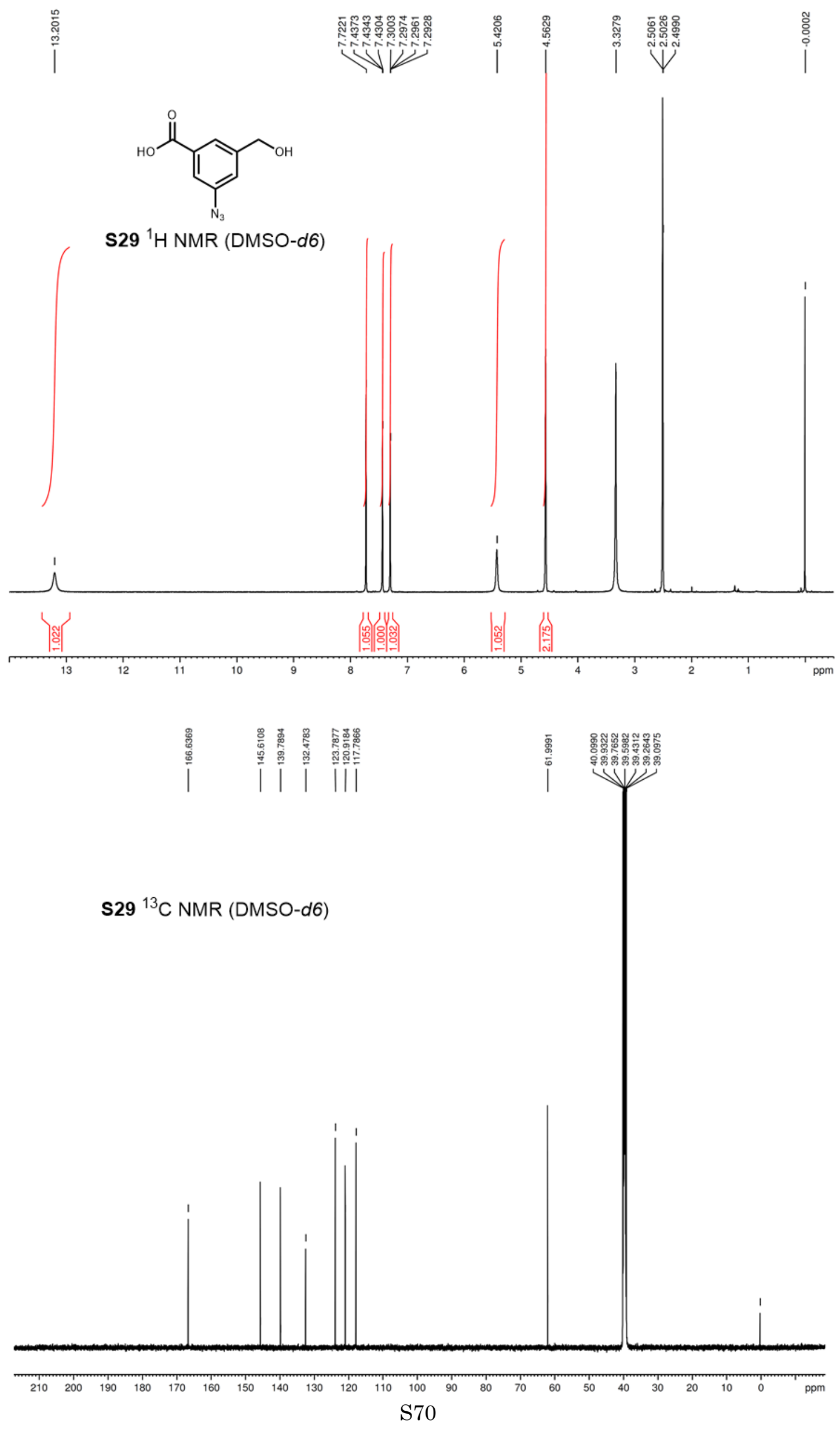


|
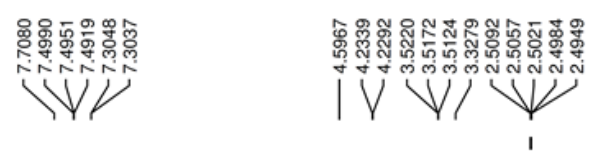

iั<smiles>C#CCOCc1cc(N)cc(C(=O)O)c1</smiles>

S30 ${ }^{1} \mathrm{H}$ NMR (DMSO-d6)

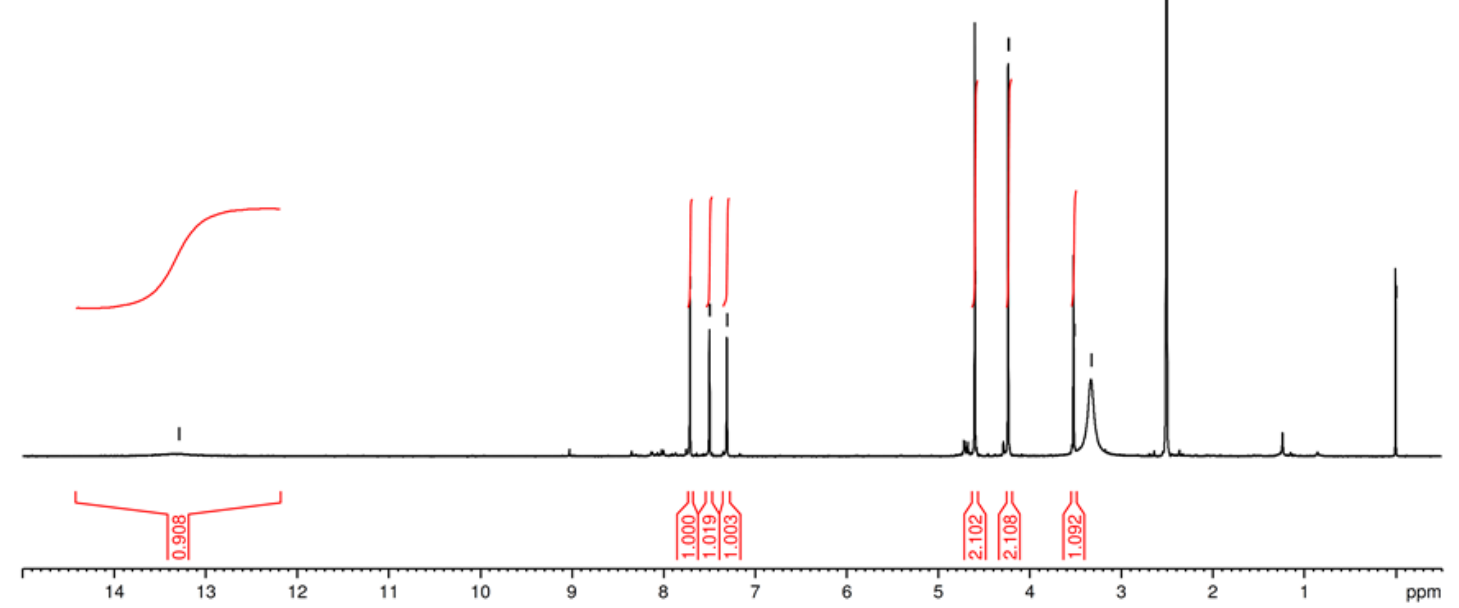

s30 ${ }^{13} \mathrm{C}$ NMR (DMSO-d6)

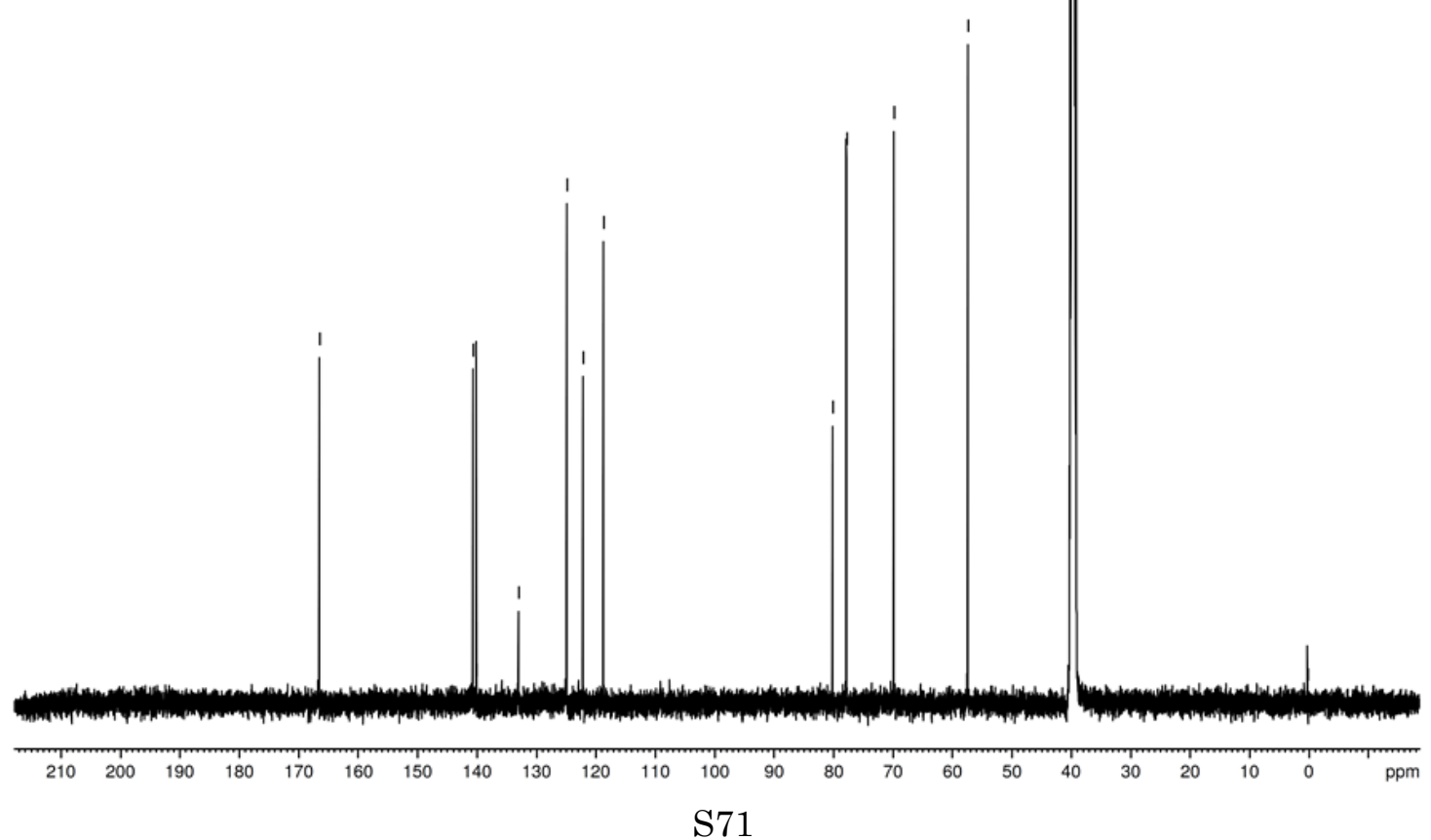




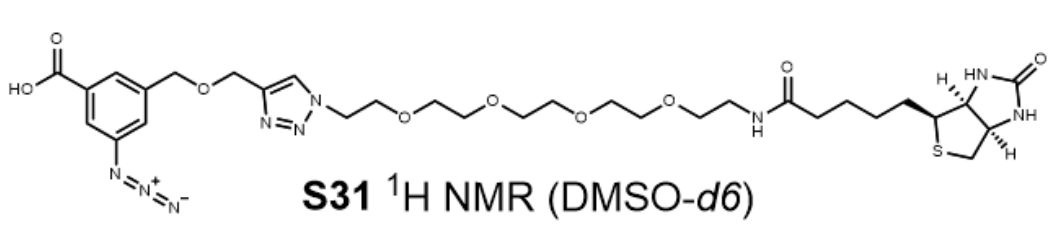

S31 ${ }^{1} \mathrm{H}$ NMR (DMSO-d6)

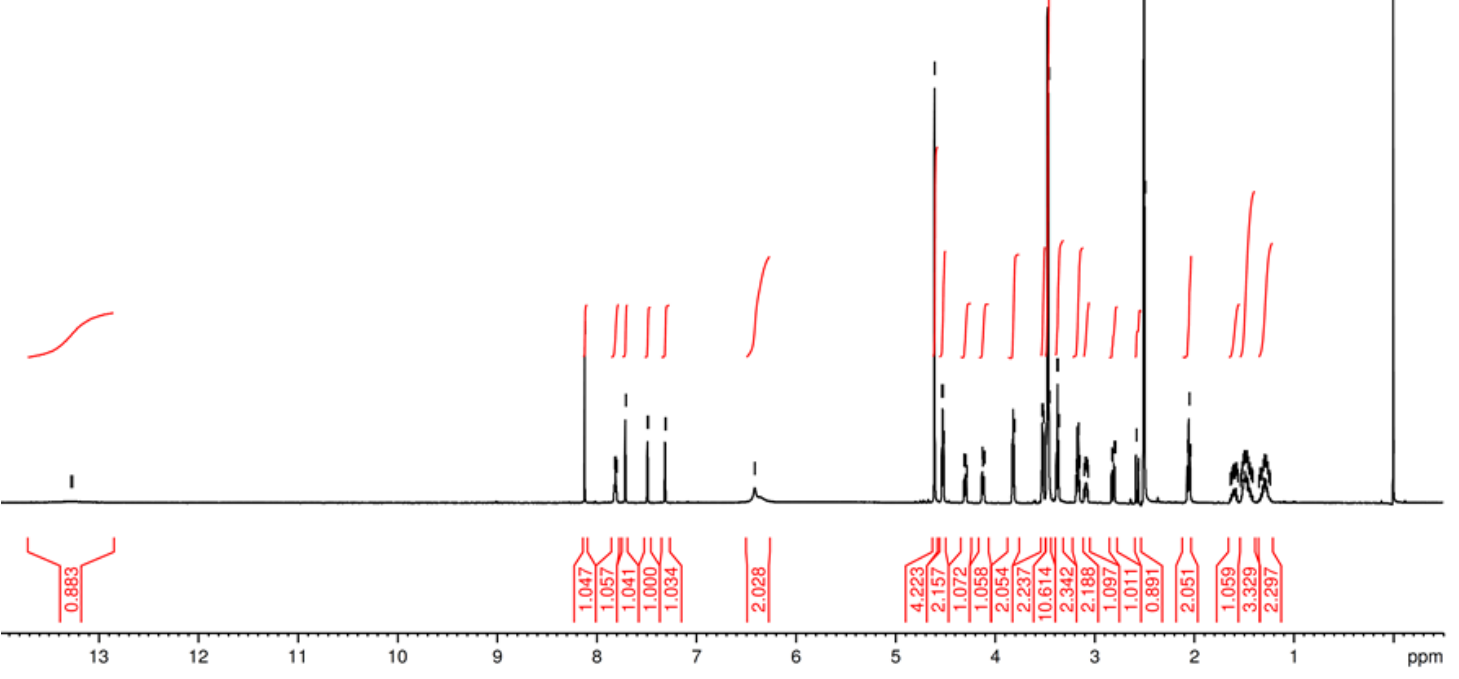

||

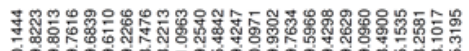

웅ㅎㅇ $+N 1111$ W 111

S31 ${ }^{13}$ C NMR (DMSO-d6)

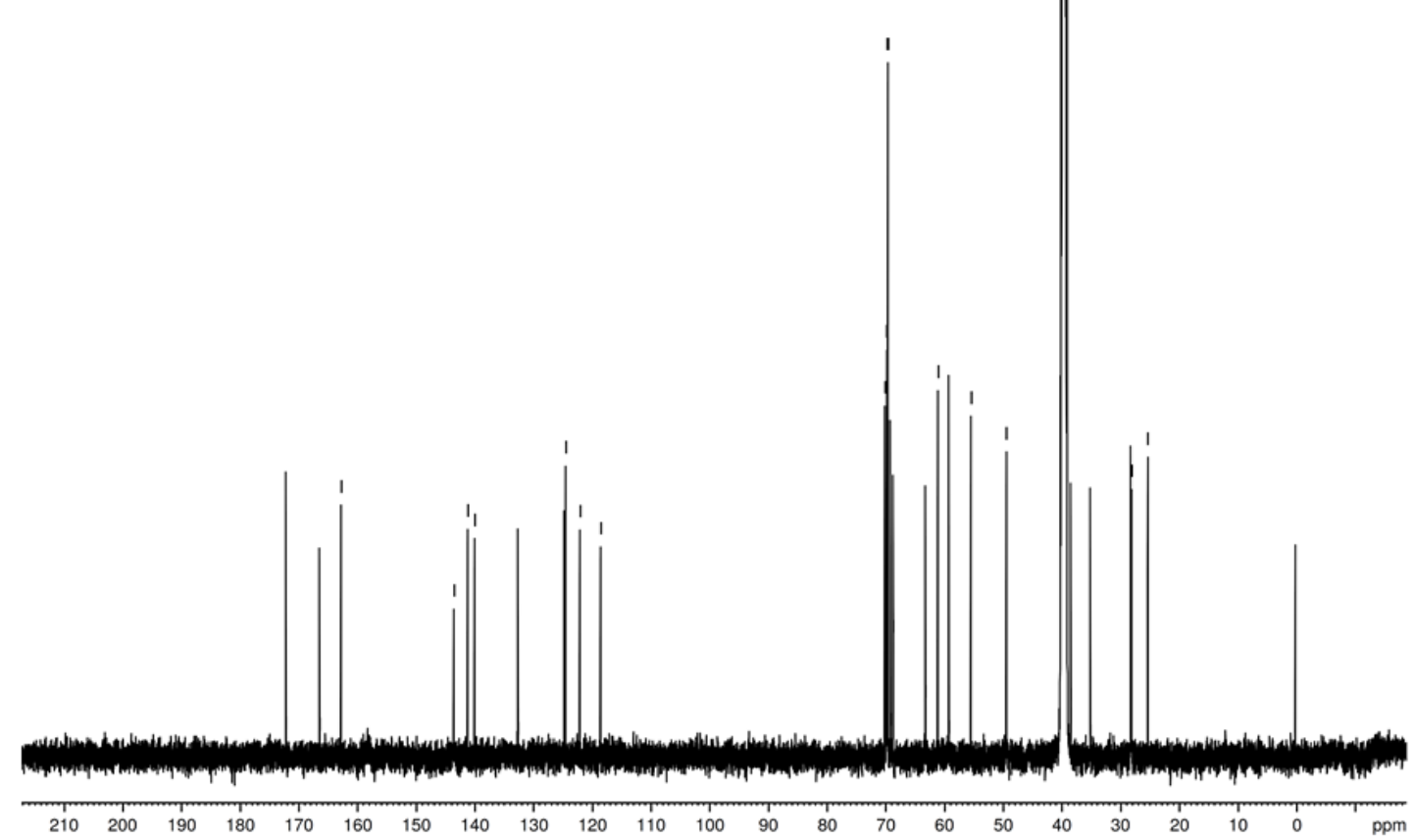




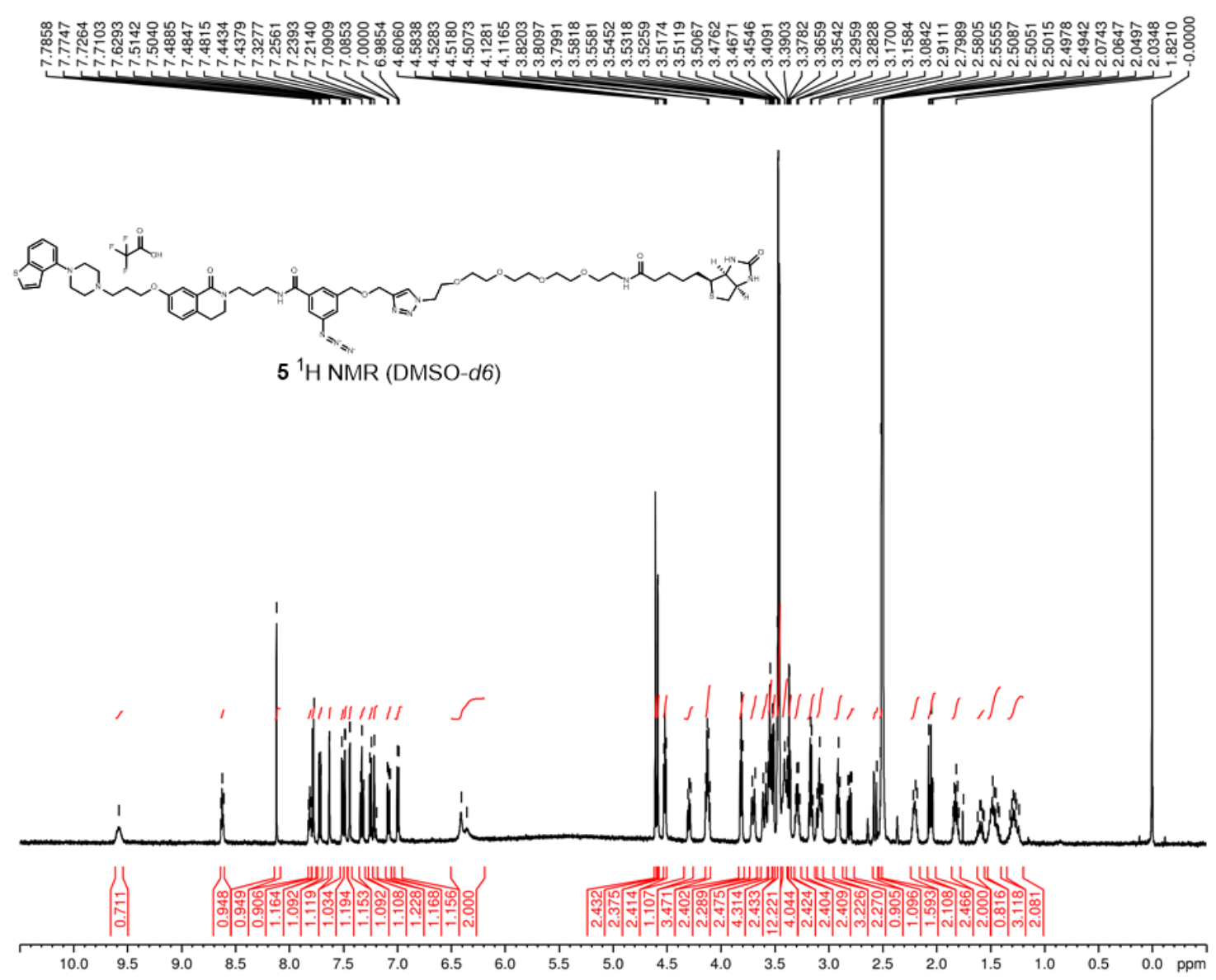

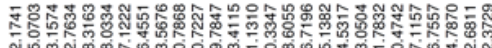

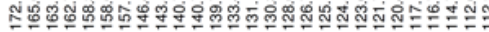

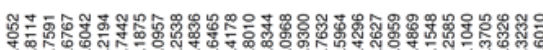

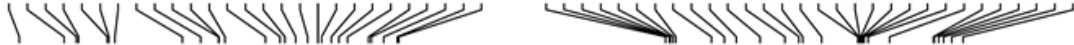

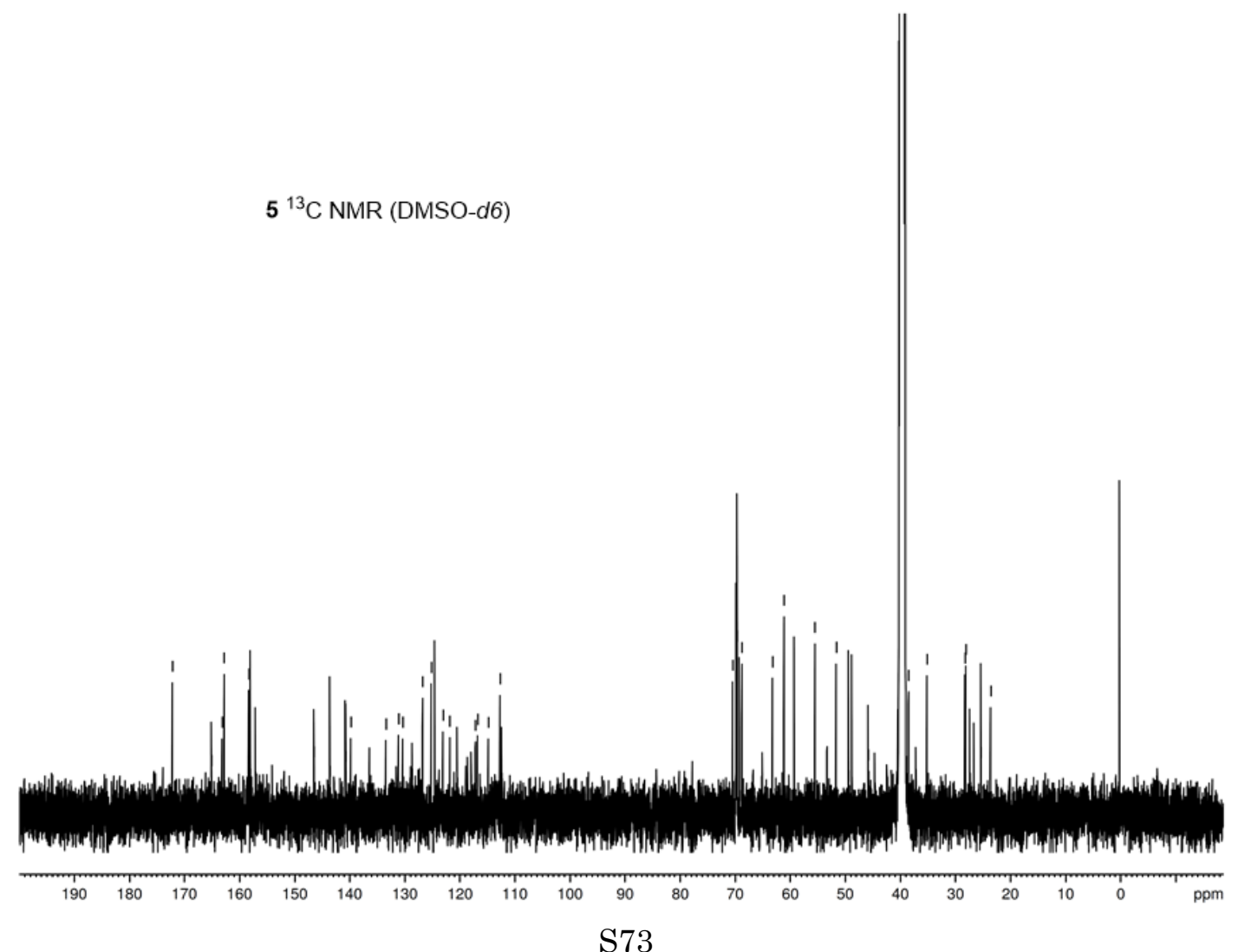



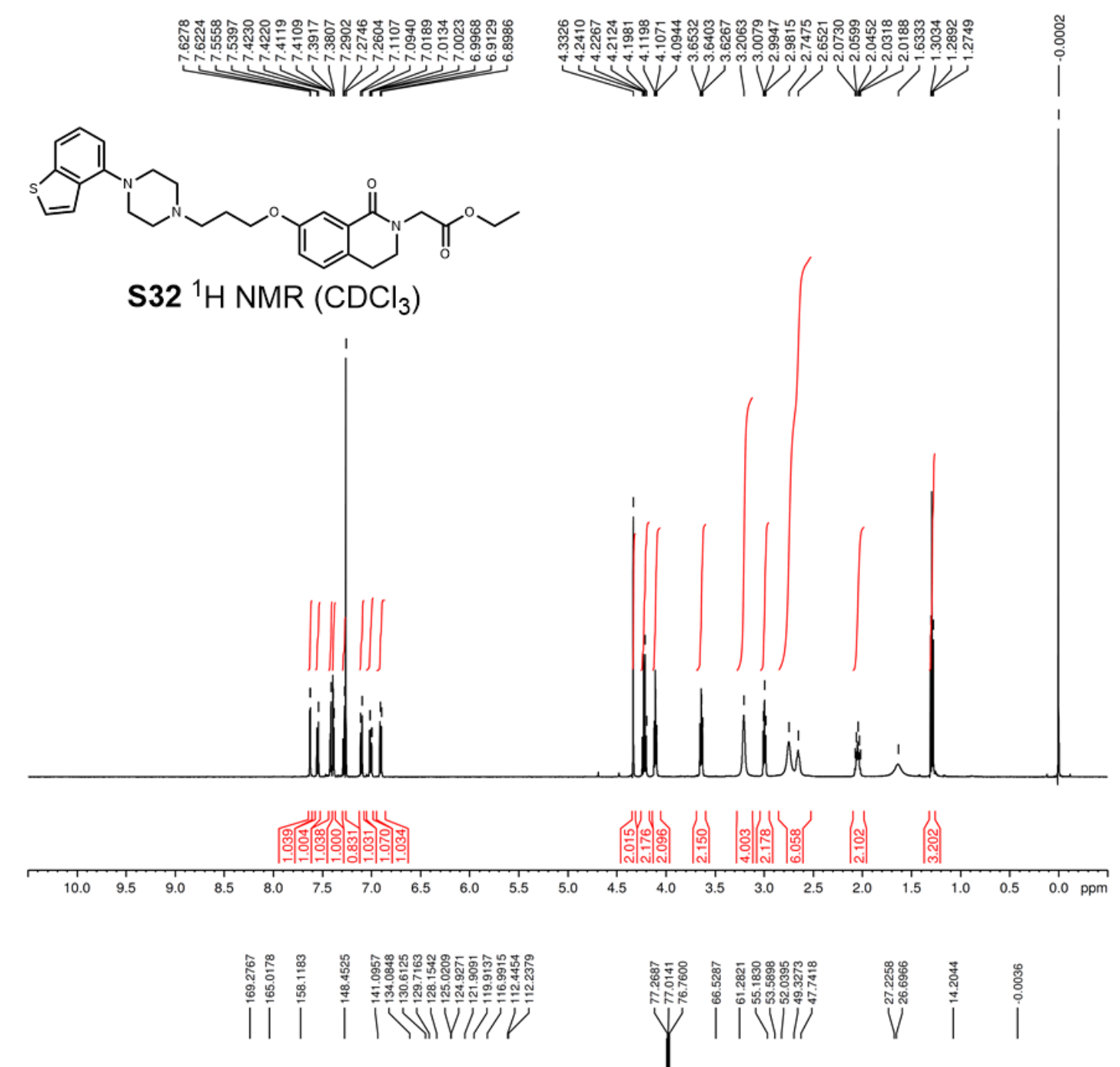

S32 ${ }^{13} \mathrm{C} \mathrm{NMR}\left(\mathrm{CDCl}_{3}\right)$

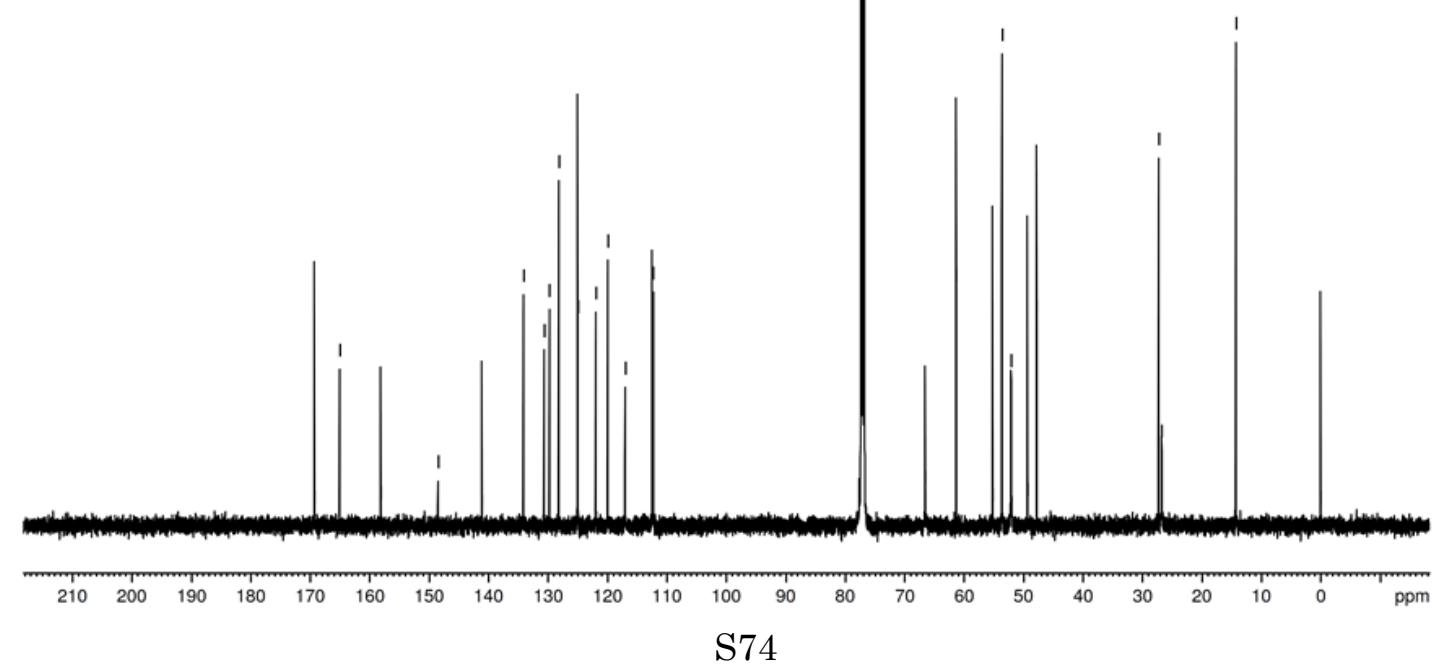



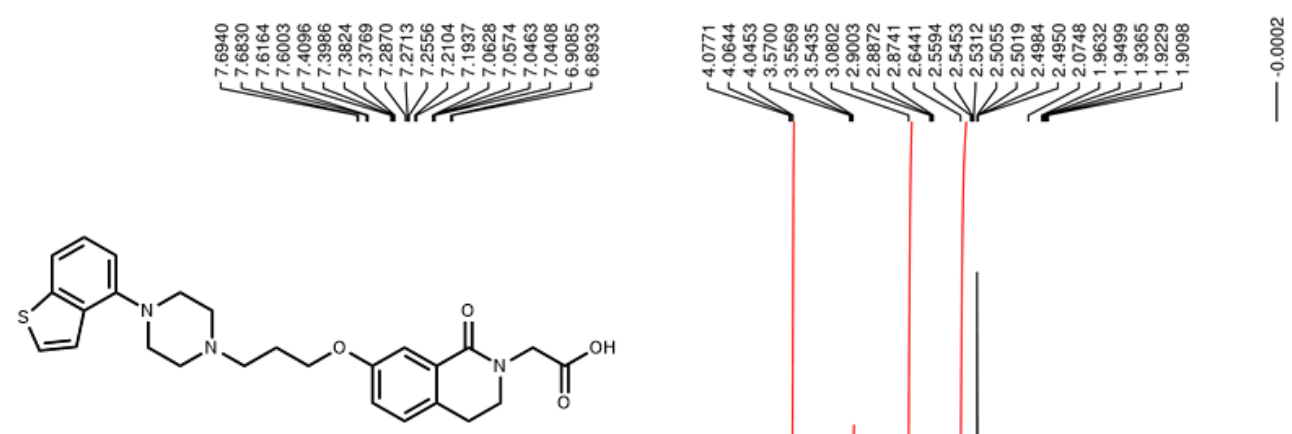

S33 ${ }^{1} \mathrm{H}$ NMR (DMSO- $d 6$ )
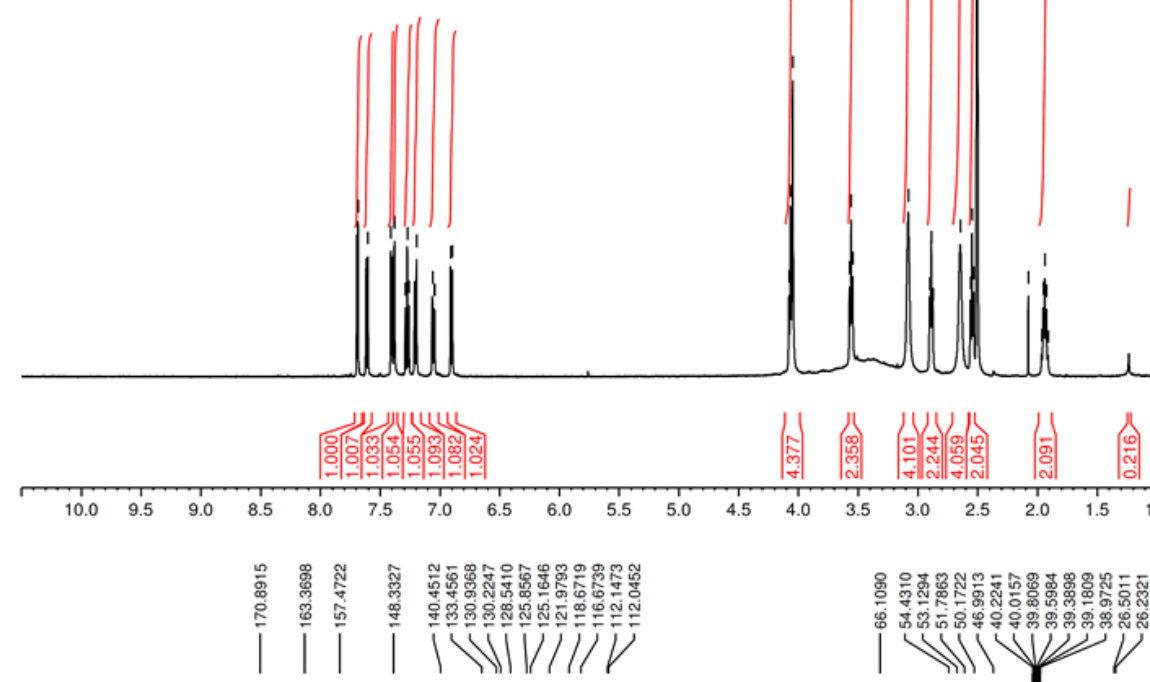

S33 ${ }^{13} \mathrm{C}$ NMR (DMSO-d6)

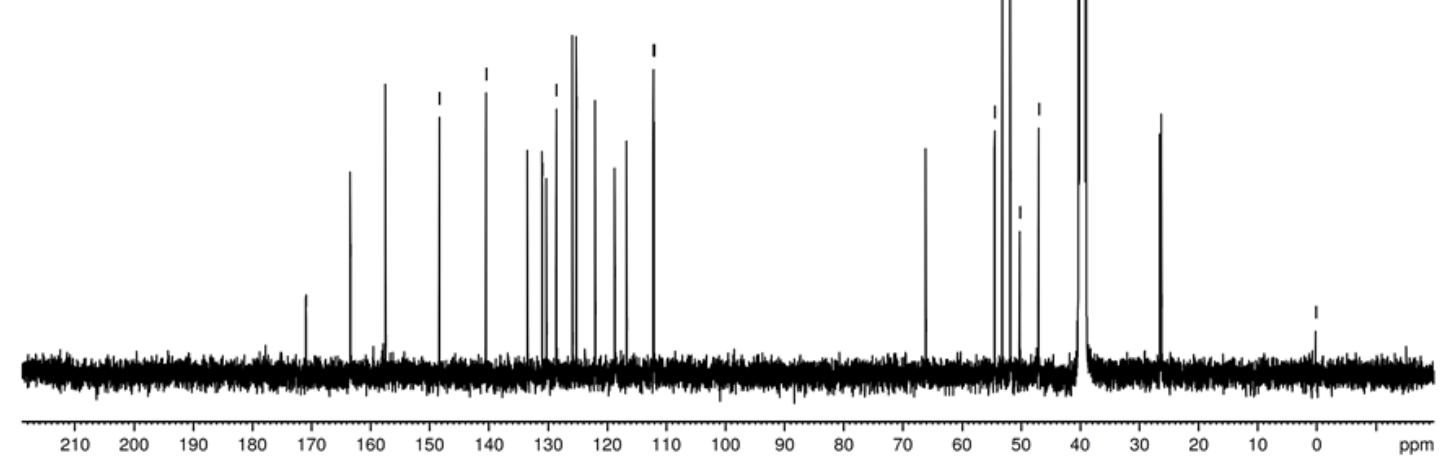




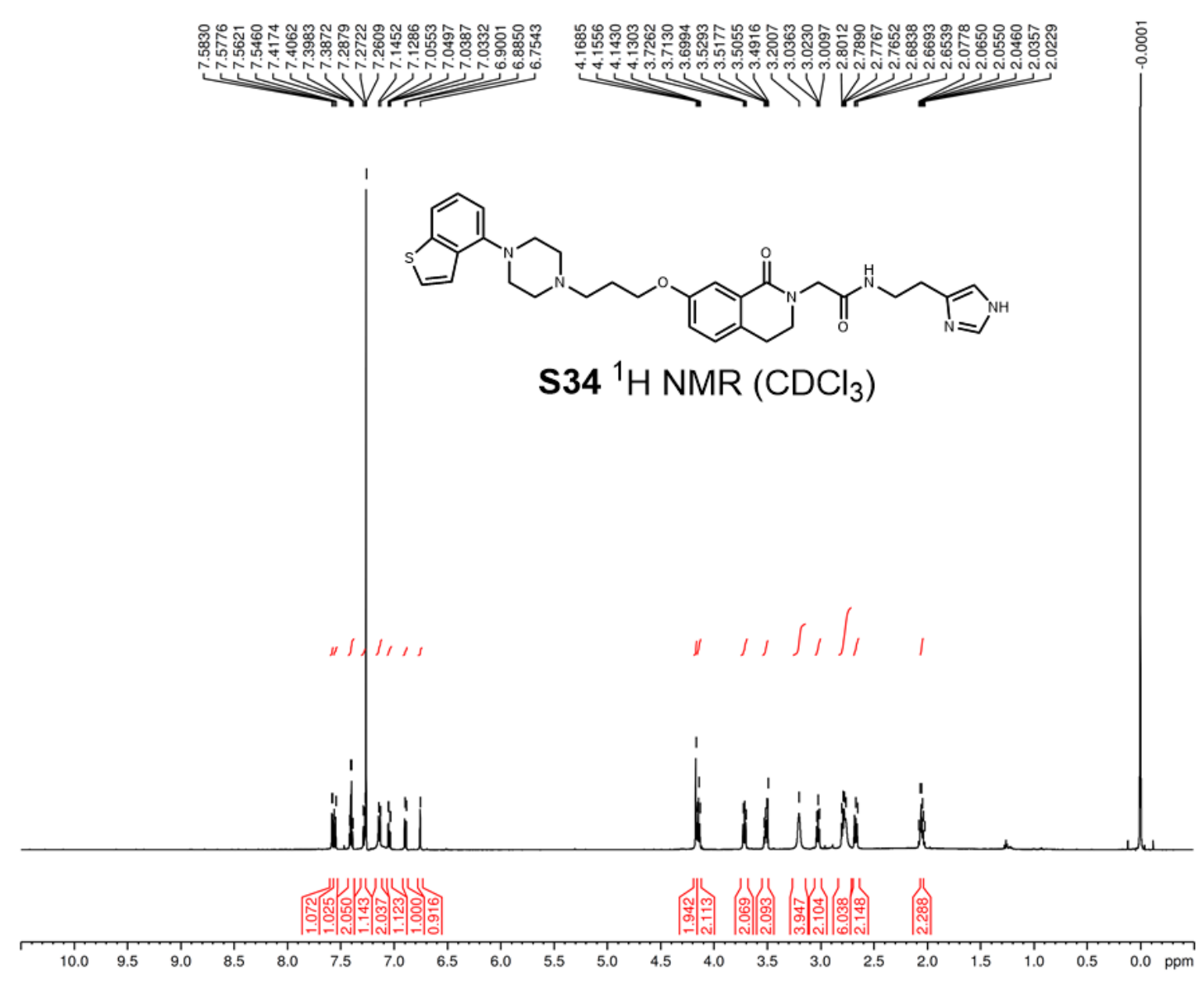

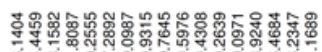 \\ 3. \\ I MW W V I}

S34 ${ }^{13} \mathrm{C}$ NMR (DMSO-d6)

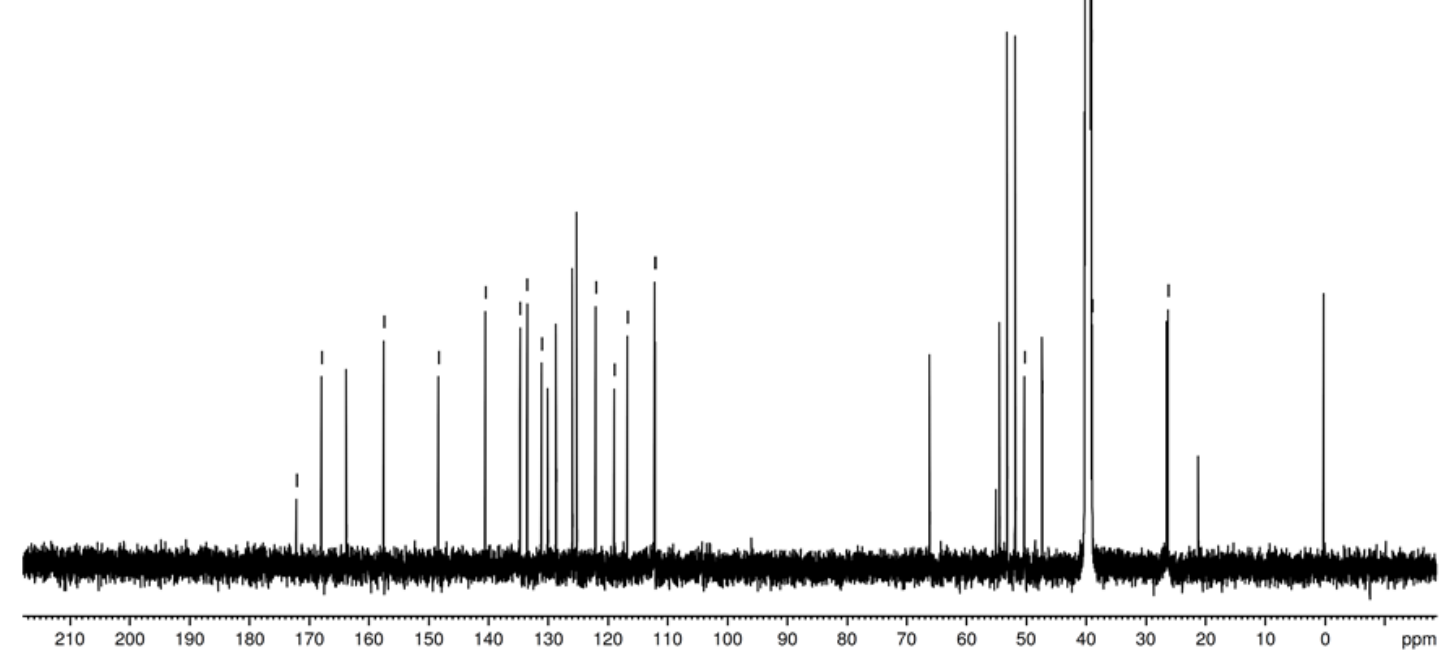




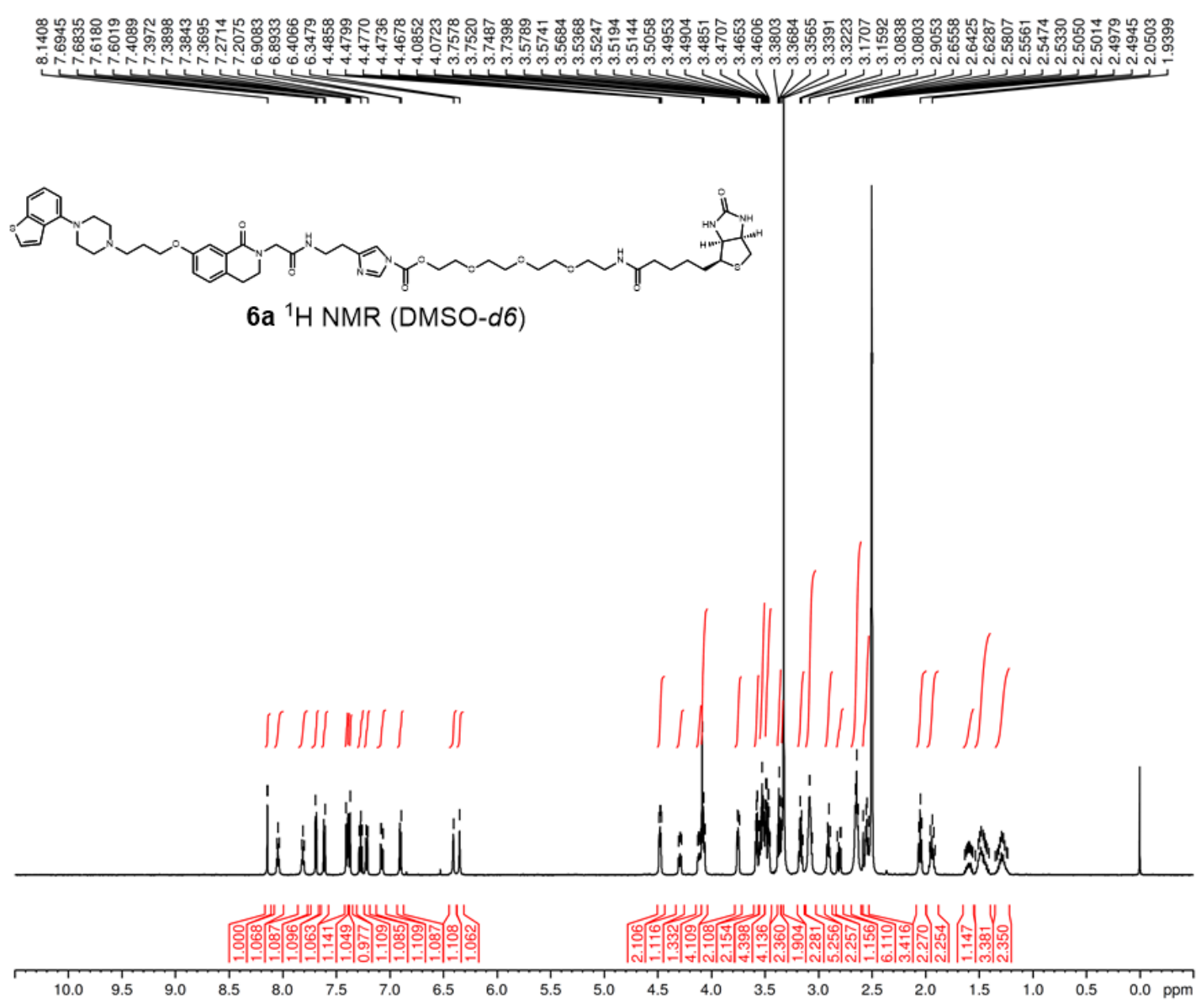

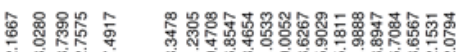

N

iII T UIMIIIIIIIV

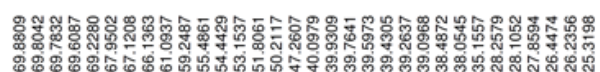

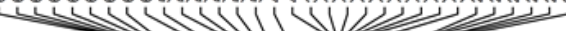

$6 a^{13} \mathrm{C}$ NMR (DMSO-d6)

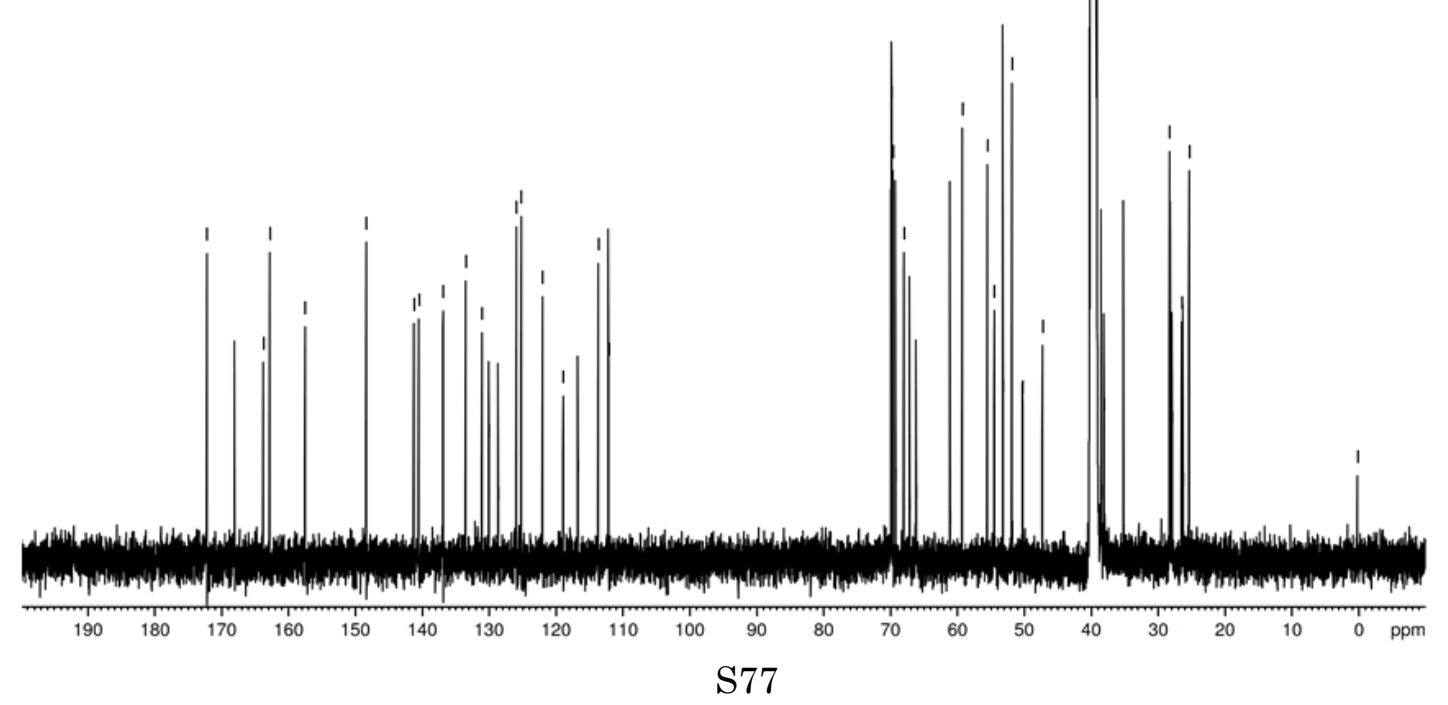



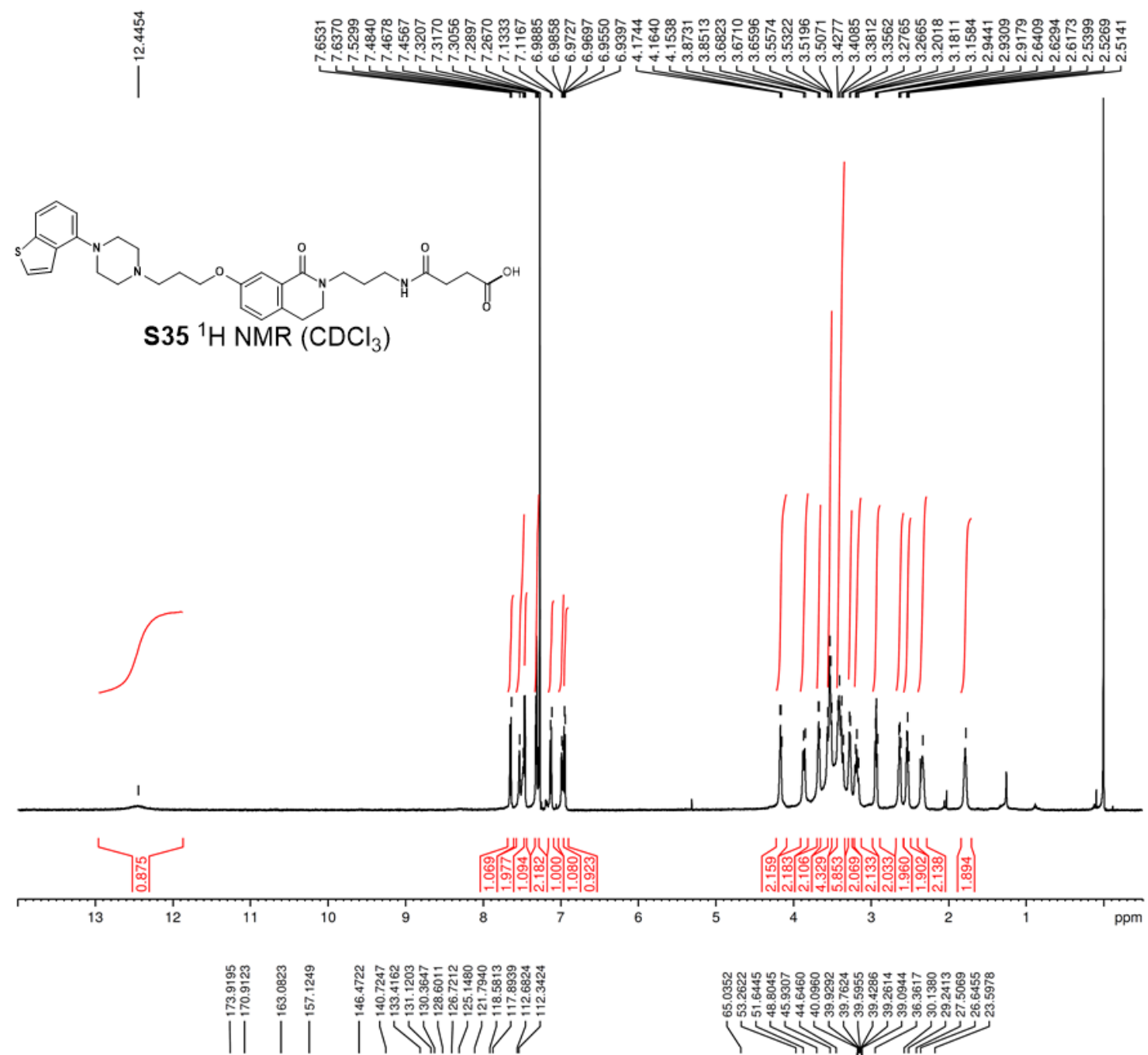

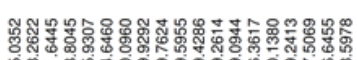

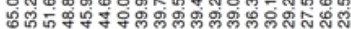

$\underbrace{-10}$

S35 ${ }^{13} \mathrm{C}$ NMR (DMSO-d6)

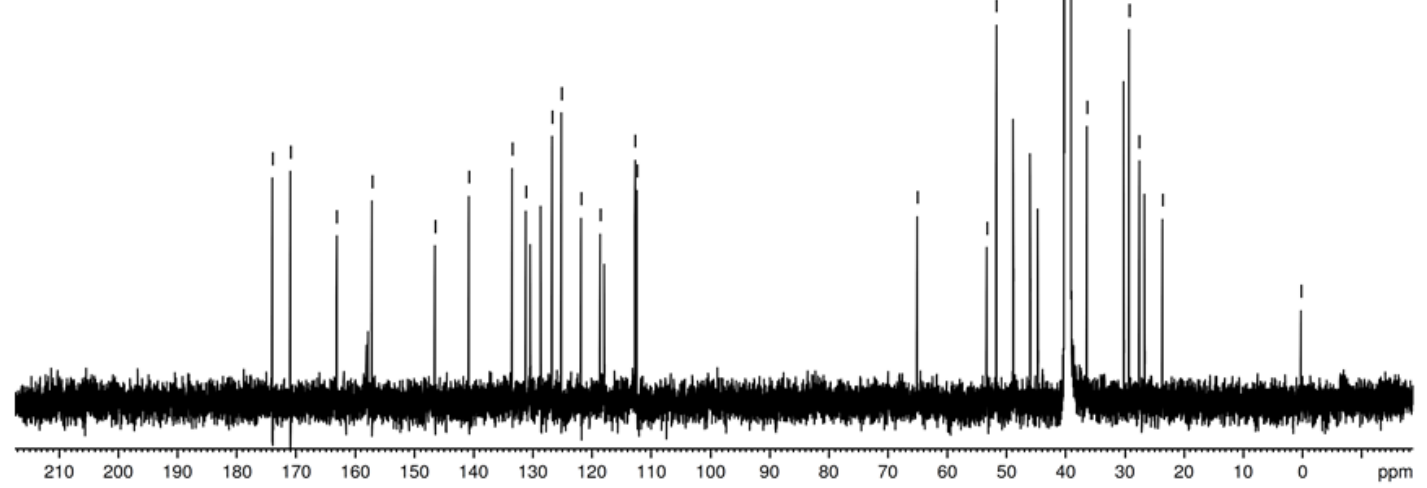



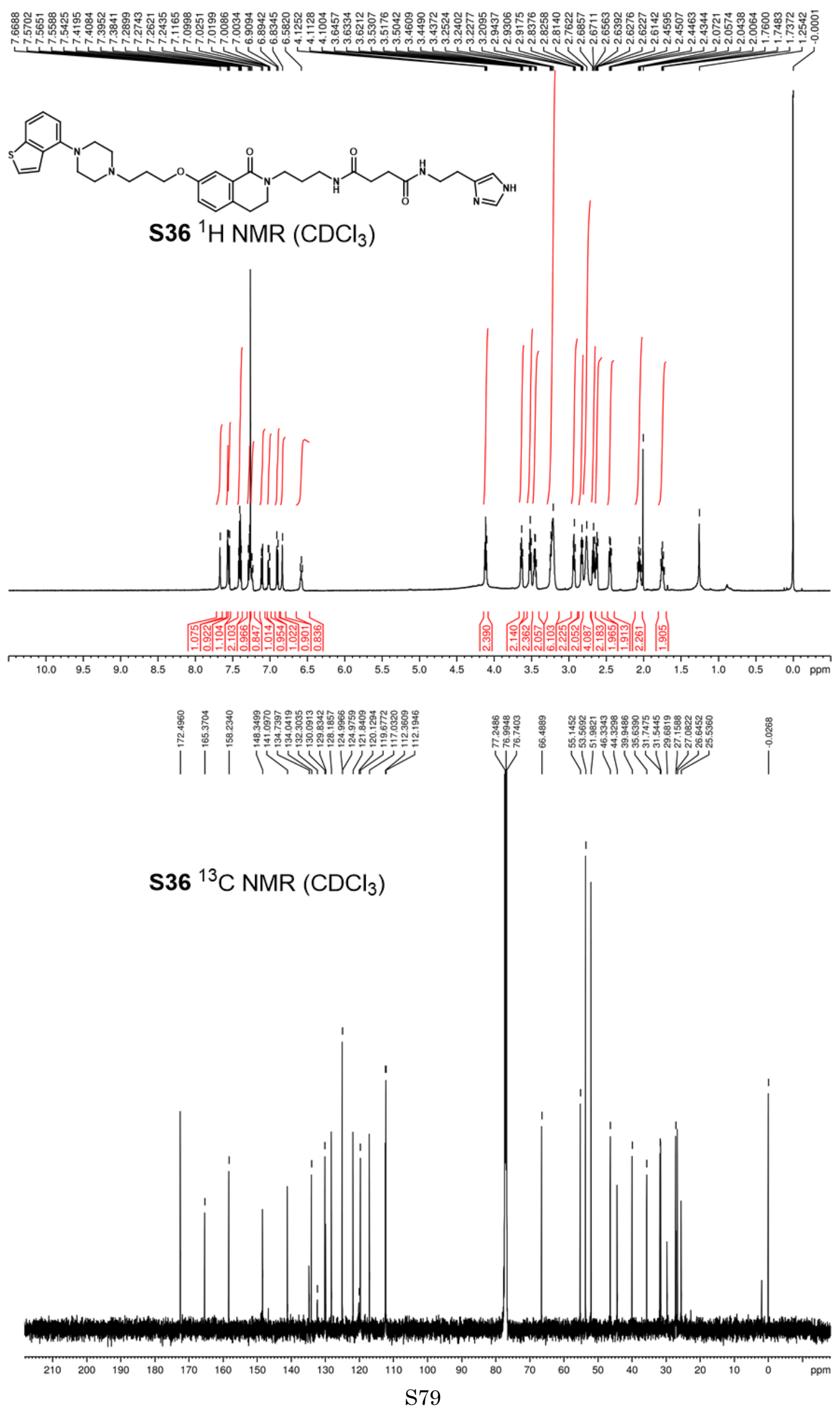


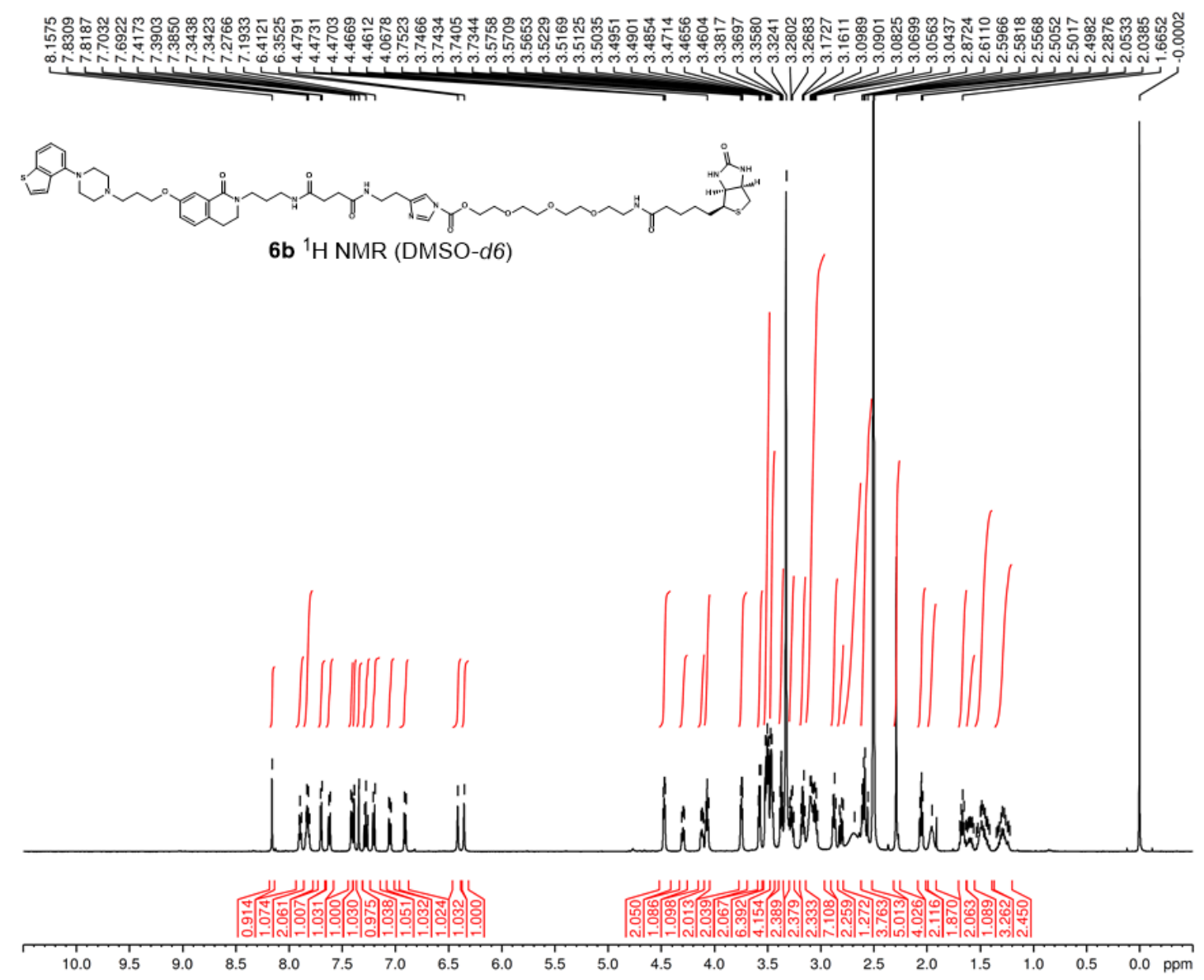

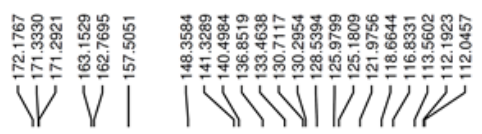

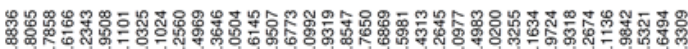

ஆั

6b ${ }^{13} \mathrm{C}$ NMR (DMSO-d6)

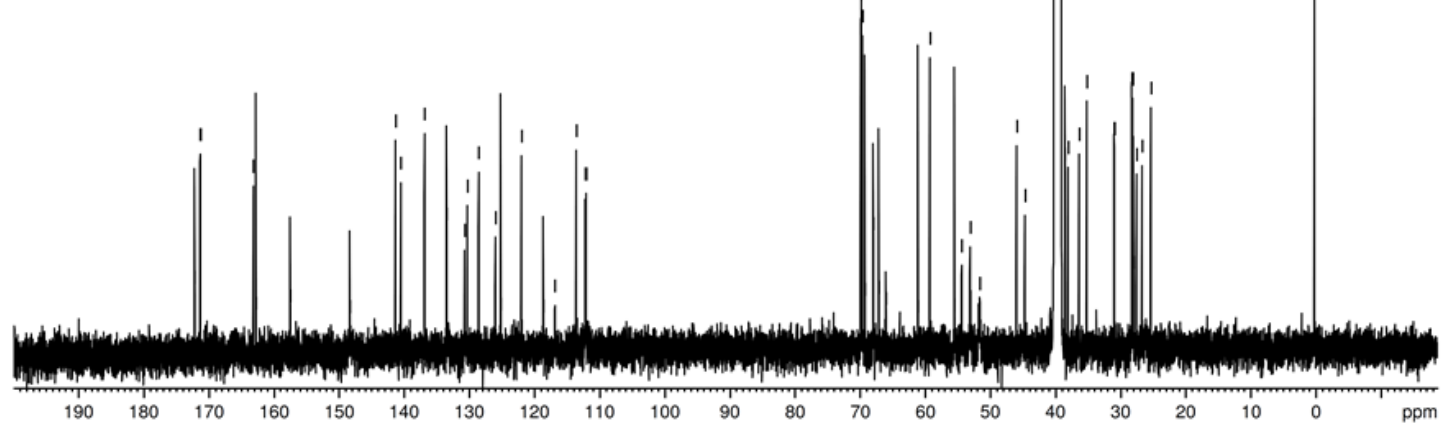




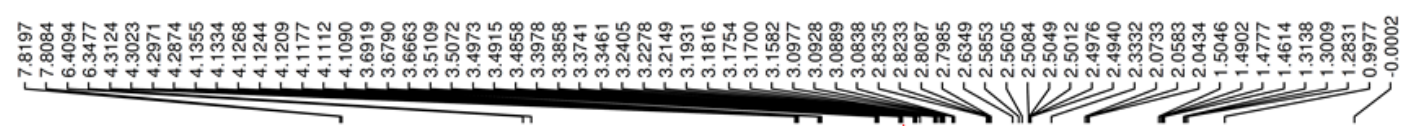

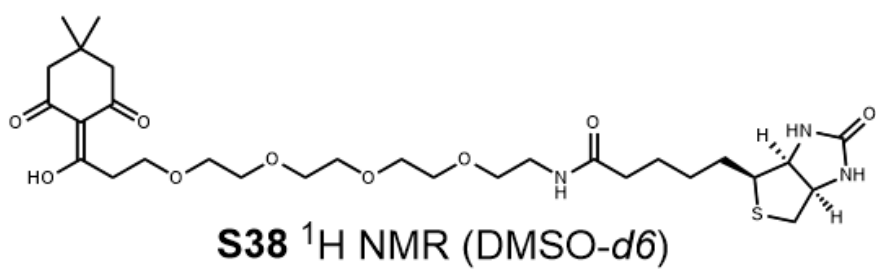

S38 ${ }^{1} \mathrm{H}$ NMR (DMSO-d6)

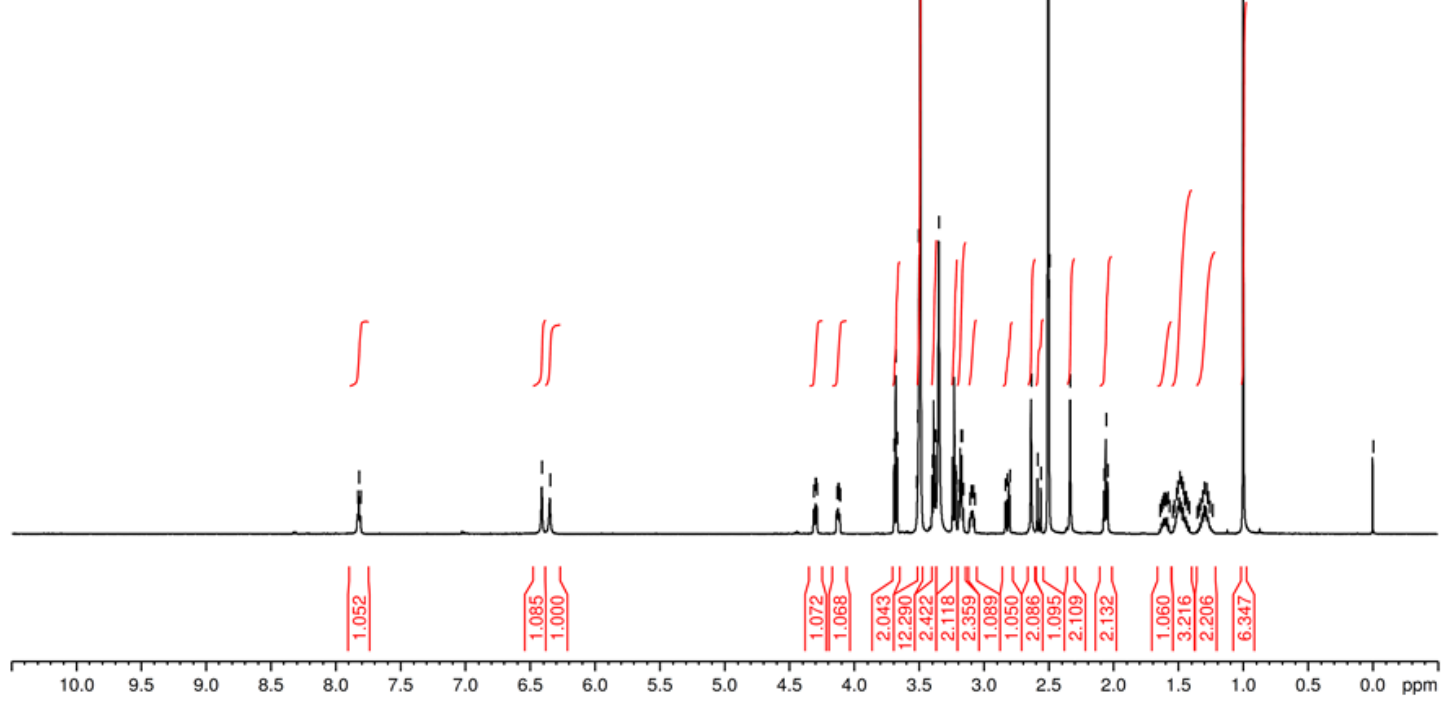

||

S38 ${ }^{13} \mathrm{C}$ NMR (DMSO-d6)

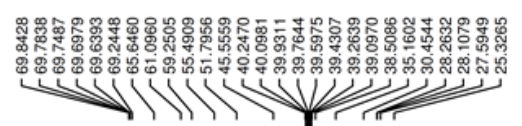

|

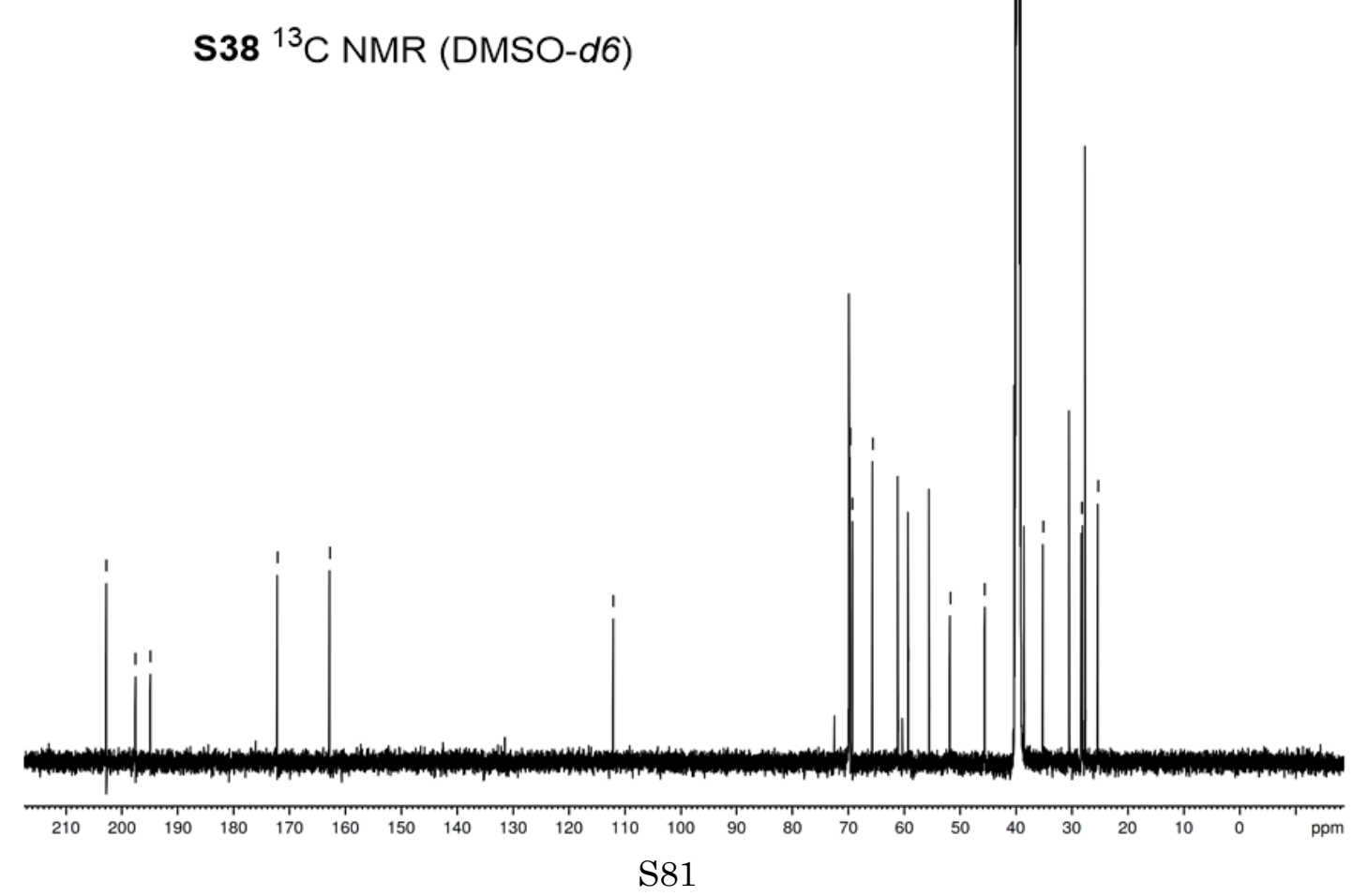



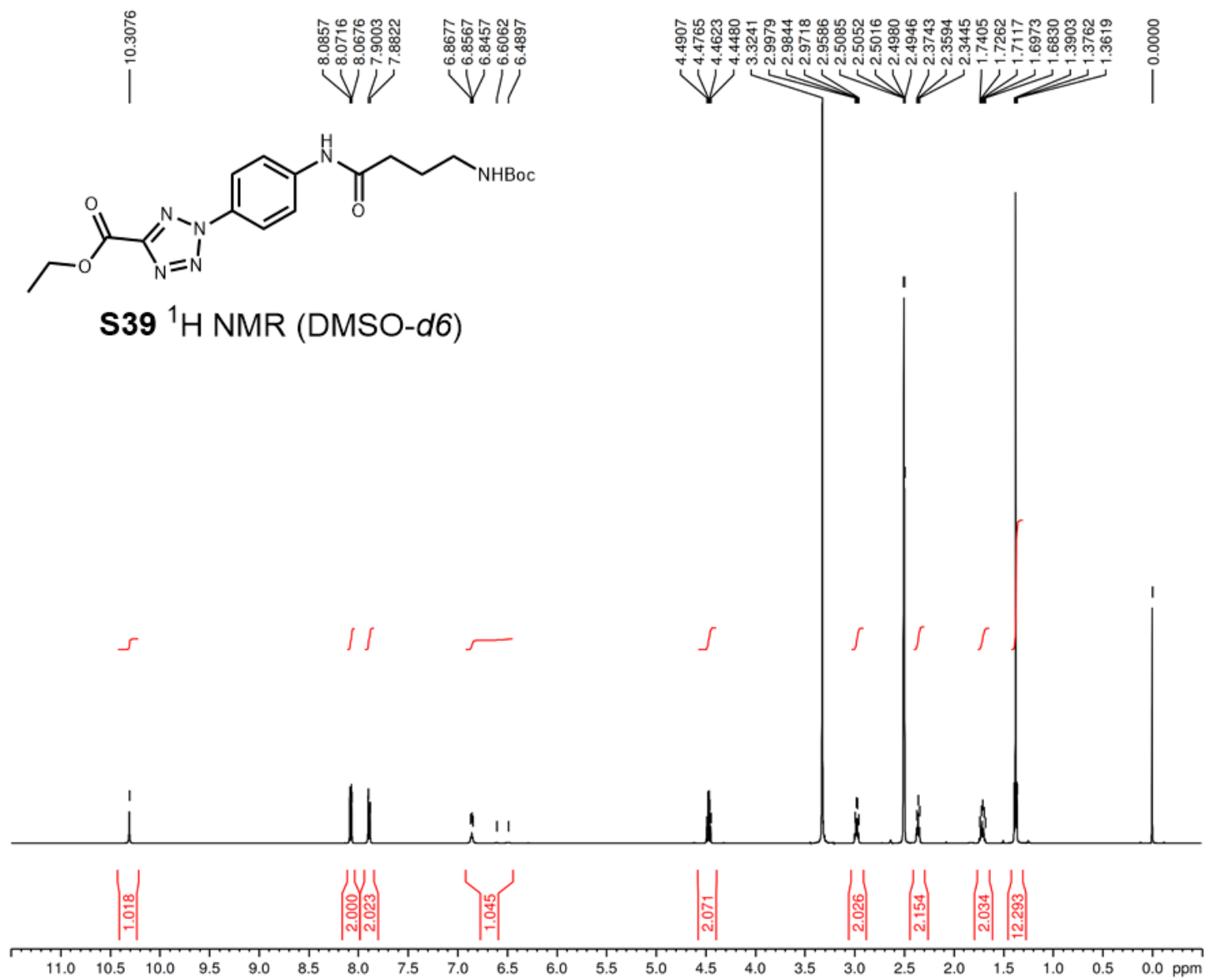
|

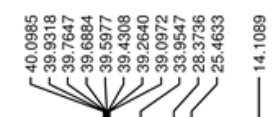

S39 ${ }^{13} \mathrm{C}$ NMR (DMSO-d6)

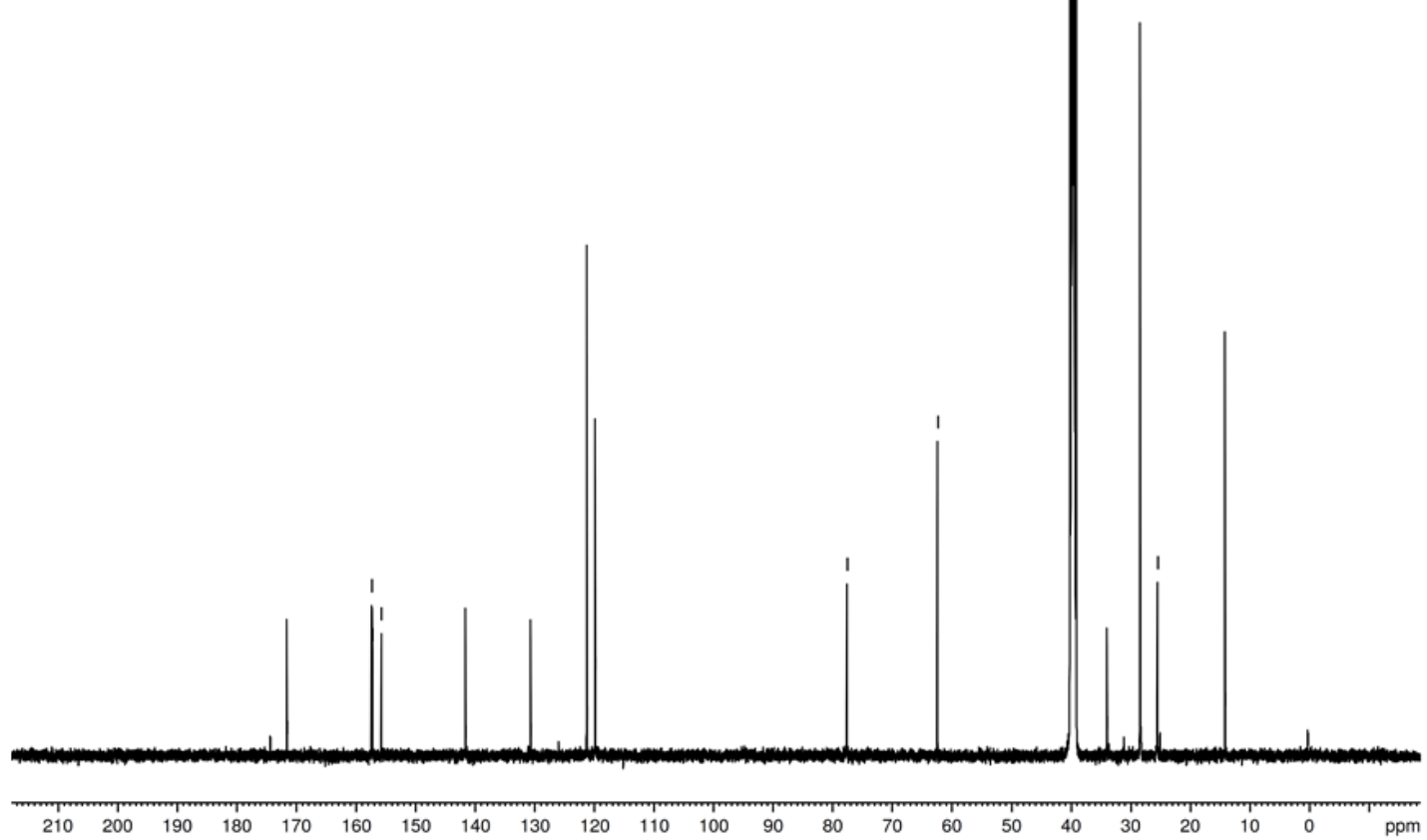


|

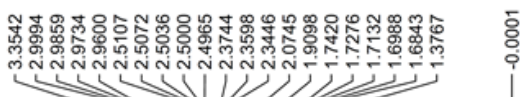<smiles>NCCCCC(=O)Nc1ccc(-n2nnc(C(=O)O)n2)cc1</smiles>

S40 ${ }^{1} \mathrm{H}$ NMR (DMSO-d6)

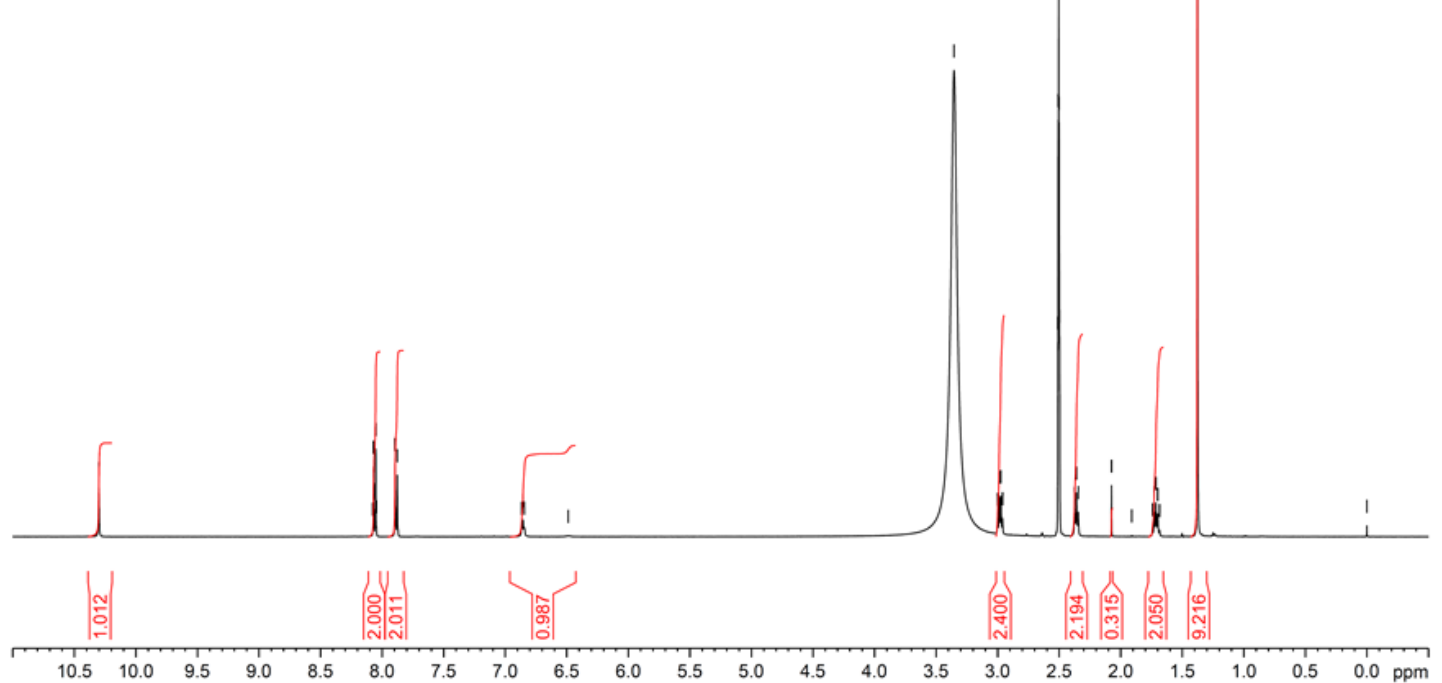

|

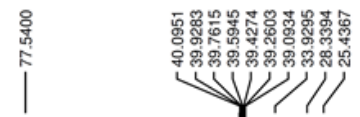

S40 ${ }^{13} \mathrm{C}$ NMR (DMSO-d6)

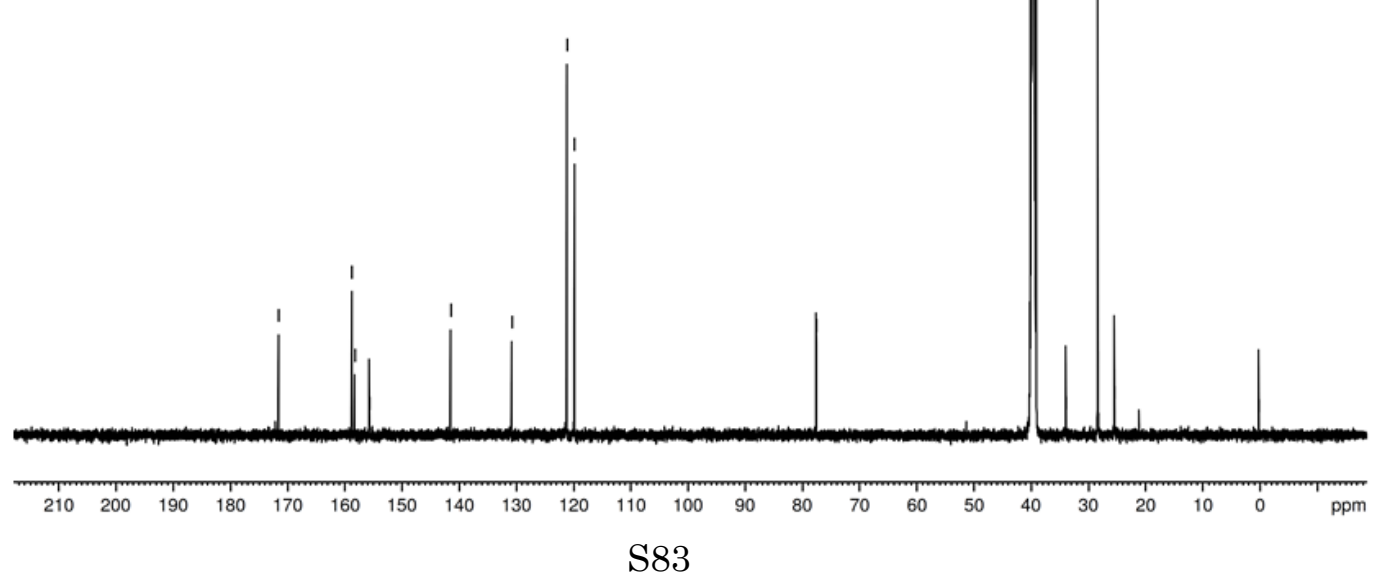




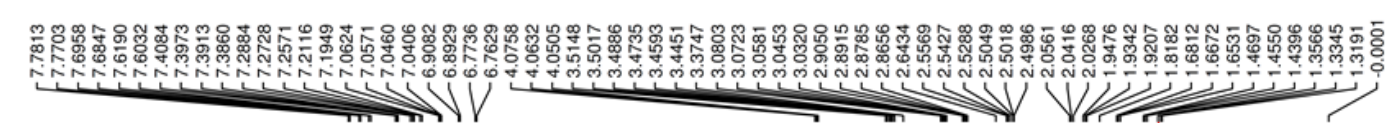

(c)

S41 ${ }^{1} \mathrm{H}$ NMR (DMSO-d6)

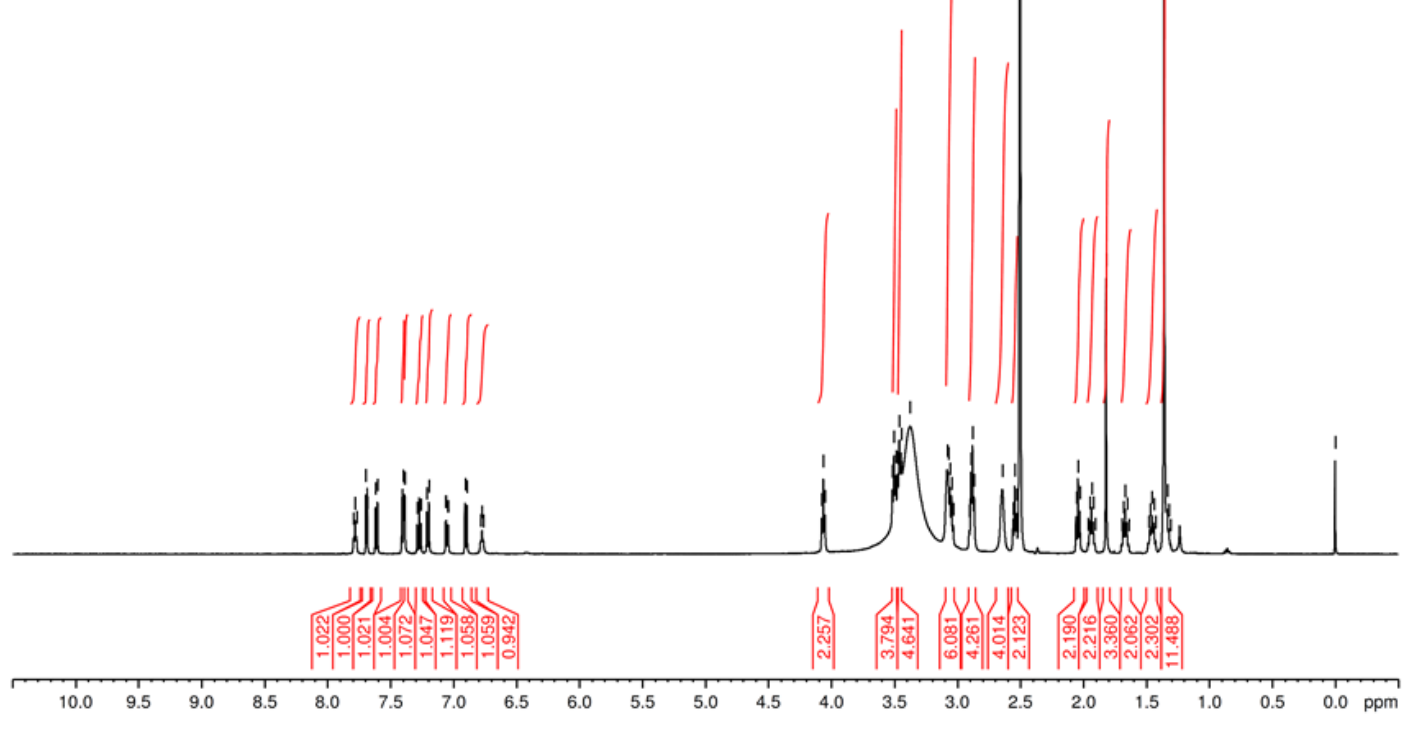

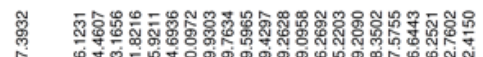

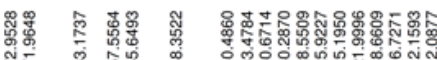

NE

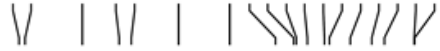

S41 ${ }^{13} \mathrm{C}$ NMR (DMSO-d6)

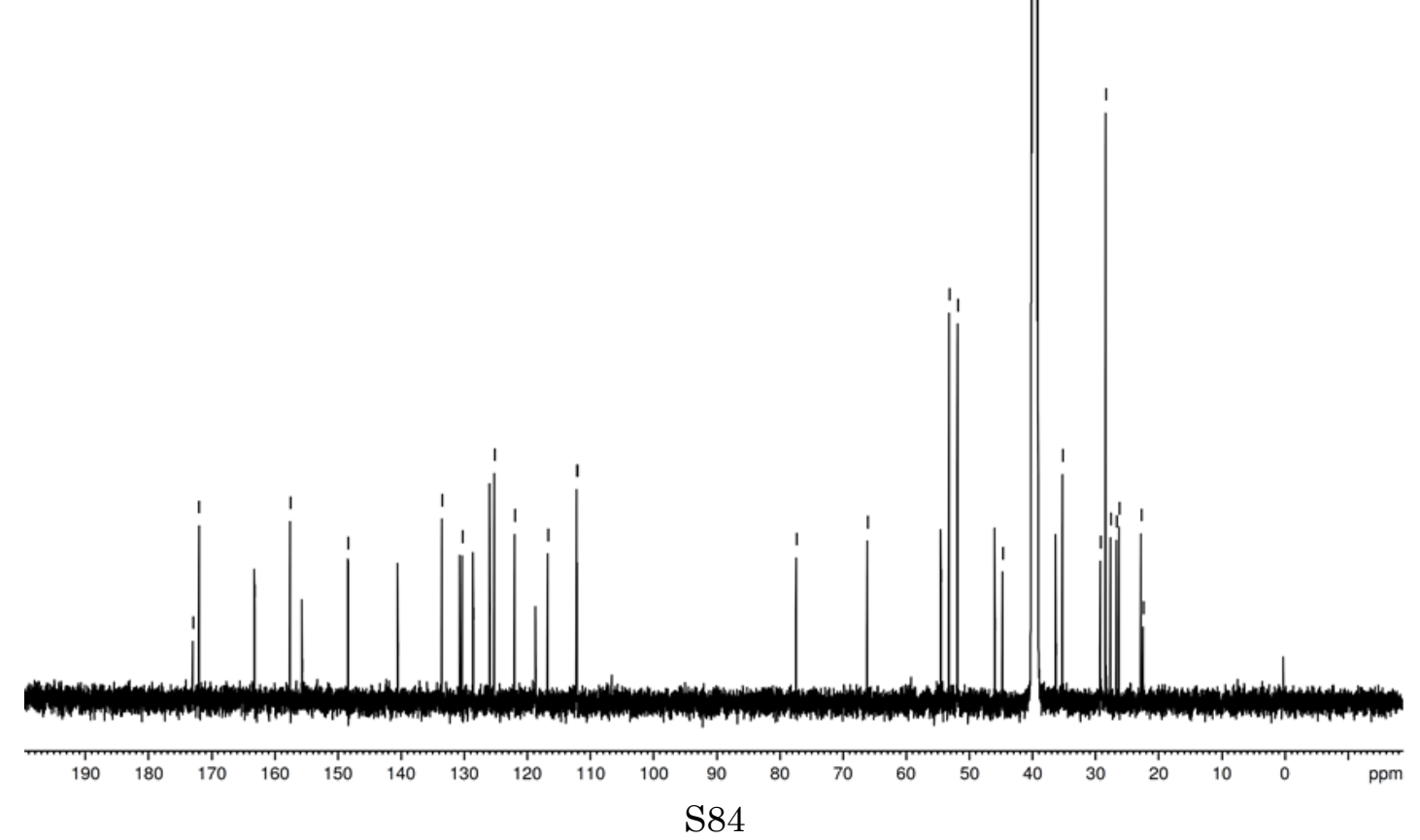



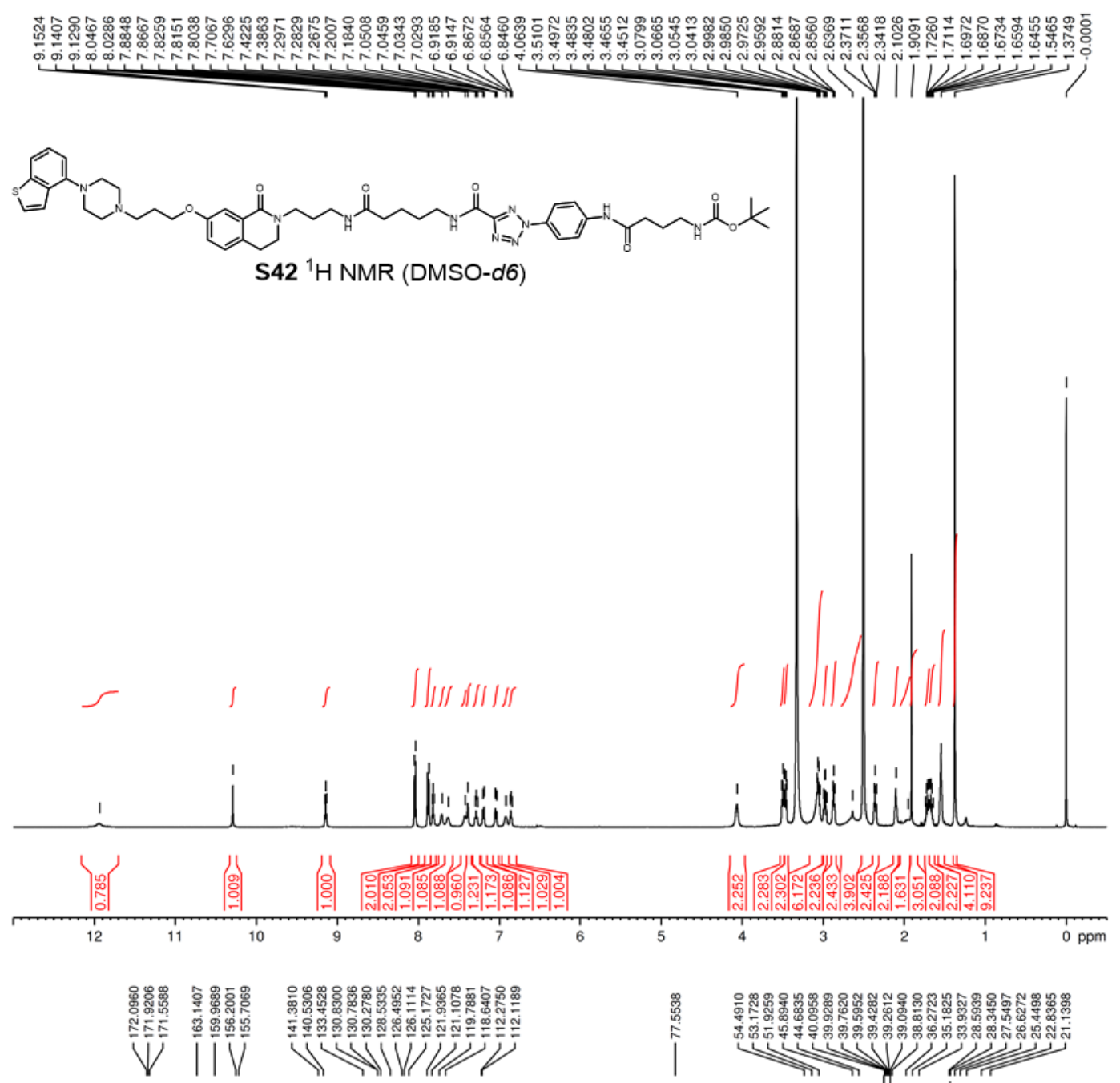

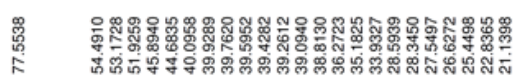

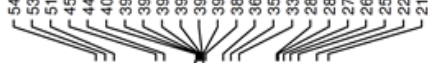

$\mathbf{S 4 2}{ }^{13} \mathrm{C}$ NMR (DMSO-d6)

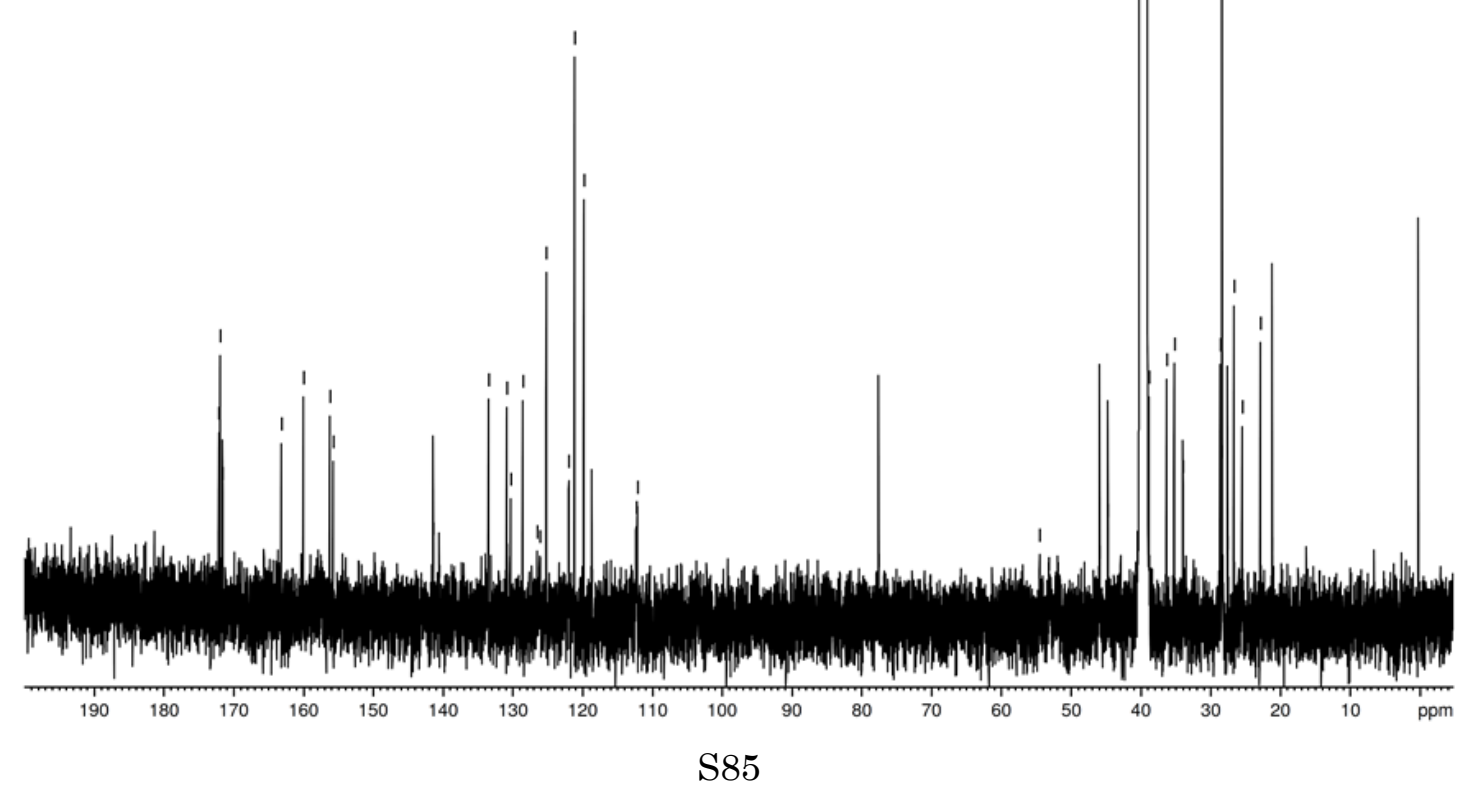




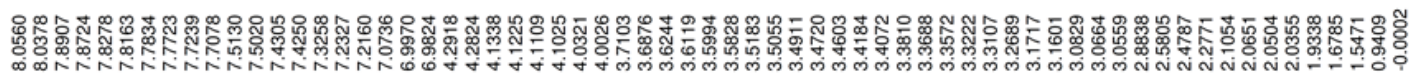

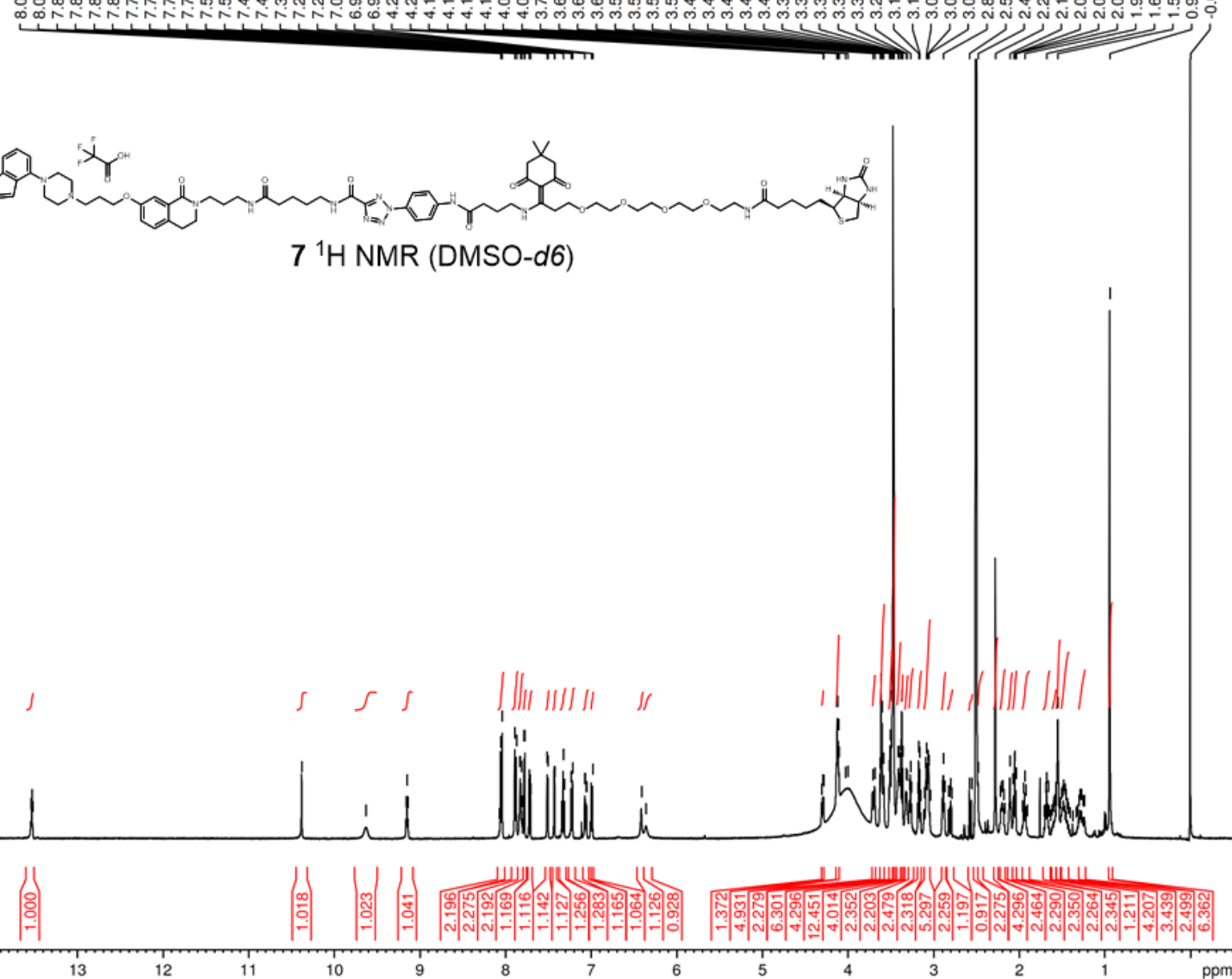

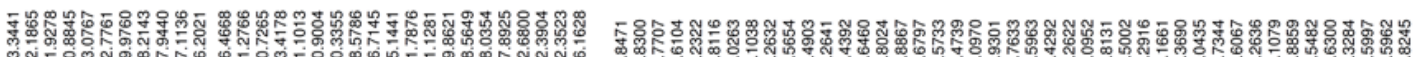

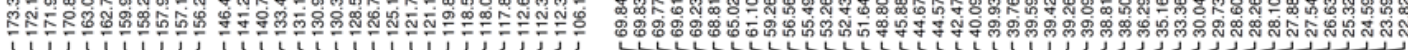

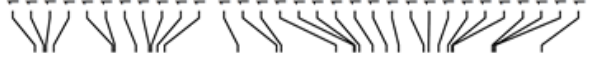

$7{ }^{13} \mathrm{C}$ NMR (DMSO-d6)

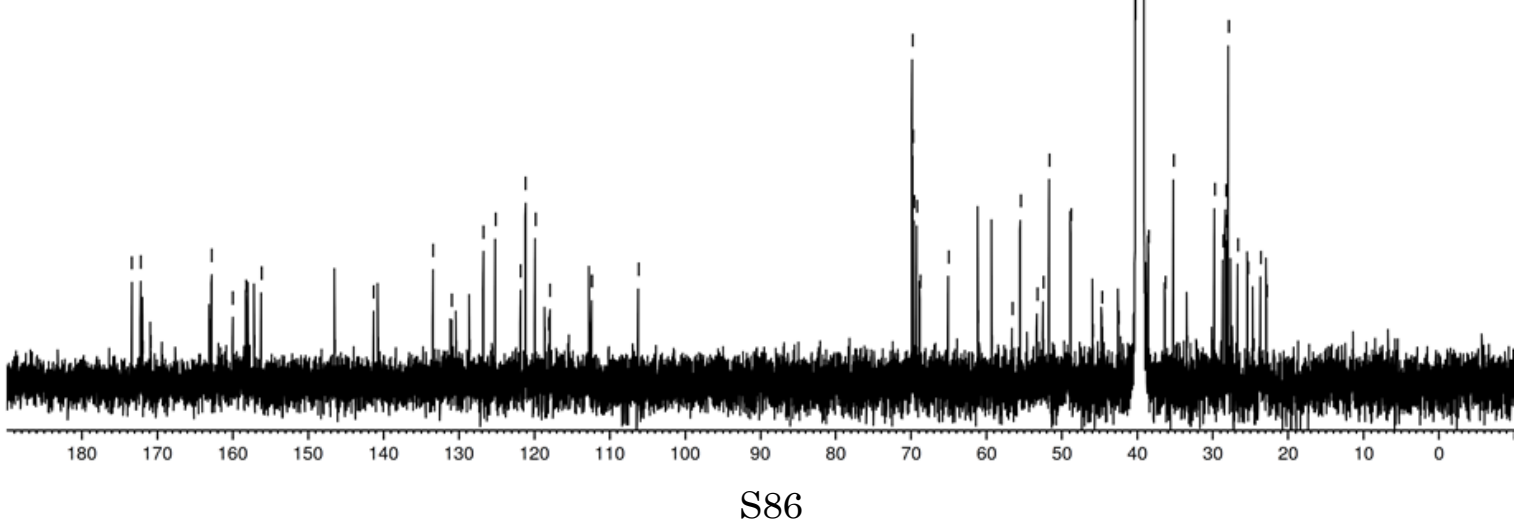




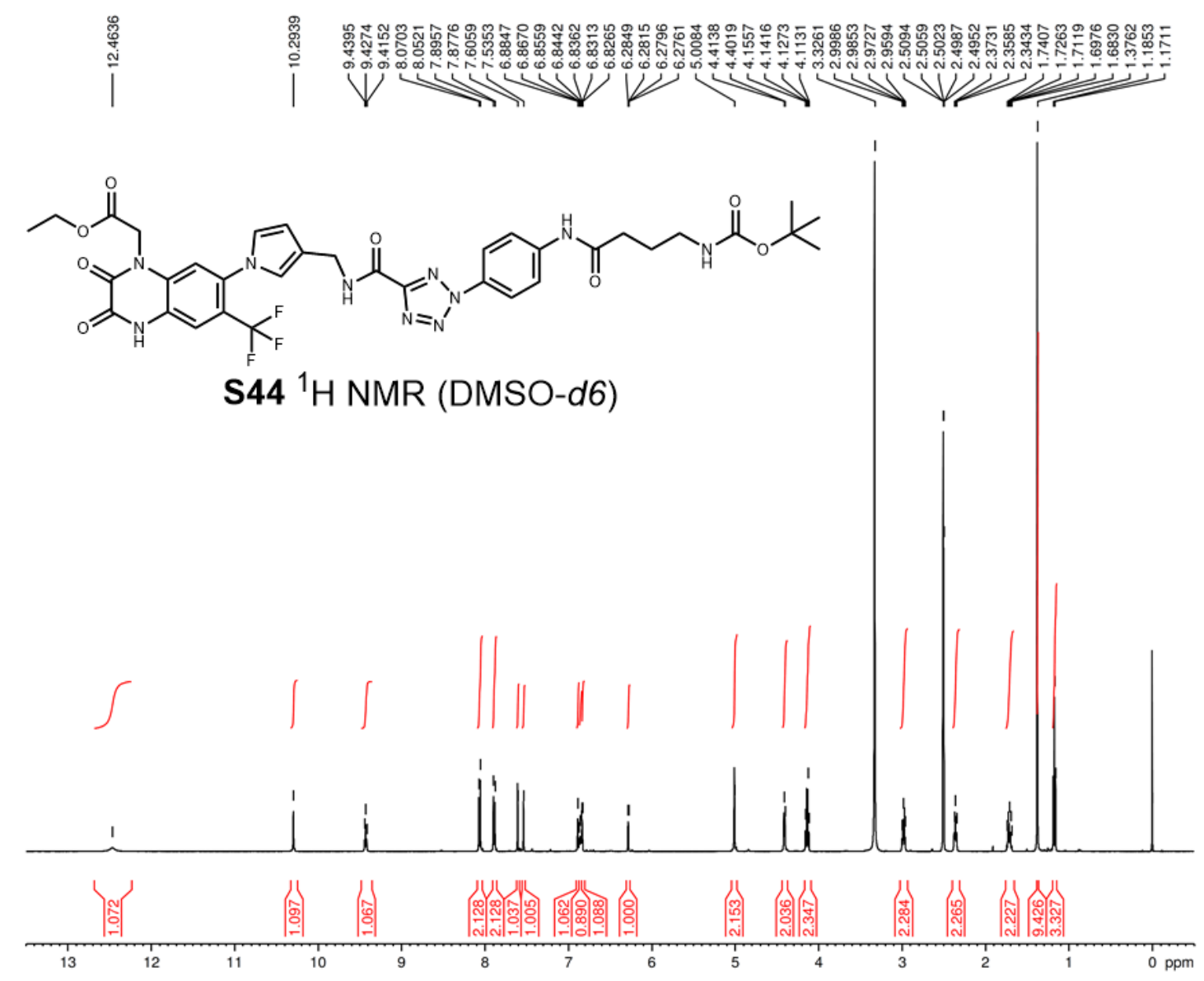

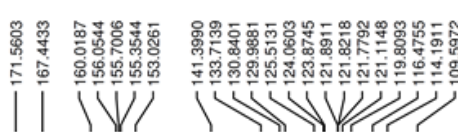

S44 ${ }^{13} \mathrm{C}$ NMR (DMSO-d6)

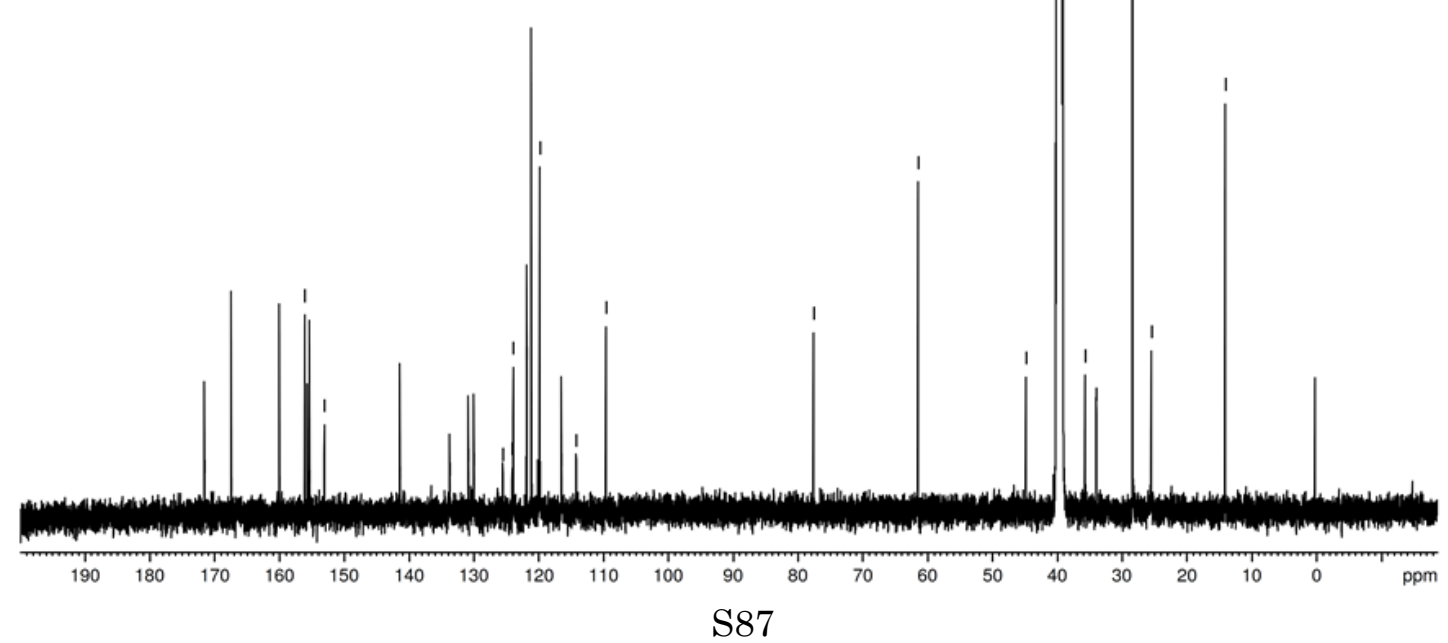




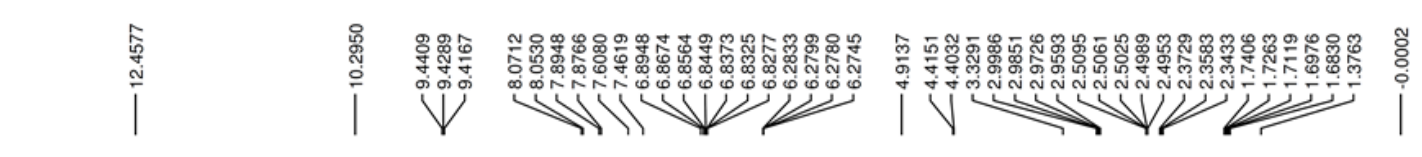<smiles>CC(C)(C)OC(=O)NCCCC(=O)Nc1ccc(-n2nnc(C(=O)NCc3ccn(-c4cc5c(cc4C(F)(F)F)[nH]c(=O)c(=O)n5CC(=O)O)c3)n2)cc1</smiles>

S45 ${ }^{1} \mathrm{H}$ NMR (DMSO-d6)

S45 ${ }^{13} \mathrm{C}$ NMR (DMSO-d6)

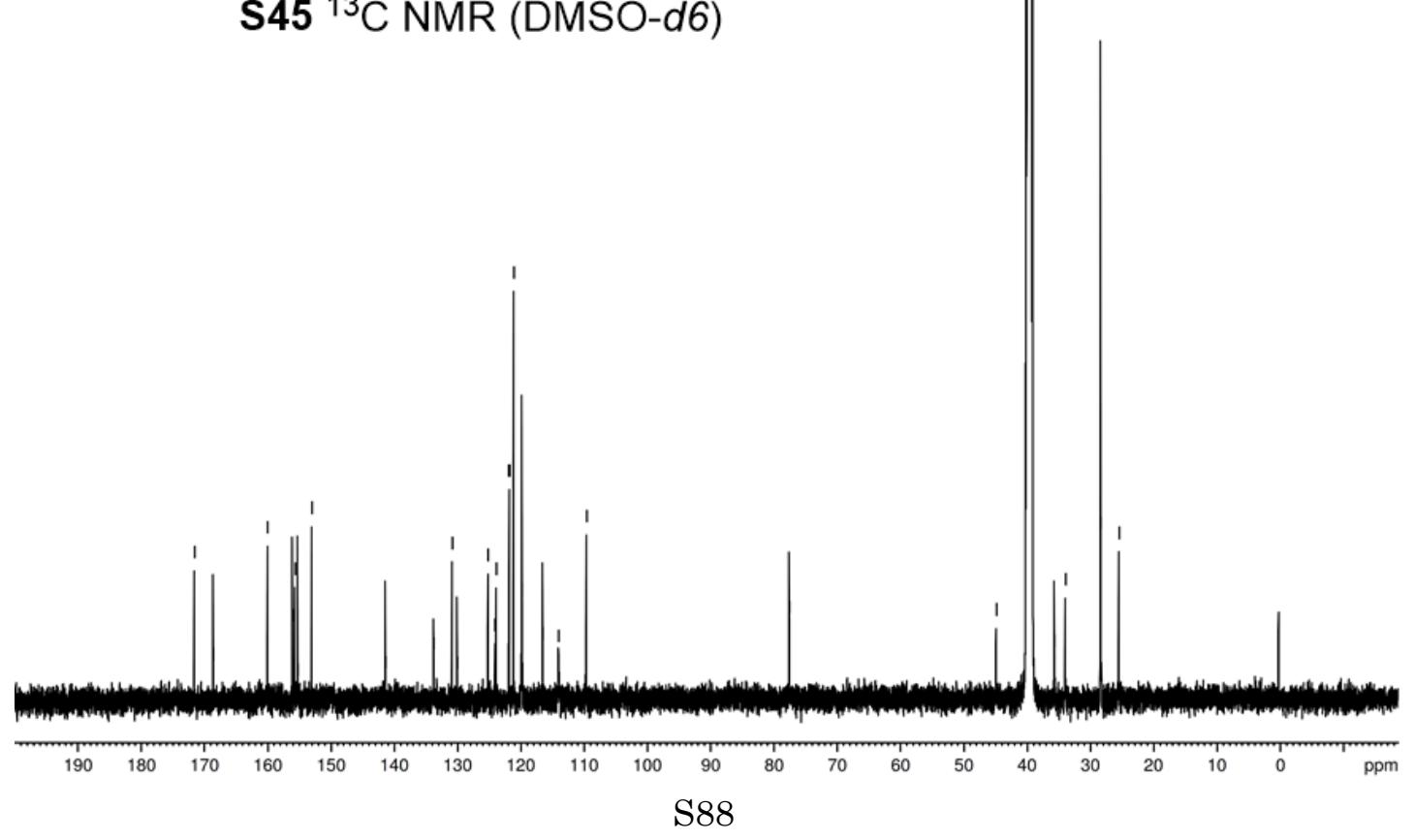




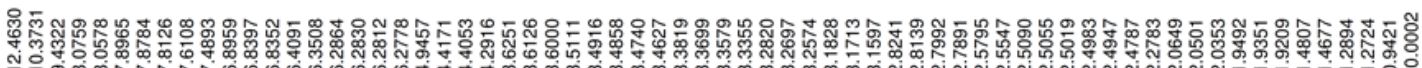

2

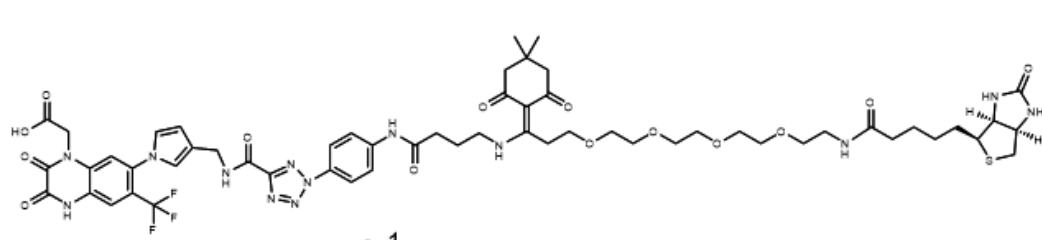
$8{ }^{1} \mathrm{H}$ NMR (DMSO-d6)

$8{ }^{13} \mathrm{C}$ NMR (DMSO-d6)

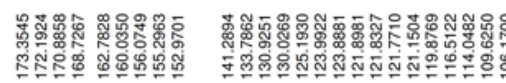
V/I IIVI

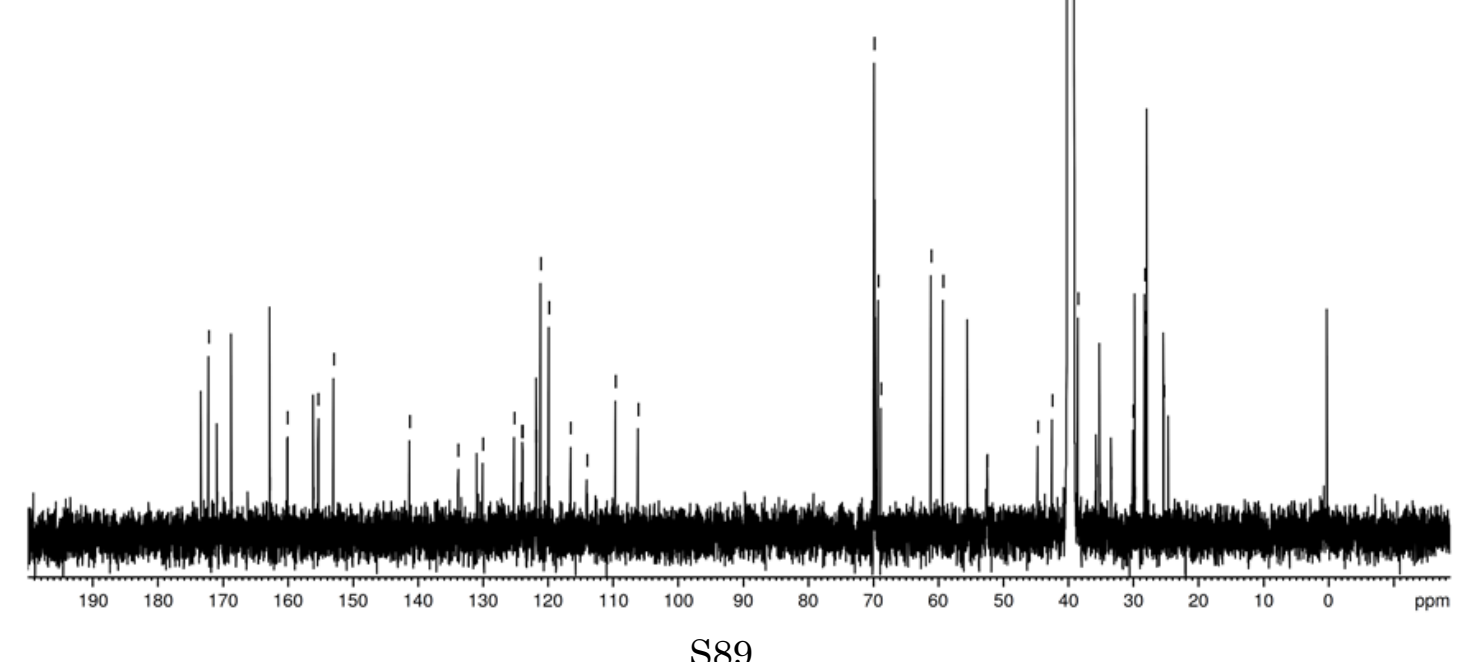



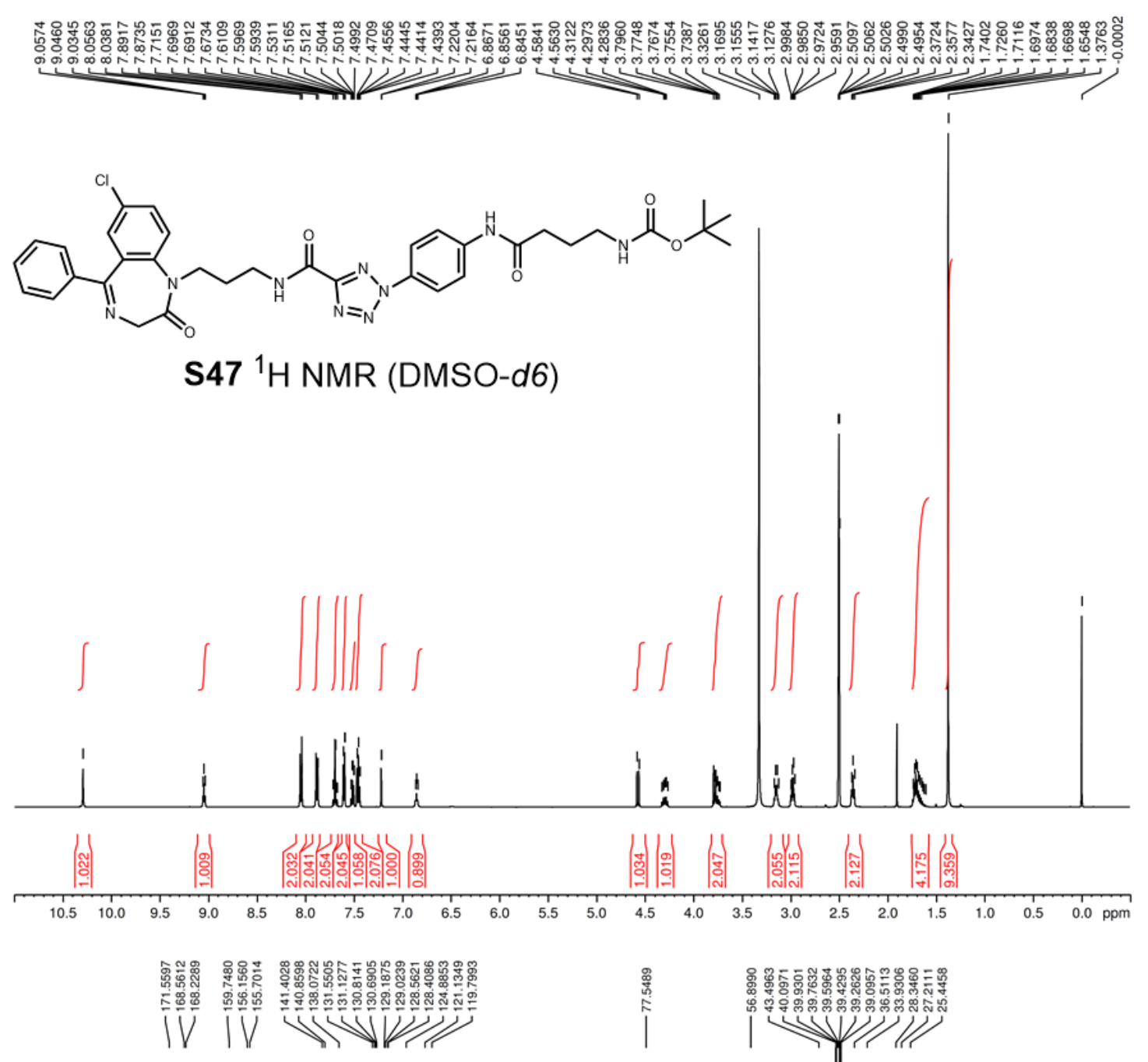

S47 ${ }^{13} \mathrm{C}$ NMR (DMSO-d6)

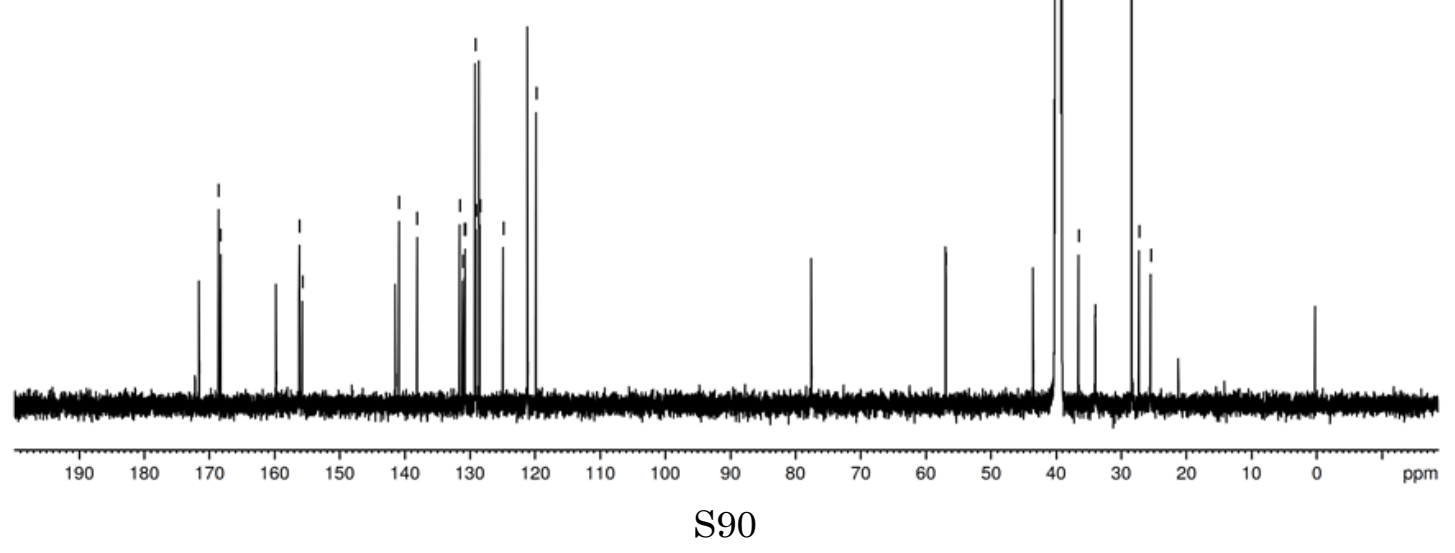




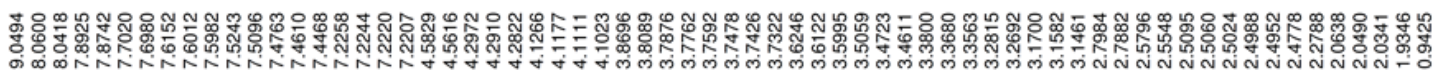

(1)

$9^{1} \mathrm{H}$ NMR (DMSO-d6)

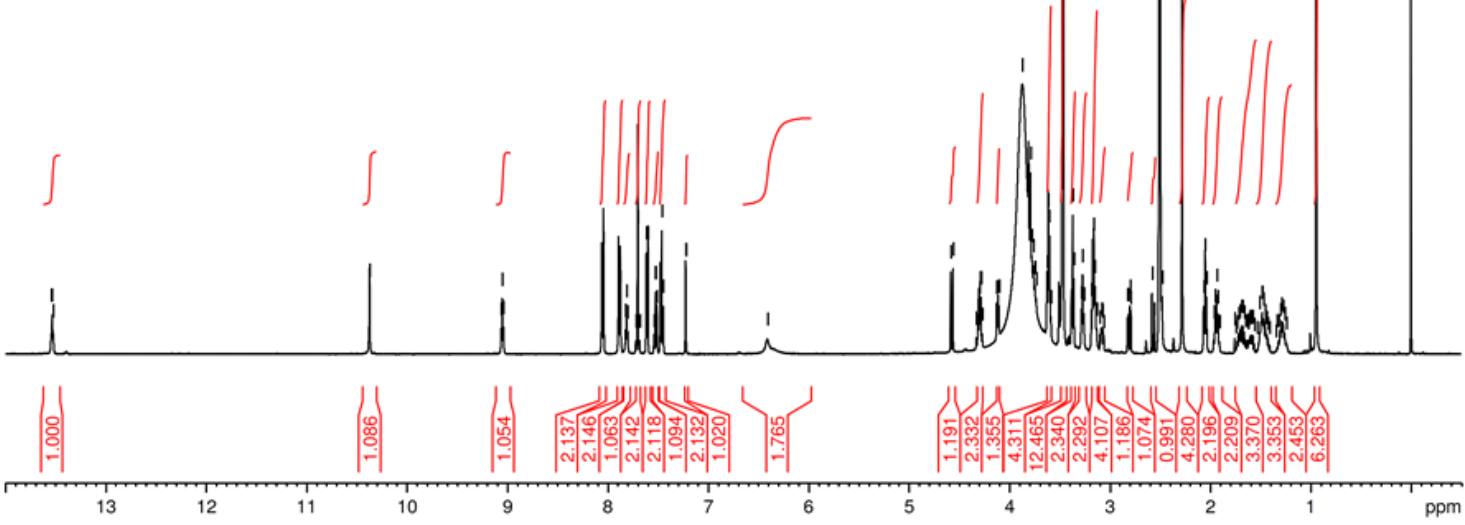

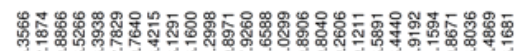

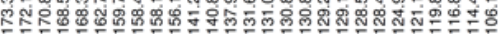

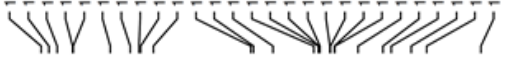

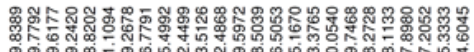

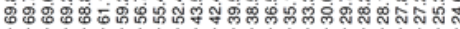

W YIII WMIIVIII,

$9{ }^{13} \mathrm{C}$ NMR (DMSO-d6)

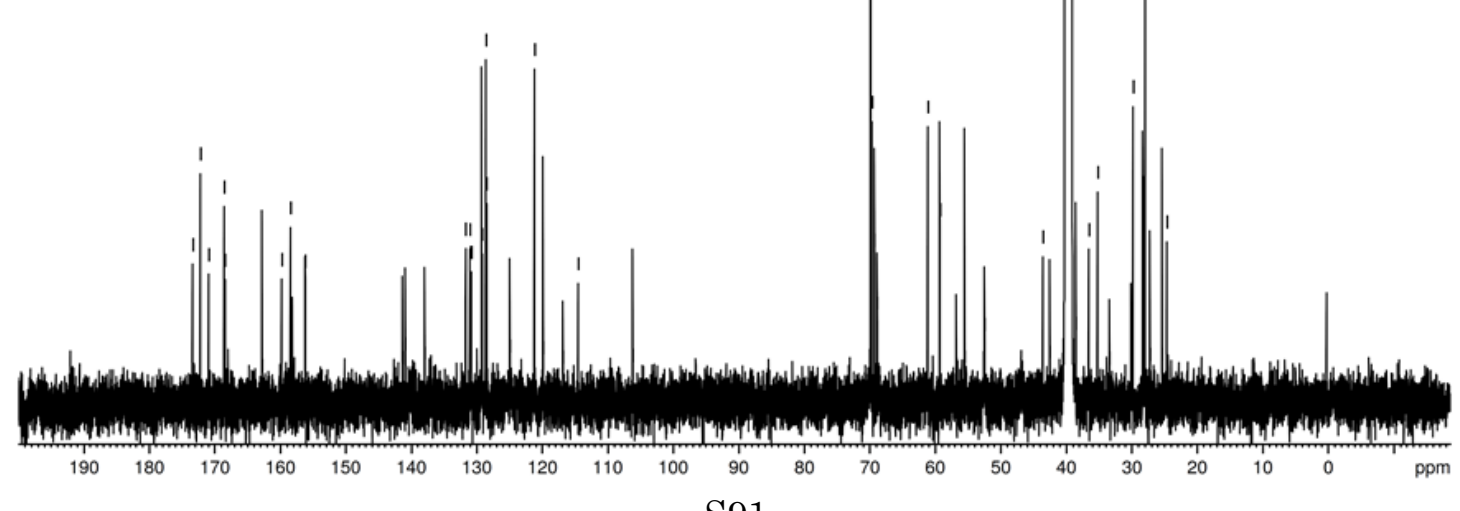




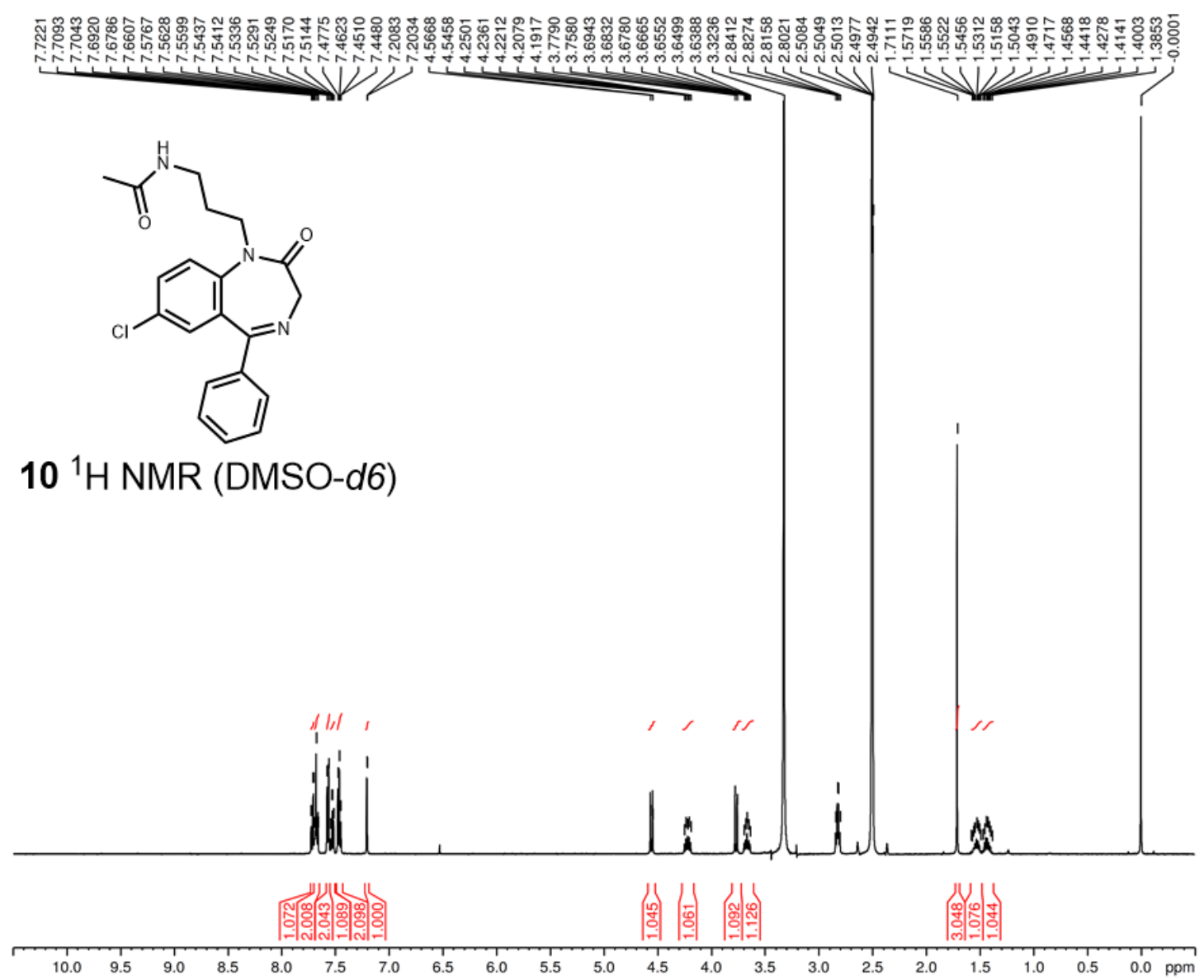

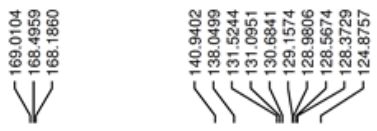

$10^{13} \mathrm{C}$ NMR (DMSO-d6)

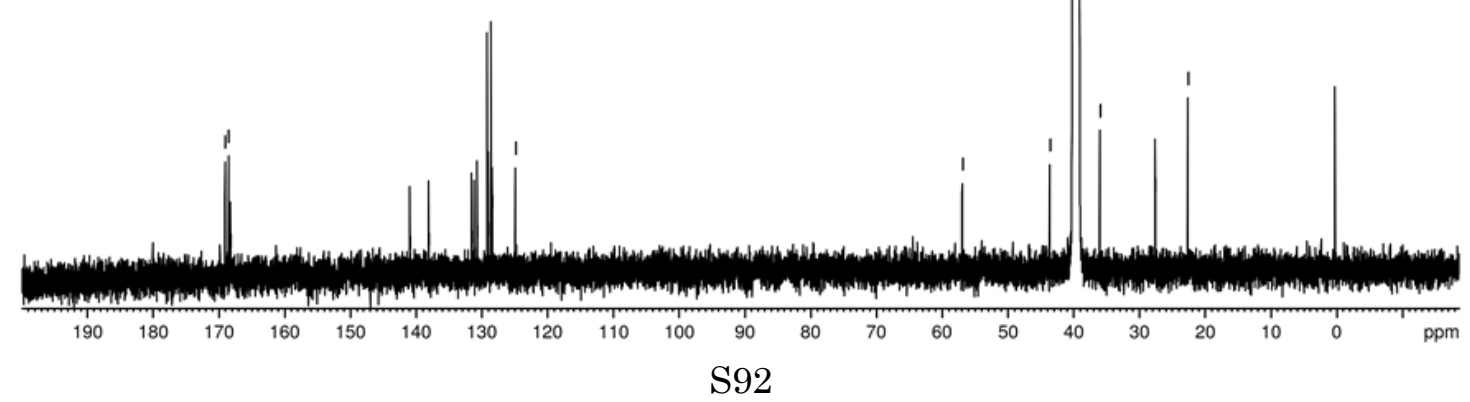




\section{References}

[1] Wang, S., Che, T., Levit, A., Shoichet, B. K., Wacker, D., and Roth, B. L. (2018) Structure of the D2 dopamine receptor bound to the atypical antipsychotic drug risperidone. Nature 555, 269-273.

[2] Masiulis, S., Desai, R., Uchanski, T., Serna Martin, I., Laverty, D., Karia, D., Malinauskas, T., Zivanov, J., Pardon, E., Kotecha, A., Steyaert, J., Miller, K. W., and Aricescu, A. R. (2019) GABA A receptor signalling mechanisms revealed by structural pharmacology. Nature 565, 454-459.

[3] Tadori, Y., Miwa, T., Tottori, K., Burris, K. D., Stark, A., Mori, T., and Kikuchi, T. (2005) Aripiprazole's low intrinsic activities at human dopamine D2L and D2S receptors render it a unique antipsychotic. Eur. J. Pharmacol. $515,10-19$.

[4] Maeda, K., Sugino, H., Akazawa, H., Amada, N., Shimada, J., Futamura, T., Yamashita, H., Ito, N., McQuade, R. D., Mork, A., Pehrson, A. L., Hentzer, M., Nielsen, V., Bundgaard, C., Arnt, J., Stensbol, T. B., and Kikuchi, T. (2014) Brexpiprazole I: in vitro and in vivo characterization of a novel serotonin-dopamine activity modulator. $J$. Pharmacol. Exp. Ther. 350, 589-604.

[5] Hughes, C. S., Foehr, S., Garfield, D. A., Furlong, E. E., Steinmetz, L. M., and Krijgsveld, J. (2014) Ultrasensitive proteome analysis using paramagnetic bead technology. Mol. Syst. Biol. 10, 757.

[6] Sielaff, M., Kuharev, J., Bohn, T., Hahlbrock, J., Bopp, T., Tenzer, S., and Distler, U. (2017) Evaluation of FASP, SP3, and iST Protocols for Proteomic Sample Preparation in the Low Microgram Range. J. Proteome Res. $16,4060-4072$.

[7] Wakayama, S., Kiyonaka, S., Arai, I., Kakegawa, W., Matsuda, S., Ibata, K., Nemoto, Y. L., Kusumi, A., Yuzaki, M., and Hamachi, I. (2017) Chemical labelling for visualizing native AMPA receptors in live neurons. Nat. Commun. 8, 14850.

[8] Miyamoto, D. K., Flaxman, H. A., Wu, H. Y., Gao, J., and Woo, C. M. (2019) Discovery of a Celecoxib Binding Site on Prostaglandin E Synthase (PTGES) with a Cleavable Chelation-Assisted Biotin Probe. ACS Chem. Biol. 14, 2527-2532.

[9] Yamashita, H., Matsubara, J., Oshima, K., Kuroda, H., Ito, N., Miyamura, S., Shimizu, S., Tanaka, T., Oshiro, Y., Shimada, J., Maeda, K., Tadori, Y., Amada, N., Akazawa, H., Yamashita, J., Mori, A., Uwahodo, Y., Masumoto, T., Kikuchi, T., Hashimoto, K., and Takahashi, H. (2006) Piperazine-Substituted Benzothiophenes for Treatment of Mental Disorders. Patent WO2006112464 A1.

[10] Herner, A., Marjanovic, J., Lewandowski, T. M., Marin, V., Patterson, M., Miesbauer, L., Ready, D., Williams, J., Vasudevan, A., and Lin, Q. (2016) 2-Aryl-5-carboxytetrazole as a New Photoaffinity Label for Drug Target Identification. J. Am. Chem. Soc. 138, 14609-14615.

[11] Li, Z., Hao, P., Li, L., Tan, C. Y., Cheng, X., Chen, G. Y., Sze, S. K., Shen, H. M., and Yao, S. Q. (2013) Design and synthesis of minimalist terminal alkyne-containing diazirine photo-crosslinkers and their incorporation into kinase inhibitors for cell- and tissue-based proteome profiling. Angew. Chem., Int. Ed. 52, $8551-8556$.

[12] Fujii, S., Yamamoto, Y., Shimizu, F., Inai, M., and Hirohashi, M. (1992) Preparation of Polypeptide Derivatives for Treatment of Hypercalcemia. Patent US5162305 A.

[13] Ahad, A. M., Jensen, S. M., and Jewett, J. C. (2013) A traceless Staudinger reagent to deliver diazirines. Org. 
Lett. 15, 5060-5063.

[14] Graham, E., Rymarchyk, S., Wood, M., and Cen, Y. (2018) Development of Activity-Based Chemical Probes for Human Sirtuins. ACS Chem. Biol. 13, 782-792.

[15] Neelarapu, R., Holzle, D. L., Velaparthi, S., Bai, H., Brunsteiner, M., Blond, S. Y., and Petukhov, P. A. (2011) Design, synthesis, docking, and biological evaluation of novel diazide-containing isoxazole- and pyrazole-based histone deacetylase probes. J. Med. Chem. 54, 4350-4364.

[16] Lubisch, W., Behl, B., and Hofmann, H. P. (1996) Pyrrolylquinoxalinediones: A new class of AMPA receptor antagonists. Bioorg. Med. Chem. Lett. 6, 2887-2892.

[17] Wang, N. Y., Keegan, C. L., Heiman, D. F., Flentge, C. A., and Wang, P. P. (1988) Benzodiazepines assay, tracers, immunogens and antibodies. Patent EP264797 A2. 